\title{
WestVirginiaUniversity
}

THE RESEARCH REPOSITORY @ WVU

Graduate Theses, Dissertations, and Problem Reports

2006

\section{Oxidative stress in skin induced by chemical and physical agents}

Ashley Rebecca Murray

West Virginia University

Follow this and additional works at: https://researchrepository.wvu.edu/etd

\section{Recommended Citation}

Murray, Ashley Rebecca, "Oxidative stress in skin induced by chemical and physical agents" (2006).

Graduate Theses, Dissertations, and Problem Reports. 2399.

https://researchrepository.wvu.edu/etd/2399

This Dissertation is protected by copyright and/or related rights. It has been brought to you by the The Research Repository @ WVU with permission from the rights-holder(s). You are free to use this Dissertation in any way that is permitted by the copyright and related rights legislation that applies to your use. For other uses you must obtain permission from the rights-holder(s) directly, unless additional rights are indicated by a Creative Commons license in the record and/ or on the work itself. This Dissertation has been accepted for inclusion in WVU Graduate Theses, Dissertations, and Problem Reports collection by an authorized administrator of The Research Repository @ WVU.

For more information, please contact researchrepository@mail.wvu.edu. 


\title{
Oxidative Stress in Skin Induced by Chemical and Physical Agents
}

\author{
Ashley Rebecca Murray \\ Dissertation submitted to the School of Medicine at \\ West Virginia University \\ in partial fulfillment of the requirements for the degree of \\ Doctor of Philosophy \\ in \\ Physiology and Pharmacology
James Antonini, Ph. D.
Vincent Castranova, Ph.D.
Michael Gunther, Ph.D.
Mark Reasor, Ph.D. \\ Anna A. Shvedova, Ph.D., D.Sc., Chair \\ Department of Physiology and Pharmacology \\ Morgantown, WV \\ 2006
}

Keywords: skin, oxidative stress, antioxidant network, phenol, cumene hydroperoxide, simulated solar light 


\section{Oxidative Stress in Skin Induced by Chemical and Physical Agents}

\section{Ashley Rebecca Murray}

Free radicals threaten various tissues and are involved in the development and progression of many pathological states and diseases. More than other tissues, the skin is exposed to a variety of chemical, environmental, and physical agents which are capable of inducing radical formation resulting in the development of oxidative stress. The skin possesses an elaborate antioxidant network to deal with reactive oxygen species (ROS); however, excessive exposure and/or radical production can overwhelm the antioxidant capabilities of the skin causing oxidative damage to proteins, DNA, and lipids. The central hypothesis of these studies is that exposure to oxidizible chemicals and/or environmental agents to skin are able to induce free radical formation with subsequent antioxidant reduction, oxidative DNA, lipid and protein damage, and inflammation. Excessive inflammatory-based oxidative modification of the major skin constituents following long-term exposure could trigger redox-sensitive cell-signaling pathways via activator protein 1 (AP-1) expression thereby causing the development of skin cancer. The specific aims of the project are: (1) To study the mechanisms of phenol (PhOH)induced oxidative injury in skin of animals with normal and reduced antioxidant milieu; (2) To assess the role of the antioxidant defense system of the skin of young and old mice exposed to cumene hydroperoxide (Cum-OOH); (3) To investigate the role of oxidative stress and the activation of AP-1 protein in the development of skin cancer; (4) To study the mechanisms of simulated solar light (SSL) induced skin injury with respect to antioxidant imbalance, oxidative damage of DNA, protein, and lipids. Results obtained from these studies provide critical knowledge about the mechanisms of dermal toxicity of phenolic compounds, organic peroxides and UV light with regard to reactive oxygen intermediates formed in skin. The efficiency of the antioxidant network is essential to withstand an oxidative skin injury due to aging, occupational and environmental exposures. 


\section{TABLE OF CONTENTS}

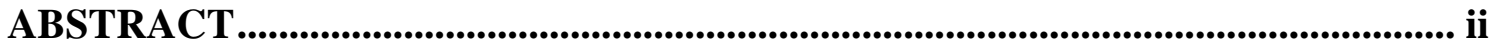

TABLE OF CONTENTS ..................................................................................ii

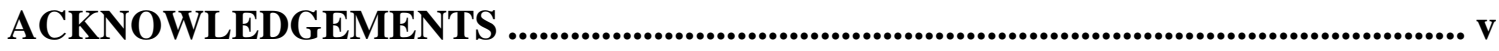

LIST OF TABLES ...................................................................................................... vi

LIST OF FIGURES ........................................................................................................ vii

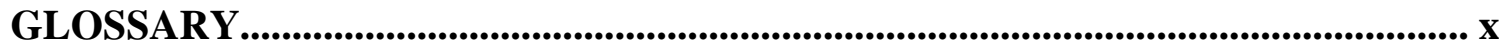

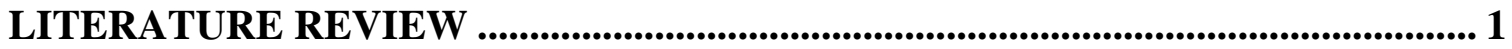

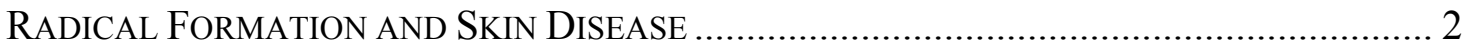

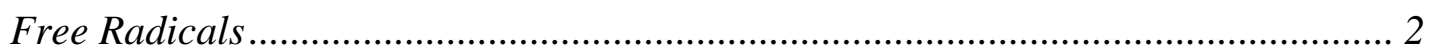

Free Radical Mediated Skin Damage ................................................................... 5

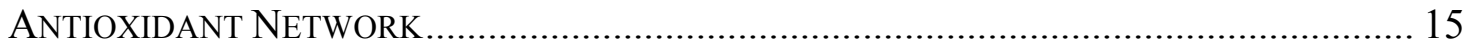

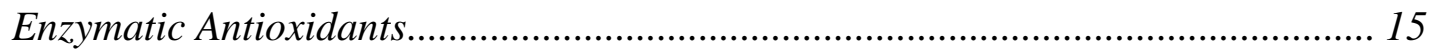

Nonenzymatic Antioxidants............................................................................. 16

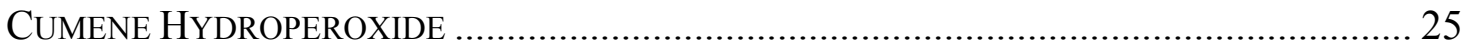

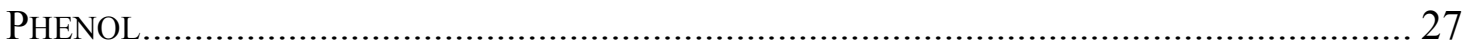

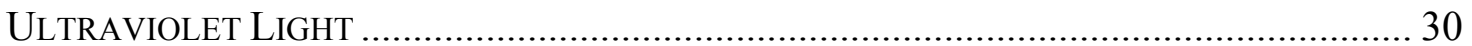

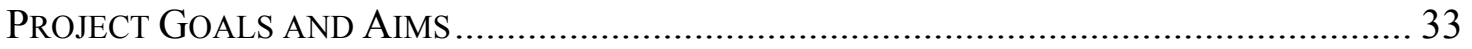

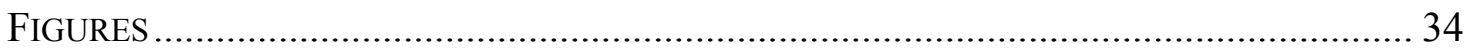

STUDY 1: PHENOL-INDUCED IN VIVO OXIDATIVE STRESS IN SKIN: EVIDENCE FOR ENHANCED FREE RADICAL GENERATION, THIOL OXIDATION AND ANTIOXIDANT DEPLETION.................................................. 36

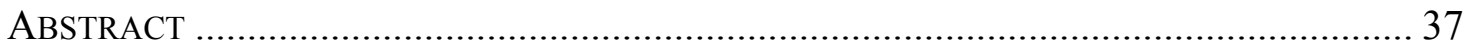

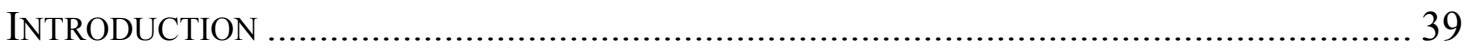

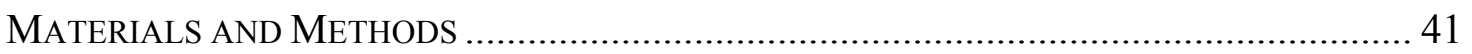

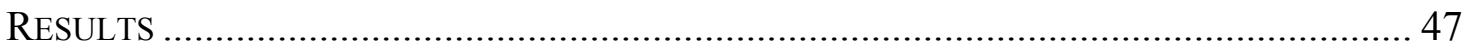

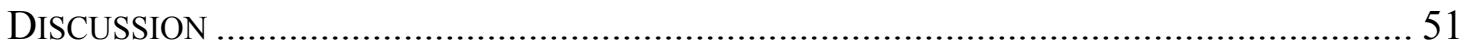

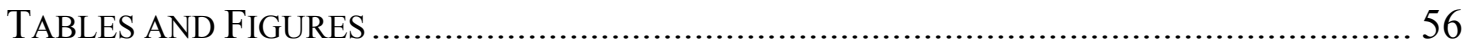

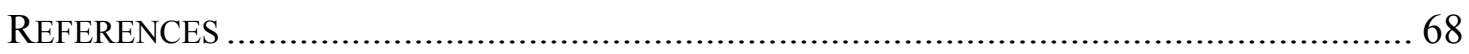

STUDY 2: ROLE OF VITAMIN E IN THE ANTIOXIDANT DEFENSE SYSTEM OF SKIN IN YOUNG AND OLD MICE EXPOSED TO CUMENE

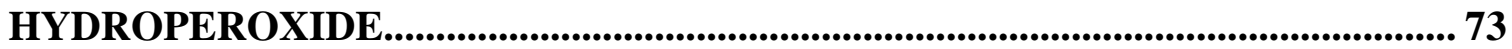

ABSTRACT 
STUDY 3: INTERPLAY BETWEEN PRO/ANTIOXIDANT STATUS AND AP-1 TRANSCRIPTION FACTOR IN MURINE SKIN FOLLOWING TOPICAL EXPOSURE TO CUMENE HYDROPEROXIDE .................................................. 110

ABSTRACT

STUDY 4: SIMULATED SOLAR UV LIGHT (SSL) INDUCES INFLAMMATION AND OXIDATIVE STRESS IN THE SKIN OF SKH-1 HAIRLESS MICE........... 141

ABSTRACT




\section{ACKNOWLEDGEMENTS}

To my advisor, Dr. Anna Shvedova, who's help and encouragement has been invaluable before, during, and beyond my time in graduate school. Without her expert guidance, motivation, and support, I wouldn't have been able to accomplish all that I have done and all that I hope to achieve in the future. I look toward her for knowledge of how to be successful a successful scientist as well as a kind and helpful person and friend.

To my dissertation committee, Dr. Jim Antonini, Dr. Vince Castranova, Dr. Mark Reasor, and Dr. Mike Gunther, I sincerely thank you for all of your help and scientific input which helped to make this dissertation complete. Your comments and suggestions were invaluable.

To Elena Kisin, without whom I would have not been able to complete this dissertation. Many days when I felt like giving up, your encouragement and willingness to listen helped to keep me going. Your help and knowledge was unlimited and I am forever grateful!

To all of my colleagues at NIOSH who have helped me throughout the years. Specifically, Jenny Roberts and Jim Scabilloni, for the morning "scientific discussions" and coffee breaks which kept me going through the tough days and weeks!

And lastly and most importantly, to my family for all of their motivation and support. First, to my sisters, Meredith and Julia, who put up with endless amounts of complaining, crying and frustration, but still managed to keep me laughing with their endless energy, senseless comments, and antics! To my Mom and Dad, who pushed me without really pushing and kept me going even when I was ready to quit. They always encouraged me to reach for the stars and achieve my best. I love you all! 


\section{LIST OF TABLES}

\section{Study 1}

Table 1.1. Antioxidant depletion in the skin of B6C3F1 mice after topical treatment with

phenol.

\section{Study 2}

Table 2.1. Composition of vitamin E sufficient and deficient animal diets.............99

Table 2.2. Tissue depletion of antioxidants in the skin of BALB/C mice fed a vitamin $E$ deficient diet........................................................93

Table 2.3. Level of vitamin $\mathrm{E}$ in the skin of $\mathrm{B} 6 \mathrm{C} 3 \mathrm{~F} 1$ or $\mathrm{BALB} / \mathrm{c}$ mice given basal or vitamin $\mathrm{E}$ deficient diets.............................................. 94

\section{Study 3}

Table 3.1. Biomarkers of inflammation and oxidative stress in skin of AP-1 mice after 29 weeks of Cum-OOH or TPA-induced tumor promotion 


\section{LIST OF FIGURES}

Figure 1. The structure of the skin................................................ 34

Figure 2. The antioxidant network of the skin.................................... 35

\section{$\underline{\text { Study } 1}$}

Figure 1.1.A. Dose-dependent increase in skin bi-fold thickness as a result of dermal phenol exposure in B6C3F1 mice.......................................57

Figure 1.1.B. Time-dependent increase in skin bi-fold thickness as a result of dermal

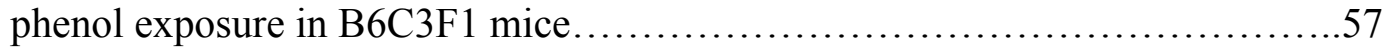

Figure 1.2.A. Time-course depletion of glutathione by 1,3-bis(chloroethyl)-1nitrosourea (BCNU) in the skin of B6C3F1 mice.............................58

Figure 1.2.B. Time-course depletion of glutathione by L-buthione-[S,R]-sulfoximine in the skin of B6C3F1 mice. .............................................58

Figure 1.3.A. ESR detection of lipid-derived PBN spin-trapped free radicals formed in vivo in the skin of B6C3F1 mice topically treated with phenol.................59

Figure 1.3.E. Average integrated intensity of lipid-derived carbon-centered radicals obtained from B6C3F1 mice topically exposed to phenol as detected by ESR....59

Figure 1.4. Computer simulation of carbon-centered radicals from B6C3F1 mice topically treated with phenol as obtained by ESR..........................60

Figure 1.5. The effect of $\mathrm{BCNU} / \mathrm{PhOH}$ or $\mathrm{BSO} / \mathrm{PhOH}$ exposure on the level of GSH...61

Figure 1.5,Inset. Effect of phenol plus BCNU on the level of protein thiols in the skin of B6C3F1 mice.

Figure 1.6. The effect of $\mathrm{BCNU} / \mathrm{PhOH}$ exposure on the level of vitamin $\mathrm{E}$ in the skin of B6C3F1 mice.

Figure 1.7. The effect of $\mathrm{BCNU} / \mathrm{PhOH}$ on the level of total antioxidant reserve in the skin of B6C3F1 mice..................................................63

Figure 1.8. Skin histology of B6C3F1 female mice treated topically with phenol

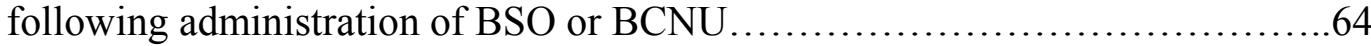

Figure 1.9.A. Time course of prostaglandin $\mathrm{E}_{2}$ release by JB-6 cells following phenol/BSO exposure. 63 1.9.B. Level of prostaglandin E2 in JB-6 cells following 18 hours of $\mathrm{PhOH} / \mathrm{BSO}$

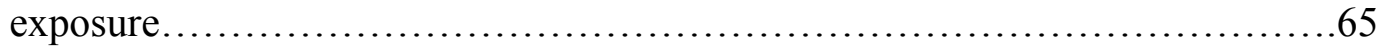

Figure 1.10. Effect of COX-2 inhibitor on the level of prostaglandin E2 in JB-6 cells following 18 hours of phenol/ BSO exposure.

Figure 1.11.A. Time course of IL-1 $\beta$ expression in JB-6 cells following exposure to phenol............................................................67

Figure 1.11.B. IL-1 $\beta$ Expression by JB-6 cells 18 hours following phenol exposure.....68

\section{Study 2}

Figure 2.1. Vitamin $\mathrm{E}$ in the skin of Balb/c mice (32 weeks old) given basal or vitamin $\mathrm{E}$ deficient diets following topical exposure to Cumene Hydroperoxide...........95 
Figure 2.2.A. Cumene Hydroperoxide induced reduction of GSH in the skin of young $\mathrm{Balb} / \mathrm{c}$ mice given basal or vitamin $\mathrm{E}$ deficient diets...........................96

Figure 2.2.B. Cumene Hydroperoxide induced reduction of GSH in the skin of old $\mathrm{Balb} / \mathrm{c}$ mice given basal or vitamin $\mathrm{E}$ deficient diets

Figure 2.3.A. Total antioxidant reserve in the skin of young Balb/C mice given basal or vitamin E deficient diets following topical exposure to Cumene Hydroperoxide.97

Figure 2.3.B. Total antioxidant reserve in the skin of old Balb/C mice given basal or vitamin $\mathrm{E}$ deficient diets following topical exposure to Cumene Hydroperoxide.97

Figure 2.4. Ascorbate in the skin of Balb/c mice (32 weeks old) given basal or vitamin $\mathrm{E}$ deficient diet following topical exposure to Cumene Hydroperoxide...............98

Figure 2.5. Cumene Hydroperoxide-induced accumulation of 8-hydroxy-2'deoxyguanosine in the skin of young (13 weeks old) and old (32 weeks old) Balb/c mice.

Figure 2.6. Cumene Hydroperoxide-induced accumulation of 8-hydroxy-2'deoxyguanosine in skin of Balb/c mice (32 weeks old) given basal or vitamin $\mathrm{E}$ deficient diets...........................................................99

Figure 2.7. Skin photomicrographs of young (13 weeks old) and old (32 weeks old) $\mathrm{Balb} / \mathrm{c}$ mice given basal diet and topically treated with Cumene Hydroperoxide.

Figure 2.8. Skin photomicrographs of old (32 week old) Balb/c mice given basal or vitamin $\mathrm{E}$ diet and topically treated with Cumene Hydroperoxide................102

Figure 2.9. Vitamin $\mathrm{E}$ in the skin of $\mathrm{C} 57 \mathrm{BL} / 6$ mice given a diet deficient in vitamin $\mathrm{E}$ or mice with a genetic deletion of the $\alpha$-tocopherol transporter protein $(\alpha-T T P)$ following Cumene Hydroperoxide exposure........................... 103

Figure 2.10. Cumene Hydroperoxide reduced the level of GSH in the skin of C57BL/6 Mice given a diet deficient in vitamin $\mathrm{E}$ or mice with a genetic deletion of the $\alpha$ -

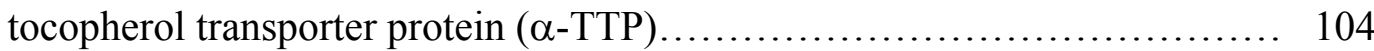

Figure 2.11. Ascorbate in the skin of C57BL/6 mice given a diet deficient in vitamin $\mathrm{E}$ or mice with a genetic deletion of the $\alpha$-tocopherol transporter protein $(\alpha-$ TTP) following exposure to Cumene Hydroperoxide.

\section{$\underline{\text { Study } 3}$}

Fig. 3.1. Cum-OOH-induced AP-1 activation in JB6 P+ cells........................130

Fig. 3.2.A. Effect of Cum-OOH on the level of GSH in JB6 P+cells...................131

Figure 3.2.B. Effect of Cum-OOH on the level of protein thiols in JB6 P+ cells.......131

Fig. 3.3. Morphological alterations and tumor promotion in skin of AP-1 transgenic mice treated with DMBA/Cum-OOH or DMBA/TPA (29 weeks)................. 132

Fig. 3.4. Incidence of tumors in AP-1 transgenic mice treated with DMBA/Cum-OOH or

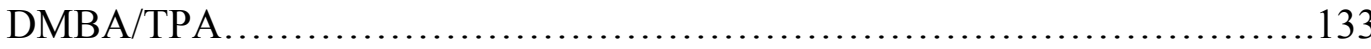

Fig. 3.5. Number of tumors in AP-1 transgenic mice treated with DMBA/Cum-OOH and DMBA/TPA ........................................................ 134

Figure 3.5, Inset. Number of papillomas per mouse in AP-1 transgenic mice treated with DMBA/Cum-OOH and DMBA/TPA......................................134 
Fig. 3.6. AP-1 transactivation in the skin of AP-1 - luciferase transgenic mice treated with DMBA/Cum-OOH and DMBA/TPA.

\section{Study 4}

Figure 4.1.A. Effects of simulated solar light on the levels of glutathione in skin homogenates of SKH-1 mice.

Figure 4.1.B. Effects of simulated solar light on the levels of protein thiols in skin homogenates of SKH-1 mice.

Figure 4.2. Effects of simulated solar light on the level of vitamin $\mathrm{E}$ in skin homogenates of SKH-1 mice

Figure 4.3. Total antioxidant reserve in skin homogenates of SKH-1 mice exposed to simulated solar light.

Figure 4.3, Inset. Characteristic chemiluminscence response generated by AAPH with luminol in the presence and in the absence of skin homogenates............. 158

Figure 4.4. Accumulation of lipid peroxidation products in skin homogenates of SKH-1 mice exposed to SSL

Figure 4.5. Pyrimidine dimer formation in the skin of SKH-1 mice after exposure to SSL.

Figure 4.6. Photomicrographs of skin of SKH-1 mice after exposure to SSL ....... 160

Figure 4.6.C. Myeloperoxidase activity in skin homogenates of SKH-1 mice exposed to SSL 


\section{GLOSSARY}

2,2'-DP: 2,2'-dipyridyl

3-AT: 3-amino-1,2,4-triazole

8-OHdG: 8-hydroxy-2`-deoxyguanosine

$\alpha$-TTP: $\alpha$-tocopherol transport protein

AAALAC: Association for Assessment and Accreditation of Laboratory Animal Care

AAPH: 2,2' azobis(2-aminodinopropane)-dihydrochloride

ACD: allergic contact dermatitis

ACGIH: American Conference of Governmental Industrial Hygienists

ACS: American Cancer Society

ACUC: Animal Care and Use Committee

AP-1: activator protein-1

ATP: adenosine triphosphate

ATSDR: Agency for Toxic Substances and Disease Registry

BCNU: 1,3-bis(2-chloroethyl)-1-nitrosourea

ANOVA: analysis of variance

BSO: L-buthione-[S,R]-sulfoximine

$\mathrm{C}$ : carbon

$\mathrm{CH}_{3} \mathrm{OH}$ : methanol

CIE: Commission Internationale de l'Éclairage

COX-2: cyclooxygenase-2

cPLA 2 : cytosolic phospholipase $\mathrm{A}_{2}$

Cum-OOH: cumene hydroperoxide

DMBA: dimethyl-benz[a]anthracene

DNA: deoxyribonucleic acid

ELISA: enzyme linked immunosorbent assay

EPR: electron paramagnetic resonance

ESR: electron spin resonance

FBS: fetal bovine serum

GPx: glutathione peroxidase

GSH: glutathione 
GSSG: oxidized glutathione

h: hour

$\mathrm{H}_{2} \mathrm{O}$ : water

$\mathrm{H}_{2} \mathrm{O}_{2}$ : hydrogen peroxide

HaCaT: immortalized human keratinocyte cell line

HEPA: high efficiency particulate air

$\mathrm{H} \& \mathrm{E}$ : hematoxylin and eosin

HP: Hewlett Packard

HPLC: high performance liquid chromatography

HO-1: heme oxygenase-1

HRP: horseradish peroxidase

hSA: human serum albumin

ICD: irritant contact dermatitis

I $\mathrm{B}-\alpha$ : cytosolic inhibitory- $\kappa \mathrm{B}-\alpha$

IL: interleukin

MAPK: mitogen-activated protein kinase

$\mathrm{MED}^{\text {biol }}$ : measurable edema dose

MEM: minimum essential medium

MMP: matrix metalloproteins

MPO: myeloperoxidase

NAC: N-acetyl-cysteine

$\mathrm{NADP}+$ : nicotinamide adenine dinucleotide phosphate

NADPH: reduced nicotinamide adenine dinucleotide phosphate

$\mathrm{NF \kappa B}$ : nuclear factor kappa B

NHEK: normal human epidermal keratinocytes

NIEHS: National Institute of Environmental Health Sciences

NO: nitric oxide

$\mathrm{O}_{2}$ : oxygen

$\mathrm{O}_{2}{ }^{\circ}$ : superoxide

$\mathrm{OH} \cdot:$ hydroxyl radical

OP: organic peroxides 
${ }^{32} \mathrm{P}$ : radioactive phosphorus

PBN: $\alpha$-phenyl-N-tert-butylnitrone

PBS: phosphate buffered saline

PhOH: phenol

PKC: protein kinase $\mathrm{C}$

ROS: reactive oxygen species

SDS: sodium dodecyl sulfate

SEM: standard error of measurement

SH: protein thiols

SOD: superoxide dismutase

SSL: simulated solar light

TBARS: thiobarbituric acid-reactive substances

TNF: tumor necrosis factor

TPA: 12-O-tetradecanoylphorbol-13-acetate

UVA: ultraviolet A (320-400 nm)

UVB: ultraviolet B (290-320 nm)

UVC: ultraviolet C $(<290 \mathrm{~nm})$

UVR: ultraviolet radiation 


\section{LITERATURE REVIEW}

The skin is the largest bodily organ and is comprised of 3 separate layers: the epidermis, the dermis, and the subcutaneous tissue (Figure 1). Each of these layers is distinct in its composition and cellular makeup. The subcutaneous layer of the skin is composed of adipose tissue while the dermis is comprised of connective tissue and an extracellular matrix of collagen and elastin. The microvasculature, which supplies the epidermis with blood and nutrients, as well as connective tissue mast cells and macrophages are located within the dermis (Elmets et al., 1994).

The epidermis is comprised largely of keratinocytes (greater than $95 \%$ of cells), as well as melanocytes, Langerhans' cells, and Merkel cells. Within the epidermis, the basal keratinocytes morphometrically differentiate into anucleate cells thereby forming the stratum corneum. Melanocytes produce melanin which provides the skin pigmentation. Merkel cells are neuroendocrine cells thought to function as mechanoreceptors for tactile responses thereby allowing the manipulation of objects. Langerhans cells are bone marrow derived antigen presenting cells (McKenzie and Sauder, 1990; Bos and Kapsenberg,, 1993; Elmets et al., 1994).

The overproduction of reactive oxygen species (ROS) has generally been accepted as a major contributor to the development of various cutaneous disorders, skin diseases, and skin aging. The skin is exposed to numerous environmental, chemical, and physical stressors, such as ultraviolet radiation (UVR), which result in the development of oxidative stress and skin tissue damage. While the skin possesses an elaborate antioxidant 
defense system to prevent oxidative damage, excessive exposure to occupational and environmental insults can overwhelm the cutaneous antioxidant capacity and lead to oxidative injury and premature aging.

\section{$\underline{\text { Radical Formation and Skin Disease }}$}

\section{Free Radicals}

Free radicals are reactive intermediates containing one or more unpaired electrons and are capable of choosing their directional spin which tends to change constantly. Free radicals are less stable and more reactive than non-radical species. A radical can donate its unpaired electron to another molecule or accept one electron from another species resulting in production of an electron pair. This can also result in the formation of new radical species which will subsequently trigger a propagation of chain reactions (Wolf et al., 1998; Thiele, 2000).

Many free radicals are highly reactive intermediates with an extremely short life span. Free radical production occurs continuously in vivo by enzymatic and non-enzymatic reactions such as those resulting from regular phagocytic processes (Trenam et al., 1992). Free radicals can be endogenously derived during normal metabolism, immune reactions, and/or pathological conditions (Powers and Hamilton, 1999). Additionally, free radicals can be formed exogenously after environmental insults from pollution, atmospheric gases, ultraviolet radiation, microorganisms, viruses, and xenobiotics (Fuch et al., 1989; Nishi et al., 1991; Halliwell and Cross, 1994; Tyrrell, 1994; Evelson et al., 1997; Thiele et al., 1997; Podda et al., 1998; Lopez-Torres et al., 1998). 
Oxygen-derived free radicals are of particular importance to biological systems (Halliwell, 1999, 2000). Oxygen radicals are able to reversibly or irreversibly damage of all biochemical classes of molecules including nucleic acids, proteins, amino acids, lipids and lipoproteins, and carbohydrates (Halliwell, 1999, 2000). Oxygen has a ground state containing an even number of electrons. Molecular oxygen contains 2 unpaired electrons in different orbitals; however, covalently bound $\mathrm{O}_{2}$ has an even number of electrons. Under certain conditions, $\mathrm{O}_{2}$ can be reduced to form superoxide. Some superoxide anion $\left(\mathrm{O}_{2}{ }^{-}\right)$is formed when the mitochondrial inner membrane leaks electrons to $\mathrm{O}_{2}$ during cellular respiration. The conversion of $\mathrm{O}_{2}$ to superoxide occurs as a result of the enzymatic activities of xanthine oxidase, aldehyde oxidase, and the membrane-associated nicotinamide adenine dinucleotide phosphate (NADPH) oxidases (Halliwell, 1999, 2000; Gutteridge and Halliwell, 2000; Wolf et al., 1998).

Another radical species which is of importance to biological systems is the hydroxyl radical $(\mathrm{OH} \cdot) \cdot \mathrm{OH} \cdot$ is the most oxidizing species found in water because any oxidizing species in water is immediately converted to $\mathrm{OH}$. As a result of this, $\mathrm{OH} \cdot$ are the most reactive intermediates known and can attack and damage many biomolecules found in living cells and organs. It has been shown that formation of $\mathrm{OH} \cdot$ can occur when organs and tissues are exposed to radiation, chemicals, and/or carcinogens (Halliwell, 2000).

Uncontrolled production of reactive oxygen species (ROS) can lead to the damage of biomolecules in the human body resulting in the development of a number of diseases (Briganti and Picardo, 2003). Overproduction and/or inadequate removal of ROS can 
interfere with metabolism causing alterations in signal transduction pathways that contribute to the pathological state and injury within the cells and tissues (Trouba et al., 2002). Overproduction of free radicals has been involved in lipid and protein oxidation and modification, DNA mutations and breakage, and enzyme inactivation observed in many different tissues (Trouba et al., 2002).

Free radicals can cause lipid peroxidation of polyunsaturated fatty acids (Gate et al., 1999). A hydroxyl radical and/or other strong one electron oxidants are able to initiate lipid peroxidation by abstracting a hydrogen atom from methylene carbon in the polyalkyl carbon of the fatty acid. The fatty acid molecules with an unpaired electron are able to undergo molecular rearrangement by a reaction with $\mathrm{O}_{2}$ to generate a peroxyl radicals. The peroxyl radicals are highly reactive intermediates that are known to alter membrane structure. The radicals are also able to abstract hydrogen molecules from adjacent unsaturated fatty acids whose chemical structure makes them a target for free radical attack and results in the formation of lipid hydroperoxides and subsequently inducing the propagation of lipid peroxidation (Gate et al., 1999; Halliwell, 1999).

DNA damage can also be a consequence of free radical overproduction. Hydroxyl radicals are able to oxidize guanosine residues to 8-hydroxy-2'-deoxyguanosine (8OHdG) which is a well recognized biomarker of oxidative DNA damage. Alterations in DNA (Kasai et al., 1986) have been known to be essential in mutagenesis (Ames, 1983), carcinogenesis (Floyd, 1990), aging (Fraga et al., 1990), and the development of inflammatory diseases (Ames, 1983). Under normal conditions, altered DNA bases are 
repaired by DNA glycosylase; however, overproduction of ROS and the resulting oxidative stress are able to circumvent DNA repair mechanisms and induce mutagenesis and carcinogenesis (Chung et al., 1991).

Proteins are also a major target of free radicals and oxidative modification. ROS could cause modifications of amino acid residues in proteins resulting in changes in their functional activity thus affecting important structural and/or enzymatic properties (Dean et al., 1997; Grune et al., 1997). Oxidative reactions are in charge of mediating intra- and intermolecular cross-linking of peptides, proteins, and lipids (Davies, 1987; Stadtman, 1992; Shacter et al., 1994; Grune et al., 1997). ROS-induced protein oxidation could result in alterations in signal transduction pathways, cellular transport systems and/or enzymatic activities (Wiseman and Halliwell, 1996).

\section{Free Radical Mediated Skin Damage}

The skin provides the outermost barrier between the body and the environment and protects against environmental and chemical insults, reactive electrophiles, and oxygenderived radicals. The skin is directly exposed to a variety of occupational and environmental hazards such as radiation, chemicals and certain drugs which are known to be capable of initiating free radical reactions (Halliwell, 1999, 2000; Wolf et al., 1998). Free radicals threaten various tissues and are involved in pathological outcomes particularly the development of a variety of cutaneous disorders (Miyachi et al., 1986; Kang et al., 2001; Oztas et al., 2003). Oxidative stress and inflammation have been linked to the development of psoriasis, eczema and burns, atopic dermatitis, and contact dermatitis (Lontz et al., 1995; Filipe et al., 1997; Maresca et al., 1997; Kokcam and 
Naziroglu, 1999; Pereira et al., 1999; Wolber et al., 1996; DeLuca et al., 1998; Mundt et al., 1999; Niwa and Iizawa, 1994; Antille et al., 2002; Miyachi et al., 1985; Sharkey et al., 1991; Finnen et al., 1984; Schmidt et al., 1990; Senaldi et al., 1994; Fuchs and Milbradt, 1994; Hirai et al., 1997; Lange et al., 1998; Somani and Babu, 1989; Camera et al., 1998; Willis et al., 1998; Kimura et al., 1998; Sarnstrand et al., 1999; Fuchs et al., 2001).

\section{Phototoxic Skin Damage}

The occurrence of phototoxic skin reactions, e.g. contact photosensitization, druginduced chemotherapy and phototoxicity, porphyrias, and photosensitivity, are all well described events related to ROS production (Miyachi, 1987). UVR has been shown to induce acute and chronic changes in skin, e.g. increased vascular permeability, sunburn cell formation, epidermal cell disorganization and desquamation, leukocyte infiltration, alterations found in lysosomes and lysosomal enzymes, cell proliferation, accelerated production of melanin, and an increase in size and density of melanocytes (Pathak and Stratton, 1968). Ground state $\mathrm{O}_{2}$ is excitable by UVR and results in the production of a variety of ROS which are responsible for photochemical and photooxidative reactions that are able to damage cells (Cunningham et al., 1985). Lipid peroxidation, destruction of antioxidant enzymes, and the increased activities of cyclooxygenase and lipoxygenase also have been observed following exposure to UVR (Punnonen et al., 1991).

\section{Atopic Dermatitis}

Atopic dermatitis is characterized by cellular infiltration of lymphocytes, monocytes, and eosinophils. These inflammatory cells release a variety of bioactive substances, e.g. proinflammatory cytokines, chemokines and ROS, upon immunological and non- 
immunological stimulation. Increased oxidative stress has been associated with and contributes to the pathophysiology of atopic dermatitis (Wolber et al., 1996; DeLuca et al., 1998; Mundt et al., 1999; Niwa et al., 1994; Fuchs et al., 2001; Antille et al., 2002). ROS production has been reported to result in increased protein kinase $\mathrm{C}$ (PKC) activation with subsequent upregulation of AP-1 and hyperproduction of proinflammatory cytokines (Antille et al., 2002). Antioxidants interfere with redoxsensitive transcription factors causing an activation and/or inhibition of AP-1 at the transcriptional or post-transcriptional levels (Antille et al., 2002; Briganti and Picardo, 2003; Aggarwal et al., 2006). Antioxidant supplementation has been proposed to potentially regulate the signal transduction pathways responsible for the development of atopic dermatitis (Antille et al., 2002; Briganti and Picardo, 2003; Aggarwal et al., 2006).

\section{Psoriasis}

The development of psoriasis is characterized by abnormalities in essential fatty acid metabolism, lymphokine secretion, free radical generation, lipid peroxidation, and eicosanoid metabolism. Large amounts of superoxide have been found to be generated by inflammatory and other cell types in psoratic skin lesions thereby resulting in an upregulation of heme oxygenase-1 (HO-1) which stimulates keratinocyte proliferation (Hanselmann et al., 2001). Psoriasis patients have been shown to have an accumulation of biomarkers of lipid peroxidation, e.g. malondialdehyde, along with reduced levels of low molecular weight antioxidants present in skin, e.g. $\beta$-carotene and $\alpha$-tocopherol, and reduced activities of catalase and glutathione peroxidase (GPx) found both in plasma and red blood cells. This indicates the importance of the antioxidant defense system in the development and persistence of psoriasis (Lontz et al., 1995; Filipe et al., 1997; 
Marescaet et al., 1997; Kokcam and Naziroglu, 1999; Pereira et al., 1999; Briganti and Picardo, 2003). Therapeutic intervention using radical scavenging drugs, e.g. metronidazole, has been successful in the treatment of psoriasis (Ormedod et al., 2000; Peus et al., 2000).

Acne

ROS production by neutrophils, which are recruited in response to chemicals or bacteria, has been implicated in the irritation/destruction of the follicular wall and has been associated with the inflammatory progression of acne (Thiele et al., 1999). Several known acne therapeutic treatments using deoxcycline hydrochloride and metronidazole are partially successful due to inhibition of ROS generation (Akamatsu and Horio, 1998; Akamatsu et al., 1990). Another widely used drug for acne treatement, benzoyl peroxide, has been shown to oxidize vitamin $\mathrm{E}$ in skin inducing lipid peroxidation. This oxidative alteration of skin integrity by benzoyl peroxide increases skin permeability thereby facilitating the cellular uptake of the drug by dermal tissue. Once intracellular, benzoyl peroxide is able reduce the level of glutathione (GSH) and stimulate expression of proinflammatory cytokines and trigger production of free radicals that are essential to preclude bacterial growth (Valacchi et al., 2001).

\section{Contact Dermatitis}

The development of contact dermatitis has been associated with oxidative stress and inflammation (Miyachi et al., 1985; Sharkey et al., 1991; Finnen et al., 1984; Schmidt et al., 1990; Senaldi et al., 1994; Fuchs and Milbradt, 1994; Hirai et al., 1997; Lange et al., 1998; Somani and Babu, 1989; Camera et al., 1998; Willis et al., 1998; Kimura et al., 1998; Sarnstrand et al., 1999; Fuchs et al., 2001). Contact dermatitis is a very common 
and important condition in clinical and occupational dermatology which can be classified in to 2 categories: allergic contact dermatitis (ACD) and irritant contact dermatitis (ICD). ICD accounts for $50-80 \%$ of all skin disease cases (Fuchs et al., 2001). ACD is a cellmediated immune type IV hypersensitivity reaction while ICD is a non-immunological inflammatory skin disease. ACD requires pre-existing genetic susceptibility, an immunocompetent individual and a chemical antigen which is able to absorb transepidermally (Wakem and Gaspari, 2000). ICD can occur from exposure to a variety of industrial and in-house used chemicals.

Acids, alkalis, solvents, and oxidizing agents are all among a broad class of chemicals that can induce ICD, while allergens necessary to induce ACD are less abundant. Most skin irritants and allergens are redox inactive; however, a few of them are able to generate free radicals via metabolic activiation, redox cycling, and/or other activation mechanisms, e.g. covalent binding to cellular constituents. Organic peroxides and hydroperoxides, phenols, quinones, and primary amines are some examples of oxidizing and oxidizable agents which are able to form free radicals (Vessey et al., 1992; Vessey and Lee, 1993; Iannone et al., 1993; Timmins and Davies, 1993; Kensler et al., 1995; Taffe et al., 1987; Athar et al., 1989; Hess et al., 1991; Thompson et al., 1995; Stoyanovsky et al., 1995; Stoyanovsky et al., 1996; Bogadi-Sare et al., 1997; Shvedova et al., 2000; Svingen et al., 1981; Daugherty and Khurana, 1985; Powis, 1989; Monks et al., 1992; Hajarizadeh et al., 1994; Bekerecioglu et al., 1998; Chignel, 1985; Cavalieri and Rogan, 1985; Brennan and Schiestl, 1997; Hlavica et al., 1997). These chemicals and their radicals are able to alter cell function and/or trigger release and induction of 
endogenous chemicals in skin, e.g. histamine, components of the complement pathway, arachidonic acid metabolites, ROS and cytokines (Corsini and Galli, 1998).

Chemical exposures can cause the production and release of inflammatory cytokines by resident epidermal cells, dermal fibroblasts, endothelial cells, and invading inflammatory cells facilitating the development of skin irritation. Keratinocytes, representing $95 \%$ of epidermal cells (McKenzie and Sauder, 1990), are known to contribute to the development of ICD and ACD by generating and releasing pro-inflammatory cytokines (IL-1 $\alpha$ and TNF- $\alpha$ ) and leukocyte recruitment.

Antioxidants are capable of modulating the effects of skin irritation. Application of substances that possess antioxidant properties such as $\alpha$-hydroxyacids (Morreale and Livrea, 1997; Barardesca et al., 1997), ascorbate, uric acid, glutathione, and vitamin E (Weber et al., 1995; Thiele et al., 1995) have been shown to modulate stratum corneum barrier function and prevent skin irritation (Barardesca et al., 1997). It is important to note that intracellular redox homeostasis is modulated by sulfur containing low molecular weight antioxidants particularly glutathione (Meister, 1988; Schafer and Buettner, 2001; Sies, 1999).

Chemical irritants are able to activate NFKB via mechanisms involving ROS production in the skin (Allen and Tresini, 2000; Bauerle and Henkel, 1994; Sen and Packer, 1996; Flohe et al., 1997; Gius et al., 1999) which have been reported to subsequently trigger the production of IL-1, IL-6, TNF- $\alpha$, and the expression of adhesion molecules expressed in 
human endothelial cells and keratinocytes (Corsini and Galli, 1998; McKenzie and Sauder, 1990; Kupper, 1990). NFkB activation has been associated with the induction of contact hypersensitivity while antioxidants, such as $\alpha$-tocopherol and ascorbic acid, have been shown efficiently ameliorate the clinical manifestations of contact dermatitis (Miyachi et al., 1985; Sharkey et al., 1991; Finnen et al., 1984; Schmidt et al., 1990; Senaldi et al., 1994; Fuchs and Milbradt, 1994; Hirai et al., 1997; Lange et al., 1998; Somani and Babu, 1989; Camera et al., 1998; Willis et al., 1998; Kimura et al., 1998; Sarnstrand et al., 1999; Fuchs et al., 2001; Briganti et al., 2001; Briganti and Picardo, 2003).

\section{Vitiligo}

Vitiligo is a pigmented disease of the skin which occurs due to the programmed cell death of melanocytes due to their inherent sensitivity to oxidative stress arising from the formation of melanin toxic intermediates upon UV exposure. Vitiligo manifests itself as expanding depigmented lesions of the skin (LePoole et al., 1993; Jimbow et al., 2001). The mechanism by which vitiligo occurs is not well understood; however, the formation of radical intermediates formed during melanin synthesis has been implicated in the predisposition of melanocytes to self-destruction (Lerner, 1971). The initial pathogenic event involved in melanocyte degeneration is oxidative stress (Jimbow et al., 2001). An imbalance in the antioxidant system as exhibited by altered enzymatic activity of thioredoxin reductase, catalase (Schallreuter et al., 1991), superoxide dismutase, and glutathione reductase (Schallreuter et al., 1986, 1987) has been proposed to play a pivotal role for depigmentation of the skin of patients with vitiligo. Consequently, it was 
demonstrated that melanocytes from vitiligo patients are extremely sensitive to high doses of UVR and treatments with pro-oxidant chemicals (Jimbow et al., 2001).

\section{Rosacea}

Rosacea is a skin disorder which presents as central facial distribution of erythema. The pathophysiology is not well understood but it is believed to occur as a result of neurovascular hyperreactivity, infection, UV light, and possibly numerous inflammatory mediators (Dahl, 2001; Millikan, 2003). The presence of ROS has been proposed to contribute to the clinical outcomes of rosacea (Akamatsu et al., 1990). ROS have been proposed to be a key event involved in neutrophil inflitration and damage of facial follicles in patients with rosacea (Miyachi et al., 1986). The subsequent oxidative burst by neutrophils has been linked to the development of facial erythema observed in patients with rosacea (Marks, 1968). Activation of matrix metalloproteinases (MMPs) in skin has been shown to occur as a result of UV-light induced ROS production. This activation of MMPs increases the destruction of dermal collagen contributing to the development of rosacea (Kang et al., 2001). Some of the pathophysiologic mechanisms that are involved in photoaging have been also implicated in the development of rosacea (Dahl, 2001; Marks, 1968; Neumann and Frithz, 1998).

\section{Carcinogenesis}

Chemical carcinogens induce various stages of cancer development via metabolic modifications of cellular compartments and molecular events. Chemicals which act as carcinogens are classified as genotoxic or epigenetic based upon their mechanism of action. Genotoxic agents directly damage DNA leading to a mutation, while epigenetic 
chemicals act through indirect DNA damaging mechanisms. Epigenetic agents modulate cell growth and death via a mechanism which is not fully understood (Valko et al., 2006).

Cancer, a multistage process, can occur by the cumulative action of multiple events within a single cell. The development of malignant skin cancers is a multistage process involving 3-steps including initiation, promotion, and progression, which are mediated by various factors derived from environmental, biochemical, cellular, and molecular events (Marnett, 2000). The initiation stage results in a permanent alteration of the cellular genotype (Black, 1993). ROS can affect all stages of multistage carcinogenesis. Free radical production has been shown to induce DNA damage and trigger the genetic alterations observed in several proto-oncogenes and tumor suppressor genes affecting the integrity of epidermal cells by making them resistant to signals for terminal differentiation (Marnett, 2000). Excessive-oxidative DNA damage could lead to mutation, alteration of phenotypic expression, and cell death (Taffe and Kensler, 1989). There is also evidence that ROS play a prominent role in skin tumor carcinogenesis through a secondary mechanism involving activation of pro-carcinogens, e.g. 7,12dimethylbenz(a)anthracene (DMBA), in skin (Quintanilla et al., 1986).

Tumor promotion is the process of clonal expansion of cells containing the altered DNA by induction of cell proliferation and/or inhibition of apoptosis. The cancer promotion stage requires the constant presence of a tumor promoter for the development of an identifiable focal lesion (Loft and Poulsen, 1996). Conversion, which is the $1^{\text {st }}$ stage of promotion, is a partially reversible step and occurs when initiated cells are shifted to a 
state of increased promotability (Ordman et al., 1985). Propagation, known as the $2^{\text {nd }}$ stage of promotion, is an irreversible process. Tumor promoters exert their effects at the stage of cell propagation and differentiation probably through accelerated ROS production (Kawanishi et al., 2001).

Tumor progression is the $3^{\text {rd }}$ stage during carcinogenesis and involves cellular and molecular changes by inducing the transition of pre-neoplastic to neoplastic lesions (Klaunig and Kamendulis, 2004; Marnett, 2000). This is an irreversible process and is characterized by the cellular transformation from benign to malignant state involving genetic instability and distruption of chromosome integrity (Valko et al., 2006). Oxidizable compounds, e.g. benzoyl peroxide, have been reported to have an increased effect on the malignant conversion of skin tumors (Athar et al., 1989; Warren et al., 1993). Inflammation has been shown to be a critical component of tumor progression (Valko et al., 2006). Free radicals produced during chronic inflammation can induce a number of alterations including gene mutations and post-translational modifications of cancer regulating proteins (Valko et al., 2006). These alterations can lead to the disruption of important cellular events and processes, e.g. DNA repair, cellular checkpoints, differentiation and apoptosis (Hussain et al., 2003; Coussens and Werb, 2002).

Production of reactive oxygen species can occur both endogenously and exogenously (Trenam et al., 1992; Halliwell and Cross, 1994; Powers and Hamilton, 1999). The formation of these radicals can have many adverse effects on skin constituents. Molecular 
changes via oxidation of proteins, DNA, and lipids are capable of manifesting dermal toxicity and contributing to a number of pathological skin conditions, e.g. phototoxicity, photoaging and carcinogenesis.

\section{$\underline{\text { Antioxidant Network }}$}

The skin relies on an interactive antioxidant network that is imperative to protect against oxidant stress induced by exposures to sunlight, pollution, and chemicals (Thiele et al., 2000). Intracellular antioxidants include low molecular weight scavengers of oxidizing species and enzymes, e.g. superoxide dismutase (SOD), catalase, and glutathione peroxidase (GPx), which degrade superoxide and hydroperoxides. These antioxidant systems prevent the uncontrolled formation of free radicals, regulate activation of oxygen species, and ameliorate ROS reactions with biological constituents (Chaudiere and Ferrari-Iliou, 1999). Two antioxidant systems are present in the skin environment that control ROS production by enzymatic and non-enzymatic mechanisms. These antioxidants interact within skin thereby providing efficient protection from oxidative insults.

\section{Enzymatic Antioxidants}

The antioxidant enzymes primarily function within cells. One of the principal intracellular enzymes which removes $\mathrm{O}_{2} \cdot{ }^{-}$is superoxide dismutase (SOD) (McCord and Fridovich, 1969; Fridovich, 1974). SOD is present in the cytosol, mitochondrial matrix, and is also present in the extracellular compartment bound to cellular surfaces and collagen. It removes $\mathrm{O}_{2} \cdot{ }^{-}$by converting it to hydrogen peroxide $\left(\mathrm{H}_{2} \mathrm{O}_{2}\right)$ which is also known as a potent oxidant that is toxic to cells. Catalase is an enzyme present in the peroxisomes of plants, animal cells, and aerobic bacteria (Mates et al., 1999). Catalase 
detoxifies $\mathrm{H}_{2} \mathrm{O}_{2}$ (Levander, 1987) by converting it to $\mathrm{H}_{2} \mathrm{O}$ and $\mathrm{O}_{2}$. Glutathione peroxidase (GPx), specifically the selenium-dependent GPx, also converts $\mathrm{H}_{2} \mathrm{O}_{2}$ into water via the oxidation of reduced glutathione (GSH) to the oxidized form (GSSG). Glutathione reductase is a flavoprotein that recycles GSH by conversting GSSG to GSH via the oxidation of the cofactors NADPH to NADP+ (Sipowicz et al., 1997). These enzymatic activities are present in higher concentration in the epidermis than in the dermis of rodents and humans (Shindo et al., 1994).

\section{Nonenzymatic Antioxidants}

Because alterations in antioxidant enzymatic activity can occur due to non-oxidative factors, nonenzymatic antioxidants are used as major tool for the identification of oxidative stress (Halliwell, 1999; Podda and Grundmann-Kollman, 2001; Gate et al.,1999; Kohen and Gati, 2000). Nonenzymatic antioxidants known as low molecular weight antioxidants, e.g. L-ascorbic acid, uric acid, and GSH, are water-soluble and

present in the cellular and extracellular compartments. The lipid-soluble antioxidants vitamin $\mathrm{E}$ and ubiquinol are associated with cellular and inner mitochondrial membranes. The epidermis has been shown to possess higher levels of nonenzymatic antioxidant constituents than the dermis (Gate et al., 1999; Podda and Grundmann-Kollman, 2001; Pinnell, 2003)

The low molecular weight antioxidants function in tissues as a coordinated network (Podda and Grundmann-Kollman, 2001). Generation of ROS in lipophilic compartments is quenched by the presence of $\alpha$-tocopherol. Oxidized tocopherol can be regenerated by ubiquinol or L-ascorbic acid (Kagan et al., 1992) resulting in the formation of 
dehydroascorbic acid. The dehydroascorbate can then be reduced by glutathione (Pinnell, 2003). This mechanism is involved in the recycling of $\alpha$-tocopherol at the expense of ascorbate and GSH (Figure 2).

\section{L-Ascorbic Acid}

L-ascorbic acid, otherwise known as vitamin $\mathrm{C}$, is the body's major aqueous-phase reductant (Colven and Pinnell, 1996; Rumsey et al., 1999) and is a major antioxidant present in the skin. L-ascorbic acid is synthesized by plants (Gate et al., 1999) and rodents while human beings must obtain ascorbate from the diet (Nishikimi et al., 1994). The concentration of L-ascorbic acid in the skin of humans is 15 -fold greater than glutathione, 200-fold greater than vitamin E, and 1000-fold greater than ubiquinol (Shindo et al., 1994). Human skin has an average of $7600 \mathrm{nmol}$ ascorbate/g tissue in the epidermis and $1300 \mathrm{nmol}$ ascorbate/g tissue in the dermis (Pinnell, 2003).

Ascorbate is an $\alpha$-ketolactone that exists as a hydrophilic monovalent hydroxyl anion. Acting as an antioxidant, L-ascorbic acid donates an electron forming an ascorbyl radical. Ascorbyl radicals are more stable than other free radicals and are capable of acting as free radical scavengers. Loss of the second electron results in the formation of dehydroascorbic acid which can be regenerated by dehydroascorbic acid reductase to ascorbate (Colven and Pinnell, 1996; Pinnell, 2003).

Along with antioxidant function, the presence of 1-ascorbic acid is essential for collagen biosynthesis, and serves as a cofactor for prolyl and lysyl hydroxylases, enzymes which provide molecular stability and intermolecular, cross-linking in various tissues (Kivirikko 
and Myllya, 1985). Decreased levels of 1-ascorbic acid have been known to cause an inhibition of elastin biosynthesis (Davidson et al., 1997), and reduce formation of melanin pigment in skin by suppressing tyrosinase activity (Maeda and Fukuda, 1996). It has also been demonstrated that L-ascorbic acid improves epidermal skin barrier function (Pasonen-Seppanen et al., 2001; Ponec et al., 1997; Savini et al., 2002). Recent reports show the ability of ascorbic acid to regulate factors influencing gene expression, apoptosis, and other cellular function (You et al., 2000). Ascorbate, due to its antioxidant ability, is able to protect against cell death triggered by a variety of stimuli. Ascorbate is also believed to regulate AP-1 as well as the Fos and Jun protein superfamilies (Valko et al., 2006; Lopez-Lluch et al., 2001; Catani et al., 2001).

Ascorbate has been shown to provide efficient protection against membrane lipid peroxidation via a vitamin E recycling pathway (Wefers and Sies, 1988; Retsky et al., 1999). It serves to regenerate oxidized vitamin $\mathrm{E}$ by functioning as a reducing agent (Pugliese, 1998; Carr and Frei, 1999; Kojo, 2004). Ascorbate is able to react with superoxide and peroxyl radicals resulting in the formation of an ascorbyl radical (Beyer, 1994; Colven and Pinnell, 1996; Pinnell, 2003). Ascorbyl radical can be converted back to ascorbate via the glutathione/NADPH reaction regulated by dehydroascorbate reductase (Stocker et al., 1986; Weber et al., 1999).

\section{Vitamin $E$}

While humans synthesize other antioxidants, such as GSH and ubiquinol, vitamin E has to be received via dietary intake. Some of the common sources of vitamin E are fresh vegetables, vegetable oils, cereals, and nuts (Thiele et al., 2005). Vitamin E is the body's 
major lipid soluble antioxidant (Packer et al., 2001, Munne-Bosch and Alegre, 2002). It consists of 8 molecular forms of which 4 are tocopherols and 4 are tocotrienols. The molecular structure of the forms consists of a hydrophobic prenyl tail which anchors in membranes. The difference in tocopherols and tocotrienols is in the structure of the prenyl tails. Tocopherols have a linear, saturated tail while tocotrienols have a nonlinear unsaturated tails. Tocopherol is a 6-chromanol derivative containing a phenolic $\mathrm{OH}$ group at carbon 6 and a branched side chain with chiral $\mathrm{C}$ atoms at 2, 4, and 8 (Nachbar and Korting, 1995; Fuchs et al., 2003). Each form has an identical chromanol head with $\alpha-, \beta-, \chi-$, and $\delta$-isomers dependent upon different substituents at positions 5 and 7 of the ring (Nachbar and Korting, 1995). Both tocopherol and tocotrienol contain an essential hydroxyl group necessary for its antioxidant properties, while methyl groups have been shown to vary in number and position.

The antioxidant activity of vitamin $\mathrm{E}$ in humans predominately involves $\alpha$-tocopherol due to the presence of a specific $\alpha$-tocopherol transporter protein, which selectively transfers $\alpha$-tocopherol into lipoproteins (Azzi et al., 2000; Gohil et al., 2004). As a result, $\alpha$-tocopherol is considered to be the most important of the isomers. It comprises $90 \%$ of the tocopherols in tissue with the greatest biological activity (Goodman and Gilman, 1990). The relative antioxidant efficiency of tocopherols in the lipid systems is $\alpha>\beta>\chi>\delta$ (Munne-Bosch and Alegre, 2002). Tocopherols have shown greater antioxidant capabilities in lipid structures than tocotrienols in the epidermis of the skin (Packer et al., 2001; Packer and Valacci, 2002). 
Vitamin $\mathrm{E}$ is one of the most important nonenzymatic, lipid-soluble antioxidant (Chow, 1990; Furuse, 1987). The protective effect of vitamin $\mathrm{E}$ is due to its ability to reduce free radicals, e.g. oxygen-centered and/or lipid derived radicals (Valko et al., 2006). The major antioxidant function of vitamin $\mathrm{E}$ is to prevent damage caused by these free radical particularly lipid peroxidation. The role of vitamin $\mathrm{E}$ as an antioxidant is mediated by the phenolic OH group of the chromanol ring. $\alpha$-Tocopherol is incorporated into biological membranes and localized near polyunsaturated fatty acids of membrane phospholipids. Reactive oxygen species react with the double bonds of lipids resulting in the formation of a lipid-derived radicals. The addition of molecular oxygen transforms the lipid radical into a lipid peroxyl radical. The lipid peroxyl radical is then able to attack unsaturated lipids thereby resulting in the formation of additional lipid radicals and lipid hydroperoxide (Huang et al., 1988; Nachbar and Korting, 1995). This radical chain reaction threatens the structural integrity of the membrane (Munne-Bosch and Alegre, 2002). Tocopherols and tocotrienols are capable of scavenging the peroxyl radical thereby limiting propagation of the chain reaction. The initial oxidation of tocopherol results in the formation of a metastable tocopheroxyl radical which can be reduced by ascorbate to tocopherol or react with another lipid peroxyl radical resulting in the formation of a tocopherol quinone (Kamal-Eldin and Appelqvist, 1996). As a result of these reactions, tocopherol is able to quench two peroxyl radicals (Thiele et al., 2005).

The physiologic ratio of tocopherols to polyunsaturated phospholipids is 1:1000. As a result, the recycling of tocopherol is necessary in order to maintain sufficient antioxidant protection (Thiele et al., 2005). Once vitamin E is oxidized, ascorbate or glutathione are 
able to regenerate tocopherol from the tocopheroxyl radical (Packer et al., 1979). In vitro studies have demonstrated that ubiquinol 10 (coenzyme Q10) has been shown to be capable of preventing the photo-oxidation of $\alpha$-tocopherol by recycling mechanisms (Stoyanovsky et al., 1995). Depletion of these water-soluble antioxidants can alter the antioxidant network and subsequently diminish the antioxidant function of vitamin $\mathrm{E}$ leading to impaired protection of lipid membranes as well as the lipophilic constituents of organs and tissues (Thiele et al., 2005).

Providing the outermost defense system for the protection of the body, the stratum corneum is the first skin layer to encounter physical, chemical, and biological agents. Vitamin E plays an important and pivotal role in protecting the lipid structures of the stratum corneum and guarding the proteins and lipids from oxidative stress (Pinnell, 2003). A variety of studies investigating the efficiency of non-enzymatic antioxidants in the stratum corneum revealed that vitamin $\mathrm{E}$ is the predominant and major physiological antioxidant providing a sufficient skin barrier (Thiele et al., 2001). Vitamin E is especially abundant in the stratum corneum due to delivery via the sebum (Podda et al., 1996; Thiele, 2001). The epidermis of human skin has an average of $34.2 \mathrm{nmol} / \mathrm{g}$ tissue of $\alpha$-tocopherol, while the dermis has $18.0 \mathrm{nmol} / \mathrm{g}$ tissue of $\alpha$-tocopherol (Pinnell, 2003).

\section{Glutathione}

Glutathione (GSH) is water-soluble and one of the body's major sulfur-containing antioxidants. GSH synthesis has been shown to be activated by oxidants. GSH and its precursor, N-acetyl-cysteine (NAC), have been shown to inhibit the production and release of the inflammatory mediators including TNF (Peristeris et al., 1992; Zimmerman 
et al., 1989; Ghezzi et al., 2005). The GSH system is one of the body's first lines of defense against peroxidation. The GSH system includes glutathione peroxidase, glutathione reductase, and glutathione transferase. Glutathione peroxidase (GPx) acts to detoxify $\mathrm{H}_{2} \mathrm{O}_{2}\left(\mathrm{H}_{2} \mathrm{O}_{2}+\mathrm{GPx}+\mathrm{GSH} \rightarrow \mathrm{GSSG}+\mathrm{H}_{2} \mathrm{O}\right)$ prior to catalase involvement; however, in some cases catalase is necessary to provide sufficient removal of $\mathrm{H}_{2} \mathrm{O}_{2}$ (Mates et al., 1999; Valko et al., 2006).

GSH refers to the reduced form of GSH. GSH is a tripeptide $\gamma$-L-glutamyl-L-cysteinylL-glycine and is the major nonprotein thiol in the body. GSH does not easily enter into cells, therefore, intracellular production of GSH occurs as a result of synthesis. Three amino acids, L-glutamine, L-cysteine, and L-glycine, are necessary for the assembly of GSH by the 2 enzymes: $\gamma$-glutamylcysteine synthetase, and glutathione synthase (Gate et al., 1999).

The major protective roles of GSH against oxidative stress within the tissue are that: (1) GSH is a cofactor for several detoxifying enzymes such as GPx and glutathione transferase; (2) it participates in amino acid transport through the plasma membrane; (3) GSH scavenges hydroxy radicals directly, detoxifies $\mathrm{H}_{2} \mathrm{O}_{2}$ and lipid peroxide by glutathione peroxidase; (4) GSH is able to regenerate vitamin E and C to their active reduced forms (Masella et al., 2005).

GSH has been known to play an important role in xenobiotic detoxification by conjugation facilitated by glutathione-S-transferase. This reaction increases the 
hydrophilic properties of xenobiotics thereby favoring elimination of the latter from the body (Gate et al., 1999). As a result of its role in xenobiotic transformation and antioxidant capabilities, GSH is found in large quantities in organs which are exposed to toxins including the kidney, liver, and lungs (De Leve and Kaplowitz, 1991). GSH plays a major role in protein and DNA synthesis, amino acid transport, and cellular detoxification (Gate et al., 1999).

GSH is an important quencher of free radicals and is able to donate an electron or a hydrogen atom via an oxidation-reduction pathway. It is able to scavenge hydroxyl radicals and singlet oxygen. The reaction between GSH and hydroxyl radical results in the formation of thiyl radicals, GS. These radicals are less reactive than hydroxyl radicals and are able to react with ferrous iron. Glutathione thiyl radicals are able to combine into a disulfide (GSSG). Glutathione disulfide must be reduced again to form $\mathrm{GSH}\left(\mathrm{GSSG}+\right.$ glutathione reductase $\left.+\mathrm{NADPH} \rightarrow 2 \mathrm{GSH}+\mathrm{NADP}^{+}\right)$to serve as an $\mathrm{H}$ donor.

GSH has also been shown to protect the cells against apoptosis. The protection is provided by a multifactorial mechanism involving detoxification and modulation of cellular redox state via the regulation of redox-sensitive cell signaling pathways and the interaction of pro- and anti-apoptotic signals (Masella et al., 2005).

Within the skin, GSH is mostly present in the epidermis with a relatively small amount formed in the dermis (Tyrell and Pidoux, 1986). The stratum corneum contains fewer 
thiols compared to the nonkeratinized lower layers of the epidermis. Under normal conditions, the GSH/GSSG ratio in the cytosol is 1000:30 (Hwang et al., 1992; Ghezzi et al., 2005). A large ratio of GSH/GSSG indicates more GSH than GSSG; while, a small GSH/GSSG ratio indicates that GSH has been oxidized to GSSG during oxidative metabolism. The human epidermis contains on average $480 \mathrm{nmol} \mathrm{GSH} / \mathrm{g}$ tissue while the dermis has $84 \mathrm{nmol} \mathrm{GSH} / \mathrm{g}$ tissue (Pinnell, 2003).

The nonenzymatic antioxidants within skin tissues work together forming an antioxidant network which is an important mechanism of prevention of free radical oxidative tissue damage. During oxidative stress, ROS are reduced by $\alpha$-tocopherol thereby resulting in the formation of a tocopheroxyl radical. The oxidized tocopheroxyl radical is then be regenerated by L-ascorbic acid to form dehydroascorbate. The dehydroascorbate can then be reduced or recycled by glutathione (Pinnell, 2003). The overproduction of ROS and other free radicals are able to overwhelm the antioxidant network and subsequently increase the susceptibility of organs and tissues to the development of oxidative stress (Figure 2).

The skin is continuously exposed to a variety of physical and chemical agents, e.g. ultraviolet radiation, phenolic compounds and organic peroxides of occupational and environmental origin. Skin contact with chemicals during manufacturing is considered to be the major route of exposure. Toxic outcomes of exposure can lead to the development of a variety of skin disorders such as rashes, burns, inflammation, irritant and allergic dermatitis, and cancer promotion (Ames et al., 1975; Bracher et al., 1990). In most cases, 
the underlying mechanism by which these chemicals cause dermal toxicity is not well understood.

\section{Cumene Hydroperoxide}

Cumene hydroperoxide (Cum- $\mathrm{OOH})$ is produced by the oxidation of cumene with air in the presence of aqueous sodium bicarbonate acting as a catalyst. The production occurs at $\sim 130^{\circ} \mathrm{C}$ (Lewis, 1993). Approximately 1.1 million pounds of Cum-OOH are produced in the United States, while 7 billion pounds are consumed yearly indicating that the majority used in the US is imported (Lewis, 1993). The majority (95\%) of the Cum$\mathrm{OOH}$ produced in the US is from the oxidation of cumene. This cumene is then cleaved to form acetone and phenol (Grayson, 1985). It is also used as a catalyst for rapid polymerization, as a curing agent for unsaturated polyester resins and as an initiator for the polymerization of styrene and acrylic monomers, and a chemical intermediate for the cross-linking agent, e.g. dicumyl peroxide (Lewis, 1993).

Exposure to $\mathrm{Cum}-\mathrm{OOH}$ can take place in occupational or environmental settings. Workplace exposures to $\mathrm{Cum-OOH}$ can occur through contact with emissions during its use in the production of acetone and phenol (Grayson, 1985; Lewis, 1993). Cum-OOH may be released into the environment by industrial discharges and spills, and as a byproduct of fuel oil slicks exposed to UV light. Cumene can react with alkylperoxy radicals and oxygen in natural waters to form $\mathrm{Cum-OOH}$ which is easily decomposed by UV light. 
Dermal exposure to organic peroxides and hydroperoxides such as $\mathrm{Cum}-\mathrm{OOH}$ has been shown to cause a delayed reaction in skin resulting in severe erythema, edema and vesiculation (Floyd and Stokinger, 1958). Little data exist on the specific effects of dermal exposure to $\mathrm{Cum}-\mathrm{OOH}$ in humans. Dermal exposure can result in a number of toxic outcomes such as allergic and irritant contact dermatitis, rash, defattening of the dermis and hair loss, burns, and epidermal hyperplasia (Hathaway et al., 1996; Adams, 1999). Animals dermally exposed to Cum-OOH exhibited strong irritation (Eastman Kodak, 1964), skin necrosis, lethargy, hyperemia, and weight loss (Dow Chemical, 1952).

Exposure to Cum-OOH can also cause cytotoxic effects such as intracellular oxidative stress and cellular necrosis (Persoon-Rothert et al., 1992). Some cells have exhibited a physiological resistance to $\mathrm{Cum}-\mathrm{OOH}$ due to the induction of antioxidant enzymes such as SOD, GPx, and glutathione reductase. The addition of free radical scavengers results in decreased cytotoxicity due to inhibition of lipid peroxidation (Munkres and Colvin, 1976). Cum-OOH is believed to be genotoxic due to its ablility to induce DNA damage and mutations. Cum-OOH exposure in vitro is capable of inducing DNA single strand breaks (Cohen et al., 1984). The addition of the antioxidant uric acid prevents DNA damage indicating that the formation of hydroperoxyl radicals were genotoxic (Cohen et al., 1984).

Normal human epidermal keratinocytes are able to metabolize organic peroxides such as Cum-OOH resulting in the formation of methyl radicals (Iannone et al., 1993). 
Subsequent studies showed that $\mathrm{Cum}-\mathrm{OOH}$ induced the formation of 2 radical species in keratinocytes thus providing evidence that dermal cells are able to metabolize cumene hydroperoxide into oxygen and carbon centered radicals (Athar et al., 1989; Kensler et al., 1995; Taffe et al., 1987). Topical application of Cum-OOH to murine skin flaps resulted the production of radicals which are then able to interact with ascorbate in the viable cells of the epidermis or dermis (Timmins and Davies, 1993). These radicals are then able to undergo addition, hydrogen-abstraction, or substitution reactions and cause damage and/or modification of proteins, DNA and lipids (Kensler, 1989; Trush and Kensler, 1991; Kensler et al., 1995). This radical production and resulting oxidative stress indicated a possibility for Cum-OOH as a potential promoter (Athar, 1989; Trush and Kensler, 1991).

\section{Phenol}

Phenol $(\mathrm{PhOH})$ ranks in the top 50 in production volumes for chemicals produced in the United States. It is used in a variety of manufacturing processes and products. The most common use of $\mathrm{PhOH}$ is as an intermediate in the production of phenolic resins. It is also used for the manufacturing of nylon and synthetic fibers and bisphenol A. PhOH is also present within a wide variety of consumer products such as ointments, ear and nose drops, cold sore creams, mouthwashes, analgesic rubs, throat lozenges, and antiseptic lotions. PhOH is also a major metabolite of benzene (Subrahmanyam et al., 1991). It is a colorless to white solid man-made compound, but when found in commercial products it is a liquid (ATSDR, 1997). 
An estimated 584,000 people are exposed to $\mathrm{PhOH}$ at work annually. In the workplace, exposure to $\mathrm{PhOH}$ can occur by breathing contaminated air and via contact with the skin. Skin contact during manufacturing is considered the major route of exposure (ACGIH, 1991; ATSDR, 1997). Dermal exposure to phenolic compounds is known to cause skin rashes, burns and ulceration, dermal inflammation and necrosis, irritant and allergic contact dermatitis, eczematous "black-spot" dermatitis, leukoderma, and cancer promotion (Ames et al., 1975; Bracher et al., 1990)

Dermal contact allows for $\mathrm{PhOH}$ to easily penetrate the skin and enter the body. The amount of $\mathrm{PhOH}$ entering the body is dependent upon the concentration of $\mathrm{PhOH}$, the length of time of skin contact, and the area of exposed skin. A large skin area exposed to a diluted concentration of area of will have a greater absorbed concentration than a smaller area of skin exposed to an equal $\mathrm{PhOH}$ concentration of the same volume. Shortterm exposure of $\mathrm{PhOH}$ to the skin of animals caused blister and burn formation. Death has also been observed following dermal exposure to PhOH (ATSDR, 1997).

Topical application of $\mathrm{PhOH}$ directly affects the skin by inducing inflammation and tissue necrosis (Horch et al., 1994; Merliss, 1972; Trupmann and Ellenby, 1979). Severe edema, erythema, and necrosis occur as a result of application of PhOH $(100 \mathrm{mg} / \mathrm{kg}$; Brown et al., 1975 or $107.1 \mathrm{mg} / \mathrm{kg}$; Conning and Hayes, 1970). Murine studies have been done to determine the dose-response and time-course of skin irritation and inflammation (Patrick et al., 1985). Application of $12 \mathrm{mg} / \mathrm{cm}^{2} / \mathrm{kg} \mathrm{PhOH}$ has been shown to induce swelling of the ear pinna following 1-hour exposure. Application of 18 
$\mathrm{mg} / \mathrm{cm}^{2} / \mathrm{kg}$ resulted in a persistent inflammation which lasted 6 weeks (Patrick et al., 1985). The severity of $\mathrm{PhOH}$-induced skin irritation increases in a dose-dependent fashion.

Measurements have also been done in humans to assess the absorption of $\mathrm{PhOH}$ through the skin. The percutaneous absorption (mg PhOH absorbed through the skin per hour/ mg $\mathrm{PhOH}$ per $\mathrm{m}^{3}$ of air) of $\mathrm{PhOH}$ was determined to be equivalent of $0.35 \mathrm{~m}^{3} /$ hour (Piotrowski, 1971). $\mathrm{PhOH}$ easily absorbs through the skin where it is rapidly excreted in the urine as free $\mathrm{PhOH}$ or conjugates within 24 hours (Piotrowski, 1971).

The skin is considered the primary route of entry for occupational exposure to $\mathrm{PhOH}$ (ACGIH 1991). $\mathrm{PhOH}$ and phenolic compounds are known to cause a variety of cytotoxic and genotoxic effects in skin (Adam, 1980; Kensler et al., 1995; McCartney, 1996; Toro et al., 1996; Shvedova et al., 2000). Subtoxic concentrations have been shown to cause oxidative stress in normal human keratinocytes (Shvedova et al., 2000). The observed oxidative stress and possibly the resulting toxicity of $\mathrm{PhOH}$ are most likely due to its ability to form oxygen radicals (Shvedova et al., 2000).

$\mathrm{PhOH}$ is a redox-cycling aryl compound (Stoyanovsky et al., 1995) which provides a good substrate for peroxidase (Hewson and Dunford, 1976; Dunford, 1995). The oneelectron oxidation of $\mathrm{PhOH}$ and phenolic compounds by oxidative enzymes, e.g. peroxidase, prostaglandin synthetase and tyrosinase, leads to the formation of phenoxyl radical intermediates (Dunford and Adeniran, 1986; Sakurada et al., 1990; Einstein et al., 
1992). These phenoxyl radicals are able to be reduced by glutathione and other antioxidants thus regenerating the phenolic compound (Ross et al., 1985; Subrahmanyam and O'Brien, 1985; Schreiber et al., 1989). There is limited evidence to support the redox-cycling of PhOHs in vitro or in vivo. An in vitro study using HL-60 lymphoblast cells found intracellular redox cycling of $\mathrm{PhOH}$-induced severe oxidative stress (Goldman et al., 1999; Day et al., 1999; Subrahmanyam et al., 1991). PhOH redoxcycling and its contribution to oxidative stress and injury are important factors facilitating the PhOH-induced dermal toxicity.

\section{Ultraviolet Light}

Solar radiation is an important factor triggering skin damage. The skin is extremely susceptible to UV radiation. Overexposure to UV light has been associated with the manifestation of a variety of skin disease, e.g. premature aging and carcinogenesis (Davies and Forbes, 1986; Jurkiewicz and Buettner, 1994). Cutaneous melanoma has been shown to increase in incidence after chronic exposure to sunlight (MacKie and Rycroft, 1988) with approximately 62,190 new cases of melanoma diagnosed yearly (ACS, 2006). From 1973 to 2006 , there has been a $50 \%$ increase in the mortality rate for melanoma (ACS, 2006). There is an inverse correlation between latitude and sun exposure as well as time of day and the development of melanoma incidence (Kvam and Dahle, 2003). At noon during summer during which the maximal UVR is reaching the earth, the minimal edema dose (MED) can vary from $250 \mathrm{~mW} / \mathrm{m}^{2}$ at $20^{\circ} \mathrm{N}$ latitude to 125 $\mathrm{mW} / \mathrm{m}^{2}$ at $60^{\circ} \mathrm{N}$ latitude (NASD, 1997). Although sunburn reactions are widely studied, the mechanisms responsible for skin damage are not fully explored (Fuchs and Kern, 1998). 
The solar radiation reaching the earth's surface consists mainly of ultraviolet A (320-400 $\mathrm{nm}$ ) and ultraviolet B radiation $(290-320 \mathrm{~nm})$ with over $95 \%$ represented by UVA (Sander et al., 2002). Both UVA and UVB are able to induce photo-oxidative stress, skin injury and premature aging (Gasparro, 2000). The damaging effects of UV radiation on the skin manifest themselves through the generation of free radical species. ROSmediated UV damage has been reported to cause DNA, protein, and lipid modifications (Beehler et al., 1992; Ogura et al., 1991). UV exposure has been shown to induce expression of surface lectins (Condaminet et al., 1997), and the release of inflammatory cytokines in a squamous carcinoma keratinocyte cell line (Leverkus et al., 1998).

The generation of reactive oxygen species and subsequent oxidative stress are the key mechanisms of phototoxicity due to UVA exposure (Gasparro, 2000). UV-initiated ROS production has been detected in human skin cells (Peus et al., 1998; Gniadecki et al., 2000; Peus and Pittelkow, 2001), skin homogenates (Nishi et al., 1991), and skin flaps ex vivo (Jurkiewicz and Buettner, 1994; Yasui and Sakurai, 2000; Herrling et al., 2003).

Antioxidants play an important role in modulating the effects of UVA radiation (Kvam and Dahle, 2003). Exposure to UVA has been shown to decrease antioxidant levels (Fuchs et al., 1989), inactivate antioxidant enzymes (Shindo et al., 1993), and increase lipid peroxidation found in skin homogenates (Ogura et al., 1991). Depletion of GSH in fibroblasts is strongly associated with increased susceptibility to UVA (Tyrrell and 
Pidoux, 1986). Increased lipid peroxidation was found in melanocytes following exposure to UVA (Kvam and Dahle, 2003). Excessive UVA exposure has also been shown to induce epidermal tumor formation (Ananthaswamy and Pierceall, 1990).

Depletion of the stratospheric ozone layer has increased the amount of ultraviolet B radiation reaching the earth's surface (Noonan et al., 2003). DNA absorbs light maximally from $245-290 \mathrm{~nm}$ which is in the UVB and UVC regions of the spectrum. Under normal conditions, the outer cornified layers of the skin are efficiently capable blocking UVC penetration and thus protecting sensitive proliferating basal cells of the epidermis. UVB is more prevalent in sunlight and is able to penetrate more deeply into the skin. As a result, UVB radiation is able to directly damage DNA by forming cyclobutane pyrimidine dimers (Brash et al., 1991; Kress et al., 1992; Sage, 1993; Anderson and Parrish, 1981; Biesalski and Obermueller-Jevic, 2001). This direct interaction of UVB and DNA is of principal importance in the cytotoxic, mutagenic, and carcinogenic effects of ultraviolet radiation (Ananthaswamy and Pierceall, 1990; Brash et al.,1991; Kress et al., 1992; Sage, 1993; Doniger et al., 1981).

UVB has been shown to initiate immunosuppression in humans (Hershey et al., 1983; Kelly et al., 2000) and animals (Fisher and Kripke, 1977; De Fabo and Kripke, 1979, 1980). This UV-induced immunosuppression contributes to the development of skin cancer (Fisher and Kripke, 1977, 1982; De Fabo and Kripke, 1979, 1980). 
Humans are exposed to UVA and UVB radiation. UVA radiation exerts its deleterious effects via the formation of free radicals and oxidative stress. UVB is able to interact with DNA directly contributing to its mutagenic and carcinogenic potential. The combined effects of UVA/UVB exposure can trigger a cascade of events initiating the development of skin disorders including phototoxicity, photo-aging and premature aging, and skin cancer.

\section{Project Goals and Aims}

The oxidative mechanism and dermal toxicity caused by chemical and environmental exposures in vivo is not clearly defined. This project was designed to determine whether chemical and physical agents are able to induce skin damage via an oxidative mechanism. The central hypothesis of this work is that dermal exposure to chemical and/or environmental factors triggers the formation of free radicals, which are able to induce an antioxidant imbalance, oxidative stress, and inflammation that could affect skin integrity. Excessive inflammatory-based oxidative modification of the major skin constituents following long-term exposure could trigger redox-sensitive cell-signaling pathways via activation protein 1 (AP-1) expression thereby causing the development of skin cancer. The specific aims of the project are: (1) To study the mechanisms of phenol (PhOH)induced oxidative injury in skin of animals with normal and reduced antioxidant milieu; (2) To assess the role of the antioxidant defense system of the skin of young and old mice exposed to cumene hydroperoxide (Cum-OOH); (3) To investigate the role of oxidative stress and the activation of AP-1 protein in the development of skin cancer; (4) To study the mechanisms of simulated solar light (SSL) induced skin injury with respect to antioxidant imbalance, oxidative damage of DNA, protein, and lipids. 


\section{Figures}

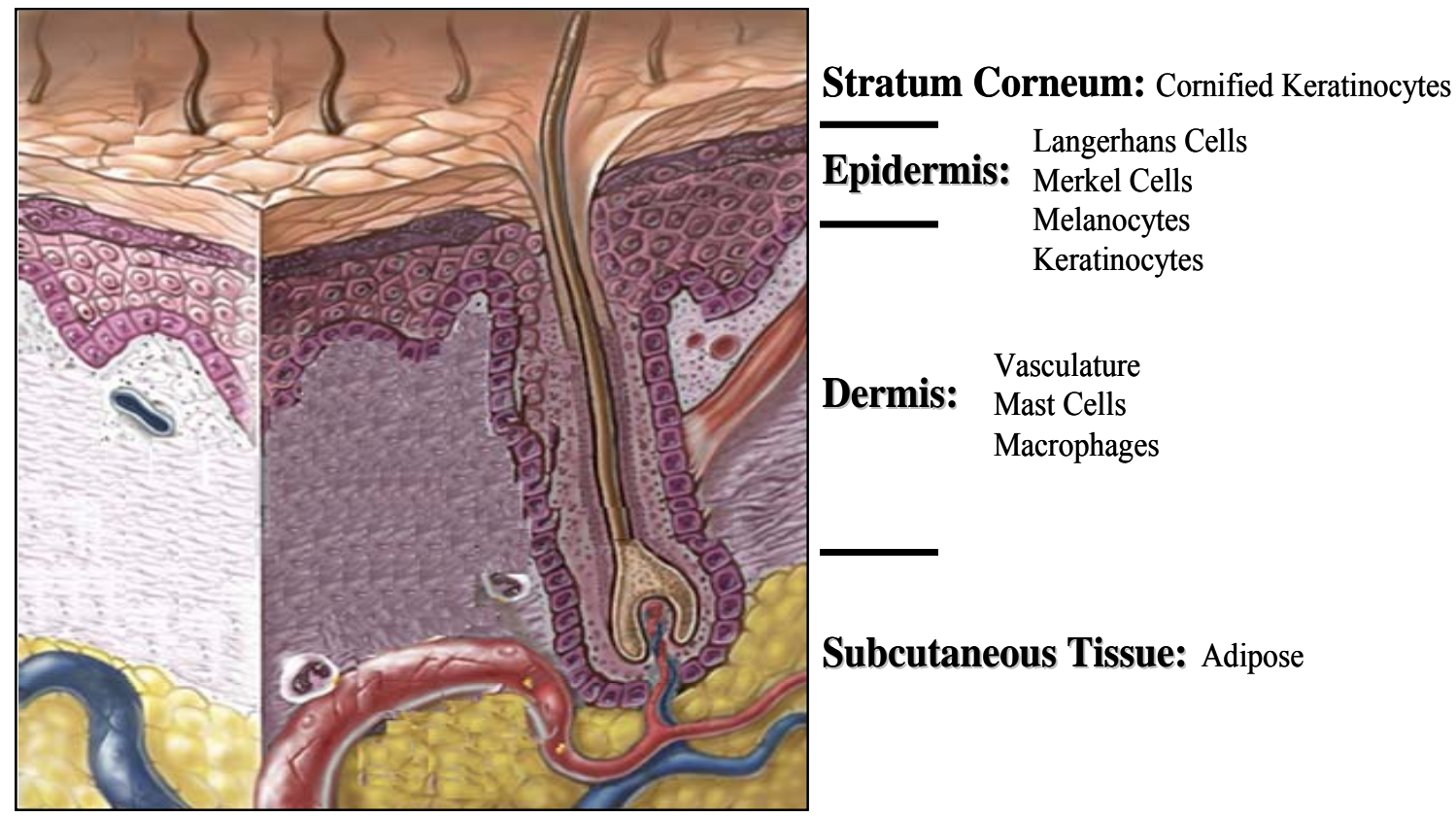

Figure 1. The Structure of the Skin. 


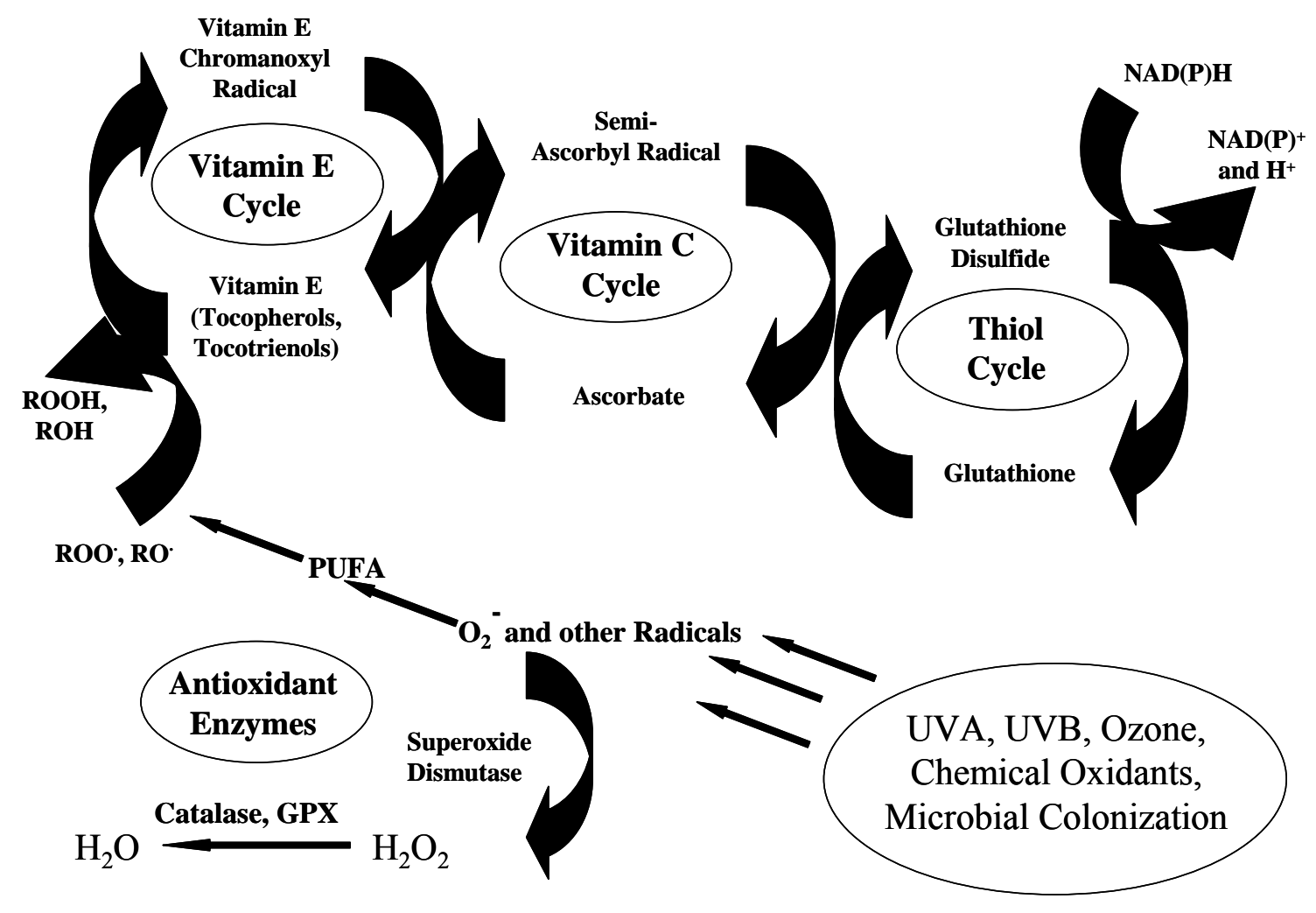

Figure 2. The Antioxidant Network of the Skin. 
STUDY 1: PHENOL-INDUCED IN VIVO OXIDATIVE STRESS IN SKIN: EVIDENCE FOR ENHANCED FREE RADICAL GENERATION, THIOL OXIDATION AND ANTIOXIDANT DEPLETION. 


\section{$\underline{\text { Abstract }}$}

A variety of phenolic compounds are utilized in industry (e.g., for production of phenol (PhOH)-formaldehyde resins, paints and lacquers, cosmetics and pharmaceuticals). They can be toxic to skin causing rash, dermal inflammation, contact dermatitis, depigmentation, and cancer promotion. The biochemical mechanisms for dermal toxicity of phenolic compounds are not well understood. We hypothesized that enzymatic oneelectron oxidation of $\mathrm{PhOH}$ compounds, resulting in generation of phenoxyl radicals, may be an important contributor to dermal toxicity by stimulating the induction and release of inflammatory mediators. To test this hypothesis, we 1) monitored in vivo the formation of $\alpha$-phenyl-N-tert-butylnitrone (PBN)-spin-trapped radical adducts by ESR spectroscopy, 2) measured glutathione (GSH), protein thiols, vitamin E and total antioxidant reserves in skin of $\mathrm{B} 6 \mathrm{C} 3 \mathrm{~F} 1$ mice topically treated with $\mathrm{PhOH}$, and 3) compared the responses with those produced by $\mathrm{PhOH}$ in mice with diminished levels of GSH. We found that dermal exposure to $\mathrm{PhOH}(3.5 \mathrm{mmol} / \mathrm{kg}, 100 \mu \mathrm{l}$ on the shaved back, for $30 \mathrm{~min}$ ) caused oxidation of GSH and protein thiols and decreased vitamin $\mathrm{E}$ and total antioxidant reserves in skin. The magnitude of the $\mathrm{PhOH}$-induced generation of PBNspin-trapped radical adducts in skin of mice with diminished levels of GSH (pre-treated with 1,3-bis(2-chloroethyl)-1-nitrosourea, BCNU, an inhibitor of glutathione reductase or L-buthione-[S,R]-sulfoximine, BSO, an inhibitor of $\gamma$-glutamylcysteine synthetase) was markedly higher compared to radical generation in mice treated with $\mathrm{PhOH}$ alone. Epidermal mouse cells exposed to phenolic compounds showed the induction of early inflammatory response mediators, such as prostaglandin $E_{2}$ and IL- $1 \beta$. Since dermal exposure to $\mathrm{PhOH}$ produced ESR-detectable PBN spin-trapped signals of lipid-derived 
radicals, we conclude that redox-cycling of a one-electron oxidation product of $\mathrm{PhOH}$, its phenoxyl radical, is involved in oxidative stress and dermal toxicity in vivo. 


\section{Introduction}

Occupational exposure to phenol and phenolic compounds is estimated to affect over a half million people in the United States annually (ATSDR, 1997). The major route of exposure is through skin contact (ACGIH, 1991) during production of phenolformaldehyde resins, paints and lacquers, cosmetics, and pharmaceuticals. This exposure to phenolic compounds is known to cause skin rashes, burns, ulceration, dermal inflammation, necrosis, irritant and allergic contact dermatitis, eczematous black-spot dermatitis and leukoderma, and is believed to play a role in cancer promotion. The mechanism underlying the toxic effects of phenol is unknown.

The cytotoxic and genotoxic effects which result from occupational exposure to phenol may be due to the one-electron oxidation of phenolic compounds to free radical intermediates known as phenoxyl radicals (Bogadi-Sare et al., 1997; Chen and Eastmond, 1995; Corbett et al., 1992; Hess et al., 1991; Hiramoto et al., 1998; Paolini et al., 1998; Thompson et al., 1995; Tuo et al., 1998). Radical generation may be an important contributor to the dermal toxicity of phenolic compounds. Enzymes expressed in the skin, such as prostaglandin synthase, lipoxygenase, and tyrosinase (Bickers, 1980; Pnece and Neylor, 1990; Punnonen et al., 1991; Schmidt and Cheng, 1992; Shindo et al., 1994; Applegate et al., 1998), may provide a favorable redox environment for the oxidation of phenolic compounds. We hypothesize that phenoxyl radicals, formed by the enzymatic metabolism of phenolic compounds, trigger free radical cascades thereby inducing oxidative stress and antioxidant depletion and causing an inflammatory response in skin. 
Reactive oxygen species (ROS) play an important role in the initiation and progression of many conditions where inflammatory mediators are implicated (Alder et al., 1999; Keane and Strieter, 2002). The presence of ROS causes an upregulation in the release and production of various pro-inflammatory mediators, such as IL-1, IL-6, IL-8, TNF- $\alpha$, leukotrienes and prostaglandins, which may be responsible for the inflammation seen following exposure to an irritant chemical such as phenol (Luger and Schwarz, 1990). The release of such inflammatory mediators stimulates the production of other cytokines and further amplifies the inflammatory response (Effendy et al., 2000).

Glutathione (GSH) is involved in maintaining normal intracellular redox status and in regulating the cellular defenses and controlling oxidative stress (Meister, 1988; Schafer and Buettner, 2001; Sies, 1999). GSH directly scavenges ROS, and the loss of GSH is associated with an augmented pro-inflammatory state (Haddad, 2002). Depletion of GSH upregulates ROS and results in enhanced cytokine secretion (Gossett et al., 1999). Antioxidants prevent cytokine production via the reduction of intracellular thiols (Haddad et al., 2001; Hudson, 2001; Napoli and Lerman, 2001; Petroff et al., 2001).

Exposure of normal human epidermal keratinocytes (NHEK) to a variety of phenolic compounds causes oxidative stress and cytotoxicity (Shvedova et al., 2000). Cytotoxicity of studied phenols has been shown to correlate with GSH loss. To study the role of glutathione in the redox-cycling of phenol and inflammation in skin in vivo, we used 1,3bis(chloroethyl)-1-nitrosourea (BCNU, an inhibitor of glutathione reductase) and Lbuthione-[S,R]-sulfoximine (BSO, an inhibitor of $\gamma$-glutamylcysteine synthetase) to 
decrease basal GSH levels. In particular, we determined: 1) whether BSO or BCNU induced accelerated oxidative stress and augmented depletion of antioxidants in the skin of $\mathrm{B} 6 \mathrm{C} 3 \mathrm{~F} 1$ mice after topical exposure with phenol, 2) whether topical exposure of B6C3F1 mice to $\mathrm{PhOH}$ induced formation of free radical adducts assessed ex vivo by ESR spectroscopy in the skin of animals with normal and reduced levels of GSH achieved by pre-treatment with $\mathrm{BSO}$ or BCNU, and 3) whether cyclooxygenase (COX-2) activation is involved in the generation of inflammatory mediators following $\mathrm{PhOH}$ or $\mathrm{BSO} / \mathrm{PhOH}$ exposure in murine epidermal JB6 cells.

\section{Materials and Methods}

\section{Chemicals}

Fatty acid-free human serum albumin (hSA), luminol, sodium dodecyl sulfate (SDS), 2,2'-dipyridyl (2,2'-DP), $\quad \alpha$-phenyl-N-tert-butylnitrone $\quad(\mathrm{PBN}), \quad$ phenol $\quad(\mathrm{PhOH})$, glutathione (GSH), 1,3-bis(chloroethyl)-1-nitrosourea (BCNU), and L-buthione-[S,R]sulfoximine (BSO) were purchased from Sigma Chemicals Co. (St. Louis, MO). Methanol, ethanol, chloroform, hexane and water (HPLC grade) were purchased from Aldrich Chemical Co. (Milwaukee, WI). Thio-Glo-1 was obtained from Covalent Inc. (Wobum, MA). 2,2'-Azobis(2-aminodinopropane)-dihydrochloride (AAPH) was purchased from Wako Chemicals USA, Inc. (Richmond, VA). Prostaglandin E2 ELISA Kits were obtained from Cayman Chemical Co. (Ann Arbor, MI). ELISA Kits were obtained from BioSource International (Camarillo, CA).

\section{Animals}

B6C3F1 mice (3-4 weeks; 16-18 g in weight) were obtained from Harlan Lab Animals (Indianapolis, IN). Each mouse was housed in an individual ventilated cage with Alpha- 
Dri cellulose chips and hardwood Beta-chips for bedding and provided HEPA-filtered air under controlled environmental conditions in an Association for Assessment and Accreditation of Laboratory Animal Care (AAALAC) accredited, specific pathogen-free facility. Food and water were provided ad libitum. All animal procedures were performed in accordance with an approved Animal Care and Use Committee (ACUC) protocol.

\section{Animal Exposures}

B6C3F1 mice were injected with 1,3-bis(chloroethyl)-1-nitrosourea (BCNU), or Lbuthione-[S,R]-sulfoximine (BSO) to achieve a 30\% decrease in the level of glutathione in the skin. $\mathrm{BCNU}(40 \mathrm{mg} / \mathrm{kg}, 100 \mu \mathrm{l})$ was injected intraperitoneally (i/p) 3 hours prior to phenol exposure. BSO $(2 \mathrm{mmol} / \mathrm{kg}, 100 \mu \mathrm{l})$ was injected $\mathrm{i} / \mathrm{p} 2$ times within 21 hours. Following GSH depletion, the dorsal area $\left(1.5 \times 2.0 \mathrm{~cm}^{2}\right)$ of the mouse skin, which had been shaved 24 hours prior to exposure, was topically exposed to $\mathrm{PhOH}(3.5 \mathrm{mmol} / \mathrm{kg}$, $100 \mu \mathrm{l})$. Thirty minutes following PhOH exposure, mice were sacrificed by inhalation of excess carbon dioxide.

\section{Skin Collections and Preparation of Homogenates}

Skin flaps from the intrascapular area of the back of mouse were excised and samples taken for ESR studies, histopathology and biochemical analysis. Skin for biochemical analysis was immediately frozen at $-80^{\circ} \mathrm{C}$ until processed. The skin homogenates were prepared from frozen tissues with ice-cold phosphate-buffered saline (PBS, 7.4) using a tissue tearer (model 985-370, Biospec Products, Inc., Racine, WI). 


\section{Fluorescence Assay of Glutathione (GSH) and Protein Sulfhydryls}

Total thiol concentration in homogenates of skin was determined using ThioGlo-1, a maleimide reagent which produces a highly fluorescent product upon its reaction with sulfhydryl groups (Shvedova et al., 2000). A standard curve was established by addition of GSH $(0.04-2.0 \mu \mathrm{M})$ to $0.1 \mathrm{M}$ phosphate buffer $(\mathrm{pH}$ 7.4) containing $10 \mu \mathrm{M}$ ThioGlo-

1. GSH content was estimated by an immediate fluorescence response registered upon addition of ThioGlo-1 to tissue homogenates. Total protein sulfhydryls were determined from the additional fluorescence response after the addition of SDS (4 $\mathrm{mM})$ to the same homogenate. A Shimadzu spectrofluorometer RF-5000 U (Shimadzu, Japan) was employed in the assay: excitation $388 \mathrm{~nm}$ and emission $500 \mathrm{~nm}$. The data were acquired using an excitation slit of $1.5 \mathrm{~nm}$ and an emission slit of $5 \mathrm{~nm}$. The wavelengths were exported from the spectrofluorometer using RF-5000 U PC Personal Fluorescence software (Shimadzu, Japan).

\section{Determination of Skin Bi-fold Thickness as an Inflammatory Biomarker}

To assess the extent of $\mathrm{PhOH}$ induced edema in mouse skin following treatment, a dial caliper (The Dyer Company, Lancaster, PA) was used to measure the skin bi-fold thickness. Changes in skin bi-fold thickness were determined by the measurements of 3 random locations within the area of exposure per mouse. Edema formation was expressed as net increase in skin bi-fold thickness between experimental $(\mathrm{PhOH})$ and control groups.

\section{ESR Study of Generation of Free Radicals in Skin}

The skin used to assess the free radical generation was obtained from the intrascapular region of the mouse back. Equal amounts of the skin $(1.5 \times 2.0 \mathrm{~cm})$ were obtained from 
the control and experimentally treated animals. Following BCNU or BSO exposure, the mice were injected subcutaneously in the dorsal lumbar area with the spin-trap $\alpha$-phenylN-tert-butylnitrone $(\mathrm{PBN} ; 1 \mathrm{mmol} / \mathrm{kg}, 100 \mu \mathrm{L})$ dissolved in saline. Ten minutes following injection with PBN, the intrascapular area of the back was painted with saline $(100 \mu \mathrm{L})$ or phenol $(3.5 \mathrm{mmol} / \mathrm{kg}, 100 \mu \mathrm{l})$. Thirty minutes following phenol exposure, the animals were sacrificed and skin flaps were collected. Samples were minced and homogenized with $15 \mathrm{~mL}$ chloroform/methanol (2:1 mixture) and $1.0 \mathrm{~mL} \mathrm{2,2'-dipyridyl}$ (30 $\mathrm{mM}$ ) to prevent oxidation during lipid extraction (Kagan and Gorbunov, 1998). The skin homogenates were then centrifuged $\left(2000 \mathrm{rpm}, 10 \mathrm{~min}, 4^{\circ} \mathrm{C}\right)$ and the chloroform layer was collected. The lipid extracts from the skin were dried under nitrogen. One $\mathrm{mL}$ of lipid extracts from the mouse skin was used to detect spin-trapped free radicals. ESR spectra were recorded immediately at room temperature using a quartz flat cell and a Bruker EMX with a Super High Q cavity. Instrumental settings were as follows: microwave power, $20 \mathrm{~mW}$; modulation amplitude, $1.0 \mathrm{G}$; conversion time, $0.6 \mathrm{~s}$; time constant, $1.3 \mathrm{~s}$. Spectra were recorded on an IBM-compatible computer interfaced to the spectrometer. The determination of the coupling constants was done in chloroform/methanol. Hyperfine coupling constants were determined using the Win-Sim program of the NIEHS public EPR software tools package, which is available over the Internet (http://EPR.niehs.nih.gov/). The program was allowed to systematically vary the hydrogen and nitrogen hyperfine coupling constants and the relative concentrations of each species to achieve the best fit to the experimental spectra. 


\section{HPLC Assay of $\alpha$-Tocopherol}

Extracts of $\alpha$-tocopherol from skin homogenates were prepared using a procedure described by Lang et al. (1986). A Waters HPLC system with a 717 auto sampler, a Hewlett Packard ODS Hypersil column (5 mm; 200 X 4.6 mm), a Waters 600 Controller pump, and a 474 fluorescence detector was used to measure $\alpha$-tocopherol in the samples. The wavelengths employed in the assay were $292 \mathrm{~nm}$ (excitation) and $324 \mathrm{~nm}$ (emission). Both the excitation and emission slits were $5 \mathrm{~nm}$. Eluent was $\mathrm{CH}_{3} \mathrm{OH}$ with a flow rate of $1 \mathrm{ml} / \mathrm{min}$. Under these conditions, the retention time for $\alpha$-tocopherol was $8.2 \mathrm{~min}$. The minimum detection level for $\alpha$-tocopherol in the samples was $0.1 \mathrm{pmol} / \mathrm{mg}$ of protein. The data acquired were exported from the Waters 474 detector using Millennium 2000 software (Waters Associates, Milford, MA).

\section{Chemiluminescence Measurements of Total Antioxidant Reserve}

A water-soluble azo-initiator, 2,2'-azobis(2-aminodinopropane)-dihydrochloride (AAPH), was used to produce peroxyl radicals (Niki, 1990). Oxidation of luminol by AAPH-derived peroxyl radicals was assayed by the chemiluminescence response. A delay in the chemiluminescence response caused by the interaction of endogenous antioxidants with AAPH-derived peroxyl radicals was observed upon addition of homogenates. Based on the known rate of peroxyl radical generation by AAPH, the amount of peroxyl radicals scavenged by endogenous antioxidants was evaluated. The incubation medium contained $0.1 \mathrm{M}$ phophate buffer $(\mathrm{pH} 7.4)$ at $37^{\circ} \mathrm{C}$, AAPH $(50 \mathrm{mM})$, and luminol $(0.4 \mathrm{mM})$. The reaction was started by the addition of AAPH. Luminescent analyzer 633 (Coral Biomedical, Inc., San Diego, CA) was employed for determination. 


\section{Cell Culture}

JB6 murine epidermal cells were cultured in Eagle's MEM containing 5\% fetal calf serum and $2 \mathrm{mM}$ L-glutamine. The cells were grown at $37^{\circ} \mathrm{C}$ with $5 \% \mathrm{CO}_{2}$. Cells were grown in 96 -well plates or $75 \mathrm{~cm}^{2}$ tissue culture flasks for 18 hours prior to exposure to allow for adherence. Cells were exposed to BSO $(10 \mu \mathrm{M})$ for 4 hours. After 4 hours, the media was changed and the cells were exposed to phenol (15 mM) and BSO for $1 / 2,1,2$,

or 18 hours. At the completion of the experiment, cellular supernatant was stored for ELISA analysis while cells were suspended in PBS. All samples were frozen at $-80^{\circ} \mathrm{C}$ until analyzed.

\section{Pro-inflammatory cytokine protein quantification}

Enzyme Linked Immunosorbent Assay (ELISA) was utilized to measure the proinflammatory mediators, interleukin-1 $\beta$ (IL-1 $\beta)$ and prostaglandin $E_{2}$ in supernatants from JB6 cells exposed to phenol. The concentration of IL-1 $\beta$ in cultured supernatants was measured using a commercially available ELISA immunoassay kit (Biosource International, Camarillo, CA) which is sensitive for IL-1 $\beta$ concentrations ranging from $7.8 \mathrm{pg} / \mathrm{ml}$ to $1000 \mathrm{pg} / \mathrm{ml}$. Concentration of prostaglandin $\mathrm{E}_{2}$ in cultured supernatants was measured using prostaglandin $E_{2}$ EIA Kit-Monoclonal (Cayman Chemical, Ann Arbor, MI) which ranges in sensitivity from $7.8 \mathrm{pg} / \mathrm{ml}$ to $1000 \mathrm{pg} / \mathrm{ml}$. Each supernatant was assayed at two dilutions and each dilution was assayed in duplicate.

\section{Protein Assay}

Measurements of protein in homogenates from mouse skin were run using a Bio-Rad protein assay kit, catalog no. 500-0006 (Richmond, CA). 


\section{Statistics}

Data were expressed as the mean \pm SEM for each group. A one-way ANOVA test was employed to compare the responses between treatments. Statistical significance was set at $\mathrm{p}<0.05$.

\section{$\underline{\text { Results }}$}

\section{Phenol-Induced Oxidative Stress}

Dermal exposure to $\mathrm{PhOH}$ was found to cause a significant depletion in the overall antioxidant status of murine skin. A significant decrease in GSH (73.3\%) in the skin of B6C3F1 mice was observed as early as 1 hour post-exposure to $\mathrm{PhOH}$. Protein thiol, vitamin $\mathrm{E}$, and total antioxidant reserve levels were also significantly reduced by $82 \%$, $50 \%$, and $52.7 \%$, respectively (Table 1.1 ).

\section{Skin Inflammation of B6C3F1 Mice Following PhOH Exposure}

Skin bi-fold thickness was assessed as a measure of skin inflammation following exposure to phenol $(1.75,3.5,7.0 \mathrm{mmol} / \mathrm{kg} ; 0.5,1,2,3$, and 6 hours $)$. Phenol exposure resulted in significant dose-dependent increase in skin bi-fold thickness of B6C3F1 mice as compared to control (Figure 1.1A). The observed increase in skin bi-fold thickness following exposure to $\mathrm{PhOH}(3.5 \mathrm{mmol} / \mathrm{kg})$ was not time-dependent. A $90 \%$ increase in skin bi-fold thickness occurred as early as 0.5 hours post-exposure and the same levels persisted through 6 hours post-exposure (Figure 1.1B). No changes in skin bi-fold thickness were observed in vehicle (phosphate buffered saline) exposed mice.

\section{Depletion of GSH in Skin of B6C3F1 Mice by Treatment with BSO and BCNU}

$\mathrm{BCNU}$ inhibits glutathione reductase thereby causing a depletion in glutathione. A timecourse study of the effects of BCNU revealed no significant differences once a $30 \%$ 
decrease was achieved 3 hours post-exposure (Figure 1.2A). BSO irreversibly inhibits the enzyme $\gamma$-glutamylcysteine synthetase. An initial decrease in glutathione levels of $52.2 \%$ was achieved with 2 injections of BSO in a 21 hour time period. A time course study of the effects of BSO revealed no further significant differences in the level of GSH at later time points (Figure 1.1B).

\section{Formation of Lipid-derived Radicals following PhOH Exposure}

Phenol exposure resulted in the development of lipid-derived radicals in the skin of B6C3F1 mice as detected by ESR spectroscopy 0.5 hours following dermal exposure. Topical exposure with $\mathrm{PhOH}$ in animals with a reduced level of GSH, as a result of BSO or BCNU treatment, caused a higher degree of free radical formation (Figure 1.3C, D).

Computer simulation of the detected radical adducts was consistent with the presence of 2 radical species in the skin of $\mathrm{PhOH}$ and $\mathrm{BCNU} / \mathrm{PhOH}$ exposed animals. The radical adducts had coupling constants of (1) $\mathrm{a}^{N}=15.6 \mathrm{G} ; \mathrm{a}^{H}=3.2 \mathrm{G}$ and (2) $\mathrm{a}^{N}=14.8 ; \mathrm{a}^{H}=2.7$. Radical 1 consisted of $60-75 \%$ of the obtained spectra and was identified as a carboncentered lipid adduct, i.e. a methyl radical, (Figure 1.4; Shvedova et al., 2002). Radical 2 was $25-40 \%$ of the obtained spectra and was determined to be an oxygen-centered lipid radical, i.e. lipoxyl radical.

The spectra obtained from the $\mathrm{BSO} / \mathrm{PhOH}$ exposed animals were slightly different compared to those obtained from $\mathrm{PhOH}$ and $\mathrm{BCNU} / \mathrm{PhOH}$ exposed animals. In particular, the ESR spectra from the $\mathrm{BSO} / \mathrm{PhOH}$-exposed animals consisted of 2 radical species. Radical 1 had coupling constants which corresponded to radical 1 from the 
$\mathrm{PhOH}$ and $\mathrm{BCNU} / \mathrm{PhOH}$ exposed animals and was determined to be a carbon-centered lipid adduct $\left(\mathrm{a}^{N}=15.2 \mathrm{G} ; \mathrm{a}^{H}=3.35 \mathrm{G}\right)$. In contrast, radical 2 was an ascorbate radical $\left(\mathrm{a}^{\mathrm{H}}=1.9 \mathrm{G}\right)$.

The major radical product detected was a carbon-centered radical adduct. Integration of the carbon-centered radical was done to determine the extent of the radical formation. Phenol exposure alone resulted in a carbon-centered radical with an integrated intensity of 7.3 , while in $\mathrm{BCNU} / \mathrm{PhOH}$ or $\mathrm{BSO} / \mathrm{PhOH}$ exposed animals significantly higher production of carbon-centered radicals with an integrated intensities of 17.4 and 11.8 arbitrary units, respectively (Figure 1.3E).

\section{Glutathione and Protein Thiol Oxidation as a Result of PhOH Exposure}

Topical exposure to $\mathrm{PhOH}(3.5 \mathrm{mmol} / \mathrm{kg} ; 30$ minutes) reduced GSH levels in the skin of mice by $68 \%$. Exposure to BCNU/PhOH resulted in significant lower of level of GSH in the skin of mice ( $80 \%$ decrease versus control) compared to mice treated with $\mathrm{PhOH}$ alone (68\% decrease versus control) (Figure 1.5). $\mathrm{BSO} / \mathrm{PhOH}$ exposure also significantly decreased the level of GSH ( $75 \%$ decrease versus control) in the skin of mice as compared to those treated with $\mathrm{PhOH}$ alone.

Oxidation of protein thiols also occurred as a result of $\mathrm{PhOH}$ exposure. Topical exposure to phenol resulted in a significant (82\%) reduction in protein thiol levels. Animals exposed to $\mathrm{PhOH}$ as well as those with $\mathrm{BCNU}$-depleted glutathione prior to phenol exposure had a significant $82 \%$ reduction in protein thiol levels (Figure 1.5, Inset). 
Exposure of mice to $\mathrm{PhOH}$ or $\mathrm{BCNU} / \mathrm{PhOH}$ had similar effects on the level of vitamin $\mathrm{E}$ resulting in a 50\% reduction (Figure 1.6).

\section{Vitamin E Levels in Murine Skin following PhOH Exposure}

Topical Exposure to $\mathrm{PhOH}$ significantly decreased vitamin E levels by $45 \%$ in the skin of B6C3F1 mice exposed to $\mathrm{PhOH}$ (3.5 mmol/kg; 30 minutes). Glutathione depletion via BCNU administration also resulted in a significant decrease in vitamin E levels (45\%) as compared to control mice (Figure 1.6).

\section{Total Antioxidant Reserve Status of Murine Skin following PhOH Exposure}

Topical $\mathrm{PhOH}$ exposure caused a significant 53\% reduction in the total antioxidant status as compared to the skin of control mice. Depletion of glutathione with BCNU prior to phenol exposure resulted in a $64 \%$ reduction in total antioxidant reserves as compared to control animals (Figure 1.7).

\section{Skin Histopathology after PhOH Exposure}

Animals painted with saline (Figure 1.8A) as well as animals treated with BCNU (Figure $1.8 \mathrm{E}$ ) or BSO (Figure 1.8C) had normal skin structure. Topical exposure to $\mathrm{PhOH}$ (1 hour) was shown to cause recruitment of inflammatory cells as observed by the presence of inflammatory cells within the blood vessels of the skin (Figure 1.8E, inset). Depletion of $\mathrm{GSH}$ with $\mathrm{BCNU}$ or $\mathrm{BSO}$ prior to $\mathrm{PhOH}$ exposure caused a more dispersed inflammation in the skin, i.e. inflammatory cells were seen throughout the tissue after $\mathrm{PhOH}$ exposure in mice pretreated with BCNU and BSO (Figure 1.8D, F). 


\section{Prostaglandin $E_{2}$ Levels in JB6 Mouse Epidermal Cells following PhOH Exposure}

To reveal whether $\mathrm{PhOH}$ exposure induced the release of inflammatory mediators, JB6 mouse epidermal cells were exposed to phenol $(15 \mathrm{mM})$. Figure $9 \mathrm{~A}$ reveals a timedependent increase in the release of prostaglandin $\mathrm{E}_{2}$ after $\mathrm{PhOH}$ exposure $(15 \mathrm{mM} ; 1 / 2$, 1,2 , and 18 hours). In cells exposed to $\mathrm{BSO} / \mathrm{PhOH}$, the amount of prostaglandin $\mathrm{E}_{2}$ was more significantly increased (7.6-fold) as compared to control and phenol exposed cells (1.6-fold). The observed increases in prostaglandin $E_{2}$ persisted through 18 hours postexposure (Figure 1.9B). The COX-2 inhibitor, aspirin, reduced the observed increase in prostaglandin $\mathrm{E}_{2}$; however, the levels did not return to the control levels (Figure 1.10).

\section{IL-1 $\beta$ release by JB6 Mouse Epidermal Cells following PhOH Exposure}

Cellular exposure to $\mathrm{PhOH}$ induced the release of IL-1 $\beta$ (1.8-fold versus control) into the cellular supernatant. A diminished level of $\mathrm{GSH}(\mathrm{BSO})$ prior to $\mathrm{PhOH}$ exposure further enhanced the release of IL-1 $\beta$ (2.2-fold). At early time points $(1 / 2,1$, and 2 hours), $\mathrm{PhOH}$ exposure led to a $50 \%$ increase in the level of IL- $1 \beta$ while $\mathrm{BSO} / \mathrm{PhOH}$ exposure caused a $60 \%$ increase in IL-1 $\beta$ as compared to control (Figure 1.11A). These results were time-dependent with a significant difference observed 18 hours post-exposure (Figure 1.11B). At later time points (18 hours), $\mathrm{PhOH}$ exposure led to a 4.5 -fold increase in IL-1 $\beta$ released by the cells pretreated with $\mathrm{BSO}$, while $\mathrm{PhOH}$ alone caused a 2.5 -fold increase in IL-1 $\beta$ (Figure 1.11B).

\section{$\underline{\text { Discussion }}$}

Dermal exposure to phenolic compounds are known to cause skin rashes, burns and ulceration, dermal inflammation and necrosis, irritant and allergic contact dermatitis, 
eczematous "black-spot" dermatitis, leukoderma, and cancer promotion (Ames et al., 1975; Bracher et al., 1990). Topical application of $\mathrm{PhOH}$ directly affects the skin by inducing inflammation and tissue necrosis (Horch et al., 1994; Merliss, 1972; Trupmann and Ellenby, 1979). Severe edema, erythema, and necrosis occur as a result of application of PhOH (Brown et al., 1975; Conning and Hayes, 1970).

A potential mechanism for the toxic effects of $\mathrm{PhOH}$ has been described as "futile thiol pumping". The one electron oxidation of phenol and phenolic compounds by oxidative enzymes, such as peroxidases, prostaglandin synthetase and tyrosinase, leads to the generation of phenoxyl radicals (Eisenstein et al., 1992). Metabolism of phenol has been shown to result in the formation of phenoxyl radical (Kolachana et al., 1993). These enzymatically formed phenoxyl radicals may then be reduced by thiols to regenerate the phenolic compound as a substrate for repeated enzyme catalyzed one-electron oxidation. Oxidation of thiols generates thiyl radicals, which are subsequently able to interact with intracellular thiols and oxygen and initiate new oxidative cascades that generate new ROS, such as superoxide and hydroxyl radicals (Shvedova et al., 2000). If redox-cycling of $\mathrm{PhOH}$ was occurring, depletion of glutathione prior to $\mathrm{PhOH}$ exposure would allow for an accumulation of phenoxyl radicals within the tissue. The results of this study show increased radical formation in animals with depleted glutathione prior to $\mathrm{PhOH}$ exposure. In addition, depletion of glutathione prior to $\mathrm{PhOH}$ exposure also caused a significant depletion of the antioxidant network, i.e. vitamin $\mathrm{E}$ and total antioxidant reserves, of the skin (Figure 2) thereby making the animal more susceptible to toxic outcomes, i.e. increased inflammation and tissue damage, resulting from $\mathrm{PhOH}$ exposure. Therefore, 
these results show that the redox cycling of phenoxyl radicals are capable of generating significant oxidative stress. An imbalance in the antioxidant status of the tissue particularly may result in enhanced generation of ROS and oxidative damage to protein, DNA, and lipids (Selassie et al., 1998).

GSH plays a major role in maintaining the intracellular redox balance as well as the regulation of the oxidative stress signaling pathways (Meister, 1988; Haddad and Land, 2000; Haddad et al., 2000). Under physiological conditions, thiols are highly reductive. GSH acts as an antioxidant by detoxifing highly reactive peroxides (ROOH) via the conjugation of electophiles and metals (Coles and Kadlubar, 2003; Fujii et al., 2003; Miyamoto et al., 2003; Zelck and Von Janowsky, 2004). GSH depletion enhances the presence of radicals; therefore, GSH serves to prevent phenol-induced damage by decreasing the formation of free radicals. The current studies found that phenol exposure resulted in the production of carbon-centered lipid radical adducts. Significantly higher radical production was detected in the lipid extracts of the skin of mice with reduced glutathione prior to phenol exposure. GSH also plays a role in maintaining intracellular protein integrity by the reduction of disulfide linkages and regulating their synthesis. It acts as a regulator of cellular sulfhydryl status (Haddad and Harb, 2005).

Depletion of GSH has been linked to a variety of disease states (Cantin et al., 1989; Bunnell and Pacht, 1993; Roum et al., 1993; Saugstad, 1997). GSH depletion was achieved by BCNU or BSO. ESR simulations showed the presence of differential radicals in $\mathrm{BCNU} / \mathrm{PhOH}$ and $\mathrm{BSO} / \mathrm{PhOH}$ exposed animals. $\mathrm{ESR}$ from both $\mathrm{BCNU} / \mathrm{PhOH}$ and $\mathrm{BSO} / \mathrm{PhOH}$ exposed animals showed the presence of a carbon- 
centered lipid radicals. BCNU/PhOH ESR spectra also showed the presence of oxygencentered lipid radicals, while $\mathrm{BSO} / \mathrm{PhOH}$ ESR spectra showed ascorbate radicals. These observed differences are likely due to the transfer of the oxygen-centered radicals detected in the lipids of $\mathrm{BCNU} / \mathrm{PhOH}$ exposed mice to the aqueous phase where it is able to interact with ascorbate to form the ascorbyl radicals detected in $\mathrm{BSO} / \mathrm{PhOH}$ exposed mice. These radicals are most likely due to thiol oxidation as a result of phenol exposure generating thiyl radicals, which are subsequently able to interact with intracellular thiols and oxygen initiating new oxidative cascades with formation of superoxide and hydroxyl radicals (Shvedova et al., 2000).

Oxidative conditions play a major role in modulating redox states by altering the dynamic equilibrium of GSH homeostasis (Haddad et al., 2000). Cytokines which are mediators of inflammation and oxidative stress (Nussler et al., 1992; Desmarquest et al., 1998; Yamashita et al., 1999) can affect the GSH content thereby altering the redox equilibrium (Chen et al., 1998). GSH and GSH precursors are able to down-regulate cytokine synthesis and activation. Depletion of GSH enhances cytokine secretion by increasing the production of ROS (Gosset et al., 1999).

The expression and activation of redox-sensitive/responsive transcription factors have been shown to be affected by GSH status (Haddad and Harb, 2005). An IкB- $\alpha / N F-\alpha B$ independent pathway is responsible for mediating the redox-dependent regulation of inflammatory cytokines. Antioxidants also inhibit cytokine production via an NF-kB dependent pathway (Blanchard et al., 2001). Cytokine production is regulated by the 
presence of ROS. A decreased level of GSH, as achieved by BSO treatment, has been

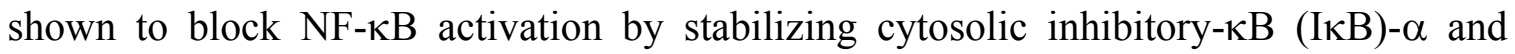
down-regulating its phosphorylation (Haddad, 2000). GSH depletion augments the oxidative stress-mediated inflammatory response via a mechanism which is not entirely NFkB dependent (Haddad, 2000). GSH depletion results in an overabundance of ROS, which subsequently leads to an increase in cytokine production. We found that topical exposure of B6C3F1 mice to phenol caused the development of oxidative stress. GSH levels were found to play a significant role in modulating the inflammatory response to phenol. In vitro experiments further supported the importance of GSH in controlling inflammation. Depletion of GSH prior to phenol exposure resulted in an amplified release of prostaglandin $E_{2}$ and IL-1 $\beta$.

In conclusion, the present study provides evidence for the role of GSH in the modulation of the inflammatory response observed following phenol exposure. We found that dermal exposure to phenol caused oxidation of GSH and protein thiols and decreased vitamin $\mathrm{E}$ and total antioxidant reserves in skin. 


\section{$\underline{\text { Tables and Figures }}$}

\begin{tabular}{|c|c|c|c|}
\hline Antioxidant & Control & Phenol & Decrease \\
\hline $\begin{array}{c}\text { Vitamin E } \\
\text { (pmol/mg) }\end{array}$ & $286.3 \pm 58.9$ & $143.1 \pm 20.9 *$ & $50.0 \%$ \\
\hline $\begin{array}{c}\text { Glutathione } \\
\text { (nmol/mg) }\end{array}$ & $13.1 \pm 1.0$ & $3.5 \pm 0.4 *$ & $73.7 \%$ \\
\hline $\begin{array}{c}\text { Protein Thiols } \\
\text { (nmol/mg) }\end{array}$ & $36.2 \pm 2.2$ & $6.5 \pm 0.9 *$ & $82.0 \%$ \\
\hline $\begin{array}{c}\text { Total Antioxidant } \\
\text { Reserve (nmol/mg) }\end{array}$ & $694.9 \pm 84.4$ & $328.5 \pm 12.7^{*}$ & $52.7 \%$ \\
\hline
\end{tabular}

Table 1.1. Antioxidant depletion in skin of $\mathrm{B} 6 \mathrm{C} 3 \mathrm{~F} 1$ mice after topical treatment with phenol. Mean \pm SEM of 3 experiments, ${ }^{*} \mathrm{p}<0.05$ versus control. 

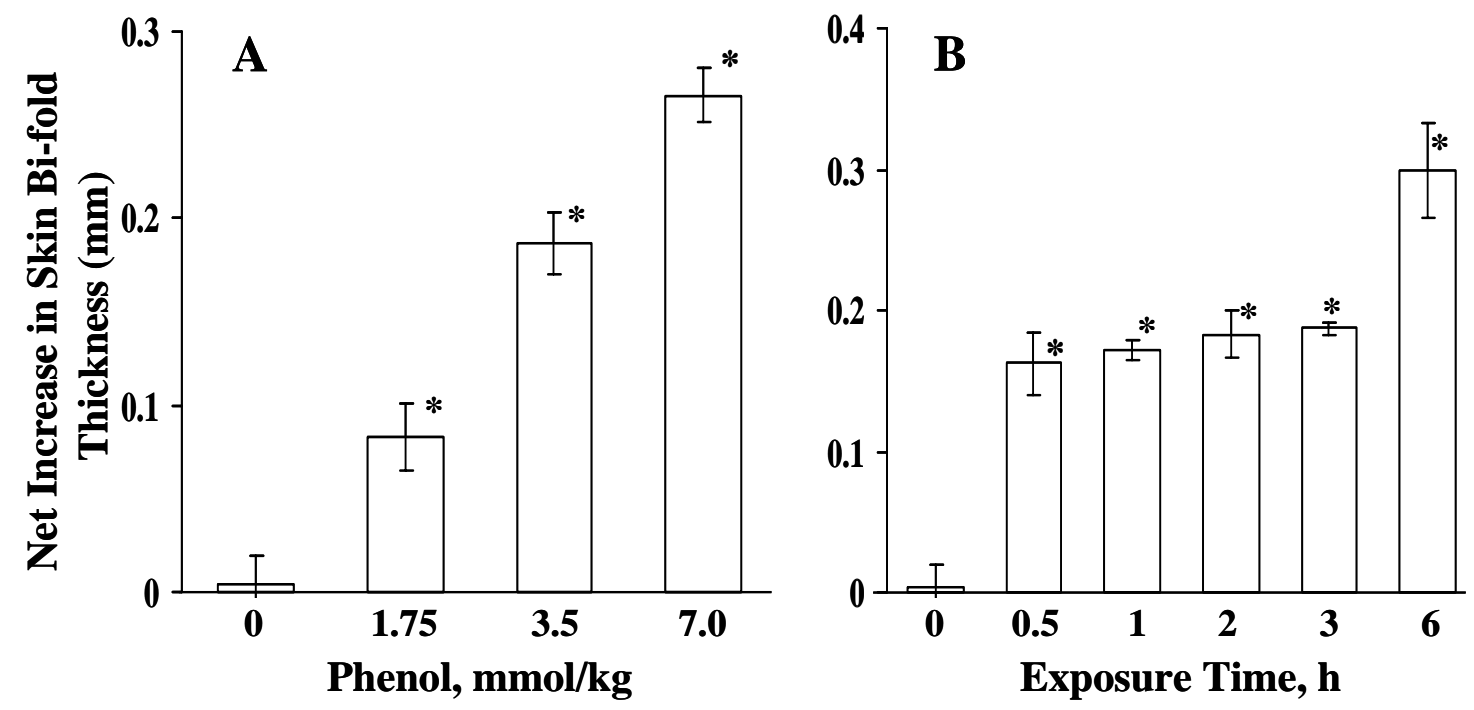

Figure 1.1. A. Dose-dependent increase in skin bi-fold thickness as a result of dermal phenol exposure in $\mathrm{B} 6 \mathrm{C} 3 \mathrm{~F} 1$ mice. Mice were painted on the dorsal area of the back with $1.75,3.5$, or $7.0 \mathrm{mmol} / \mathrm{kg} \mathrm{PhOH}$. Skin bi-fold thickness was measured 2 hours following exposure. B. Time-dependent increase in skin bi-fold thickness as a result of dermal phenol exposure in $\mathrm{B} 6 \mathrm{C} 3 \mathrm{~F} 1$ mice. Mice were painted on the dorsal area of the back with phenol $(3.5 \mathrm{mmol} / \mathrm{kg})$. Skin bi-fold thickness was measured $0.5,1,2,3$, or 6 hours following phenol exposure. Values are means \pm SEM of 3 experiments. ${ }^{*} \mathrm{p}<0.05$ versus PBS treated control mice. 

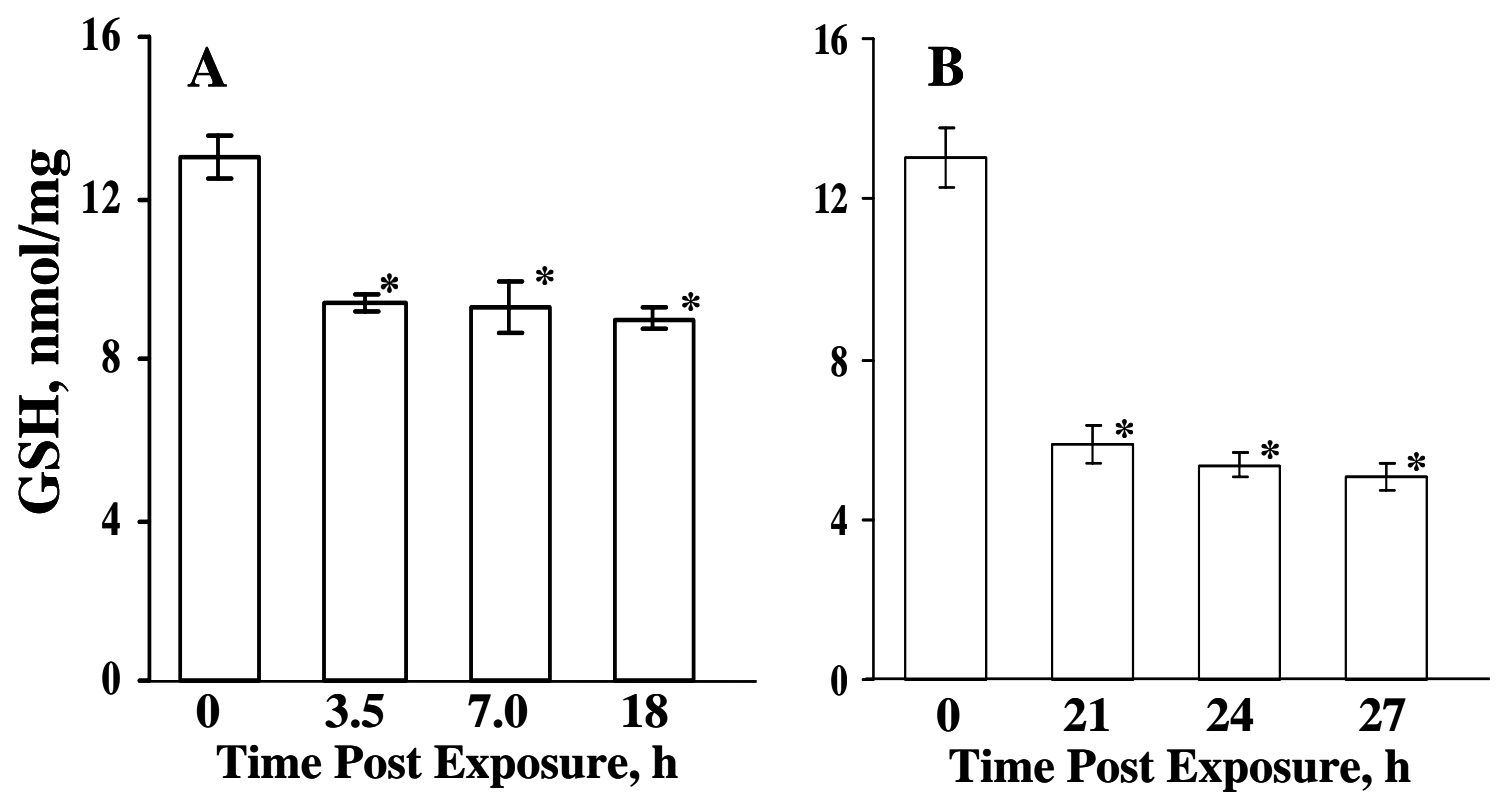

Figure 1.2. A. Time-course depletion of glutathione by 1,3-bis(chloroethyl)-1nitrosourea $(\mathrm{BCNU})$ in the skin of $\mathrm{B} 6 \mathrm{C} 3 \mathrm{~F} 1$ mice. Mice were injected intraperitoneally with BCNU $(40 \mathrm{mg} / \mathrm{kg}, 100 \mu \mathrm{l})$. Skin was collected for GSH analysis $3.5,7.0$ or 18 hours post-exposure. B. Time-course depletion of glutathione by L-buthione-[S,R]sulfoximine (BSO) in the skin of $\mathrm{B} 6 \mathrm{C} 3 \mathrm{~F} 1$ mice. Mice were injected intraperitoneally 2 times with BSO $(2 \mathrm{mmol} / \mathrm{kg}, 100 \mu \mathrm{l})$. Skin was collected for GSH analysis 21,24 , or 27 hours post-exposure. Values are means \pm SEM of 3 experiments. ${ }^{*} \mathrm{p}<0.05$ versus PBS treated control mice. 

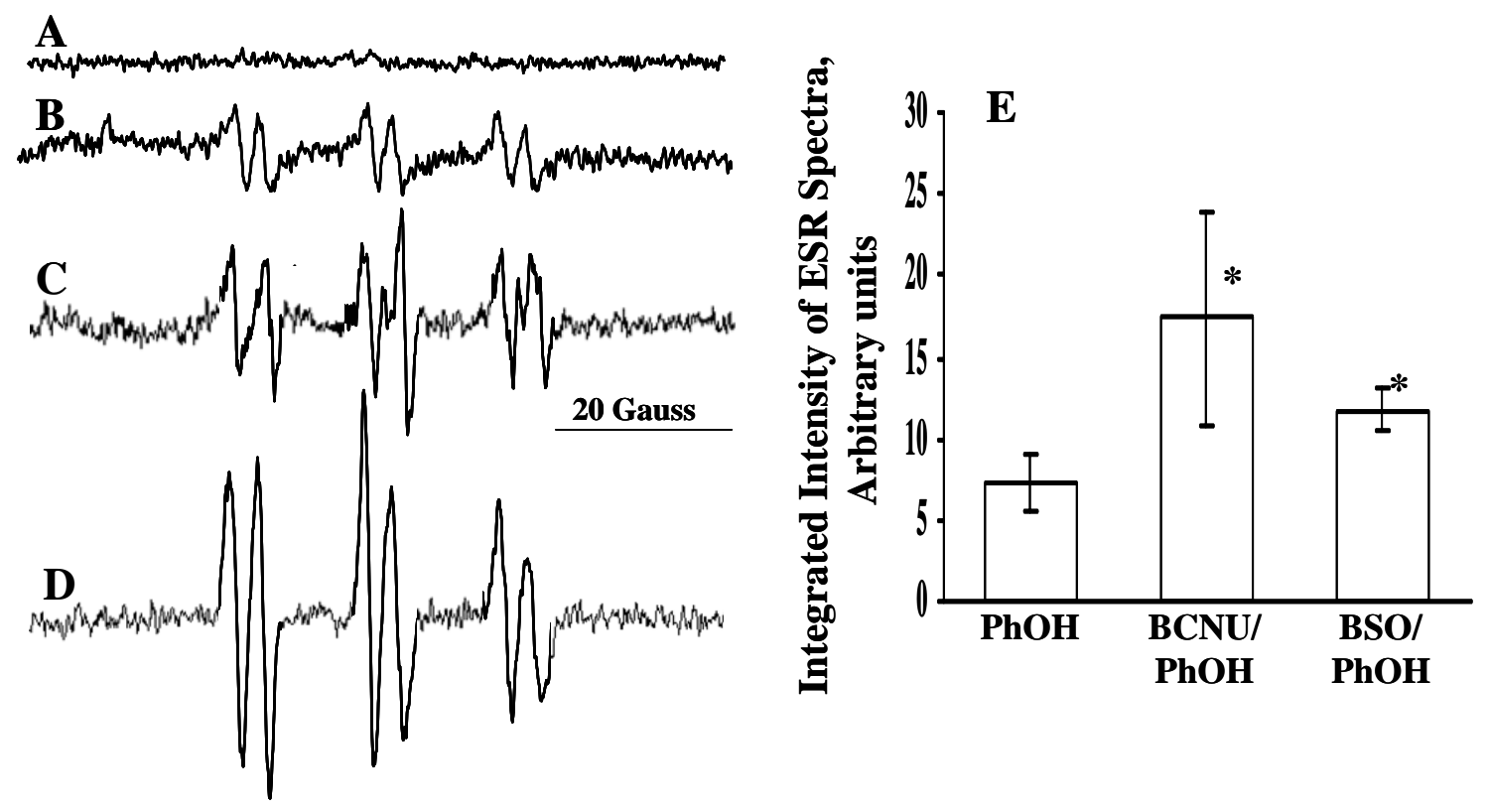

Figure 1.3. ESR detection of lipid-derived PBN spin-trapped free radicals formed in vivo in the skin of $\mathrm{B} 6 \mathrm{C} 3 \mathrm{~F} 1$ mice topically treated with phenol. Mice were intraperitoneally injected with vehicle (saline, $100 \mu \mathrm{l}), \mathrm{BCNU}(40 \mathrm{mg} / \mathrm{kg}, 100 \mu \mathrm{l})$ or BSO $(2 \mathrm{mmol} / \mathrm{kg}, 100 \mu \mathrm{l})$ then PBN was subcutaneously injected 10 minutes prior to phenol exposure. Thirty minutes following phenol exposure $(3.5 \mathrm{mmol} / \mathrm{kg})$, lipid extracts were isolated from the skin and used for ESR measurements. A. PBN- and saline-exposed animals; B. PBN- and $\mathrm{PhOH}-$ exposed animals; C. BSO-, PBN- and $\mathrm{PhOH}-$ exposed animals; D. BCNU-, PBN-, and $\mathrm{PhOH}-$ exposed animals. E. Average integrated intensity of lipid-derived carbon-centered radicals obtained from B6C3F 1 mice topically exposed to phenol as detected by ESR. Values are means \pm SEM of 3 experiments. ${ }^{*} \mathrm{p}<0.05$ versus phenol treated mice. Instrumental conditions: microwave power, $20 \mathrm{~mW}$; modulation amplitude, $1.0 \mathrm{G}$; time constant, $1.3 \mathrm{sec}$; conversion time, $0.6 \mathrm{sec}$. 


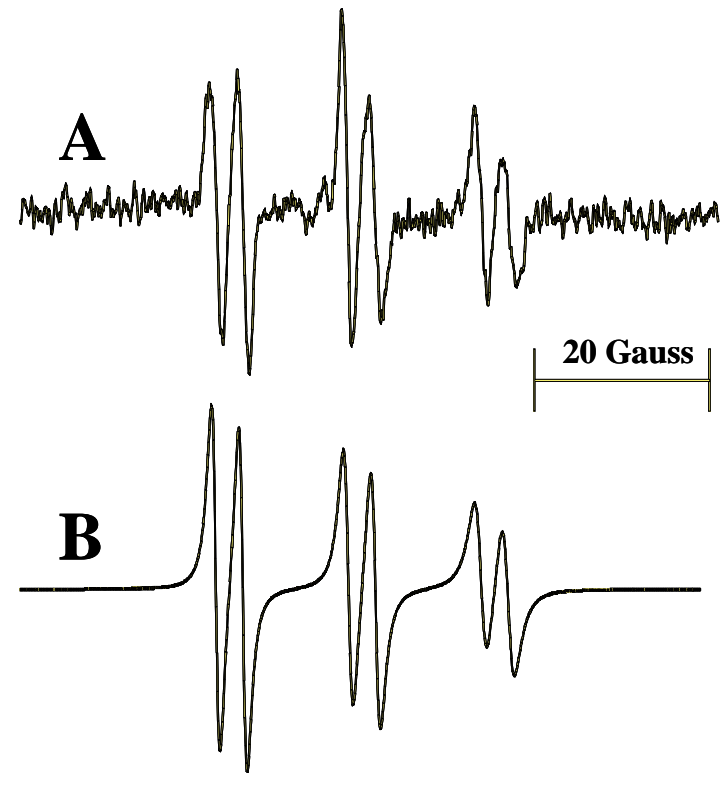

Figure 1.4. Computer simulation of carbon-centered radicals from B6C3F1 mice topically treated with phenol as obtained by ESR. A. ESR spectrum of PBN spintrapped lipid-derived radical adduct formed in vivo in skin of B6C3F1 mice injected with $\mathrm{BCNU}$ and exposed topically to $\mathrm{PhOH} ; \mathbf{B}$. Complete computer simulation of the spectrum in (A) with hyperfine coupling constants: $\mathrm{aN}=15.6 \mathrm{G}$ and $\mathrm{aH}=3.2 \mathrm{G}$. 


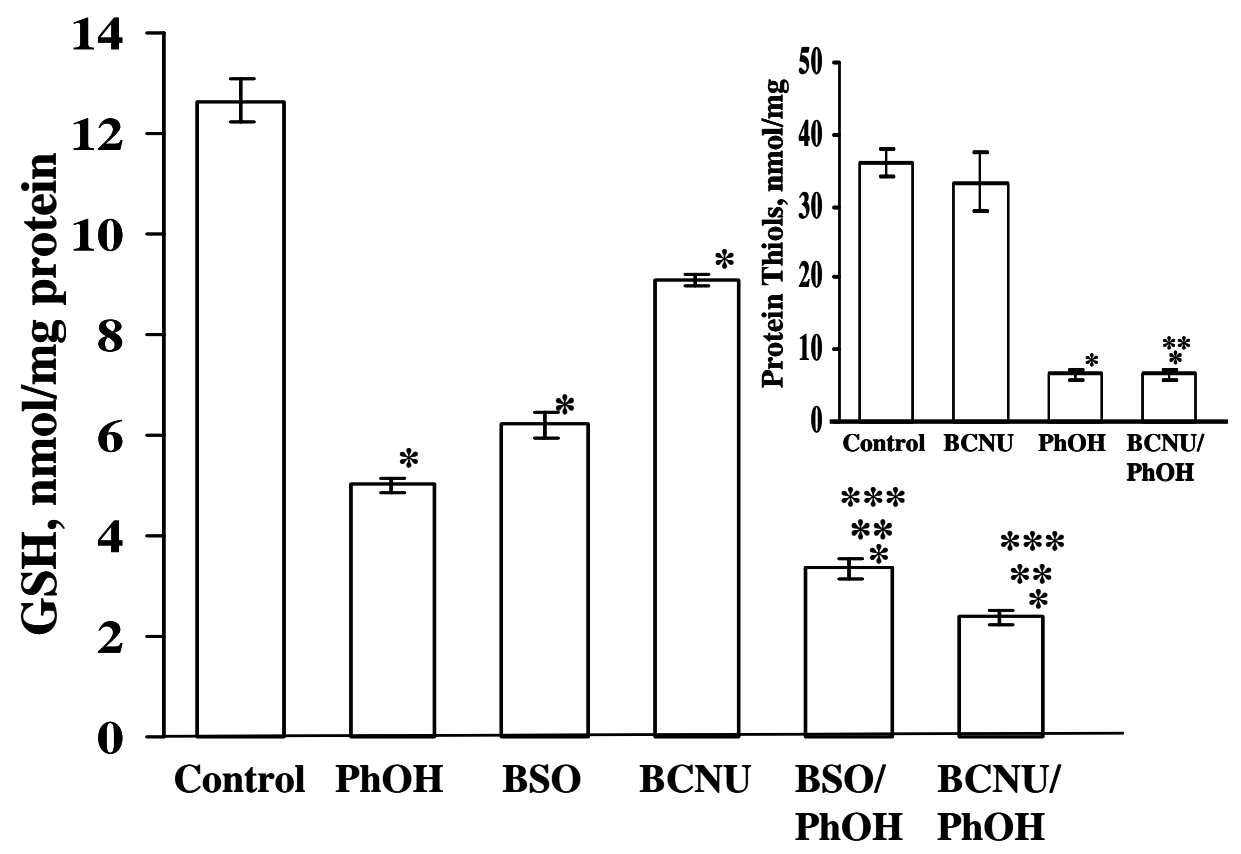

Figure 1.5. The effect of $\mathrm{BCNU} / \mathrm{PhOH}$ or $\mathrm{BSO} / \mathrm{PhOH}$ exposure on the level of $\mathrm{GSH}$. Inset- Effect of phenol plus BCNU on the level of protein thiols in the skin of $\mathrm{B} 6 \mathrm{C} 3 \mathrm{~F} 1$ mice. Mice were intraperitoneally injected with vehicle (PBS, $100 \mu \mathrm{l})$, BCNU (40 $\mathrm{mg} / \mathrm{kg}, 100 \mu \mathrm{l})$, or BSO $(2 \mathrm{mmol} / \mathrm{kg}, 100 \mu \mathrm{l})$ prior to topical phenol $(\mathrm{PhOH})$ exposure. Mice were then painted with $\mathrm{PhOH}(3.5 \mathrm{mmol} / \mathrm{kg})$ and sacrificed 0.5 hours after exposure. Values are means \pm SEM of 3 experiments. ${ }^{*} \mathrm{p}<0.05$ versus PBS-treated control mice; $* * \mathrm{p}<0.05$ versus BCNU or BSO-exposed mice; $* * * \mathrm{p}<0.05$ versus $\mathrm{PhOH}-$ exposed mice. 


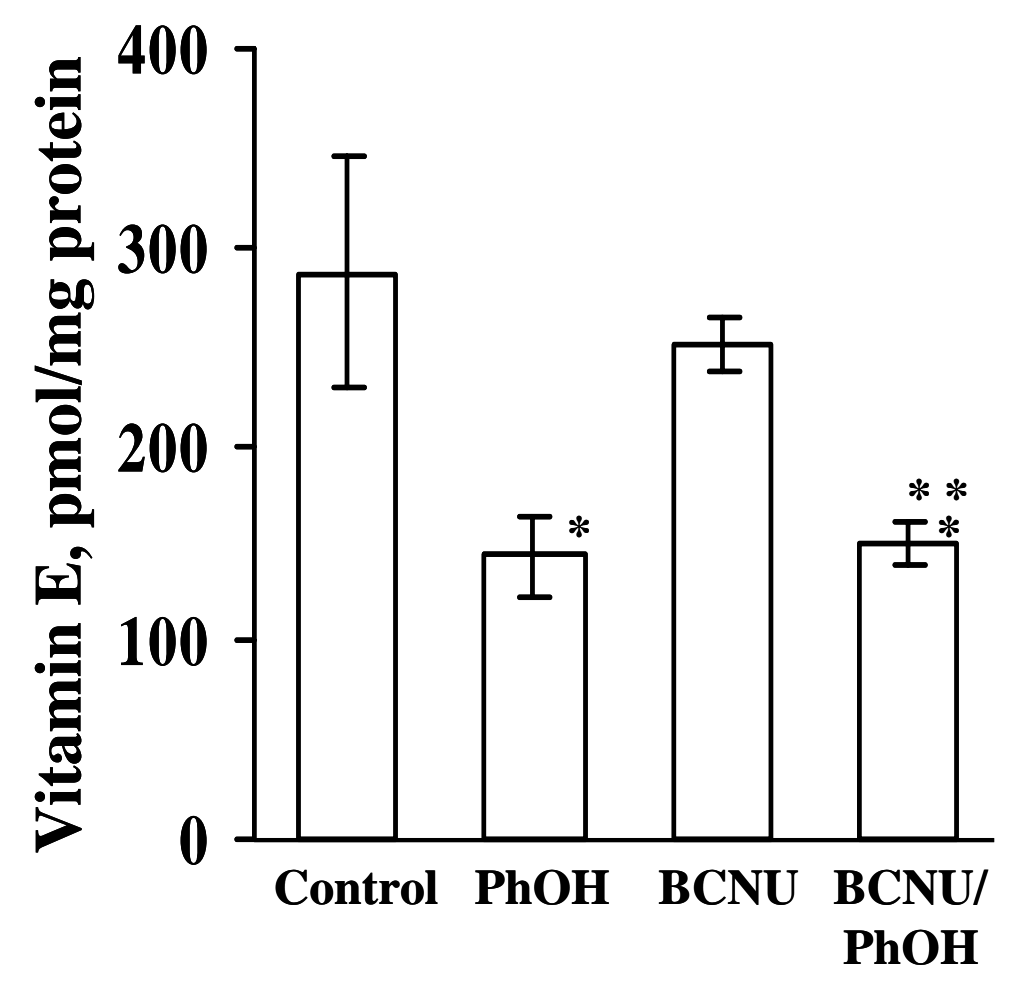

Figure 1.6. The effect of $\mathrm{BCNU} / \mathrm{PhOH}$ exposure on the level of vitamin $\mathrm{E}$ in the skin of B6C3F1 mice. Mice were intraperitoneally injected with vehicle (PBS, $100 \mu 1)$ or BCNU $(40 \mathrm{mg} / \mathrm{kg}, 100 \mu \mathrm{l}) 3$ hours prior to topical exposure to phenol $(\mathrm{PhOH})$. Mice were then painted with $\mathrm{PhOH}(3.5 \mathrm{mmol} / \mathrm{kg})$ and sacrificed 0.5 hours after exposure. Values are means \pm SEM of 3 experiments. ${ }^{*} \mathrm{p}<0.05$ versus PBS-treated control mice; ${ }^{* *} \mathrm{p}<0.05$ versus BCNU-exposed mice. 


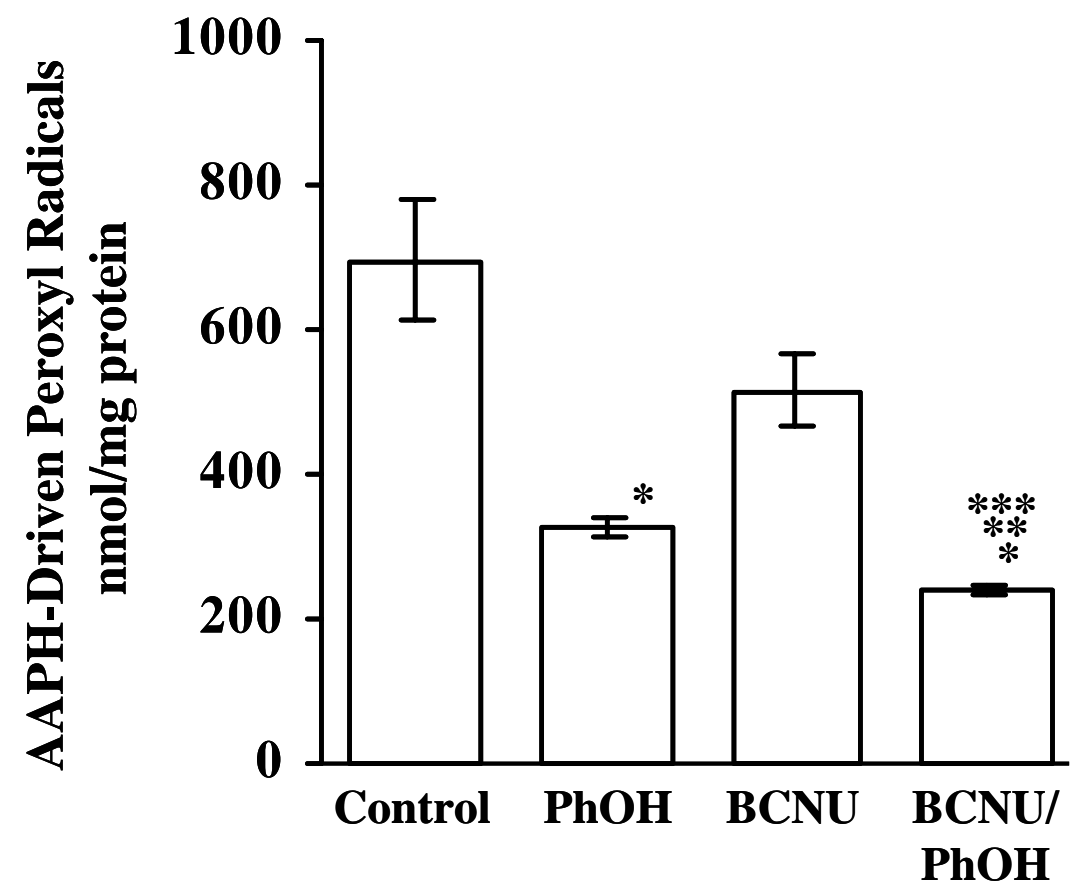

Figure 1.7. The effect of $\mathrm{BCNU} / \mathrm{PhOH}$ on the level of total antioxidant reserve in the skin of B6C3F1 mice. Mice were intraperitoneally injected with vehicle (PBS, $100 \mu \mathrm{l}$ ) or $\mathrm{BCNU}(40 \mathrm{mg} / \mathrm{kg}, 100 \mu \mathrm{l}) 3$ hours prior to topical exposure to phenol $(\mathrm{PhOH})$. Mice were then painted with $\mathrm{PhOH}(3.5 \mathrm{mmol} / \mathrm{kg})$ and sacrificed 0.5 hours after exposure. Values are means \pm SEM of 3 experiments. ${ }^{*} \mathrm{p}<0.05$ versus PBS-treated control mice; $* * p<0.05$ versus $B C N U$-exposed mice; $* * * p<0.05$ versus $\mathrm{PhOH}$-exposed mice. 

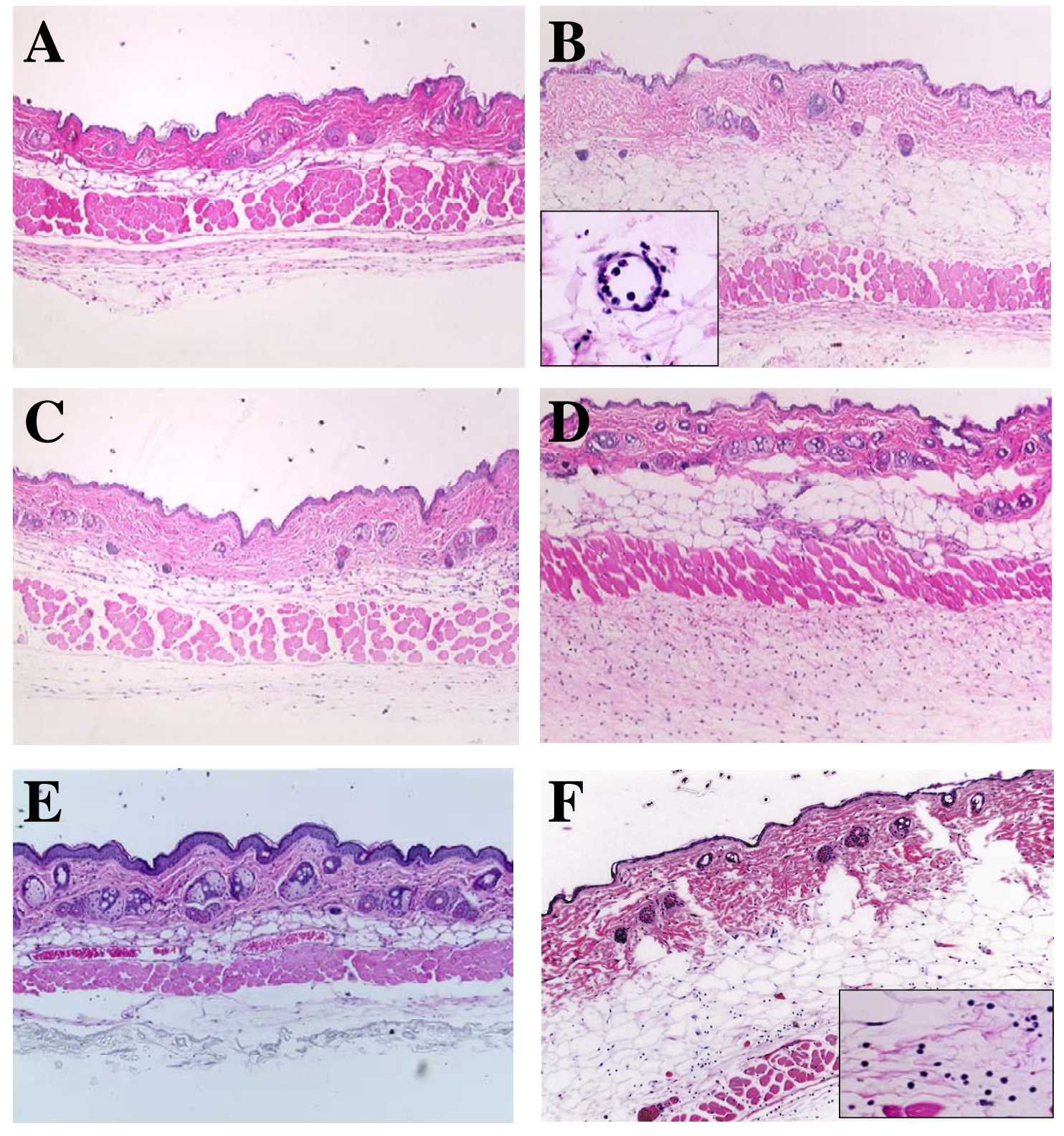

Figure 1.8. Skin histology of $\mathrm{B} 6 \mathrm{C} 3 \mathrm{~F} 1$ female mice treated topically with phenol following administration of $\mathrm{BSO}$ or BCNU. Mice were intraperitoneally injected with vehicle (PBS, $100 \mu \mathrm{l}), \mathrm{BCNU}(40 \mathrm{mg} / \mathrm{kg}, 100 \mu \mathrm{l})$, or BSO $(2 \mathrm{mmol} / \mathrm{kg}, 100 \mu \mathrm{l})$ prior to topical exposure to $\mathrm{PhOH}$. Mice were then painted with phenol $(3.5 \mathrm{mmol} / \mathrm{kg})$ and sacrificed 1 hour after exposure. A. 1 hour after painting with saline; B. 1 hour after painting with phenol; C. 1 hour after painting with saline following BSO administration; D. 1 hour after painting with phenol following administration of BSO; E. 1 hour after painting with saline following administration of BCNU; F. 1 hour after painting with phenol following administration of BCNU. Magnification: 10x; Inset Magnification: 40x. 

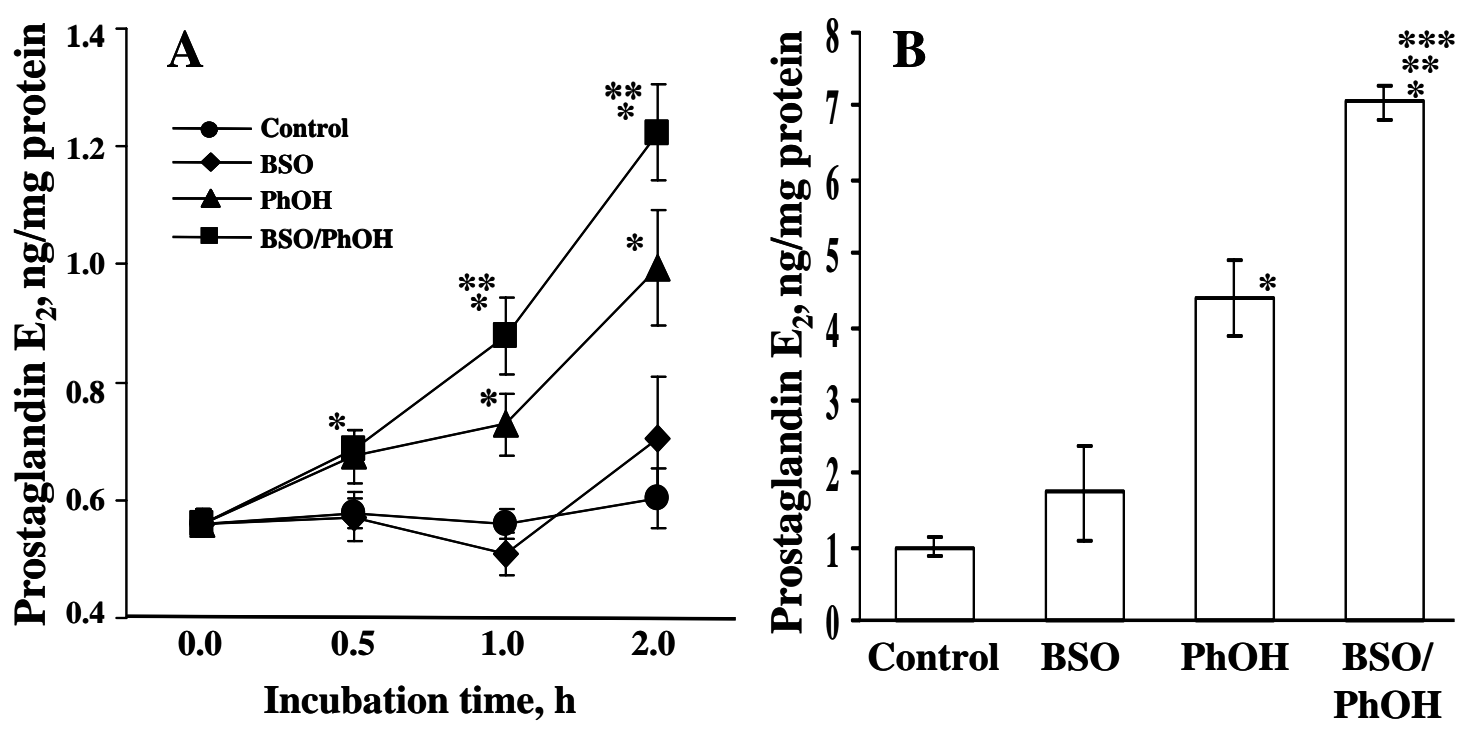

Figure 1.9. A. Time course of prostaglandin $\mathrm{E}_{2}$ release by JB-6 cells following phenol/BSO exposure. Circles- control cells; Diamonds- cells exposed to BSO $(10 \mu \mathrm{M})$; Triangles- cells exposed to $\mathrm{PhOH}(15 \mathrm{mM})$; Squares- cells exposed to $\mathrm{BSO} / \mathrm{PhOH}$. B. Level of prostaglandin $\mathrm{E}_{2}$ in JB-6 cells following 18 hours of $\mathrm{PhOH} / \mathrm{BSO}$ exposure. Cells were exposed to BSO $(10 \mu \mathrm{M})$. Three hours following BSO, cells were exposed to phenol $(15 \mathrm{mM})$. $0.5,1,2$, or 18 hours following exposure, cellular supernatant was collected and analyzed for prostaglandin $E_{2}$. Values are means \pm SEM of 3 experiments. $* \mathrm{p}<0.05$ versus control cells; $* * \mathrm{p}<0.05$ versus $\mathrm{BSO}$-exposed cells, $* * * p<0.05$ versus $\mathrm{PhOH}-\mathrm{exposed}$ cells . 


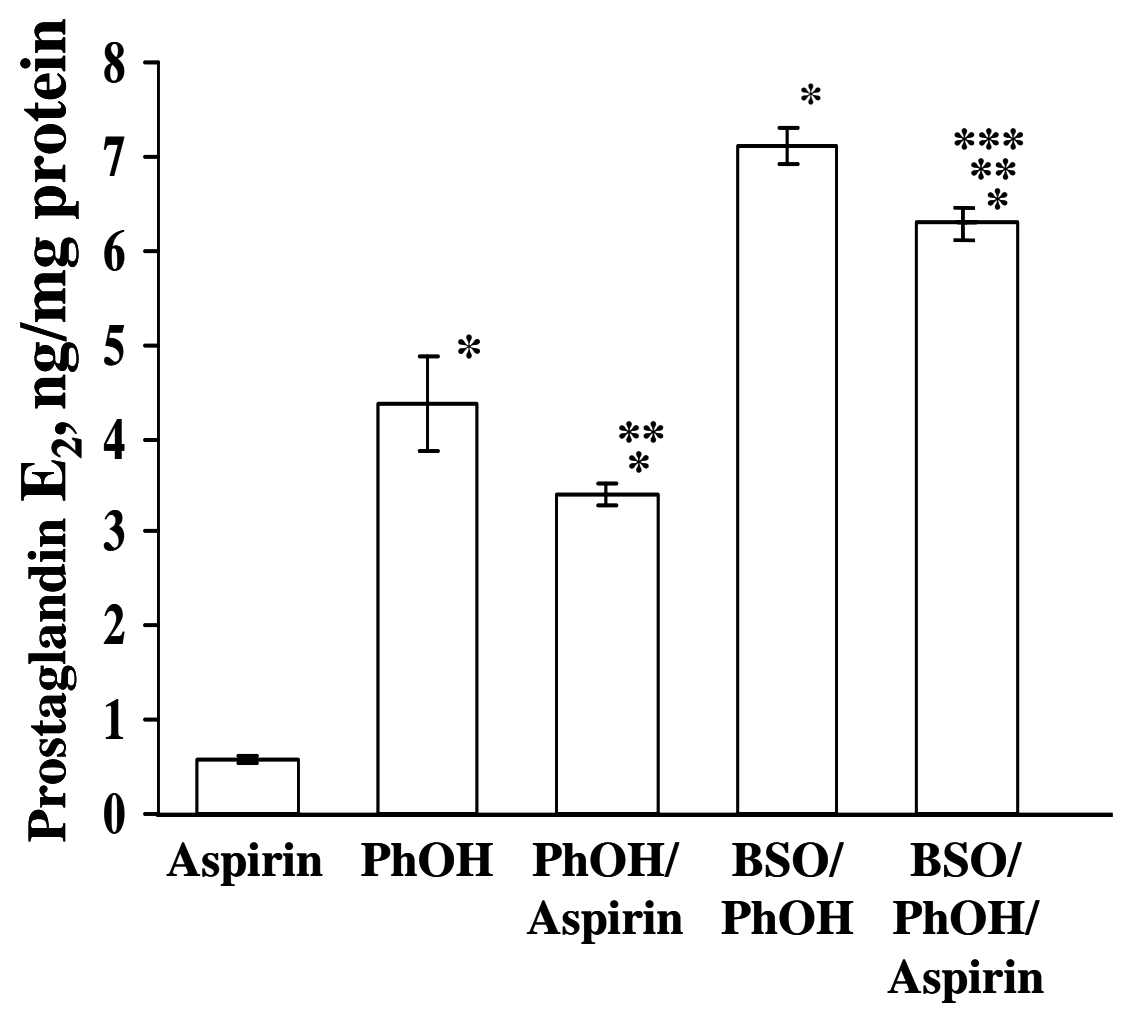

Figure 1.10. Effect of COX-2 inhibitor on the level of prostaglandin E2 in JB-6 cells following 18 hours of phenol/ BSO exposure. JB6 cells were exposed to BSO $(10 \mu \mathrm{M})$ and aspirin $(50 \mu \mathrm{M})$. Three hours following BSO, cells were exposed to phenol $(15 \mathrm{mM})$. Eighteen hours following exposure, cellular supernatant was collected and analyzed for prostaglandin $\mathrm{E}_{2}$. Values are means $\pm \mathrm{SEM}$ of 3 experiments. ${ }^{*} \mathrm{p}<0.05$ versus aspirin treated cells; ${ }^{* *} \mathrm{p}<0.05$ versus phenol-exposed cells; ${ }^{* * *} \mathrm{p}<0.05$ versus $\mathrm{BSO} / \mathrm{PhOH}-$ exposed cells. 

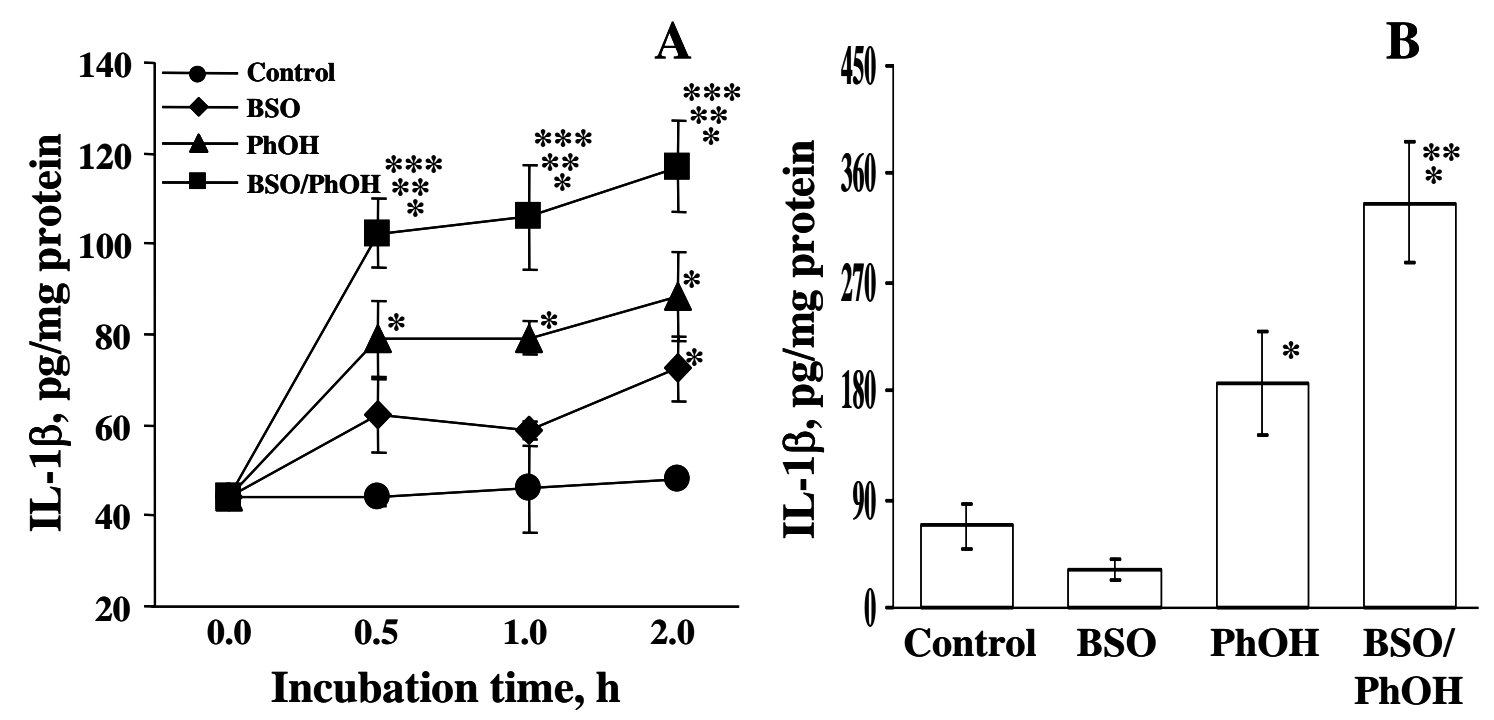

Figure 1.11. A. Time course of IL- $1 \beta$ expression in JB-6 cells following exposure to phenol. Circles- control cells; Diamonds- cells exposed to BSO $(10 \mu \mathrm{M})$; Triangles- cells exposed to $\mathrm{PhOH}(15 \mathrm{mM})$; Squares- cells exposed to $\mathrm{BSO} / \mathrm{PhOH}$. B. IL-1 $\beta$ Expression by JB-6 cells 18 hours following phenol exposure. JB6 cells were exposed to BSO (10 $\mu \mathrm{M})$ for 3 hours. Following BSH exposure, cells were exposed to phenol $(15 \mathrm{mM})$ for $0.5,1,2$, or 18 hours. Cellular supernatant was collected and analyzed for IL-1 $\beta$. Values are means \pm SEM of 3 experiments. $* p<0.05$ versus control cells; $* * p<0.05$ versus BSOtreated cells; $* * * \mathrm{p}<0.05$ versus $\mathrm{PhOH}$-treated cells. 


\section{References}

ATSDR: Toxicologic Profile for Phenol: Draft for Public Comment (Update). Atlanta, GA. U.S. Department of Health and Human Services, Public Health Service, Agency for Toxic Substances and Disease Registry (ATSDR), 1997.

ACGIH. Documentation of the Threshold Limit Values and Biological Exposures Indices. $6^{\text {th }}$ edition. American Conference of Governmental Industrial Hygienists (ACGIH). Cincinnati, OH, pp 1204-1208, BEI155-BEI158, 1991.

Alder, V., Yin, Z., Tew, K. D., and Ronai, Z. 1999. Role of redox potential and reactive oxygen species in stress signaling. Oncogene. 18: 6104-6111.

Ames, B. N., Kammen, H. O., and Yamasaki, E. 1975. Hair dyes are mutagenic: identification of a variety of mutagenic ingredients. Proc Natl Acad Sci USA. 72: 24232427.

Applegate, L. A., Scaletta, C., Panizzon, R., and Frenk, R. 1998. Evidence that ferritin is UV inducible in human skin: part of a putative defense mechanism. J Invest Dermatol. 111: 159-163.

Bickers, D. The skin as a site of drug and chemical metabolism. In: Drill VA and Lazar P (eds.). Current Concept in Cutaneous Toxicity, Academic Press, New York, pp 95$126,1980$.

Blanchard, J. A. 2nd, Barve, S., Joshi-Barve, S., Talwalker, R., and Gates, L. K. Jr. 2001. Antioxidants inhibit cytokine production and suppress NF-kappaB activation in CAPAN1 and CAPAN-2 cell lines. Dig Dis Sci. 46(12):2768-72.

Bogadi-Sare, A., Brumen, V., Turk, R., Karacic, V., and Zavalic, M. 1997. Genotoxic effects in workers exposed to benzene: with special reference to exposure biomarkers and confounding factors. Ind Health. 35: 367-373.

Bracher, M., Faller, C., Grotsch, W., Marshall, R., and Spengler, J. 1990. Studies on the potential mutagenicity of p-phenylenediamine in oxidative hair dye mixtures. Mutat Res. 241: 313-323.

Brown, V. K. H., Box, V. L., and Simpson, B. J. 1975. Decontamination procedures for skin exposed to phenolic substances. Arch Environ Health. 30: 1-6.

Bunnell, E., and Pacht, E. R. 1993. Oxidized glutathione is increased in the alveolar fluid of patients with the adult respiratory distress syndrome. Am Rev Respir Dis. 148: 174-178. 
Cantin, A. M., Hubbard, R. C., and Crystal, R. G. 1989. Glutathione deficiency in the epithelial lining fluid of the lower respiratory tract in idiopathic pulmonary fibrosis. Am Rev Respir Dis. 139: 370-372.

Chen, C. Y., Huang, Y. L., and Lin, T. H. 1998. Association between oxidative stress and cytokine production in nickel-treated rats. Arch Biochem Biophys. 356: 127-132.

Chen, H., and Eastmond, D. A. 1995. Topoisomerase inhibition by phenolic metabolites: potential metabolism for benzene's clastogenic effects. Carcinogenesis. 16: 2301-2307.

Coles, B. F., and Kadlubar, F. F. 2003. Detoxification of electrophilic compounds by glutathione S-transferase catalysis: determinants of individual response to chemical carcinogens and chemotherapeutic drugs? Biofactors. 17: 115-130.

Conning, D. M., and Hayes, M. J. 1970. The dermal toxicity of phenol: an investigation of the most effective first-aid measures. Br J Ind Med. 27: 155-159.

Corbett, M. D., Corbett, B. R., Hannothiaux, M. H., and Quintana, S. J. 1992. The covalent binding of acetaminophen to cellular nucleic acids as the result of the respiratory burst of neutrophils derived from the HL-60 cell line. Toxicol Appl Pharmacol. 113: 8086.

Desmarquest, P., Chadelat, K., Corroyer, S., Cazals, V., and Clement, A. 1998. Effect of hyperoxia on human macrophage cytokine response. Respir Med. 92: 951-960.

Effendy, I., Loffler, H., and Maibach, H. I. 2000. Epidermal cytokines in murine cutaneous irritant responses. J Appl Toxicol. 20(4): 335-41.

Eisenstein, O., Giessner-Prettre, C., Maddaluno, J., Stussi, D., and Weber, J. 1992. Theoretical study of oxyhemocyamin active site: a possible insight on the first step of phenol oxidation by tyrosinase. Arch Biochem Biophys. 296:247-255.

Fujii, T., Ikeda, Y., Yamashita, H., and Fujii, J. 2003. Transient elevation of glutathione peroxidase 1 around the time of eyelid opening in the neonatal rat. J Ocul Pharmacol Ther. 19: 361-369.

Gosset, P., Wallaert, B., Tonnel, A. B., and Fourneau, C. 1999. Thiol regulation of the production of TNF- $\alpha$, IL-6, and IL-8 by human alveolar macrophages. Eur Respir J. 14: 98-105.

Haddad, J. J. 2000. Glutathione depletion is associated with augmentating a proinflammatory signal: evidence for an antioxidant/pro-oxidant mechanism regulating cytokines in the alveolar epithelium. Cytokines Cell Mol Ther. 6: 177-187.

Haddad, J. J., and Land, S. C. 2000. O O $_{2}$-evoked regulation of HIF-1a and NF-kB signaling and oxidative stress. Biochem Biophys Res Commun. 323: 361-371. 
Haddad, J. J., Olver, R. E., and Land, S. C. 2000. Antioxidant/pro-oxidant equilibrium regulates HIF-1a and NFkB redox sensitivity. Evidence for inhibition by glutathione oxidation in alveolar epithelial cells. J Biol Chem. 275: 21130-21139.

Haddad, J. J., Safieh-Garabedian, B., Saade, N. E., and Land, S. C. 2001. Thiol regulation of pro-inflammatory cytokines reveals a novel immunopharmacological potential of glutathione in the alveolar epithelium. J Pharmacol Exp Ther. 296: 9961005.

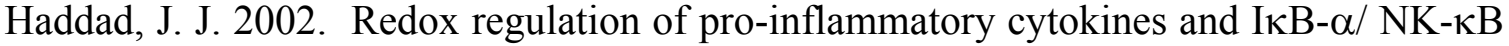
nuclear translocation and activation. Biochem Biophys Res Commun. 296: 847-856.

Haddad, J. J., and Harb, H. L. 2005. L- $\gamma$-Glutamyl-L-cysteinyl-glycine (glutathione; GSH) and GSH-related enzymes in the regulation of pro- and anti-inflammatory cytokines: a signaling transcriptional scenario for redox(y) immunologic sensor(s)? Mol Immunol. 42: 987-1014.

Hess, J. A., Molinari, J. A., Gleason, M. J., and Radecki, C. 1991. Epidermal toxicity of disinfectants. Am J Dent. 4:51-56.

Hiramoto, K., Li, X., Makimoto, M., Kato, T., and Kikugawa, K. 1998. Identification of hydroxyhydroquinone in coffee as a generator of reactive oxygen species that break DNA single strands. Mutat Res. 419: 43-51.

Horch ,R., Spilker, G., and Stark, G. B. 1994. Phenol burns and intoxications. Burns. 20: $45-50$.

Hudson, V. M. 2001. Rethinking cystic fibrosis pathology: the critical role of abnormal reduced glutathione (GSH) transport caused by CFTR mutation. Free Radic Biol Med. 30: $1440-1461$.

Kagan, V. E., and Gorbunov, N. V. 1998. EPR measurements of nitric oxide-induced chromanoxyl radicals of vitamin E. Interactions with vitamin C. Methods Mol Biol. 108:277-84.

Keane, M. P., and Strieter, R. M. 2002. The importance of balance pro-inflammatory and anti-inflammatory mechanisms in diffuse lung disease. Respir Res. 3(1): 5.

Kolachana, P., Subrahmanyam, V. V., Meyer, K. B., Zhang, L., and Smith, M. T. 1993. Benezene and its phenolic metabolises produce oxidative damage in HL-60 cells in vitro and in the bone marrow in vivo. Cancer Res. 53: 1023-1026.

Lang, J.K., Gohil, K., and Packer, L. 1986. Simultaneous determination of tocopherols, ubiquinols, and ubiquinones in blood, plasma, tissue homogenates, and subcellular fractions. Anal Biochem. 157:106-16. 
Luger, T. A., and Schwarz, T. 1990. Evidence for an epidermal cytokine network. J Invest Dermatol. 95: 100S-104S.

Meister, A. 1988. Glutathione metabolism and its selective modification. J Biol Chem. 263(33): 17205-8.

Merliss, R. R. 1972. Phenol marasmus. Occup Med. 14:55-56.

Miyamoto, S., Dupas, C., Murota, K., and Terao, J. 2003. Phospholipid hydroperoxides are detoxified by phophoplipase A2 and GSH peroxidase in rat gastric mucosa. Lipids. 38: 641-649.

Napoli, C., and Lerman, L. O. 2001. Involvement of oxidation-sensitive mechanisms in the cardiovascular effects of hypercholesterolemia. May Clin Proc. 76: 619-631.

Niki, E. 1990. Free radical initiators as a source of water- or lipid-soluble peroxyl radicals. Methods Enzymol. 186: 100-108.

Nussler, A. K., Di Silvio, M., Billiar, T. R., Hoffman, R. A., Geller, D. A., Selby, R., Madariaga, J., and Simmons, R. L. 1992. Simulation of the nitric oxide synthetase pathway in human hepatocytes by cytokines and endotoxin. J Exp Med. 176: 261-264.

Paolini, M., Pozzetti, L., Silingardi, P., Della Croce, C., Bornzetti, G., and Cantelli-Forti, G. 1998. Isolation of a novel metabolizing system enriched in phase-II enzymes for short-term genotoxicity bioassays. Mutat Res. 413:205-217.

Petroff, M. G., Petroff, B. K., and Pate, J. L. 2001. Mechanisms of cytokine-induced death of cultured bovine luteal cells. Reproduction. 121: 753-760.

Pnece, B. C., and Neylor, M. F. Effect of single-dosed ultraviolet radiation on skin. 1990. Superoxide dismutase, catalase, and xanthine oxidase in hairless mice. J Invest Dermat. 95: 213-216.

Punnonen, K., Autio, P., Kiistala, U., and Ahotupa, M. 1991. In vitro effect of solarstimulated ultraviolet irridation on antioxidant enzymes and lipid peroxidation in human epidermis. Br Dermatol. 125: 18-20.

Roum, J. H., Behld, R., McElvancy, N. G., Borok, Z., and Crystal, R. G. 1993. Systemic deficiency of glutathione in cystic fibrosis. J Appl Physiol. 75: 2419-2424.

Saugstad, O. D. 1997. Bronchopulmonary dysplasia and oxidative stress: are we closer to an understanding of the pathogenesis of BPD? Acta Pediatr. 86: 1277-1282. 
Schafer, F. Q., and Buettner, G. R. 2001. Redox environment of the cell as viewed through the redox state of the glutathione disulfide/glutathione couple. Free Radic Biol Med. 30: 1191-1212.

Schmidt, R. J., and Cheng, L. Y. 1992. Biochemical response of skin to allergenic and non-allergenic nitrohalobenzenes. Evidence that an NADPH-dependent reductase in skin may act as a prohapten-activating enzyme. Arch Dermatol Res. 284: 400-408.

Selassie, C. D., DeSoyza, T. V., Rosario, M., Gao, H., and Hansch, C. 1998. Phenol toxicity in leukemia cells: a radical process? Chemico-Biological Interactions. 113: 175190.

Shindo, Y., Witt, E., Han, D., Epstein, W., and Packer, L. 1994. Enzymic and nonenzymic antioxidants in skin. J Invest Dermatol. 102: 122-124.

Shvedova, A. A., Kommineni, C., Jeffries, B. A., Castranova, V., Tyurina, Y. Y., Tyurin, V. A., Serbinova, E. A., Fabisiak, J. P., and Kagan, V. E. 2000. Redox cycling of phenol induces oxidative stress in human epidermal keratinocytes. J Invest Dermatol. 114: 354364.

Shvedova, A. A., Kisin, E. R., Murray, A. R., Kommineni, C., Castranova, V., Mason, R. P., Kadiiska, M. B., and Gunther, M. R. 2002. Antioxidant balance and free radical generation in vitamin $\mathrm{E}$ deficient mice after dermal exposure to cumene hydroperoxide. Chem Res Toxicol. 15(11): 1451-9.

Sies, H. 1999. Glutathione and its role in cellular functions. Free Radic Biol Med. 27(9-10): 916-21.

Thompson, D. C., Perera, K., and London, R. 1995. Quinone methide formation from para isomers of methylphenol (cresol), ethylphenol, and isopropylphenol: relationship to toxicity. Chem Res Toxicol. 8: 55-60.

Trupmann , E. S., and Ellenby, J. D. 1979. Major electrocardiographic changes during chemical face peeling. Plast Reconstr Surg. 63: 44-48.

Tuo, J., Wolff, S. P., Loft, S., and Poulsen, H. E. 1998. Formation of nitrated and hydroxylated aromatic compounds from benzene and peroxynitrite, a possible mechanism of benzene genotoxicity. Free Rad Res. 4: 369-375.

Yamashita, N., Hoshida, S., Otsu, K., Asahi, M., Kuzuya, T., and Hori, M. 1999. Exercise provides direct biphasic cardioprotection via manganese superoxide dismutase activation. J Exp Med. 189: 1699-1706.

Zelck, U. E., and Von Janowsky, B. 2004. Antioxidant enzymes in intramoluscan Schistosoma mansoni and ROS-induced changes in expression. Parasitology. 128: 493501. 
STUDY 2: ROLE OF VITAMIN E IN THE ANTIOXIDANT DEFENSE SYSTEM OF SKIN IN YOUNG AND OLD MICE EXPOSED TO CUMENE HYDROPEROXIDE 


\section{$\underline{\text { Abstract }}$}

The skin is exposed to numerous environmental, chemical, and physical stressors (UVirradiation) whose injurious action is often associated with the development of oxidative stress. While the skin possesses an elaborate antioxidant defense system to prevent oxidative stress, excessive exposure to occupational and environmental insults can overwhelm the cutaneous antioxidant capacity. Age-related decline of antioxidant protection may further enhance sensitivity of skin to chemically induced oxidative damage. To assess whether aging affected the antioxidant capabilities of the skin, we studied changes in vitamin E, glutathione (GSH), ascorbate, and total antioxidant reserve levels in the skin of female mice evaluated from 4 to 32 weeks of age. We found that aging significantly reduced the antioxidant levels in the skin of mice. Among the studied antioxidants, we observed the most significant and rapid decrease occurred in vitamin E content. Because dermal exposure is a major route leading to skin toxicity, we studied the effects of topical application of cumene hydroperoxide (Cum-OOH) to the skin by assessing the effects on the antioxidant defense of the skin of young and old mice. Two animal models were used: 1) mice with an alimentary deficiency of vitamin E and 2) mice with a genetic manipulation targeting the tocopherol transporter protein $(\alpha-$ TTP knockout). We found that oxidative DNA damage (8-oxo-2'-deoxyguanosine) in skin of old mice (32 weeks) occurred independently of vitamin E status while DNA damage in skin of young animals (13 weeks) exposed to $\mathrm{Cum-OOH}$ was dependent upon vitamin E. Cum-OOH induced oxidative stress in old mice as assessed by depletion of GSH, ascorbate, and total antioxidant reserve. In vitamin E deficient animals, Cum- $\mathrm{OOH}$ induced morphological changes to a greater extent in the skin of old compared to young 
mice. Similar results were found when the $\alpha$-TTP knockout mice were exposed to Cum$\mathrm{OOH}$. In these animals, initial vitamin E-levels were only slightly reduced compared to those in the group given a vitamin $\mathrm{E}$ deficient diet. After $\mathrm{Cum}-\mathrm{OOH}$ exposure, $\alpha$-TTP knockout mice had significantly less vitamin E compared to $\alpha$-TTP knockout control mice treated with vehicle. Cum-OOH exposure of mice given a vitamin E deficient diet resulted in a depletion of vitamin $\mathrm{E}$ with no detectable amount present in skin. GSH and ascorbate were also significantly reduced in $\alpha$-TTP knockout mice following Cum-OOH exposure; however, this reduction was not as significant as the reduction of GSH and ascorbate observed in skin of mice with an alimentary deficiency in vitamin E. In conclusion, antioxidants play a prominent role in the defense of skin against oxidative injury induced in vivo. 


\section{$\underline{\text { Introduction }}$}

The skin is exposed to numerous environmental chemical and physical agents which may result in the development of oxidative stress. The skin has a well developed and efficient antioxidant system to cope with oxidative injury (Beckman and Ames, 1998). It is generally accepted that one of the major contributors to skin aging, skin disorders and skin diseases results from reactive oxygen species (ROS). Antioxidant defense mechanisms play a major role in protecting the skin and preventing the development of oxidative damage via the detoxification of ROS and reduction of inflammatory cytokine production at the expense of the antioxidant system which includes GSH, vitamin E, and vitamin C (Kohen and Nyska, 2003; Haddad et al., 2001; Hudson, 2001; Petroff et al., 2001). The age-related decline of the skin's antioxidant defense systems would certainly make the skin more susceptible to chemically induced oxidative damage.

Many peroxy compounds are well known to be a source of free radicals as they are widely used as initiators of polymerization. Organic peroxides (OP) are extensively used in chemical and pharmaceutical industries (Manly, 1956) as catalysts, intermediates, and raw materials for a number of products, e.g. reinforced plastics, rubber curing, finishing agents for acetate yarns, dental cements and restoratives, and treatments for acne. In the food industry, OP are used for bleaching flour, fats, oils, waxes and milk, and preparation of certain cheeses (Lewis, 1993; Medical Economics Co., 1997).

Cutaneous exposure to organic hydroperoxides is known to cause a delayed reaction in skin resulting in severe erythema, edema, and vesiculation (Floyd and Stokinger, 1958). OP-induced lipid peroxidation was implicated as one of the essential mechanisms of 
toxicity in keratinocytes (Vessey et al. 1992, 1995; Babich et al., 1996). The question can be raised as to whether oxidative stress occurs in vivo to yield free radicals in skin exposed to Cum-OOH. Vitamin E represents probably one of the best examples of a "perfect" lipid-soluble antioxidant in membranes and lipoproteins where it can interact and be recycled by other lipid-soluble antioxidants (e.g., coenzyme Q) (Stoyanovsky et al, 1995) and water-soluble antioxidants (e.g., vitamin C and thiols) (Kagan et al, 1992). In addition, vitamin $\mathrm{E}$ can be regenerated from its radical by electron transport in mitochondria and endoplasmic reticulum (Packer et al, 1989). It is well known that susceptibility to lipid peroxidation is affected by levels of vitamin $\mathrm{E}$ in different tissues (Comba et al, 1975; Tappel, 1980; Kadiiska et al, 1993), including skin (Machlin et al, 1977; Igarashi et al, 1989). The present study was designed to assess whether antioxidant status is changed in the skin of mice with age and whether topical exposure to $\mathrm{Cum}-\mathrm{OOH}$ differently affected the skin of young and old mice.

\section{Materials and Methods}

\section{Chemicals}

Fatty acid-free serum albumin (fSA), luminol, sodium dodecyl sulfate (SDS), cumene hydroperoxide (Cum-OOH), glutathione, and ascorbate were purchased from Sigma Chemicals Co. (St. Louis, MO). Methanol, ethanol, chloroform, hexane and water (HPLC grade) were purchased from Aldrich Chemical Co (Milwaukee, WI). Thio-Glo-1 was obtained from Covalent Inc (Wobum, MA). 2,2'-Azobis(2-aminodinopropane)dihydrochloride (AAPH) was purchased from Wako Chemicals USA, Inc. (Richmond, VA). 


\section{Animals}

C57BL/6, B6.129S4-Ttpa<tm1Far $>$ ( $\alpha$-TTP knockout on a C57BL/6 background), $\mathrm{Balb} / \mathrm{C}$, and B6C3F1 mice (3-4 weeks; 16-18 g in weight) were obtained from Jackson Laboratories (Bar Harbor, ME). Each mouse was housed in an individual ventilated cage with Alpha-Dri cellulose chips and hardwood Beta-chips for bedding and provided HEPA-filtered air under controlled environmental conditions in an AAALAC accredited, specific pathogen-free facility. After one-week acclimation, animals were placed on a basal (sufficient) or vitamin E deficient diet (Purina Mills, Richmond, IN) for 10 (132 weeks old, young) or 29 weeks (30 weeks old, old) and $\alpha$-TTP knockout mice were kept on basal diet for 29 weeks. The sufficient Diet 5755 is a purified synthetic diet that provides all essential nutrients to support maintenance, growth, gestation, and lactation in laboratory mice (Table 2.1). The vitamin E deficient diet is based on the sufficient diet 5755 from which vitamin E was removed. Animals were supplied with fresh diet daily and water was provided ad libitum. All animal procedures were performed in accordance with an approved ACUC protocol. The animals were weighed biweekly, and the food consumption was recorded monthly.

\section{Topical Exposure of Mice to Cum-OOH}

Twenty-four hours prior to exposure, animals were shaved on the dorsal area of the back. Mice were topically exposed to Cum-OOH $(100 \mu \mathrm{l} ; 12 \mathrm{mmol} / \mathrm{kg})$ for 1 or 2 hours. Following exposure, animals were sacrificed by inhalation of an excess of carbon dioxide after the termination of the treatments. Skin flaps from the inter-scapular area of the back of mice $\left(1.5 \times 2.0 \mathrm{~cm}^{2}\right)$ were excised and samples were taken for histopathology and biochemical analyses. 


\section{Skin Collections and Preparation of Homogenates}

Skin flaps from the intrascapular area of the back of mouse were excised and samples taken for histopathology and biochemical analysis. Skin for biochemical analysis was immediately frozen at $-80^{\circ} \mathrm{C}$ until processed. The skin homogenates were prepared from frozen tissues with ice-cold phosphate-buffered saline (PBS, 7.4) using a tissue tearer (model 985-370, Biospec Products, Inc., Racine, WI).

\section{Skin Preparation for Histopathology Examination}

The skin was processed after fixation in $10 \%$ neutral buffered formalin, following the standard operating procedures of the laboratory. Hematoxylin and eosin (H\&E) stained histology slides were used for light microscopy examination of the tissue. Photomicrographs were prepared using an Olympus 300 double-headed microscope (Tokyo, Japan).

\section{HPLC Assay of $\alpha$-Tocopherol}

Extracts of $\alpha$-tocopherol from skin homogenates were isolated using a procedure described by Lang et al. (1986). A Waters HPLC system with a 717 auto sampler, a Hewlett Packard ODS Hypersil column (5 mm; 200 X 4.6 mm), a Waters 600 Controller pump, and a 474 fluorescence detector was used to measure $\alpha$-tocopherol in the samples. The wavelengths employed in the assay were $292 \mathrm{~nm}$ (excitation) and $324 \mathrm{~nm}$ (emission). Both the excitation and emission slits were $5 \mathrm{~nm}$. Eluent was $\mathrm{CH}_{3} \mathrm{OH}$ with a flow rate of $1 \mathrm{ml} / \mathrm{min}$. Under these conditions, the retention time for $\alpha$-tocopherol was $8.2 \mathrm{~min}$. The minimum detection level for $\alpha$-tocopherol in the samples was $0.1 \mathrm{pmol} / \mathrm{mg}$ of protein. The data acquired were exported from the Waters 474 detector using Millennium 2000 software (Waters Associates, Milford, MA). 


\section{HPLC Assay of Ascorbic Acid}

Following protein precipiation with $10 \%$ trichloroacetic acid and sedimentation $(2000 \mathrm{~g}$ X $10 \mathrm{~min}$ ), supernatants were obtained from skin homogenates. Supernatants were used for HPLC measurements of ascorbic acid. A mobile phase of 1:24 methanol-water with $\mathrm{pH} 3.0$ adjusted by acetic acid at a flow rate of $1.0 \mathrm{ml} / \mathrm{min}$ was used. A Waters HPLC system with a 717 auto sampler, a Hewlett Packard ODS Hypersil column (5 mm; 200 X $4.6 \mathrm{~mm}$ ), a Waters 600 Controller pump, and a 474 fluorescence detector was used to measure ascorbic acid in the samples. Under these conditions, the ascorbic acid retention time was 3.0 minutes. The observed ascorbate peak was completely abolished by the addition of ascorbate oxidase.

\section{Chemiluminescence Measurements of Total Antioxidant Reserve}

A water-soluble azo-initiator, 2,2' azobis(2-aminodinopropane)-dihydrochloride (AAPH), was used to produce peroxyl radicals (Niki, 1990). Oxidation of luminol by AAPH-derived peroxyl radicals was assayed by the chemiluminescence response. A delay in the chemiluminescence response caused by interaction of endogenous antioxidants with AAPHderived peroxyl radicals was observed upon addition of homogenates. Based on the known rate of peroxyl radical generation by AAPH, the amount of peroxyl radicals scavenged by endogenous antioxidants was evaluated. The incubation medium contained $0.1 \mathrm{M}$ phosphate buffer (pH 7.4) at $37^{\circ} \mathrm{C}$, AAPH $(50 \mathrm{mM})$, and luminol $(0.4 \mathrm{mM})$. The reaction was started by the addition of AAPH. A luminescent analyzer 633 (Coral Biomedical, Inc., San Diego, CA) was employed for determination. 


\section{Glutathione (GSH) and Protein Thiols assay in tissue}

GSH and total protein sulfhydryl concentration in homogenates of skin was determined using ThioGlo $\mathrm{TM}_{-1}$, a maleimide reagent which produces a highly fluorescent product upon reaction with sulfhydryl groups (Shvedova et al., 2000). A standard curve was established by addition of GSH $(0.02-1.0 \mu \mathrm{M})$ to $0.1 \mathrm{M}$ phosphate buffer $(\mathrm{pH} 7.4)$ containing 10. $\mu \mathrm{M}$ ThioGlo ${ }^{\mathrm{TM}}-1$. GSH content was estimated from the immediate fluorescence response registered upon addition of ThioGloTM -1 to a tissue or cells homogenate. Total protein sulfhydryls were determined from the augmentation of the fluorescence response after addition of SDS $(4 \mathrm{mM})$ to the same homogenate. A spectrofluorophotometer (Shimadzu RF-5000 U, Kyoto, Japan) was employed for the assay (excitation $388 \mathrm{~nm}$ and emission $500 \mathrm{~nm}$ ).

\section{8-Hydroxy-2'-deoxyguanosine}

Skin homogenates were evaluated for the presence of an oxidative DNA damage marker, 8-hydroxy-2'-deoxyguanosine (8-OHdG). An enzyme-linked immunosorbent assay (ELISA) was used to manufacturers specifications to quantitatively measure 8 -OHdG (Oxis Health Products, Inc; Portland, OR). Briefly, an 8-OHdG monoclonal primary antibody was used to bind $8-\mathrm{OHdG}$ present within the skin homogenate. A secondary horseradish peroxidase (HRP) conjugated antibody was then used to bind the monoclonal: 8-OHdG complex. Chromogen addition results color development and absorbance is measured at $450 \mathrm{~nm}$. The concentration of $8-\mathrm{OHdG}$ is determined from a calibration curve measured simultaneously according to the manufacturer's protocol. 


\section{Protein Assay}

Measurements of protein in homogenates of tissue and cells were conducted using a BioRad protein assay kit, cat. \# 500-0006 (Richmond, CA).

\section{Statistics}

Data were expressed as the mean with \pm standard error of the mean for each group. Oneway ANOVA with Tukey test was employed to compare the responses between treatments. Statistical significance was set at $\mathrm{p}<0.05$.

\section{$\underline{\text { Results }}$}

\section{Effects of Aging on Antioxidant Status of Murine Skin}

Changes in antioxidant status occur in the skin of mice during aging and vitamin $\mathrm{E}$ alimentary deprivation. Balb/C mice were fed a diet either sufficient or deficient in vitamin $\mathrm{E}$ for 29 weeks and changes in antioxidant status of the brain, liver, skin, and plasma were monitored. Changes in vitamin E, total antioxidant reserve, and glutathione levels were observed in the liver, plasma, brain, and skin. The most drastic alteration in antioxidant levels occurred in the skin where vitamin E levels were reduced 99.4-fold following alimentary vitamin E deprivation for 29 weeks (Table 2.2).

To compare changes in vitamin $\mathrm{E}$ status, 2 strains of mice, $\mathrm{B} 6 \mathrm{C} 3 \mathrm{~F} 1$ and $\mathrm{BALB} / \mathrm{C}$, were used to determine if the observed alterations were strain-dependent. Both strains of mice exhibited an age-related decline in vitamin E. Vitamin E levels decreased $82 \%$ and $61 \%$ in $\mathrm{B} 6 \mathrm{C} 3 \mathrm{~F} 1$ and $\mathrm{Balb} / \mathrm{C}$ mice, respectively, as animals aged from 4 weeks to 32 weeks old ( 29 weeks on diet). After 29 weeks of alimentary vitamin E deprivation, we found a 99.5\% reduction in vitamin $\mathrm{E}$ in the skin of both $\mathrm{B} 6 \mathrm{C} 3 \mathrm{~F} 1$ and $\mathrm{Balb} / \mathrm{C}$ mice (Table 2.3). 


\section{Effect of Cum-OOH Exposure on Vitamin E in Skin of Young and Old Mice}

To address how old (32 weeks old, 29 weeks on diet) Balb/C mice were affected by topical exposure to $\mathrm{Cum}-\mathrm{OOH}(100 \mu \mathrm{l} ; 12 \mathrm{mmol} / \mathrm{kg})$, mice were exposed for 2 hours to Cum-OOH. Two hour Cum-OOH exposure resulted in a significant reduction in vitamin E levels. Alimentary depletion of vitamin E for 29 weeks resulted in a reduction in vitamin E levels of 99\%. Cum-OOH exposure caused a severe decrease in vitamin E content $(99.5 \%)$ in animals fed a basal diet, while animals given a vitamin E deficient diet had vitamin E levels below detectable limits following Cum-OOH exposure (Figure 2.1).

\section{Effect of Cum-OOH Exposure on the Glutathione Levels in Skin of Young and Old}

\section{Mice.}

In order to evaluate the redox status of the skin of young (13 weeks) and old (32 weeks) $\mathrm{Balb} / \mathrm{C}$ mice following exposure to $\mathrm{Cum}-\mathrm{OOH}$, the level of cellular thiols were measured. Old mice had a $38 \%$ reduction in the level of GSH present within the skin as compared to the young ones. Exposure of both young and old mice to $\mathrm{Cum-OOH}$ for 1 or 2 hours significantly reduced the levels of GSH in the skin. Animals, both young and old, fed a basal or vitamin E deficient diet had a significant reduction in GSH as a result of Cum-

$\mathrm{OOH}$ exposure (Figure 2.2). Dietary vitamin E restriction did not cause a further reduction in GSH following Cum-OOH exposure as compared to those observed in mice kept on a basal diet. 


\section{Effect of Cum-OOH Exposure on Total Antioxidant Levels in Skin of Young and Old}

\section{Mice.}

To assess changes in levels of total antioxidant reserve in the skin of $\mathrm{Balb} / \mathrm{C}$ mice following Cum- $\mathrm{OOH}$ exposure, a luminol-enhanced chemiluminescence assay was applied. A water-soluble azo-initiator, AAPH, was used to produce peroxyl radicals at a constant rate (Niki, 1990). Interaction of the peroxyl radicals generated by AAPH with luminol in phosphate buffer $\left(0.1 \mathrm{M}, \mathrm{pH} 7.4\right.$ at $\left.37^{\circ} \mathrm{C}\right)$ produced a characteristic luminol response. The addition of skin homogenate to the incubation system resulted in a lag period during which the chemiluminescence response was not observed. Skin homogenates from control animals produced a greater lag period than skin homogenates from Cum-OOH exposed mice. This lag period results because of the competition of endogenous skin antioxidants with luminol for the AAPH-derived peroxyl radicals (Kagan, 1998). Total antioxidant reserve levels were significantly reduced as a result of alimentary vitamin E deprivation. Young mice had a 35\% reduction in total antioxidant reserve levels; while, older animals had a $60 \%$ reduction in total antioxidant reserve due to dietary vitamin E restriction. Exposure to $\mathrm{Cum}-\mathrm{OOH}$ for 1 hour resulted in a $75 \%$ and $77 \%$ reduction in total antioxidant reserve found in young mice fed a basal or vitamin E deficient diet, respectively. Two-hour topical exposure to $\mathrm{Cum-OOH}$ resulted in almost no detectable antioxidant reserve levels found in the skin of young animals given a basal or deficient diet (Figure 2.3A).

Following cumene hydroperoxide exposure, similar trends were observed in changes in total antioxidant reserve in the skin of old mice given a basal or vitamin E deficient diet. Old mice given a basal or vitamin $\mathrm{E}$ deficient diet had a $75 \%$ and $62 \%$ reduction, in total 
antioxidant reserve after 1 hour exposure to $\mathrm{Cum}-\mathrm{OOH}$. Two-hour exposure to Cum$\mathrm{OOH}$ caused a drop in total antioxidant reserve to levels below detection in the skin of old animals kept on basal or vitamin E deficient diet (Figure 2.3B).

\section{Effect of Cum-OOH Exposure on Ascorbate Levels in Skin of Old Mice}

Ascorbate levels in the skin of Balb/C were also altered as a result of dietary restriction in vitamin E. A significant reduction (26\%) in ascorbate levels in the skin was observed in animals with an alimentary depletion of vitamin E. Ascorbate levels were altered as a result of exposure to Cum-OOH $(1 \mathrm{~h})$ in the skin of old mice given a vitamin E sufficient or deficient diet. Exposure to Cum-OOH for $2 \mathrm{~h}$ resulted in a $91.5 \%$ reduction in ascorbate in the skin of animals given a sufficient diet; while, animals given a vitamin E deficient diet had levels of ascorbate below detectable limits (Figure 2.4).

\section{Cum-OOH Induced DNA Damage in Skin of Young and Old Mice}

Following exposure to Cum-OOH for 1 or $2 \mathrm{~h}$, the skin of young and old Balb/C mice was evaluated for DNA damage by measuring 8-hydroxy-2'-deoxyguanosine (8-OHdG). In young mice, we found no 8-OHdG formation indicating a lack of DNA damage 1 or 2 hours post-Cum-OOH exposure. In old mice, we observed no accumulation of 8-OHdG

in skin one hour post-Cum-OOH; however, 2 hours after exposure to $\mathrm{Cum-OOH,} \mathrm{we}$ found a significant increase (112\%) in 8-OHdG formation (Figure 2.5).

\section{Cum-OOH Induced DNA Damage in Skin of Vitamin E Deficient Mice}

The skin of old Balb/C mice given a diet sufficient or deficient in vitamin $\mathrm{E}$ were also evaluated for the presence of $8-\mathrm{OHdG}$ after $\mathrm{Cum}-\mathrm{OOH}$ treatment. Exposure to Cum$\mathrm{OOH}$ for 1 hour did not cause an increase in 8-OHdG formation in the skin of animals 
given a basal or vitamin $\mathrm{E}$ deficient diet. Two hours post-exposure to $\mathrm{Cum}-\mathrm{OOH}$ produced a significant increase in $8-\mathrm{OHdG}$ in the skin of animals given a either basal or vitamin $\mathrm{E}$ deficient (Figure 2.6). This indicates that the formation of 8-OHdG in the skin of mice exposed to Cum-OOH was independent of the vitamin E skin status (Figure 2.5).

\section{Skin Histopathology of Young and Old Mice Exposed to Cum-OOH}

Alterations in skin structure were evaluated in young and old Balb/C mice following exposure to $\mathrm{Cum}-\mathrm{OOH}(1$ or $2 \mathrm{~h})$. Young and old mice both exhibited a normal epidermis with no age related differences observed in the tissue (Figure 7A, D). Cum$\mathrm{OOH}$ exposure for $1 \mathrm{~h}$ caused edema in the skin of both young and old mice. Older mice also had pronounced muscle degeneration as exhibited by hyperchromaticity and condensation in the muscle tissue than seen in the skin of younger mice exposed to Cum$\mathrm{OOH}$ for 1 hour (Figure 2.7B, E). Older animals treated with Cum-OOH for $2 \mathrm{~h}$ had more profound alterations than those observed in the younger animals (Figure 2.7C,F). The presence of profuse edema pushing the dermal connective tissue outward as well as alterations in skeletal muscle as observed by vacuolation and dissolution of the muscle fibers were observed in old mice after $2 \mathrm{~h}$ Cum-OOH treatment.

\section{Skin Histopathology of Vitamin E Deficient Mice Exposed to Cum-OOH}

Following exposure to Cum-OOH (1 or $2 \mathrm{~h}$ ), the skin of old Balb/C mice fed a basal or vitamin $\mathrm{E}$ deficient diet was evaluated for structural alterations. Basal and vitamin $\mathrm{E}$ deficient mice showed no differences in skin structure (Figure 2.8A, D). Cum-OOH exposure $(1 \mathrm{~h})$ caused the development of edema as well as muscle degeneration in the skin of mice fed a basal or vitamin $\mathrm{E}$ deficient diet. Animals deficient in vitamin $\mathrm{E}$ had extensive muscle degeneration compared to that seen in the mice supplied with basal diet 
and treated with Cum-OOH (1h; Figure 2.8B, E). Topical exposure to Cum-OOH (2 h) further augmented the skin injury seen as structural alterations of muscle accompanied by the development of extensive edema. Vitamin E deficient animals also had more prominent muscle degeneration and edema compared to that observed in the skin of animals given a basal diet after $2 \mathrm{~h}$ Cum-OOH exposure (Figure 2.8C, F).

\section{Vitamin E Levels in the Skin of $\alpha$-TTP Mice and C57BL/6 Mice Given a Vitamin E Deficient Diet after Topical Cum-OOH Exposure}

A comparison of the response of skin to $\mathrm{Cum}-\mathrm{OOH}$ exposure was done using mice with reduced levels of vitamin E via alimentary restriction and genetic manipulation of the $\alpha$ tocopherol transport protein $(\alpha-\mathrm{TTP})$. Because alimentary restriction of vitamin $\mathrm{E}$ requires 29 weeks to achieve deprivation (99\%) of vitamin E, studies could not be conducted utilizing younger mice. Measurements of vitamin E in $\alpha$-TTP knockout mice revealed that vitamin E levels in the skin of animals were reduced by $75 \%$.

Assessment of vitamin $\mathrm{E}$ in skin of C57BL/6 mice fed a basal diet, revealed a 44\% reduction of vitamin $\mathrm{E}$ in the skin after exposure to $\mathrm{Cum}-\mathrm{OOH}$. In vitamin $\mathrm{E}$ deficient mice, exposure to $\mathrm{Cum}-\mathrm{OOH}$ reduced vitamin $\mathrm{E}$ content in the skin to undetectable levels. $\alpha$-TTP knockout mice exposed to Cum-OOH exhibit a 97\% decrease in vitamin E found in skin (Figure 2.9).

\section{Glutathione Levels in the Skin of $\alpha$-TTP Knockout Mice and Mice fed a Vitamin E Deficient Diet after Topical Cum-OOH Exposure}

C57BL/6 mice given a basal diet had a 15\% reduction in GSH following exposure to Cum-OOH (Figure 2.10). During alimentary deprivation of vitamin E, GSH levels were 
reduced by $17 \%$ in skin compared to those animals given basal diet. Exposure of Cum$\mathrm{OOH}$ to vitamin $\mathrm{E}$ deficient mice caused a $95 \%$ reduction in glutathione levels in the skin. The deletion of the vitamin $\mathrm{E}$ transporter ( $\alpha$-TTP) caused no significant reduction in glutathione levels, while topical exposure to $\mathrm{Cum}-\mathrm{OOH}$ resulted in a $73 \%$ reduction in GSH skin content (Figure 2.10).

Ascorbate in the Skin after Topical Cum-OOH Exposure of $\alpha$-TTP Knockout Mice and Mice fed a Vitamin E Deficient Diet

In C57BL/6 given a basal diet, we found a $75 \%$ reduction in ascorbate following exposure to Cum-OOH. In vitamin $\mathrm{E}$ deficient mice, the levels of ascorbate were reduced by $57 \%$ as compared to animals given a basal diet. Exposure of vitamin E deficient mice to Cum-OOH resulted in a $97 \%$ reduction in ascorbate levels, while in $\alpha$ TTP knockout mice exposure to $\mathrm{Cum}-\mathrm{OOH}$ caused a $95 \%$ drop in ascorbate levels (Figure 2.11).

\section{$\underline{\text { Discussion }}$}

Aging is a naturally occurring process characterized by the progressive accumulation of

diverse deleterious cellular and tissue changes. Such changes have been proposed to subsequently increase the risk of disease and death (Harman, 1981,1993, 1994, 1996, 2003). According to the free radical theory of aging (Harman, 1981), free radical reactions occur by virtue of genetic and environmental factors which are responsible for the aging process. Both increased oxidant insult and decline in antioxidant defense capacity resulted in an elevated pro-oxidant state found in aged animal and human cells and tissue (Hagen, 2003). 
Low molecular weight antioxidants, e.g. GSH ,ascorbate and vitamin E, present in the skin are readily involved in an interlinked network providing the regulation and control of accelerated free radical induced injury. It has been shown that GSH is able to synergistically enhance the ascorbate-dependent recycling of vitamin E (Packer, 1991; Martensson et al., 1991; Kagan and Packer, 1994; Guo and Packer, 2000; Shvedova et al., 2000; Shvedova et al., 2001). Evaluation of the antioxidant status of mice over a 32week period revealed an age related decline in antioxidant skin levels specifically seen in GSH, vitamin E, and ascorbate. Antioxidant inadequacy, as a result of dietary vitamin E deficiency, genetic disorders, or aging, subsequently decreases other antioxidant of the network. This decrease in antioxidant capabilities is linked to an increase in formation of reactive oxygen species, cellular injury, and tissue disorders (Nachbar and Korting, 1995). Depletion of antioxidants found in this study affect the skin's susceptibility making chemically induced skin damage more pronounced.

We have shown in a previous studies that chemical exposures to $\mathrm{Cum}-\mathrm{OOH}$ exposure resulted in the accelerated generation of radicals found in the skin of mice fed a vitamin E deficient diet (Shvedova et al., 2002). Decreased antioxidant capabilities observed in old animals produced severe skin damage after $\mathrm{Cum}-\mathrm{OOH}$ exposure. While young and old exposed mice both exhibited oxidative stress characterized by a significant depletion of GSH, ascorbate, and vitamin E, older mice exhibited extensive skin injury including edema and inflammatory cell infiltration along with events leading to muscle degeneration after Cum-OOH treatments. 
The physiological concentration of vitamin E, specifically $\alpha$-tocopherol, is controlled by the $\alpha$-tocopherol transporter protein ( $\alpha$-TTP) (Traber and Arai, 1999; Gohil et al., 2003). The transporter protein preferentially binds $\alpha$-tocopherol and mediates its secretion into the circulation. $\alpha$-TTP regulates systemic and organ tissue concentrations of $\alpha$ tocopherol. In normal animals, $\alpha$-TTP is expressed at high levels in the liver (Arita et al., 1995; Sato et al., 1993; Yoshida et al., 1992), while relatively low levels are present in the brain, spleen, lung and kidney (Hosomi et al., 1997; Traber and Arai, 1999). Genetic deletion of $\alpha$-TTP caused a significant reduction in vitamin E levels in the skin; however, vitamin $\mathrm{E}$ was not reduced to the same levels as observed following dietary deprivation in the skin of mice given a vitamin E deficient diet (29 weeks). We found no significant reduction in glutathione or ascorbate content occurred in the skin of $\alpha$-TTP knockout mice $(29$ weeks). This difference in vitamin $\mathrm{E}$ reduction in $\alpha$-TTP and vitamin E deficient mice indicates the possibility that $\alpha$-TTP does not function as the sole source for transport of vitamin $E$ to the skin. Topical exposure of $\alpha$-TTP knockout animals to Cum-OOH resulted in decreases in GSH and ascorbate similar to those seen in wild-type animals.

Toxic outcomes of dermal exposure to $\mathrm{Cum}-\mathrm{OOH}$ were found to have differential effects when the chemical was topically applied to the skin of young and old mice. Aging resulted in a significant reduction in the antioxidants present in the skin, as observed by a reduction in $\mathrm{GSH}$, ascorbate, and vitamin $\mathrm{E}$, thereby making the skin more vulnerable to free-radical mediated tissue injury. As a result of this age-related decline in the antioxidant network in the skin, old mice had more profound tissue and muscle damage 
induced by oxidative stress following Cum-OOH exposure. Alimentary deficiency in vitamin $\mathrm{E}$ further exacerbated the observed tissue damage which occurred as a result of Cum-OOH exposure. This indicates the importance of the antioxidant network and balance in the prevention of skin injury due to exposure to oxizable occupational chemicals. 


\section{Tables and Figures}

\begin{tabular}{|c|c|c|c|c|c|c|c|}
\hline \multicolumn{2}{|l|}{ Typical Analysis } & \multicolumn{2}{|c|}{$\begin{array}{l}\text { Chemical Composition }^{1} \\
\text { Nutrients }^{2}\end{array}$} & \multicolumn{2}{|l|}{$\underline{\text { Minerals }}$} & \multicolumn{2}{|l|}{$\underline{\text { Vitamins }}$} \\
\hline Protein & $19.3 \%$ & & & Calcium, \% & 0.6 & Thiamin Hydrochloride, ppm & 20.0 \\
\hline Fat & $10.0 \%$ & Protein, \% & 19.3 & Phosphorus & 0.4 & Riboflavin, ppm & 20.0 \\
\hline Fiber & $14.3 \%$ & Fat, \% & 10.0 & Potassium, \% & 0.4 & Nicotinic Acid, ppm & 90.0 \\
\hline \multirow[t]{2}{*}{ Carbohydrate } & $60.6 \%$ & Fiber (Crude), \% & 4.3 & Magnesium, \% & 0.065 & Pyridoxine Hydrochloride, ppm & 20.0 \\
\hline & & Carbohydrate, \% & 60.6 & Sodium, \% & 0.2 & d-Calcium Pantothenate, ppm & 60.0 \\
\hline Ingredients & & Gross Energy, & & Chlorine, \% & 0.2 & Folic Acid, ppm & 4.0 \\
\hline Casein-vitamin & & kcal/gm & 4.1 & Fluorine, ppm & 5.0 & Biotin, ppm & 0.4 \\
\hline free & $21.00 \%$ & & & Iron, ppm & 60.0 & i-inositol, ppm & 200.0 \\
\hline Sucrose & $5.00 \%$ & & & Zinc, ppm & 20.0 & Vitamin, $B_{1}$ mcg/kg & 20.0 \\
\hline \multicolumn{2}{|c|}{ Non-nutritive fiber } & & & Manganese, ppm & 65.0 & Menadione Dimethylpyrimidinol & \\
\hline (Solka-floc) & $3.00 \%$ & & & Copper, ppm & 15.0 & Bisulfite, ppm & 20.0 \\
\hline Corn oil & $5.00 \%$ & & & Cobalt, ppm & 3.2 & Vitamin A Acetate, IU/gm & 22.0 \\
\hline Lard & $5.00 \%$ & & & Iodine, ppm & 0.6 & Vitamin D, IU/gm & 2.2 \\
\hline Dextrin & $43.65 \%$ & & & Chromium, ppm & 3.0 & \multicolumn{2}{|c|}{ Dl-alpha Tocopheryl Acetate, IU/kg } \\
\hline DL-methionine & $0.15 \%$ & & & Molybdenum, ppm & n 0.8 & (sufficient diet) $\quad 50$ & \\
\hline $\begin{array}{l}\text { RP vitamin } \\
\text { mixture2 }\end{array}$ & $2.00 \%$ & & & Selenium, ppm & 0.2 & (deficient diet) $\quad<10$ & \\
\hline Choline Chloride & $0.20 \%$ & & & & & & \\
\hline $\begin{array}{l}\text { RP mineral } \\
\text { mixture \#101 }\end{array}$ & 5.00 & & & & & & \\
\hline Total & $100.00 \%$ & & & & & & \\
\hline
\end{tabular}

Table 2.1. Composition of vitamin E sufficient and deficient animal diets. 


\begin{tabular}{|c|c|c|c|}
\hline & Vitamin E & $\begin{array}{c}\text { Total } \\
\text { Antioxidant } \\
\text { Reserve }\end{array}$ & GSH \\
\hline Brain & Fold decrease & Fold decrease & Fold decrease \\
\hline Skin & 3.6 & 1.6 & 1.7 \\
\hline Liver & 14.3 & 1.3 & 1.4 \\
\hline Plasma & 8.6 & N.D. & 1.2 \\
\hline
\end{tabular}

Table 2.2. Depletion of antioxidants in BALB/C mice fed a vitamin E deficient diet. Animals were fed a vitamin E deficient diet for 29 weeks. N.D.- not detected. 


\begin{tabular}{|c|c|c|c|c|}
\hline \multirow{2}{*}{ Age } & \multicolumn{2}{|c|}{ B6C3F1 } & \multicolumn{2}{c|}{ BALB/c } \\
\cline { 2 - 5 } & Basal & $\begin{array}{c}\text { Vitamin E } \\
\text { Deficient }\end{array}$ & Basal & $\begin{array}{c}\text { Vitamin E } \\
\text { Deficient }\end{array}$ \\
\hline $\begin{array}{c}3-4 \text { weeks old } \\
\text { (Naïve) }\end{array}$ & \multicolumn{2}{|c|}{$114.4 \pm 10.2$} & \multicolumn{2}{|c|}{$134.3 \pm 24.9$} \\
\hline $\begin{array}{c}11 \text { weeks old } \\
(8 \text { weeks on diet })\end{array}$ & $86.0 \pm 20.6$ & $5.2 \pm 0.4^{*}$ & $98.5 \pm 11.6$ & $2.4 \pm 0.7$ \\
\hline $\begin{array}{c}22 \text { weeks old } \\
(19 \text { weeks on diet) }\end{array}$ & $68.8 \pm 5.7^{*}$ & $1.5 \pm 0.6^{*}$ & $71.2 \pm 10.2^{*}$ & $1.5 \pm 0.3^{*}$ \\
\hline $\begin{array}{c}32 \text { weeks old } \\
(29 \text { weeks on diet) }\end{array}$ & $21.0 \pm 4.32^{*}$ & $0.61 \pm 0.13^{*}$ & $52.9 \pm 8.0^{*}$ & $0.63 \pm 0.11^{*}$ \\
\hline
\end{tabular}

Table 2.3. Level of vitamin $\mathrm{E}$ in the skin of $\mathrm{B} 6 \mathrm{C} 3 \mathrm{~F} 1$ or $\mathrm{BALB} / \mathrm{c}$ mice given basal or vitamin $E$ deficient diets. Mean \pm SE of 3 experiments. ${ }^{*} p<0.05$, versus naive mice. 


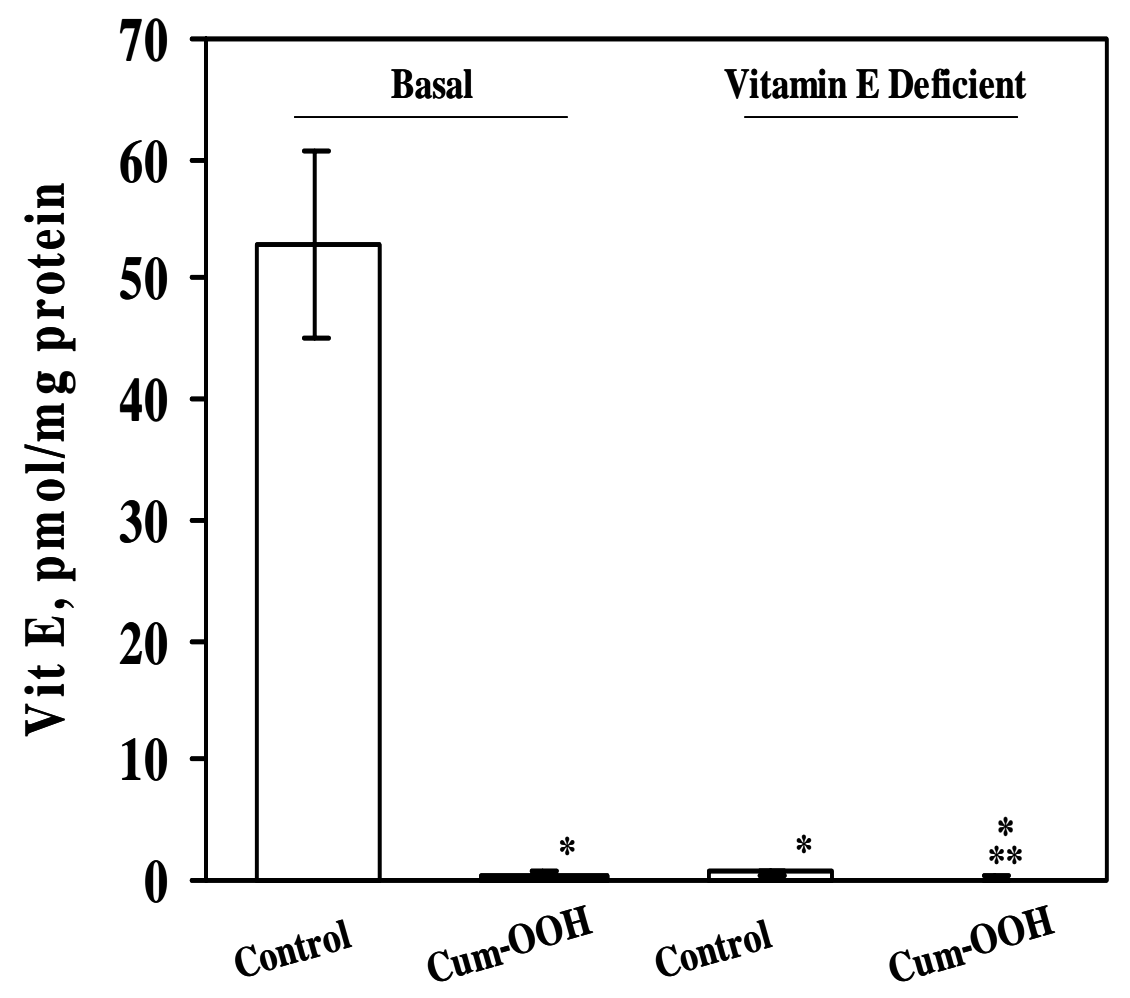

Figure 2.1. Vitamin $\mathrm{E}$ in the skin of Balb/c mice (32 Week Old) given basal or vitamin $\mathrm{E}$ deficient diets following topical exposure to cumene hydroperoxide. Mice were fed a basal or vitamin E deficient diet for 29 weeks. Mice were painted on the dorsal area of the back with $12 \mathrm{mmol} / \mathrm{kg}$ cumene hydroperoxide and sacrificed 2 hours post-exposure. Values are means \pm SEM of 3 experiments. ${ }^{*} \mathrm{p}<0.05$ versus basal fed control mice; $* * p<0.05$ versus vitamin $E$ deficient fed control. 

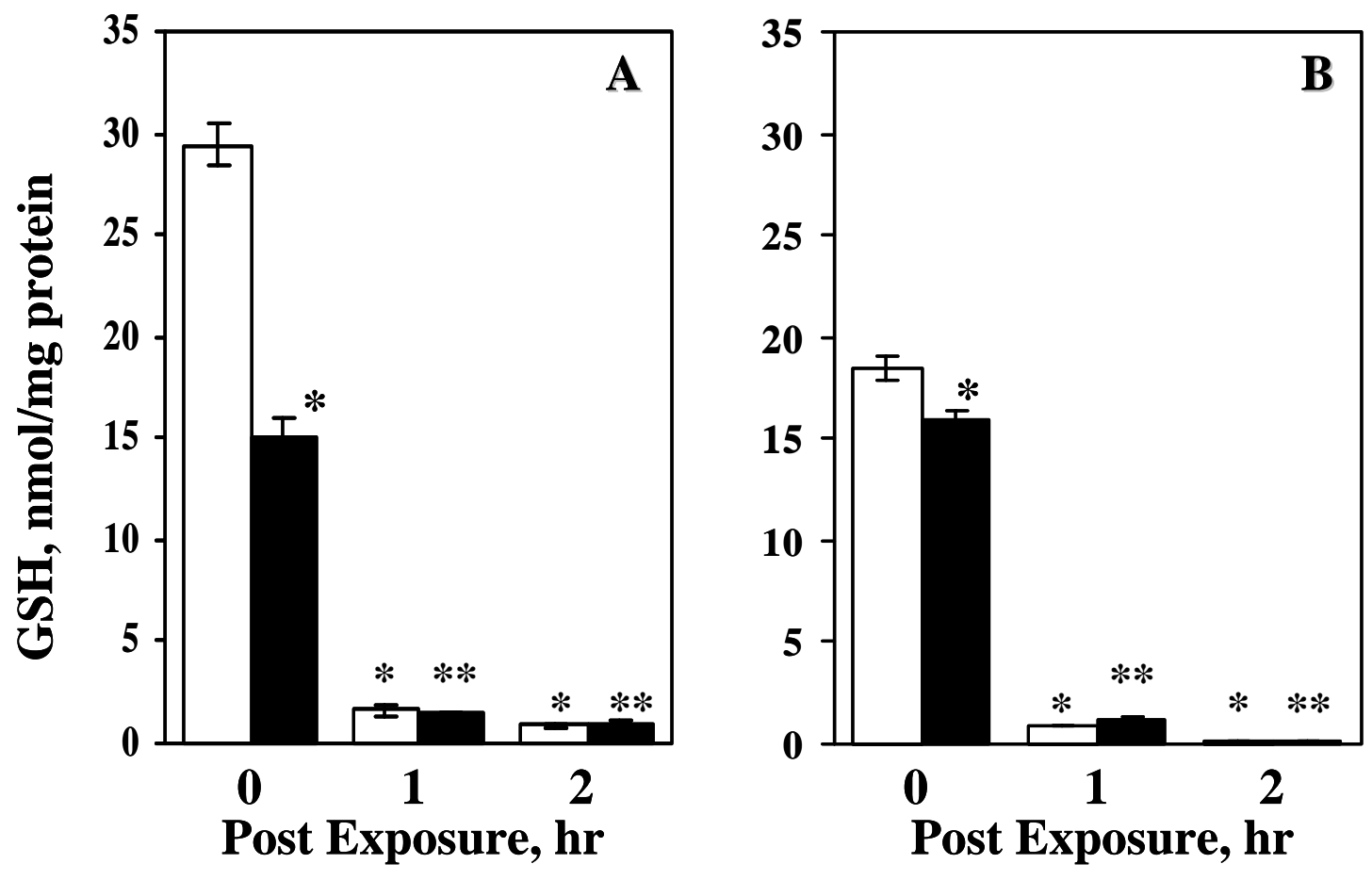

Figure 2.2. Cumene hydroperoxide induced reduction of GSH in the skin of young (A) and old (B) Balb/c mice given basal or vitamin $\mathrm{E}$ deficient diets. White bars - basal diet; Black bars - vitamin E deficient diet. Mice were fed a basal or vitamin E deficient diet for 10 (young mice) or 29 (old mice) weeks. Mice were painted on the dorsal area of the back with $12 \mathrm{mmol} / \mathrm{kg}$ cumene hydroperoxide and sacrificed 1 or 2 hours post-exposure. Values are means \pm SEM of 3 experiments. ${ }^{*} \mathrm{p}<0.05$ versus basal fed control mice; $* * \mathrm{p}<0.05$ versus vitamin $\mathrm{E}$ deficient fed control mice. 

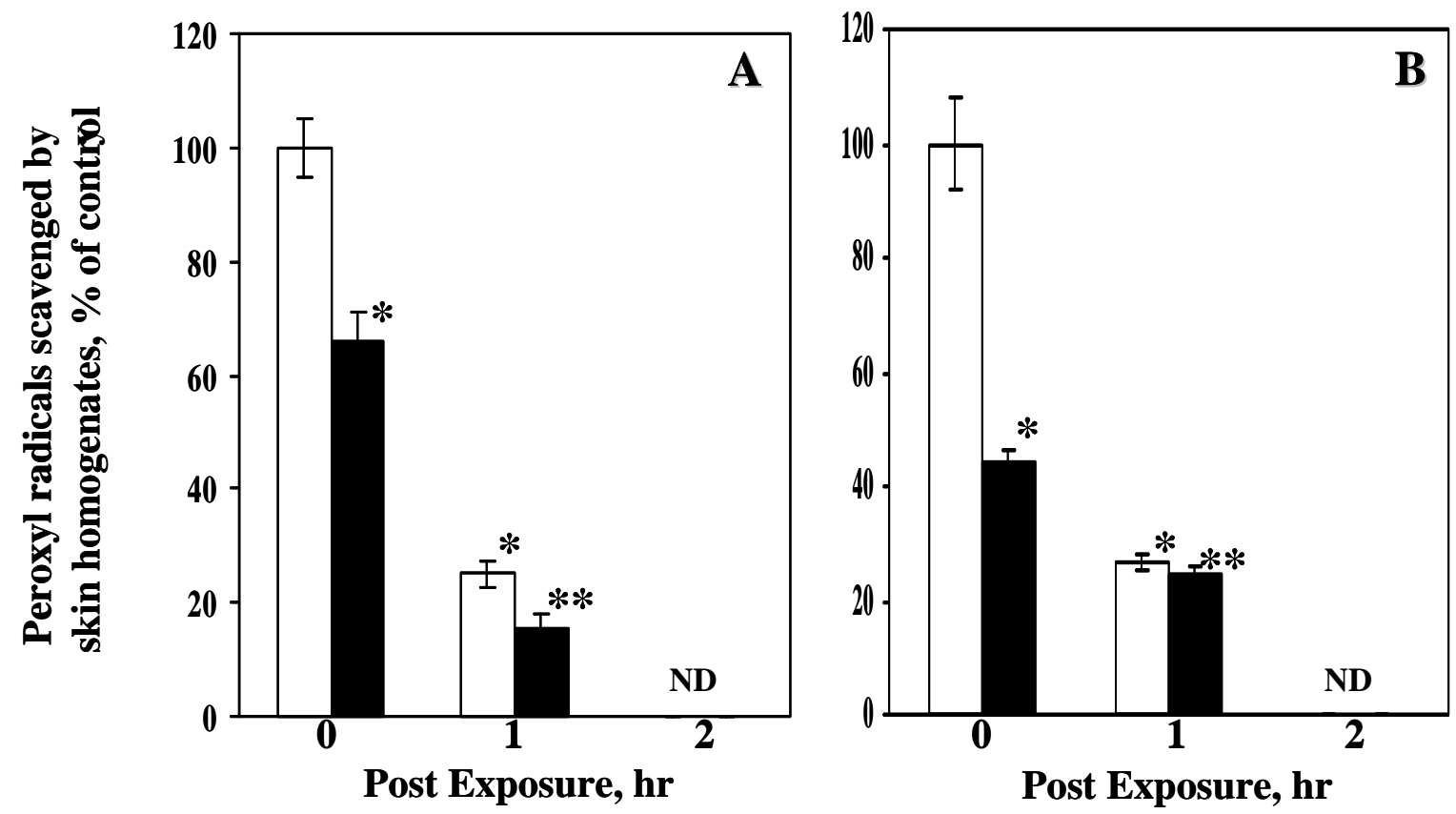

Figure 2.3. Total antioxidant reserve in the skin of young (A) and old (B) Balb/C mice given basal or vitamin $\mathrm{E}$ deficient diets following topical exposure to cumene hydroperoxide. White bars - basal diet; black bars-vitamin E deficient diet. Mice were fed a basal or vitamin E deficient diet for 10 (young mice) or 29 (old mice) weeks. Mice were painted on the dorsal area of the back with $12 \mathrm{mmol} / \mathrm{kg}$ cumene hydroperoxide and sacrificed 1 or 2 hours post-exposure. Values are means \pm SEM of 3 experiments. ND - non-detectable. ${ }^{*} \mathrm{p}<0.05$ versus basal fed control mice; ${ }^{*} \mathrm{p}<0.05$ versus vitamin E deficient fed control mice. 


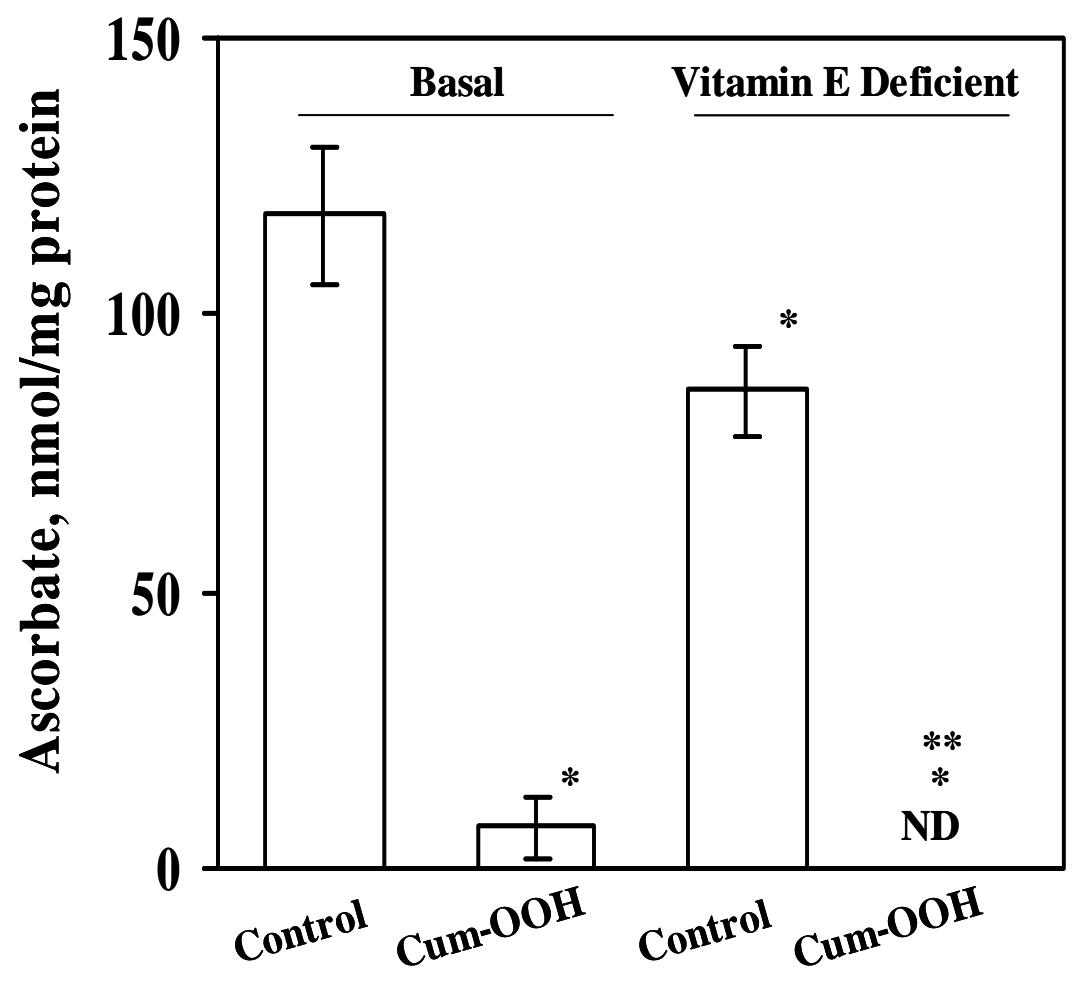

Figure 2.4. Ascorbate in the skin of Balb/c mice (32 weeks old) given basal or vitamin $\mathrm{E}$ deficient diet (29 weeks) following topical exposure to cumene hydroperoxide. Mice were painted on the dorsal area of the back with $12 \mathrm{mmol} / \mathrm{kg}$ cumene hydroperoxide and sacrificed 2 hours post-exposure. Values are means \pm SEM of 3 experiments. ND - non-detectable; ${ }^{*} \mathrm{p}<0.05$ versus basal fed control mice; $* * p<0.05$ versus vitamin E deficient fed control mice. 


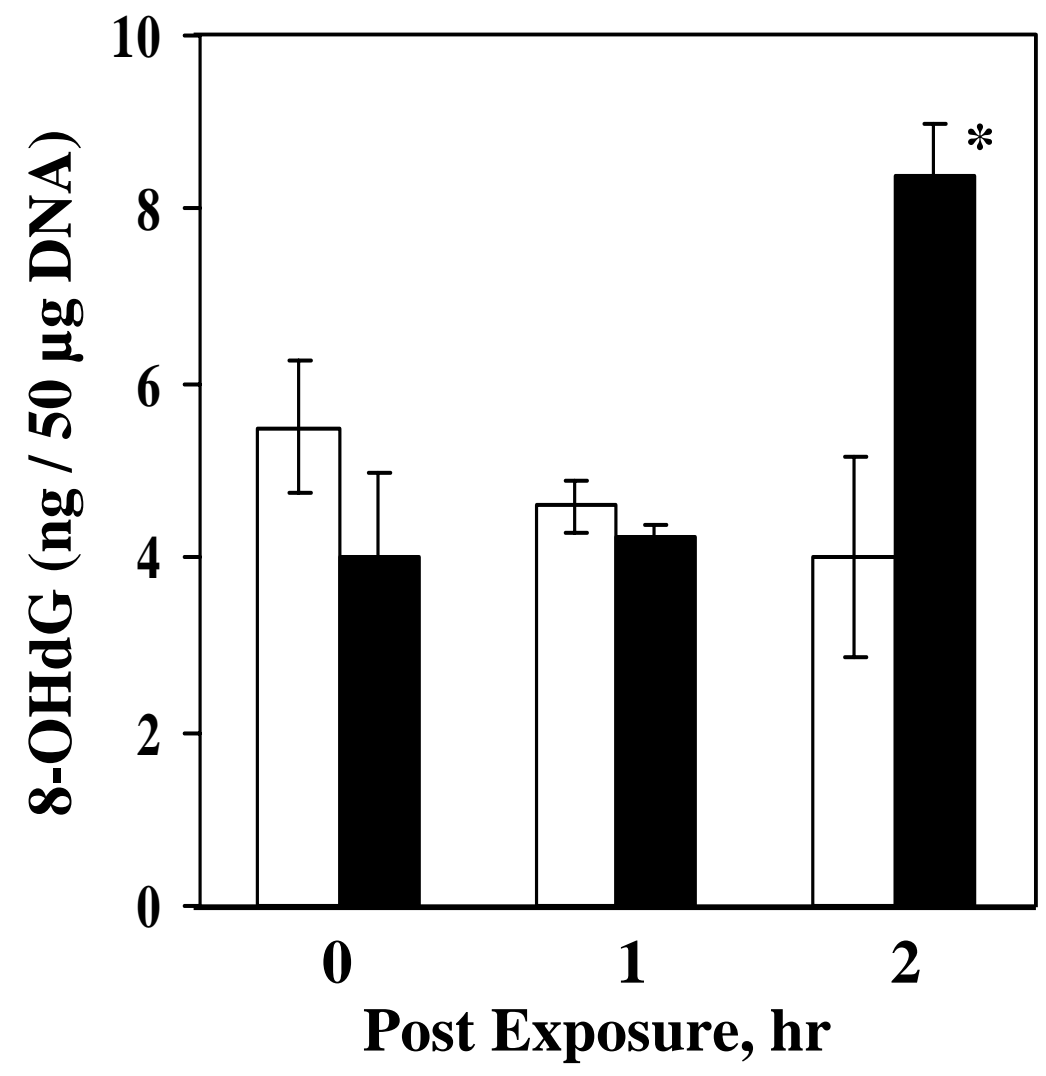

Figure 2.5. Cumene hydroperoxide-induced accumulation of 8-hydroxy-2'deoxyguanosine in the skin of young and old Balb/c mice. White bars - 13 weeks old mice; black bars - 32 weeks old mice. Mice were painted on the dorsal area of the back with $12 \mathrm{mmol} / \mathrm{kg}$ cumene hydroperoxide and sacrificed 1 or 2 hours post-exposure. Values are means $\pm \mathrm{SEM}$ of 3 experiments. ${ }^{*} \mathrm{p}<0.05$ versus 32 week control mice. 


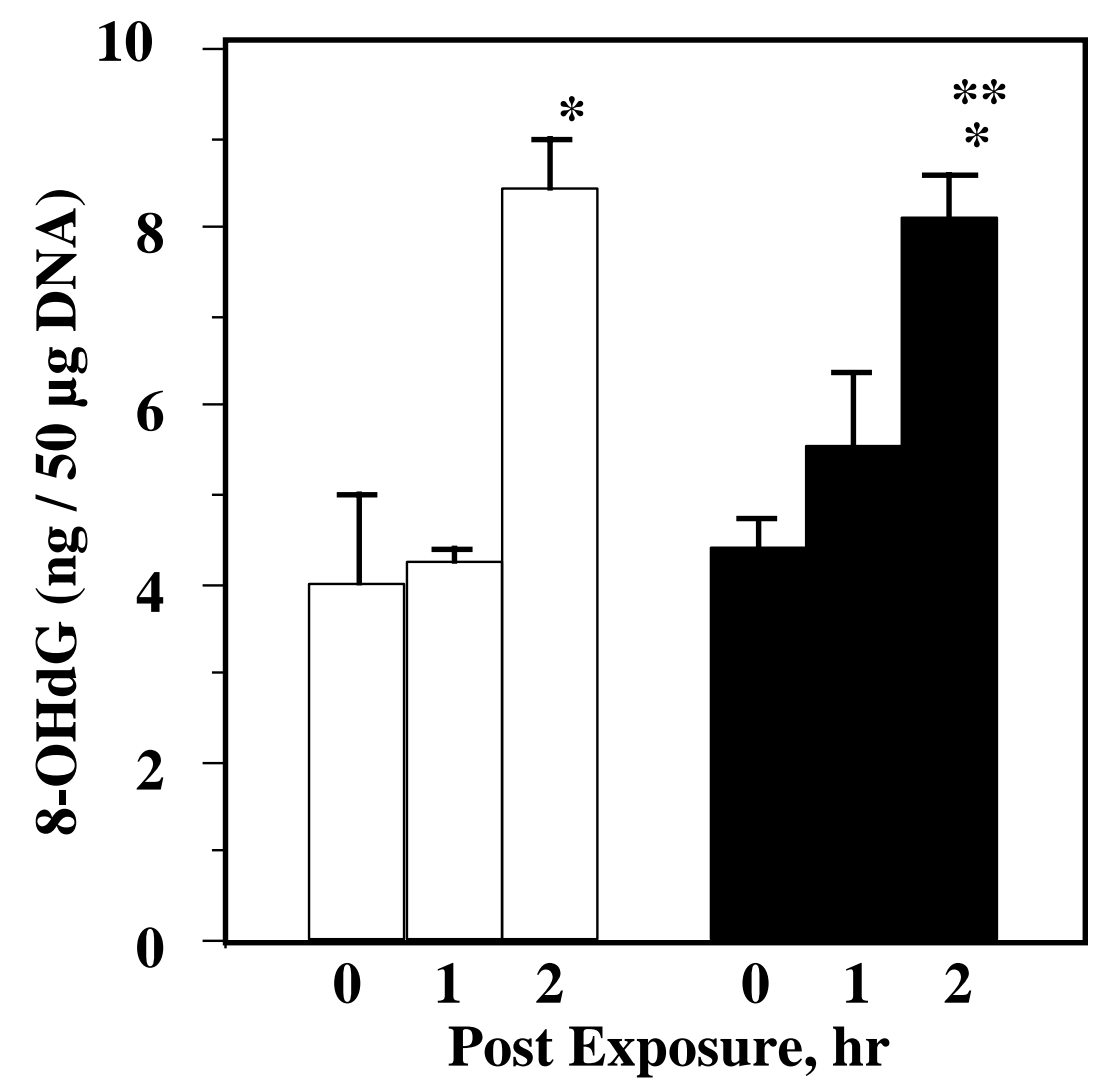

Figure 2.6. Cumene hydroperoxide-induced accumulation of 8-hydroxy-2'deoxyguanosine in skin of Balb/c mice (32 weeks old) given basal or vitamin $\mathrm{E}$ deficient diets. White bars - basal diet; black bars - vitamin E deficient diet. Mice were painted on the dorsal area of the back with $12 \mathrm{mmol} / \mathrm{kg}$ cumene hydroperoxide and sacrificed 1 or 2 hours post-exposure. Values are means \pm SEM of 3 experiments. ${ }^{*} p<0.05$ versus basal fed control mice; $* * \mathrm{p}<0.05$ versus vitamin $\mathrm{E}$ deficient fed control. 

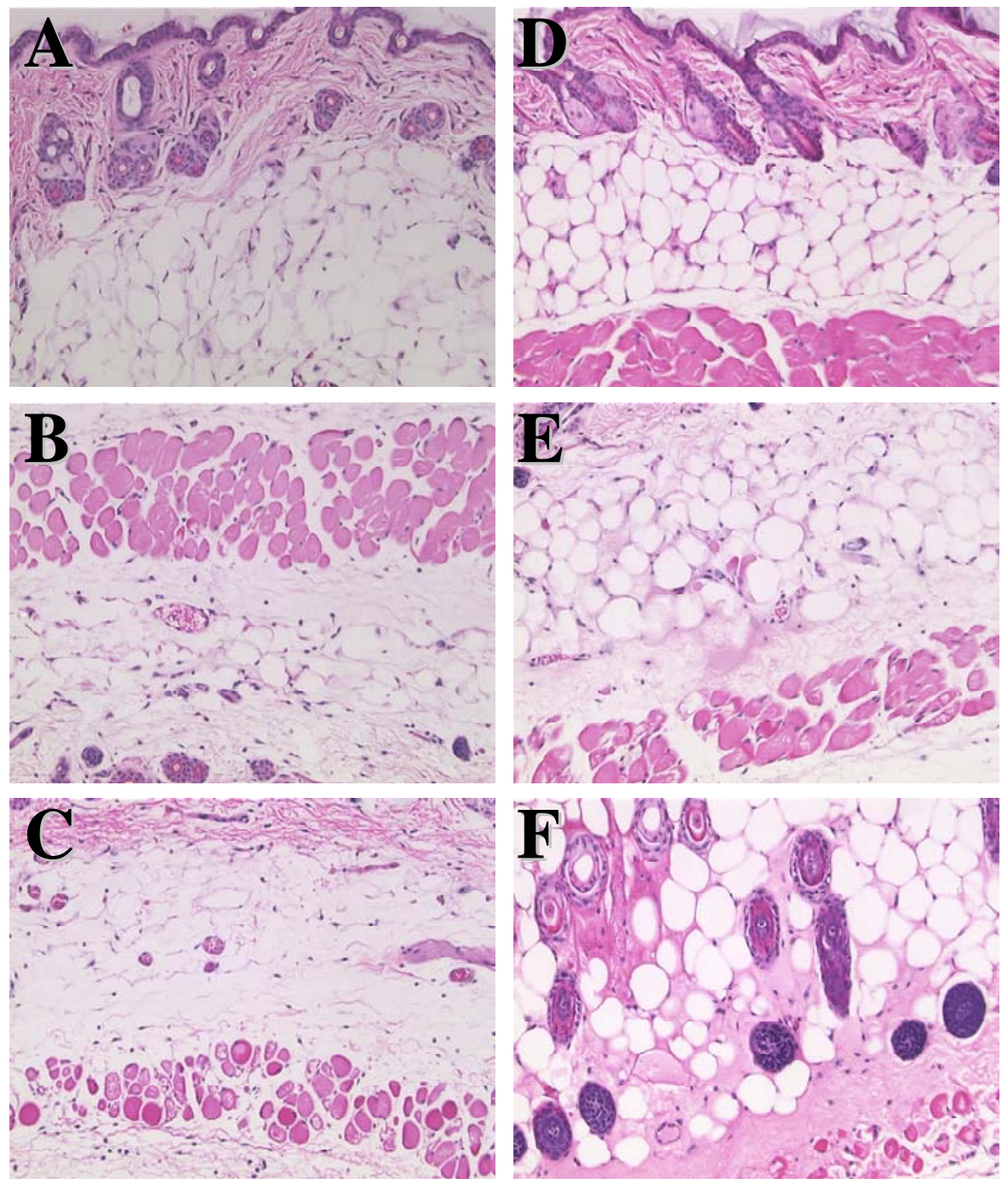

Figure 2.7. Skin photomicrographs of young (13 weeks old) and old ( 32 weeks old) Balb/c mice given basal diet and topically treated with cumene hydroperoxide. A. 13 week old control; B. 13 weeks old exposed to cumene hydroperoxide for 1 hour; C. 13 weeks old exposed to cumene hydroperoxide for 2 hours; D. 32 weeks old control; E. 32 weeks old exposed to cumene hydroperoxide for 1 hour; F. 30 weeks old exposed to cumene hydroperoxide for 2 hour. Mice were painted on the dorsal area of the back with $12 \mathrm{mmol} / \mathrm{kg}$ cumene hydroperoxide and sacrificed 1 or 2 hours post-exposure. Magnification 20X. 


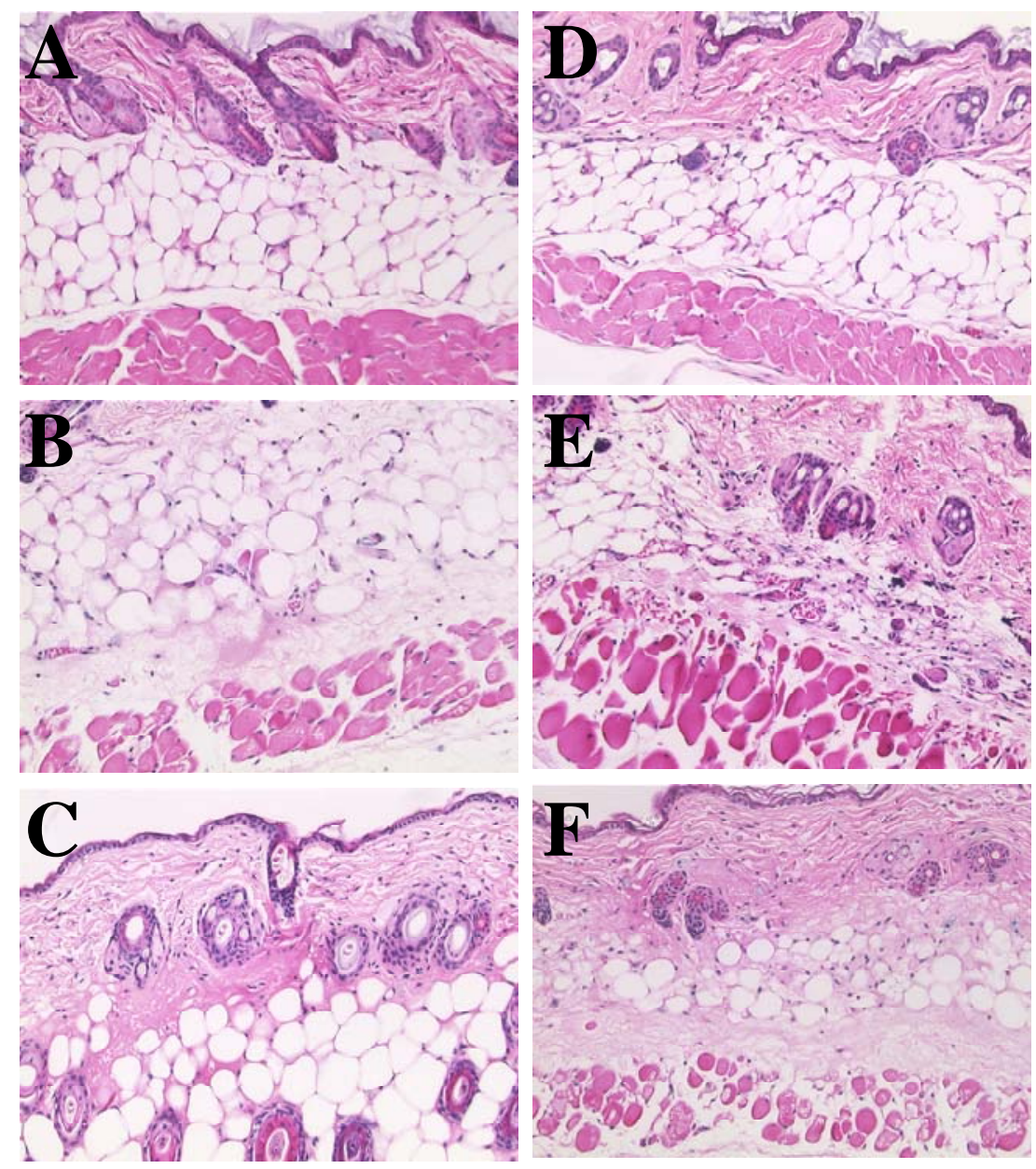

Figure 2.8. Skin photomicrographs of old ( 32 weeks old) Balb/c mice given basal or vitamin $\mathrm{E}$ diet and topically treated with cumene hydroperoxide. A. Basal diet control; B. Basal diet exposed to cumene hydroperoxide for 1 hour; C. Basal diet exposed to cumene hydroperoxide for 2 hours; D. Vitamin E deficient diet control; E. Vitamin E deficient diet exposed to cumene hydroperoxide for 1 hour; F. Vitamin E deficient diet exposed to cumene hydroperoxide for 2 hours. Mice were fed a basal diet for 10 (young mice) or 29 (old mice) weeks. Mice were painted on the dorsal area of the back with 12 $\mathrm{mmol} / \mathrm{kg}$ cumene hydroperoxide and sacrificed 1 or 2 hours post-exposure. Magnification $20 \mathrm{X}$. 


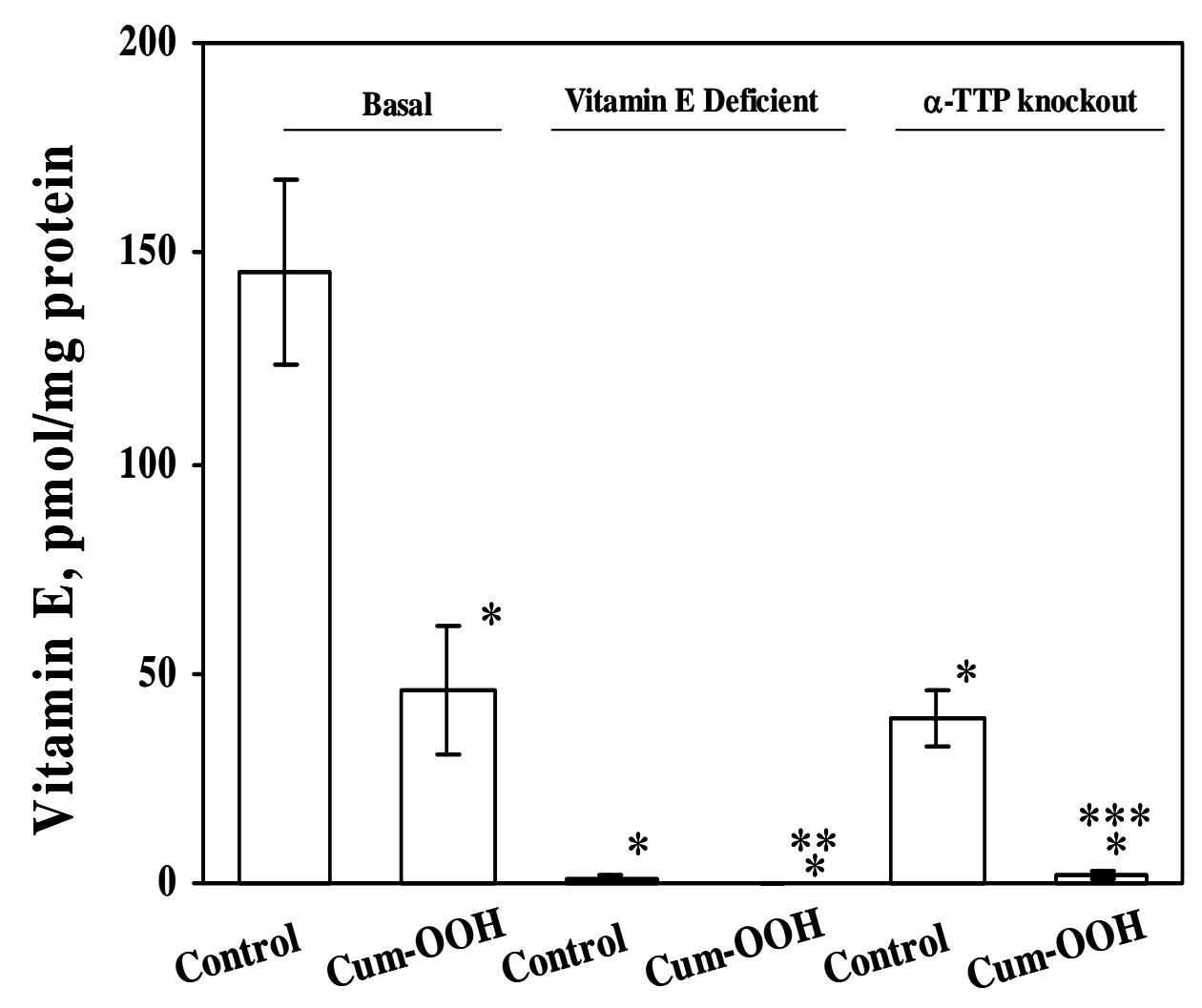

Figure 2.9. Vitamin $\mathrm{E}$ in the skin of $\mathrm{C} 57 \mathrm{BL} / 6$ mice given a diet deficient in vitamin $\mathrm{E}$ (29 weeks) or mice with a genetic deletion of the $\alpha$-tocopherol transporter protein $(\alpha-$ TTP) following cumene hydroperoxide exposure. Mice were fed a basal or vitamin E deficient diet for 29 weeks, and $\alpha$-tocopherol transport protein knockout mice were fed a basal diet for 29 weeks. Mice were then painted on the dorsal area of the back with 12 $\mathrm{mmol} / \mathrm{kg}$ cumene hydroperoxide and sacrificed 2 hours following exposure. Values are means \pm SEM. ${ }^{*} \mathrm{p}<0.05$ versus basal fed control mice; ${ }^{*} \mathrm{p}<0.05$ versus vitamin $\mathrm{E}$ deficient fed control mice, ${ }^{* * *}<<0.05$ versus $\alpha$-TTP knockout control mice. 


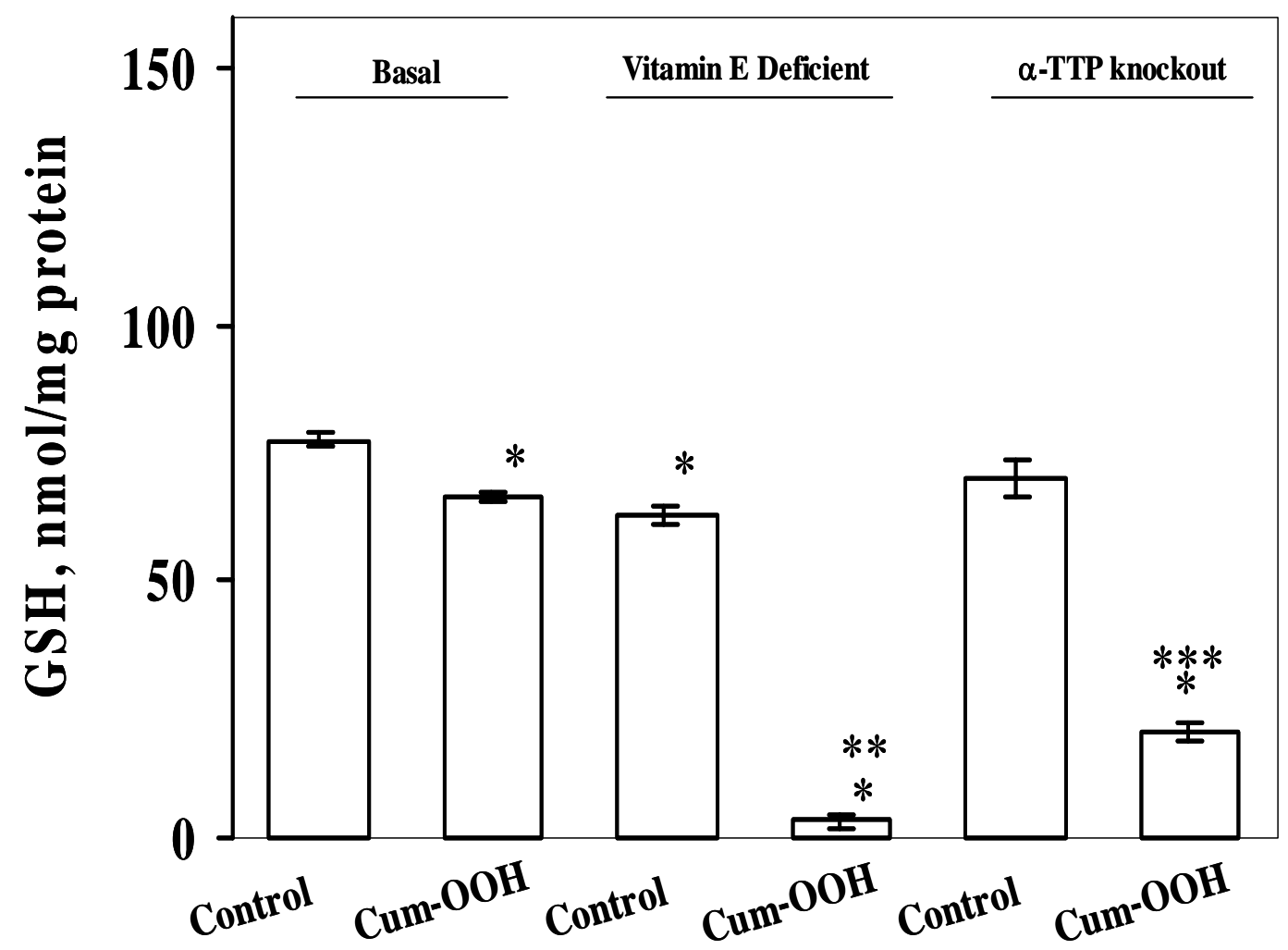

Figure 2.10. Cumene hydroperoxide reduced the level of GSH in the skin of C57BL/6 Mice given a diet deficient in vitamin $\mathrm{E}$ or mice with a genetic deletion of the $\alpha$ tocopherol transporter protein ( $\alpha$-TTP). Mice were fed a basal or vitamin E deficient diet for 29 weeks, and $\alpha$-tocopherol transport protein knockout mice were fed a basal diet for 29 weeks. Mice were then painted on the dorsal area of the back with $12 \mathrm{mmol} / \mathrm{kg}$ cumene hydroperoxide and sacrificed 2 hours following exposure. Values are means \pm SEM. ${ }^{*} p<0.05$ versus basal fed control mice; ${ }^{* *} p<0.05$ versus vitamin E deficient fed control mice, ${ }^{* * *} \mathrm{p}<0.05$ versus $\alpha$-TTP knockout control mice. 


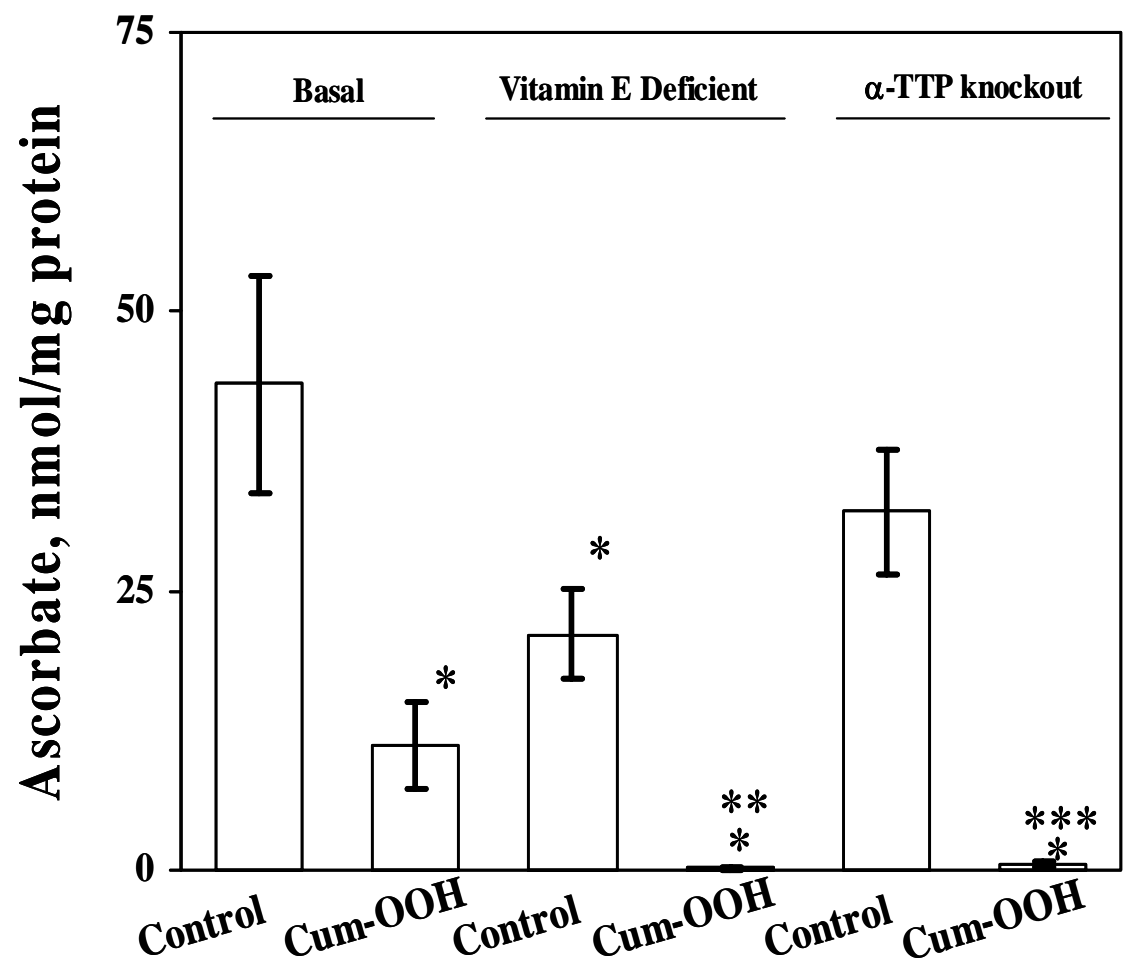

Figure 2.11. Ascorbate in the skin of C57BL/6 mice given a diet deficient in vitamin $\mathrm{E}$ or mice with a genetic deletion of the $\alpha$-tocopherol transporter protein ( $\alpha$-TTP) following exposure to cumene hydroperoxide. Mice were fed a basal or vitamin E deficient diet for 29 weeks, and $\alpha$-tocopherol transport protein knockout mice were fed a basal diet for 29 weeks. Mice were then painted on the dorsal area of the back with $12 \mathrm{mmol} / \mathrm{kg}$ cumene hydroperoxide and sacrificed 2 hours following exposure. Values are means \pm SEM. ${ }^{*} \mathrm{p}<0.05$ versus basal fed control mice; ${ }^{* *} \mathrm{p}<0.05$ versus vitamin $\mathrm{E}$ deficient fed control mice, ${ }^{* * *} \mathrm{p}<0.05$ versus $\alpha$-TTP knockout control mice. 


\section{References}

Arita, M., Sato, Y., Miyata, A., Tanabe, T., and Takahashi E. 1995. Human alphatocopherol transfer protein: cDNA cloning, expression and chromosomal localization. Biochem J. 306: 437-43.

Beckman, K. B., and Ames, B. N. 1998. The free radical theory of aging matures. Physiol Rev. 78: 547-581.

Babich, H., Zuckerbraun, H. L., Wurzburger, B. J., Rubin, Y. L., Borenfreund, E., and Blau, L. 1996. Benzoyl peroxide cytotoxicity evaluated in vitro with the human keratinocyte cell line, RHEK-1. Toxicology. 106: 187-196.

Comba, G. F., Noguchi, T., and Scott, M. L. 1975. Mechanisms of action of selenium and vitamin $\mathrm{E}$ in protection of biological membranes. Fed Proc. 84: 2090-2095.

Floyd, E. P., and Stokinger, H. E. 1958. Toxicity studies of certain organic peroxides and hydroperoxides. Ind Hyg J. 6: 205-212.

Gohil, K., Schock, B. C., Chakraborty, A. A., Tersawa, Y., Raber, J., Farese Jr., R. V., Packer, L., Cross, C. E., and Traber, M. G. 2003. Gene expression profile of oxidant stress and neurodegeneration in transgenic mice deficient in $\alpha$-tocopherol transfer protein. Free Rad Biol Med. 35: 1343-1354.

Guo, Q., and Packer, L. 2000. Ascorbate-dependent recycling of the vitamin E homologue Trolox by dihyrolipoate and glutathione in murine skin homogenates. Free Radical Biol Med. 29: 368-374.

Haddad, J. J., Safieh-Garabedian, B., Saade, N. E., and Land, S. C. 2001. Thiol regulation of pro-inflammatory cytokines reveals a novel immunopharmacological potential of glutathione in the alveolar epithelium. J Pharmacol Exp Ther. 296: 9961005.

Harman, D. 1981. The aging process. Proc Natl Acad Sci USA. 78: 7124-7128.

Harman, D. 1993. Free radical involvement in aging: pathophysiology and the therapeutic implications. Drugs Aging. 3: 60-80.

Harman, D. 1994. Aging: prospects for further increases in the functional life span. Age. 17: 119-146.

Harman, D. 1996. Aging and disease: extending the functional life span. Ann NY Acad Sci. 786: 321-336.

Harman, D. 2003. The free radical theory on aging. Antio Redox Signaling. 5: 557-561. 
Hagan, T. M. 2003. Oxidative stress, redox imbalance, and the aging process. Antioxidant Redox Signaling. 5: 503-506.

Hosomi, A., Goto, K., Kondo, H., Iwatsubo, T, and Yokota, T. 1998. Localization of alpha-tocopherol transfer protein in rat brain. Neurosci Lett. 256: 159-62.

Hudson, V. M. 2001. Rethinking cystic fibrosis pathology: the critical role of abnormal reduced glutathione (GSH) transport caused by CFTR mutation. Free Radic Biol Med. 30:1440-61.

Igarashi, A., Uzuka, M., and Nakajima, K. 1989. The effects of vitamin E deficiency on rat skin. Br J Dermatol. 12: 43-49.

Kadiiska, M. B., Hanna, P. M., Jordan, S. J., and Mason, R. P. 1993. Electron spin resonance for free radical generation in copper-treated vitamin E- and selenium-deficient rats: in vivo spin-trapping investigation. Mol Pharmacol. 44: 222-227.

Kagan, V. E., Shvedova, A., Serbinova, E., Khan, S., Swanson, C., Powell, R., and Packer, L. 1992. Dihydrolipoic acid-a universal antioxidant both in the membrane and in the aqueous phase, reduction of of peroxyl, ascorbyl, and and chromanoxyl radicals. Biochem Pharmacol. 44: 1637-1649.

Kagan, V. E., and Packer, L. 1994. Light-induced generation of vitamin E radicals: assessing vitamin E regeneration. Methods Enzymol. 234: 316-320.

Kohen, R., and Nyska, A. 2003. Oxidation of biological systems: oxidative stress phenomena, antioxidants, redox reactions, and methods for their quantification. Toxicol Pathol. 30(6): 620-50.

Lang, J. K., Gohil, K., and Packer, L. 1986. Simultaneous determination of tocopherols, ubiquinols, and ubiquinones in blood, plasma, tissue homogenates, and subcellular fractions. Anal Biochem. 157:106-16.

Lewis, R. J. 1993. Hawley's Condensed Chemical Dictionary, $12^{\text {th }}$ ed., p. 133, Van Nostrand Reinhold, New York.

Machlin, L. J., Filipski, R., Nelson, J., Horn, L. R., and Brin, M. 1977. Effects of a prolonged vitamin E deficiency in the rat. J Nutr. 107: 1200-1208.

Manly, T. D. 1956. Organic peroxy-compounds in industry. Ind Chem. 8: 319-322.

Martensson, J., Meister, A., and Martensson, J. 1991. Glutathione deficiency decreases tissue ascorbate levels in newborn rats: ascorbate spares glutathione and protects. ProC Natl Acad Sci USA. 88: 4656-4660.

Medical Economics Co. 1997. US FDA. 
Nachbar, F., and Korting, H. C. 1995. The role of vitamin E in normal and damaged skin. J Mol Med. 73(1): 7-17.

Niki, E. 1990. Free radical initiators as a source of water- or lipid-soluble peroxyl radicals. Methods Enzymol. 186: 100-108.

Packer, L., Maguire, J. J., Mehlhorn, R. J., Serbinova, E., and Kagan, V. E. 1989. Mitochondria and microsomal membranes have a free radicals reductase activity that prevents chromanoxyl radical accumulation. Biochem Biophys Res Commun. 159: 229235 .

Packer, L. 1991. Protective role of vitamin E in biological systems. Am J Clin Nutr. 53: 1050S-1055S.

Petroff, M. G., Petroff, B. K., and Pate, J. L. 2001. Mechanisms of cytokine-induced death of cultured bovine luteal cells. Reproduction. 121:753-60.

Sato, Y., Arai, H., Miyata, A., Tokita, S., and Yamamoto, K. 1993. Primary structure of alpha-tocopherol transfer protein from rat liver. Homology with cellular retinaldehydebinding protein. J Biol Chem. 268: 17705-10.

Shvedova, A. A., Kommineni, C., Jefferies, B. A., Castranova, V., Tyurina, Y. Y., Tyurin, V. A., Serbinova, E. A., Fabisiak, J. P., and Kagan, V. E. 2000. Redox cycling of phenol induces oxidative stress in human epidermal keratinocytes. J Invest Dermatol. 114: $354-364$.

Shvedova, A. A., Tyurina, Y. Y., Tyurin, V. A., Kikuchi, Y., Kagan, V. E., and Quinn, P. J. 2001. Quantitative analysis of phospholipid peroxidation and antioxidant protection in live human epidermal keratinocytes. Biosci Rep. 21: 33-43.

Shvedova, A. A., Kisin, E. R., Murray, A. R., Kommineni, C., Castranova, V., Mason, R. P., Kadiiska, M. B., and Gunther, M. R. 2002. Antioxidant balance and free radical generation in Vitamin E-deficient mice after dermal exposure to cumene hydroperoxide. Chem Res Toxicol. 15: 1452-1459.

Stoyanovsky, D. A., Osipov, A. N., Quinn, P. J., and Kagan, V. E. 1995. Ubiquinonedependent recycling of vitamin E radicals by superoxide. Arch Biochem Biophys. 323: 343-351.

Tappel, A. L. 1980. Vitamin E and selenium protection from in vivo lipid peroxidation. Ann NY Acad Sci. 355: 18-31.

Traber, M. G., and Arai, H. 1999. Molecular mechanisms of vitamin E transport. Ann Rev Nutr. 19: 343-55. 
Vessey, D. A., Lee, K. H., and Blacker, K. L. 1992. Characterization of the oxidative stress initiated in cultured human keratinocytes by treatment with peroxides. $J$ Invest Dermatol. 99: 859-863.

Vessey, D. A., Lee, K. H., and Blacker, K. L. 1995. Differentiation-induced enhancement of the ability of cultured human keratinocytes to suppress oxidative stress. J Invest Dermatol. 104: 355-358.

Yoshida, H., Yusin, M., Ren, I., Kuhlenkamp, J., and Hirano, T. 1992. Identification, purification, and immunochemical characterization of a tocopherol-binding protein in rat liver cytosol. J Lipid Res. 33: 343-50. 
STUDY 3: INTERPLAY BETWEEN PRO/ANTIOXIDANT STATUS AND AP-1 TRANSCRIPTION FACTOR IN MURINE SKIN FOLLOWING TOPICAL EXPOSURE TO CUMENE HYDROPEROXIDE 


\section{$\underline{\text { Abstract }}$}

Organic peroxides, widely used in the chemical and pharmaceutical industries, can act as skin tumor promoters and cause epidermal hyperplasia. They are also known to trigger free radical generation. The present study evaluated the effect of cumene hydroperoxide $(\mathrm{Cum}-\mathrm{OOH})$ on the induction of activator protein-1 (AP-1), which is linked to the expression of genes regulating cell proliferation, growth, and transformation. Previously, we reported that topical exposure to $\mathrm{Cum-OOH}$ caused formation of free radicals and oxidative stress in the skin of vitamin E deficient mice. The present study used JB6 P+ mouse epidermal cells and AP-1 luciferase reporter transgenic mice to identify whether exposure to $\mathrm{Cum}-\mathrm{OOH}$ in vivo cause activation of AP-1, oxidative stress, depletion of antioxidants, and tumor formation during two-stage carcinogenesis. In vitro studies found that exposure to $\mathrm{Cum}-\mathrm{OOH}$ reduced the level of glutathione (GSH) in mouse epidermal cells (JB6 P+) and caused the induction of AP-1. Mice primed with dimethylbenz[a]anthracene (DMBA) were topically exposed to Cum-OOH $(82.6 \mu \mathrm{mol})$ or $12-\mathrm{O}-$ tetradecanoylphorbol-13-acetate (TPA, 17 nmol) twice weekly for 29 weeks. Activation of AP-1 in skin was detected as early as 2 weeks following $\mathrm{Cum-OOH}$ and TPA exposures. No AP-1 expression was found 19 weeks post-initiation. Papilloma formation was observed in both the DMBA/TPA and DMBA/Cum-OOH-exposed animals while skin carcinomas were found only in the DMBA/Cum-OOH-treated mice. A greater accumulation of peroxidative products (TBARS), inflammation, and decreased levels of GSH, vitamin E and total antioxidant reserves were also observed in the skin of DMBA/Cum-OOH exposed mice. There results suggest that Cum-OOH-induced 
carcinogenesis is accompanied by increased AP-1 activation and changes in antioxidant status. 


\section{Introduction}

Peroxide compounds yield free radicals and are widely used in industry as initiators for polymerization. Organic peroxides (OP) have become the subject of occupational safety research interest due to possible genotoxic and carcinogenic risks in the work place. Cumene hydroperoxide (Cum-OOH) is bulk material for production of acetone and phenol. Cum-OOH is also used as a catalyst for rapid polymerization and production of styrene and acrylic monomers, curing agents for unsaturated polyester resins, and intermediate for cross-linking agents (Lewis, 1993). Humans are exposed to Cum-OOH during manufacturing as well as in polluted urban air resulting from the photochemical reaction of nitrogen oxide with unsaturated hydrocarbons and peroxides present in the exhaust fumes of gasoline, diesel and aviation fuels. Dermal exposure to $\mathrm{Cum}-\mathrm{OOH}$ causes a number of toxic outcomes in skin e.g. allergic and irritant dermatitis, rash, defattening of dermis and hair loss, burns, and epidermal hyperplasia (Adams, 1999). Free radical production is considered the key factor contributing to skin tumor promotion by OP.

Alteration of Ras proteins and/or elevated levels of their expression have drastic consequences for growth control and cause the development of tumors in humans (Barbasid, 1987). Recently, the role of the transcription factor activator protein 1 (AP-1) has been highlighted as a mediator of growth factors, oncogenes and the tumor promoter, TPA. AP-1 converts extracellular signals into changes in the expression of specific target genes that harbor AP-1 binding sites in their promoter/enhancer regions. AP-1 consists of a family Jun/Fos dimers including different Jun/Fos proteins (Angel et al., 1987; Angel 
and Karin, 1991; Hirai et al., 1989). AP-1 and its regulated gene expression is involved in the pre-neoplastic to neoplastic progression in different cellular models (Domann et al., 1994; Dong et al., 1995; Huang et al., 1996; Jochum et al., 2001).

Reactive oxygen species (ROS) are able to regulate AP-1 binding to the DNA. The application of tumor promoters to skin causes a significant reduction in antioxidant defense (Perchellet et al., 1987; Kisella et al., 1983; Solanki and Slaga, 1981; Amstad et al., 1997; Isbir et al., 2000). In the present study, we attempt to evaluate whether topical exposure to Cum-OOH caused tumor promotion, induction of oxidative stress and activation of AP-1 protein in mouse skin. JB6 $\mathrm{P}+$ mouse epidermal cells and AP-1 luciferase reporter transgenic mice were used to observe whether exposure to $\mathrm{Cum}-\mathrm{OOH}$ caused activation of AP-1, oxidative stress, depletion of antioxidants and skin tumor formation during two-stage carcinogenesis. Using a mouse epidermal cell line (JB6 P+) transfected with an AP-1 -luciferase reporter, we tested whether exposure to Cum-OOH reduced the level of GSH and caused the induction of AP-1. These results suggest that Cum-OOH induced carcinogenesis is accompanied by the induction of oxidative stress, increased AP-1 activation and reduced antioxidant defense in mouse skin.

\section{Materials and Methods}

\section{Chemicals}

Fatty acid-free human serum albumin (hSA), luminol, sodium dodecyl sulfate (SDS), cumene hydroperoxide (Cum-OOH), 12-o-tetradecanoylphorbol-13-acetate (TPA), 7,12dimethylbenz $[\alpha]$ anthracene (DMBA), acetone, guaiacol, cetylmethylammonium bromide, 3-amino-1,2,4-triazole (3-AT), 2-thiobarbituric acid, and glutathione were obtained from 
Sigma Chemical Co (St. Louis, MO). Fetal bovine serum (FBS) and L-glutamine were purchased from Life Technologies, Inc. (Rockville, MD). Eagle's minimum essential medium (MEM) was obtained from Bio Whittaker (Walkersville, MD). Luciferase assay kit was purchased from Promega (Madison, WI). ThioGlo-1TM was obtained from Covalent Inc. (Wobum, MA). 2,2'-azobis(2-aminodinopropane)-dihydrochloride (AAPH) was purchased from Wako Chemicals USA, Inc. (Richmond, VA).

\section{Cell Culture}

The JB6 family of mouse epidermal clonal genetic variants $\left(\mathrm{P}^{+} / \mathrm{P}^{-}\right)$provides a suitable model for studying critical gene regulation events that occur during carcinogenesis. The JB6 $\mathrm{P}^{+}$mouse epidermal cell line is transfected with the AP-1-luciferase reporter plasmids (JB6/AP). JB6/AP cells were cultured in Eagle's MEM containing 5\% fetal bovine serum and $2 \mathrm{mM} \mathrm{L-glutamine}$. The cells were grown at $37^{\circ} \mathrm{C}$ in a $5 \% \mathrm{CO}_{2}$ atmosphere.

\section{Animals}

AP-1 transgenic mice were used to study tumor promotion by Cum-OOH. AP-1luciferase reporter transgenic mice were originally established by Rincon and Flavell (1994). A C57BL/6 male mouse carrying the 2x TPA response element-luciferase transgene was crossed with a DBA2 female (Huang et al., 1997). The offspring were screened for the presence of luciferase activity. Each mouse was housed in an individual ventilated cage under controlled environmental conditions in an AAALAC accredited facility. The animals were weighed biweekly and the food consumption was recorded monthly. 


\section{Assay of AP-1 Activity in vitro}

The JB6/AP cells were placed in 96-well plates in 200. $\mu$ l per well of Eagle's MEM supplemented with $5 \%$ fetal bovine serum and $2 \mathrm{mM} \mathrm{L-glutamine.} \mathrm{Plates} \mathrm{were} \mathrm{incubated}$ at $37^{\circ} \mathrm{C}$ humidified atmosphere of $5 \% \mathrm{CO}_{2}$. Twelve hours later, cells were cultured in Eagle's MEM supplemented with $0.5 \%$ fetal bovine serum and $2 \mathrm{mM} \mathrm{L-glutamine} \mathrm{for} 24$ hours to minimize basal AP-1 activity, and then exposed to Cum-OOH or TPA in the same medium to monitor the effects on AP-1 induction. The cells were extracted with $200 \mu \mathrm{l}$ of $1 \mathrm{x}$ lysis buffer provided in luciferase assay kit by the manufacture, and the luciferase activity was measured using luminometer (Monolight 2010, Analytical Luminescence Laboratory,San Diego,CA). The results are expressed as relative AP-1 activity compared to respective controls.

\section{Tumor promotion experiment}

Eight-week-old AP-1 luciferase reporter-bearing female mice were randomly divided into six groups consisting of 8 mice in each group. The dorsal skin in the inter-scapular area was shaved with a surgical clipper 2 days before initiation, and animals showing no hair re-growth were used in the experiment. DMBA (51.2 $\mu \mathrm{g}$ dissolved in $100 \mu \mathrm{l}$ of acetone for each mouse) was used as a tumor initiator and applied to skins of mice in groups 4, 5, and 6 (Table 1). In groups 1, 2, and 3, $100 \mu \mathrm{l}$ of acetone was applied to mouse skins. Fourteen days following initiation, the mice were promoted twice a week with $17 \mathrm{nmol}$ TPA (groups 2 and 5) or $82.6 \mu \mathrm{mol} \mathrm{Cum-OOH} \mathrm{(group} 3$ and 6) dissolved in $100 \mu \mathrm{l}$ of acetone for the next 29 weeks. Negative control mice were treated with acetone alone (groups 1 and 4). The body weight of each animal and papillomas/carcinomas appearing on the shaved area of the skin were recorded at weekly intervals. Papillomas and 
carcinomas were distinguished by differences in physical size and characteristics. A certified pathologist confirmed the presence of papillomas and carcinomas at the completion of the experiment. Tumor promoting activity was evaluated by both the ratio of tumor-bearing mice and the number of tumors, $>1 \mathrm{~mm}$ in diameter, per mouse. Animals were sacrificed by inhalation of an excess of carbon dioxide after the termination of the treatments. Skin flaps from the inter-scapular area of the back of mice $\left(1.5 \times 2.0 \mathrm{~cm}^{2}\right)$ were excised and samples were taken for histopathology and biochemical analyses. Skin for biochemical studies was immediately frozen at $-80^{\circ} \mathrm{C}$ until homogenized.

\section{Assay of AP-1 Activity in vivo}

AP-1-luciferase activity was measured in dorsal skin punch biopsy samples obtained by punch biopsy (1.5 mm, Acuderm, Ft. Lauderdale, Fl). Lysis buffer (Promega, $100 \mu 1)$ was added to each skin biopsy and the tissues were lyzed overnight at $4^{\circ} \mathrm{C}$. The luciferase activity of the tissue supernatant obtained after lysis was measured with a luminometer (Monolight 2010, Analytical Luminescence Laboratory, San Diego, CA). AP-1 activity was expressed relative to the level of luciferase activity versus control groups. Samples for AP-1 activity assay were collected every 4 weeks.

\section{Skin Histopathology and Examination}

The skin was processed after fixation in $10 \%$ neutral buffered formalin, following the standard operating procedures of our laboratory. Hematoxylin and eosin stained histology slides were prepared for light microscopic examination. Photomicrographs were prepared using an Olympus 300 double-headed microscope (Tokyo, Japan). 


\section{Homogenate Preparation}

The skin was excised promptly after the mice were sacrificed, and samples for biochemical analysis were immediately frozen at $-80^{\circ} \mathrm{C}$ until processed. The skin homogenates were prepared from frozen tissues with ice-cold phosphate-buffered saline (PBS, pH 7.4) using a tissue tearer (model 985-370, Biospec Products, Inc., Racine, WI). Homogenates were stored at $-80^{\circ} \mathrm{C}$ until further processed.

\section{Inflammatory Biomarkers Determination}

The modifying effect on inflammation induced by $\mathrm{Cum-OOH}$ or TPA topical application was determined by two biomarkers, edema formation and myeloperoxidase (MPO) activity. To assess the extent of Cum-OOH or TPA induced edema in mice skin $24 \mathrm{~h}$ after last treatment, a dial caliper (The Dyer Company, Lancaster, PA) was used to measure the skin bi-fold thickness at 3 random locations per mouse. Edema formation was expressed as net increase in skin bi-fold thickness between experimental and control (acetone/acetone) groups. For the MPO activity determination, a spectrophotometric assay (Shimadzu UV 160U spectrometer, Kyoto, Japan) was used in which guaiacol oxidation was monitored by changes of absorbance at $470 \mathrm{~nm} .\left(\varepsilon=26.6 \mathrm{mM}^{-1} \mathrm{~cm}^{-1}\right)$ (Nonaka T. et al, 1992). Skin homogenates were mixed with PBS (100 mM, pH 7.4) containing cetylmethylammonium bromide $(0.02 \%)$, guaiacol $(13 \mathrm{mM})$, and 3-AT $(3.75$ $\mathrm{mM})$. The reaction was started by the addition of $\mathrm{H}_{2} \mathrm{O}_{2}(0.6 \mathrm{mM})$. Activity of MPO was calculated and expressed in nmoles of tetraguaiacol per minute per mg of protein.

\section{Determination of Peroxidative Products (TBARs)}

Peroxidative products were determined using the procedure described by Buege and Aust (1978). The formation of thiobarbituric acid-reactive substances (TBARS) was measured 
in skin homogenates. Tissue homogenates $(0.5 \mathrm{mg}$ of protein) were mixed with $1 \mathrm{ml}$ $0.67 \%$ thiobarbituric acid and $30 \%$ trichloracetic acid $(1: 1)$. The samples were heated for $20 \mathrm{~min}$ at $100^{\circ} \mathrm{C}$ and centrifuged for $15 \mathrm{~min}$ at $5,000 \mathrm{x}$ g. The absorbency of the supernatant was determined at $535 \mathrm{~nm}$ using a UV $160 \mathrm{U}$ Shimadzu spectrophotometer (Kyoto, Japan). A molar extinction coefficient of $\varepsilon=1.56 \times 10^{5} \mathrm{M}^{-1} \mathrm{~cm}^{-1}$ was used for calculations.

\section{Chemiluminescence Measurements of Total Antioxidant Reserve}

A water-soluble azo-initiator, 2,2' azobis(2-aminodinopropane)-dihydrochloride (AAPH), was used to produce peroxyl radicals (Niki, 1990). Oxidation of luminol by AAPH-derived peroxyl radicals was assayed by the chemiluminescence response. A delay in the chemiluminescence response caused by interaction of endogenous antioxidants with AAPHderived peroxyl radicals was observed upon addition of homogenates. Based on the known rate of peroxyl radical generation by AAPH, the amount of peroxyl radicals scavenged by endogenous antioxidants was evaluated. The incubation medium contained $0.1 \mathrm{M}$ phosphate buffer ( $\mathrm{pH} 7.4)$ at $37^{\circ} \mathrm{C}$, AAPH $(50 \mathrm{mM})$, and luminol $(0.4 \mathrm{mM})$. The reaction was started by the addition of AAPH. A luminescent analyzer 633 (Coral Biomedical, Inc., San Diego, CA) was employed for determination.

\section{Glutathione (GSH) and protein thiols assay in cells and tissue}

Total protein sulfhydryl concentration in homogenates of skin or cells was determined

using ThioGlo $\mathrm{TM}_{-}$, a maleimide reagent which produces a highly fluorescent product upon reaction with sulfhydryl groups (Shvedova et al., 2000). A standard curve was established by addition of GSH $(0.02-1.0 \mu \mathrm{M})$ to $0.1 \mathrm{M}$ phosphate buffer $(\mathrm{pH} 7.4)$ 
containing $10 \mu \mathrm{M}$ ThioGloTM-1. GSH content was estimated from the immediate fluorescence response registered upon addition of ThioGlo $\mathrm{TM}_{-1}$ to a tissue or cells homogenate. Total protein sulfhydryls were determined from the augmentation of the fluorescence response after addition of $\operatorname{SDS}(4 \mathrm{mM})$ to the same homogenate. A spectrofluorophotometer (Shimadzu RF-5000 U, Kyoto, Japan) was employed in the assay (excitation $388 \mathrm{~nm}$ and emission $500 \mathrm{~nm}$ ).

\section{Protein Assay}

Measurements of protein in homogenates of tissue and cells were conducted using a BioRad protein assay kit, cat. \# 500-0006 (Richmond, CA).

\section{Statistics}

Data were expressed as the mean with \pm standard error of the mean for each group. Oneway ANOVA with Tukey test was employed to compare the responses between treatments. Statistical significance was set at $\mathrm{p}<0.05$.

\section{$\underline{\text { Results }}$}

\section{AP-1 Activity in vitro after Cum-OOH Exposure}

To determine whether Cum-OOH induced AP-1 activation, we incubated the JB6 cells with Cum-OOH or TPA (positive control). As shown on Fig. 3.1, exposure to JB6 cells to Cum-OOH (24 h) causes a dose-dependent activation of AP-1. JB6 cells incubated with $50 \mu \mathrm{M}, 100 \mu \mathrm{M}$, and $200 \mu \mathrm{M}$ of Cum-OOH for $24 \mathrm{hr}$ produced a significant 0.9-, 1.8-, and 2.2-fold increase of luciferase activity compare to vehicle-treated control cells, respectively $(\mathrm{p}<0.05)$. No further AP-1 activation was observed appears after incubation JB6 cells with Cum-OOH (48 hours; data not shown). 


\section{Levels of GSH and Protein Thiols in vitro after Cum-OOH Exposure}

Levels of GSH and protein thiols were dramatically reduced after incubation of JB6 cells with Cum-OOH for 24 or $48 \mathrm{~h}$ (Figure 3.2). Incubation of JB6 cells with $50 \mu \mathrm{M}, 100 \mu \mathrm{M}$, and $200 \mu \mathrm{M}$ of $\mathrm{Cum}-\mathrm{OOH}$ for $24 \mathrm{hr}$ resulted in a $47 \%, 85 \%$, and $91 \%$ decrease in the level of GSH compared to cells treated with vehicle, respectively. Exposure of JB6 cells to $\mathrm{Cum}-\mathrm{OOH}(50 \mu \mathrm{M}, 100 \mu \mathrm{M}, 200 \mu \mathrm{M})$ for 48 hours resulted in a further reduction $(59 \%, 93 \%$ and $95 \%$, respectively) in GSH (Figure 3.2A) as compared to vehicle-treated controls. As shown on Figure 3.2B, incubation of JB6 cells with $50 \mu \mathrm{M}, 100 \mu \mathrm{M}$, and $200 \mu \mathrm{M}$ of Cum-OOH for $24 \mathrm{hr}$ resulted in a $45 \%, 56 \%$, and $67 \%$ decrease in the level of protein thiols compared to cells treated with vehicle, while exposure to $\mathrm{Cum}-\mathrm{OOH}$ for 48 hours resulted in a $50 \%, 70 \%$ or $73 \%$, respectively, as compared to vehicle-treated cells.

\section{Effects of Cum-OOH or TPA on morphological alterations in the skin of AP-1 - luciferase transgenic mice.}

To determine whether AP-1 activation preceded papilloma formation during two-stage Cum-OOH induced cancer promotion, AP-1- luciferase reporter transgenic mice were used for the study. Initially, we examined the histopathological changes in the skin of AP-1-luciferase reporter transgenic mice $24 \mathrm{~h}$ after the last topical application of Cum$\mathrm{OOH}$ and TPA. We observed epidermal hyperplasia in DMBA/Cum-OOH and DMBA/TPA groups (29 weeks of treatment) but not in control groups given DMBA/acetone (Figure 3.3A and 3.3B) or acetone/acetone (data not shown). In DMBAinitiated mice, topical treatment with $\mathrm{Cum}-\mathrm{OOH}$ resulted in increased epidermal thickness as compared with TPA-treated mice. Histological observation of mouse skin exposed to DMBA/Cum-OOH displayed a marked increase in the amount of melanin, 
moderate increase in the number and size of sebaceous gland epithelial cells, and the hair follicles show an activated epithelium. Both DMBA/Cum-OOH and DMBA/TPA applications resulted in an increase in the number of blood vessels and inflammatory infiltrates as compared to control (DMBA/acetone). However, accumulation of inflammatory cells in the skins of mice given DMBA/Cum-OOH was greater compared to that in the skins of mice treated with DMBA/TPA (Figure 3.3B).

\section{Effect of Cum-OOH or TPA Treatment on Tumor Promotion}

In terms of carcinoma incidence, high tumor promoting activity of Cum- $\mathrm{OOH}$ was observed throughout the experiment (Figure 3.4). Tumors appeared on the skin of AP-1 transgenic mice starting from 7 weeks of treatment. Data analysis at the termination of the experiment (29 weeks) revealed a $75 \%$ incidence of skin carcinomas in AP-1 transgenic mice and $20 \%$ incidence of papilloma formation after treatment with CumOOH following DMBA initiation (Figure 3.4). No carcinomas were observed on the skin of AP-1 transgenic mice treated with TPA following initiation, and about $80 \%$ of mice had papillomas in this group (Figure 3.4). Cum-OOH treatment following initiation with DMBA resulted in $2.5 \pm 0.2($ mean \pm SEM, $n=6)$ carcinomas per mouse and $2.0 \pm 0.2$ papillomas per mouse (Figure 3.5). After TPA treatment following DMBA initiation, we observed 7.0+1.5 (mean \pm SEM, $\mathrm{n}=6$ mice) papillomas per mouse (Figure 3.5, Inset).

\section{Effect of Cum-OOH or TPA on AP-1 Activation in the Skin of AP-1 Luciferase}

\section{Reporter Transgenic Mice}

Skin samples of transgenic mice were punch biopsied $(1.5 \mathrm{~mm})$ in the beginning of the experiment to determine the basal luciferase activity and then every 4 weeks after initiation. As shown on Figure 3.6, AP-1 activity peaked in mouse skin exposed to 
DMBA/Cum-OOH or DMBA/TPA after 4 weeks of promotion. Maximal AP-1 activation was 22.4- (DMBA/Cum-OOH) or 45.2-fold (DMBA/TPA) increased as compared to the DMBA/acetone treated group, respectively. AP-1 activation gradually declined after 8 weeks of DMBA/Cum-OOH and DMBA/TPA exposures. Interestingly, while AP-1 activity and papilloma formation were markedly higher in mice treated with DMBA/TPA (4-14 weeks of exposure), we did not observe carcinoma formation in this group (Figure 3.6). After 29 weeks of topical application with DMBA/Cum-OOH or DMBA/TPA, no differences in AP-1 activation were detected (Figure 3.6).

\section{Biomarkers of Inflammation in the Skin of Mice Exposed to Cum-OOH or TPA.}

We found that exposure to DMBA/Cum-OOH or DMBA/TPA caused skin inflammation as determined by skin thickness and measurements of myeloperoxidase (MPO) activity. Topical application of DMBA/Cum-OOH or DMBA/TPA to mouse skin resulted in a 34.8-fold or a 23.5 -fold net increase, respectively, in the skin bi-fold thickness at the termination of the experiment (29 weeks) as compared to control (DMBA/acetone) (Table 3.1). Topical exposure to DMBA/Cum-OOH or DMBA/TPA resulted in 14.2-fold or 5.5-fold increases, respectively, in myeloperoxidase activity above the levels seen in the control (Table 3.1).

\section{Biomarkers of Oxidative Stress in the Skin of Mice Exposed to Cum-OOH or TPA.}

As shown by the data in Table 3.1, topical application of DMBA/Cum-OOH or DMBA/TPA induced oxidative stress in mouse skin, as indicated by the accumulation of peroxidative products (TBARs), depletion of total antioxidant reserve, a decrease in the levels of glutathione (GSH) and protein sulfhydryls groups. After 29 weeks of treatment with DMBA/Cum-OOH or DMBA/TPA, the level of lipid peroxidative products in the 
skin of AP-1- luciferase reporter transgenic mice were increased by $63.6 \%$ or $33.3 \%$ above the levels seen in the control (DMBA/acetone) (Table 3.1). At the termination of the experiment, total antioxidant reserve levels were reduced remarkably by $85.2 \%$ or $70.5 \%$ in skin homogenates of AP-1 transgenic mice after topical application with DMBA/Cum-OOH or DMBA/TPA, respectively, as compared with DMBA/acetone treated skin (Table 3.1).

As shown in Table 3.1, after 29 weeks of treatment with DMBA/Cum-OOH or DMBA/TPA, the levels of GSH in the skin of AP-1 transgenic mice were decreased by $35.1 \%$ or $11.9 \%$ as compared to DMBA/acetone treated control mice. Along with GSH depletion, the levels of protein thiols were decreased by $11.1 \%$ or $6.8 \%$ after DMBA/Cum$\mathrm{OOH}$ or DMBA/TPA topical application as compared to DMBA/acetone treated mice (Table 3.1).

\section{Discussion}

Chemically induced skin cancer in mice has three chronological stages, initiation, promotion, and progression (Bowden, et al 1995; Hennings et al., 1993). Tumor initiation is a rapid and irreversible process, whereas promotion is a long-term process that requires chronic exposure to a tumor promoter. A tumor promoter increases proliferation of initiated cells thereby accelerating cancer progression; however, the exact mechanism of promotion is more complicated (Nguyen-Ba and Vasseur, 1999). Conversion of benign papillomas to malignant carcinomas occurs spontaneously during the promotion stage of carcinogenesis; however, this conversion occurs at a very low rate in animals undergoing repetitive TPA exposures after DMBA initiation (Bhasin et al., 2004). The conversion 
frequency of papilloma to carcinoma can be increased by exposing papilloma-bearing animals to progressing agents such as OP or hydroperoxides (Athar et al., 1989).

Free radical formation has been shown to play a role in both initiation and promotion of multistage carcinogenesis (Slaga et al., 1981; Taffee and Kensler, 1986a, b; Oberley and Oberley, 1986). Biological systems can have an abundance of free radical species as a result of normal metabolic pathways or as a result of exposure to chemical carcinogens (Perchellet and Perchellet, 1989; Sun, 1990). The effectiveness of the OP and hydroperoxides as progressing agents is related to the type of radicals produced (Kensler et al., 1995). Previous work by our lab has shown that exposure to Cum-OOH results in the production of two lipid-derived radical species which were detectable as early as 30 minutes following exposure and determined to be methyl and methoxyl radicals resulting from the metabolic oxidation of Cum-OOH (Shvedova et al., 2002). These radicals are able to interact with DNA causing oxidative damage (Floyd, 1982; Sultana et al., 1995), which may contribute to increased malignant transformation (O'Connell et al., 1986), and alterations affecting the antioxidant defense system of the organs and tissue (Taffee and Kensler, 1986a, b; Alam et al., 2000). Radical production influences a number of genes and signal transduction pathways with the most significant modifications occurring in the MAP kinase/ AP-1 pathway (Remacle et al., 1995; Allen et al., 2000; Cimino et al., 1997; Dhar et al., 2002).

Changes in the level of AP-1 activity have been correlated to different stages of melanoma development and progression (Angel et al., 2001). A well-known oncogenic 
stimulator, 12-O-tetradecanoylphorbol-13-acetate (TPA), activates protein kinase C and, subsequently, the transcription factor AP-1 (Angel et al., 2001). Cum-OOH exposure has been shown to result in a concentration-dependent activation of cytosolic phopholipase $\mathrm{A}_{2}\left(\mathrm{cPLA}_{2}\right)$ in Her14 fibroblasts. $\mathrm{PLA}_{2}$ has been implicated in cellular injury and hydrolyses of oxidation sensitive arachidonic acid (van Rossum et al., 2004). Enhanced conversion of arachidonic acid to prostaglandins via cyclooxygenase has been shown to be a potential contributor to the development of skin cancers (An et al., 2002). COX-2 overexpression has been linked to the pathophysiology of inflammation and cancer. COX-2 expression has been demonstrated to correlate with tumor proliferation and promotion (Chinery et al., 1999). Benign papillomas have been shown to have COX-2 expression localized perinuclear and cytoplasmically; while carcinomas have more intense and stronger COX-2 expression found within the tumor stroma and throughout the granular and spinous layers of tumors (An et al., 2002). Cum-OOH exposure was shown to induce human keratinocyte cells (HaCat) to release prostaglandin E2. COX-2specific inhibitors have been found to suppress the synthesis and release of prostaglandins induced by exposure to $\mathrm{Cum}-\mathrm{OOH}$ (Shvedova et al., 2004). We found that animals exposed to DMBA/TPA had higher AP-1 activation along with increased papilloma formation compared to the animals treated with DMBA/Cum-OOH. Exposure to DMBA/Cum-OOH caused carcinoma formation not seen in mice treated with DMBA/TPA. The observed carcinomas in DMBA/Cum-OOH treated mice appeared to result from the malignant conversion of benign papillomas to carcinomas which possibly occurred via a COX-2-dependent pathway that was not entirely dependent upon AP-1 activation. 
Another possible mechanism by which DMBA/Cum-OOH papillomas may be transformed from benign papillomas to malignant carcinomas may be due to excessive radical production and subsequent DNA damage. The previous study revealed oxidative DNA damage in older mice (32 weeks old) exposed to Cum-OOH (Figure 2.5, 2.6). As the animals age throughout the duration of the experiment, increased oxidative DNA damage may be occurring thereby resulting in the increased malignant conversion of papillomas to carcinomas.

Inflammation and oxidative stress are also very closely associated with modifying effects on tumor development (Nakamura et al., 2000). OP, e.g. Cum-OOH, have been shown to cause tumor promotion following topical exposure to murine skin (Slaga et al., 1981; Athar et al., 1989; Timmins and Davies, 1993). Application of free radical-scavenging compounds, e.g. antioxidants, can affect the cancer promotion stage (Perchellet and Perchellet, 1989; Kensler and Taffe, 1986; Timmins and Davies, 1993) indicating the role of free radicals during tumor promotion and development. Following DMBA/Cum-OOH exposure, we found changes in the oxidative capacity in the skin of animals as indicated by decreases in GSH, and total antioxidant reserves. Increased inflammation, e.g. increases in skin bi-fold thickness, neutrophil infiltration and elevated MPO activity, were also seen to a higher extent in DMBA/Cum-OOH treated mice compared to DMBA/TPA animals. .

From the current results, papillomas appeared on the skin of AP-1 transgenic mice starting from 7 weeks of DMBA/TPA treatment, and from week 11 of treatment with 
DMBA/Cum-OOH. The growth, external appearance and number of tumors were different between the two groups (Figure 3.5). Moreover, at the end of the experiment (week 29), 2.5 \pm 0.2 tumors found in AP-1 mice were malignant after treatment with DMBA/Cum-OOH, whereas no carcinomas were detected in DMBA/TPA treated animals. In conclusion, we found that activation of AP-1 in skin was elevated as early as 2 weeks following DMBA/Cum-OOH and DMBA/TPA exposures. Papilloma formation was observed in both the DMBA/TPA and DMBA/Cum-OOH-exposed animals while skin carcinomas were found only in the DMBA/Cum-OOH-treated mice. A greater accumulation of peroxidative products (TBARS), inflammation, and decreased levels of $\mathrm{GSH}$, and total antioxidant reserves were observed in the skin of DMBA/Cum-OOHexposed mice. There results suggest that $\mathrm{Cum-OOH}$-induced carcinogenesis is accompanied by increased AP-1 activation and changes in antioxidant status. 


\section{Tables and Figures}

\begin{tabular}{|c|c|c|c|c|c|c|}
\hline & $\begin{array}{c}\text { Acetone } \\
\text { /Acetone } \\
\text { (Group 1) }\end{array}$ & $\begin{array}{c}\text { Acetone } \\
\text { /TPA } \\
\text { (Group 2) }\end{array}$ & $\begin{array}{c}\text { Acetone } \\
\text { /Cum-OOH } \\
\text { (Group 3) }\end{array}$ & $\begin{array}{c}\text { DMBA } \\
\text { /Acetone } \\
\text { (Group 4) }\end{array}$ & $\begin{array}{c}\text { DMBA } \\
\text { /TPA } \\
\text { (Group 5) }\end{array}$ & $\begin{array}{c}\text { DMBA } \\
\text { /Cum-OOH } \\
\text { (Group 6) }\end{array}$ \\
\hline $\begin{array}{c}\text { Net Increase in Skin } \\
\text { Bi-fold, } \\
\text { Thickness (mm) }\end{array}$ & $0.00 \pm 0.01$ & $0.40 \pm 0.03^{*}$ & $0.43 \pm 0.04^{*}$ & $0.04 \pm 0.01$ & $0.94 \pm 0.11^{* \alpha \beta}$ & $1.39 \pm 0.25^{* \alpha \mu}$ \\
\hline $\begin{array}{c}\text { MPO, } \\
\text { nmol/min/mg protein }\end{array}$ & ND & $1.93 \pm 0.28 *$ & $2.05 \pm 0.51^{*}$ & ND & $4.83 \pm 0.24^{* a b}$ & $12.67 \pm 1.90^{* \alpha \mu}$ \\
\hline $\begin{array}{c}\text { TBARS, } \\
\text { nmol/mg protein }\end{array}$ & $0.30 \pm 0.01$ & $0.32 \pm 0.01$ & $0.29 \pm 0.01$ & $0.33 \pm 0.01$ & $0.44 \pm 0.03^{* a \beta}$ & $0.54 \pm 0.03^{* \alpha \mu}$ \\
\hline $\begin{array}{c}\text { Total Antioxidant } \\
\text { Reserves (Peroxyl radicals } \\
\text { scavenged by skin } \\
\text { homogenates, nmol/mg) }\end{array}$ & $173.6 \pm 24.9$ & $52.8 \pm 3.1 *$ & $41.0 \pm 6.5 *$ & $87.0 \pm 8.7 *$ & $25.7 \pm 3.8^{* \alpha \beta}$ & $12.9 \pm 3.0^{* \alpha \mu}$ \\
\hline $\begin{array}{c}\text { GSH, } \\
\text { nmol/mg protein }\end{array}$ & $25.7 \pm 0.2$ & $18.7 \pm 0.6^{*}$ & $18.0 \pm 0.3^{*}$ & $16.8 \pm 0.2^{*}$ & $14.8 \pm 0.1^{* \alpha \beta}$ & $10.9 \pm 0.3^{* \alpha \mu}$ \\
\hline $\begin{array}{c}\text { Protein Thiols, } \\
\text { nmol/mg protein }\end{array}$ & $39.6 \pm 2.2$ & $38.6 \pm 0.4$ & $36.9 \pm 0.9$ & $36.9 \pm 0.5$ & $34.4 \pm 0.9^{* \alpha \beta}$ & $32.8 \pm 0.7^{* \alpha \mu}$ \\
\hline
\end{tabular}

Table 3.1. Biomarkers of inflammation and oxidative stress in skin of AP-1mice after 29 weeks of Cum-OOH-induced or TPA-induced tumor promotion. Values are means +/- SEM. ${ }^{*} p<0.05$ versus acetone/acetone treated mice; ${ }^{\alpha} p<0.05$ versus DMBA/acetone treated mice; ${ }^{\beta} \mathrm{p}<0.05$ versus acetone/TPA treated mice; ${ }^{\mu} \mathrm{p}<0.05$ versus acetone/Cum-OOH treated mice. ND - non-detectable. 


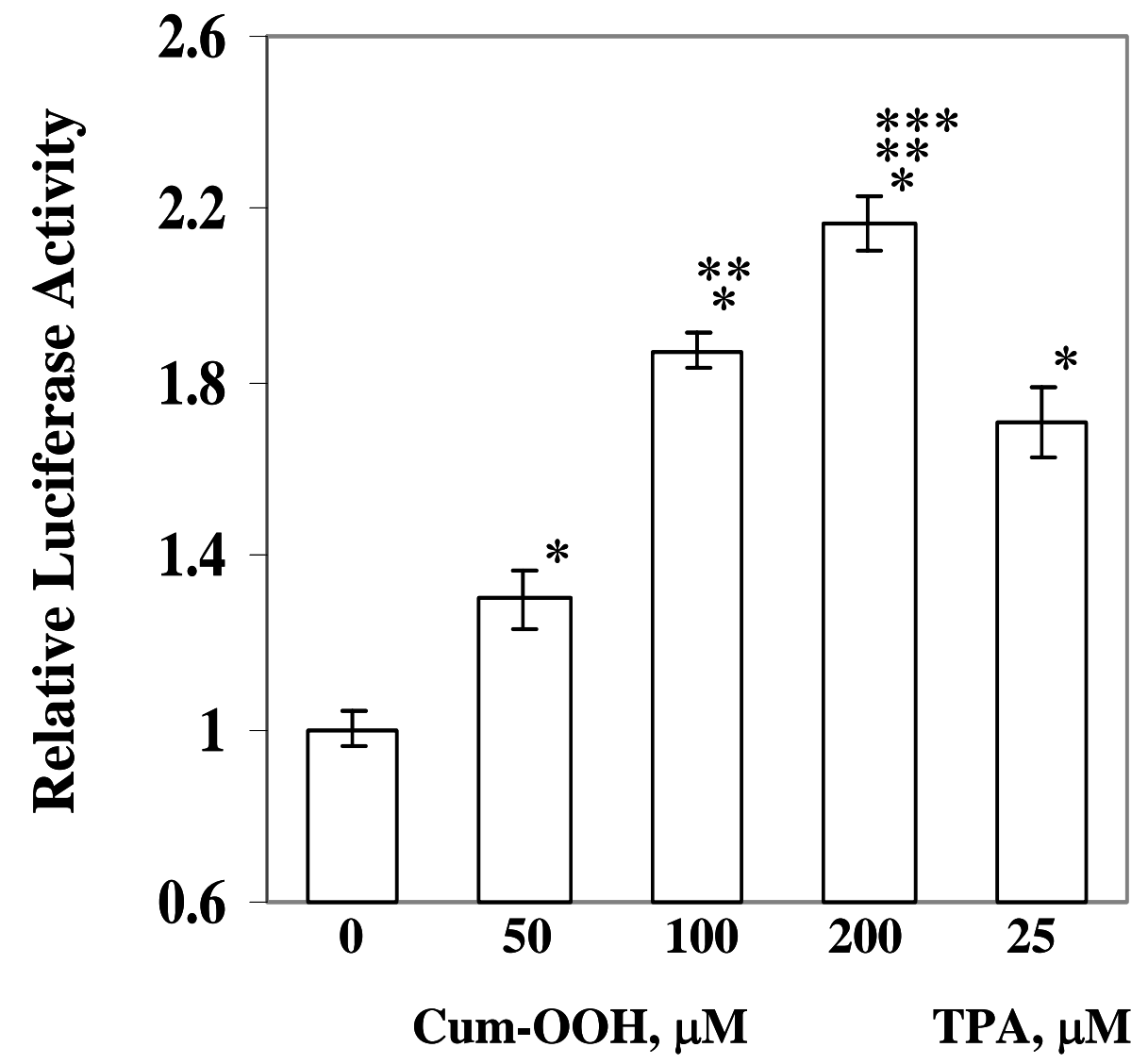

Figure 3.1. Cum-OOH-induced AP-1 activation in JB6 P+ cells. JB6 P+ cells were cultured in Eagle's MEM supplemented with $0.5 \%$ fetal bovine serum and $2 \mathrm{mM}$ Lglutamine for 24 hours to minimize basal AP-1 activity, and then exposed to Cum-OOH $(0,50,100$, or $200 \mu \mathrm{M})$ or TPA $(25 \mu \mathrm{M})$ in the same medium for 24 hours to monitor the effects on AP-1 induction. The cells were extracted with 200. $\mu$ l of 1x lysis buffer provided in luciferase assay kit by the manufacture. Values are means \pm SEM of 3 experiments. ${ }^{*} \mathrm{p}<0.05$ vs control cells, ${ }^{*} \mathrm{p} p<0.05$ versus $50 \mu \mathrm{M}$ Cum-OOH exposed cells, $* * * \mathrm{p}<0.05$ versus $100 \mu \mathrm{M}$ Cum-OOH exposed cells. 

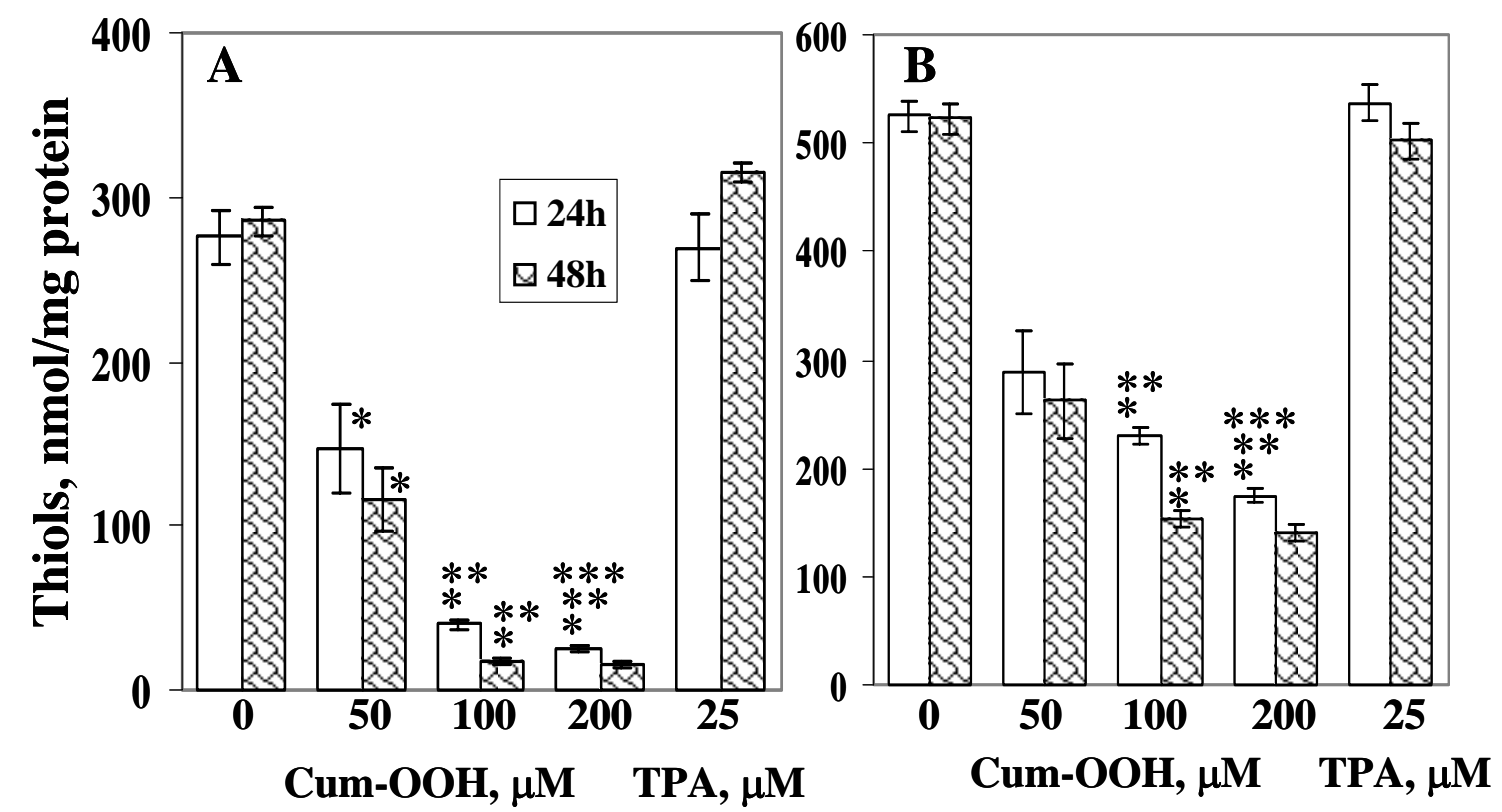

Figure 3.2. Effect of Cum-OOH on the levels of GSH and protein thiols in JB6 P+ cells. JB6 P+ cells were cultured in Eagle's MEM supplemented with $0.5 \%$ fetal bovine serum and $2 \mathrm{mM}$ L-glutamine for 24 hours to minimize basal AP-1 activity, and then exposed to Cum-OOH $(0,50,100$, or $200 \mu \mathrm{M})$ or TPA $(25 \mu \mathrm{M})$ in the same medium for 24 or 48 hours. Following exposure, cells were washed with PBS and frozen at $-80^{\circ} \mathrm{C}$. ThioGlo-1 was used to measure changes in GSH and protein thiol levels as a result of exposure. A - GSH; B - Protein thiols. White bars: 24 hours post-exposure; Pattern bars: 48 hours post-exposure. Values are means \pm SEM of 3 experiments. ${ }^{*} p<0.05$ vs control cells, ${ }^{*} \mathrm{p}<0.05$ versus $50 \mu \mathrm{M}$ Cum-OOH exposed cells, $* * * \mathrm{p}<0.05$ versus $100 \mu \mathrm{M}$ Cum$\mathrm{OOH}$ exposed cells. 


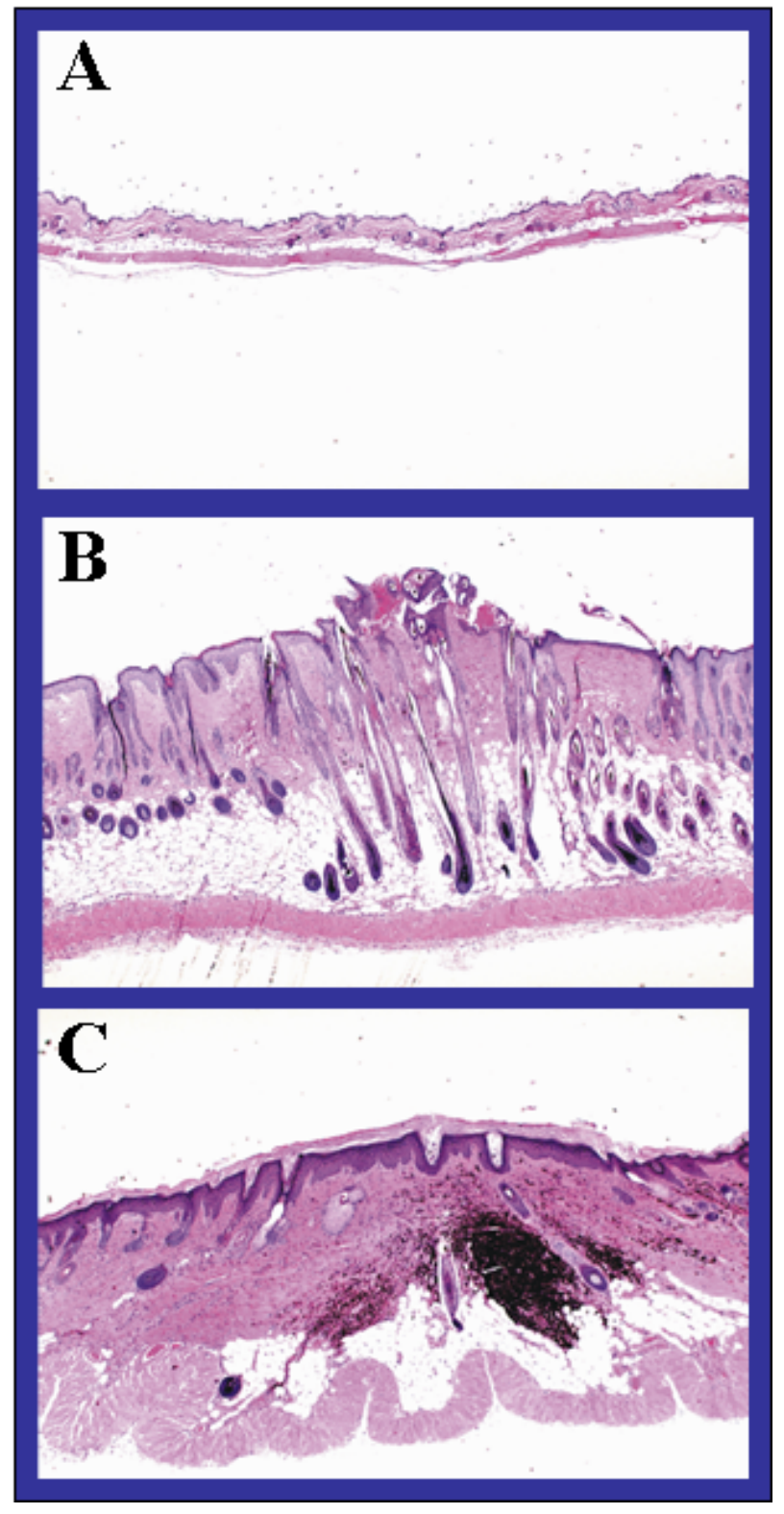

Figure 3.3. Morphological alterations and tumor promotion in skin of AP-1 transgenic mice treated with DMBA/Cum-OOH or DMBA/TPA (29 weeks). Mice were exposed to DMBA $(51.2 \mu \mathrm{g}$ dissolved in $100 \mu \mathrm{l}$ of acetone for each mouse), which was used as a tumor initiator. Fourteen days following initiation, the mice were promoted twice a week with acetone, $17 \mathrm{nmol}$ TPA, or $82.6 \mu \mathrm{mol}$ Cum-OOH dissolved in $100 \mu$ l of acetone for 29 weeks. Skin sections were collected in formalin for histological evaluation at the completion of the experiment. A - DMBA/acetone; B - DMBA/TPA; C - DMBA/Cum$\mathrm{OOH}$; Magnification x 4. 


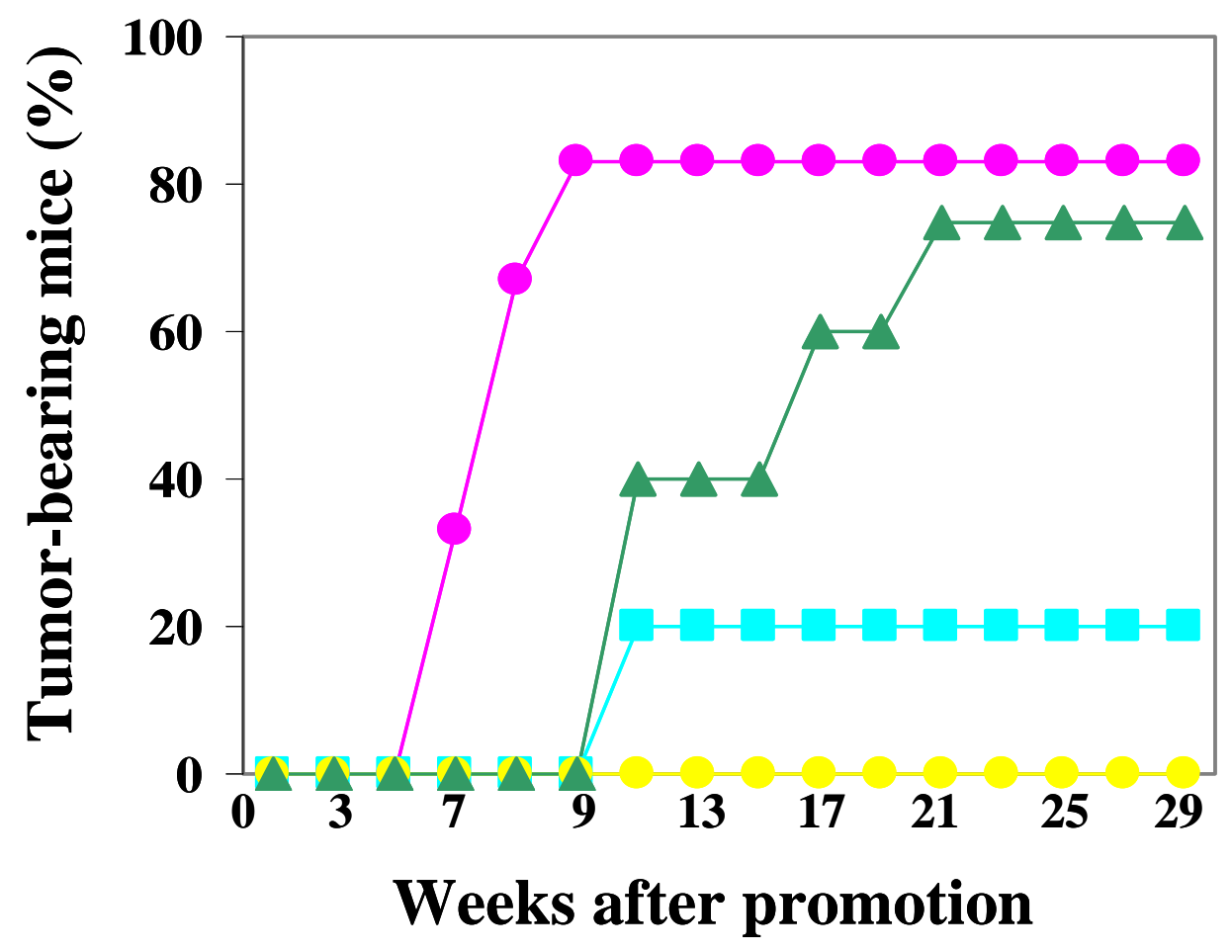

Figure 3.4. Incidence of tumors in AP-1 transgenic mice treated with DMBA/Cum-OOH or DMBA/TPA. Mice were exposed to DMBA (51.2 $\mu \mathrm{g}$ dissolved in $100 \mu \mathrm{l}$ of acetone for each mouse), which was used as a tumor initiator. Fourteen days following initiation, the mice were promoted twice a week with acetone, $17 \mathrm{nmol}$ TPA, or $82.6 \mu \mathrm{mol} \mathrm{Cum}$ $\mathrm{OOH}$ dissolved in $100 \mu \mathrm{l}$ of acetone for 29 weeks. The papillomas/carcinomas appearing on the shaved area of the skin were recorded at weekly intervals. Pink circles - percentage of animals having one or more TPA-induced papillomas; aqua squares - percentage of animals having one or more Cum-OOH-induced papillomas; green triangles - percentage of animals having one or more $\mathrm{Cum}-\mathrm{OOH}$-induced carcinomas, yellow circles-percentage of animals having one or more acetone-induced papillomas or carcinomas. Values are means of 6 mice per group. 


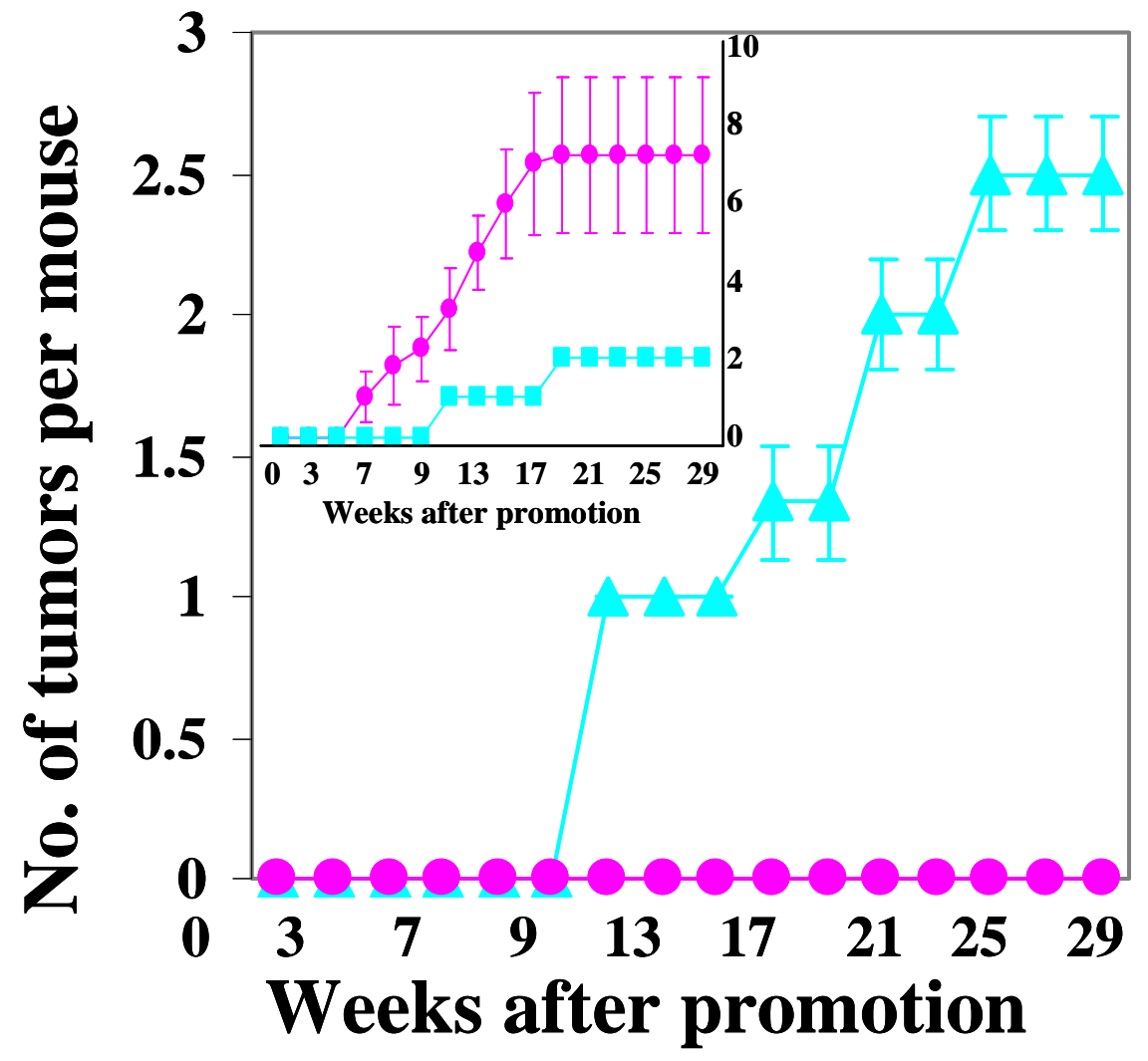

Figure 3.5. Number of tumors in AP-1 transgenic mice treated with DMBA/Cum-OOH and DMBA/TPA; Inset - number of papillomas per mouse. Mice were exposed to DMBA (51.2 $\mu \mathrm{g}$ dissolved in $100 \mu \mathrm{l}$ of acetone for each mouse), which was used as a tumor initiator. Fourteen days following initiation, the mice were promoted twice a week with acetone, $17 \mathrm{nmol}$ TPA, or $82.6 \mu \mathrm{mol}$ cumene hydroperoxide dissolved in $100 \mu \mathrm{l}$ of acetone for 29 weeks. The papillomas/carcinomas appearing on the shaved area of the skin were recorded at weekly intervals. Pink circles - number of TPA-induced papillomas/carcinomas per mouse; aqua squares - number of Cum-OOH-induced papillomas per mouse; aqua triangles - number of Cum-OOH-induced carcinomas per mouse. Values are means of 6 mice per group. 


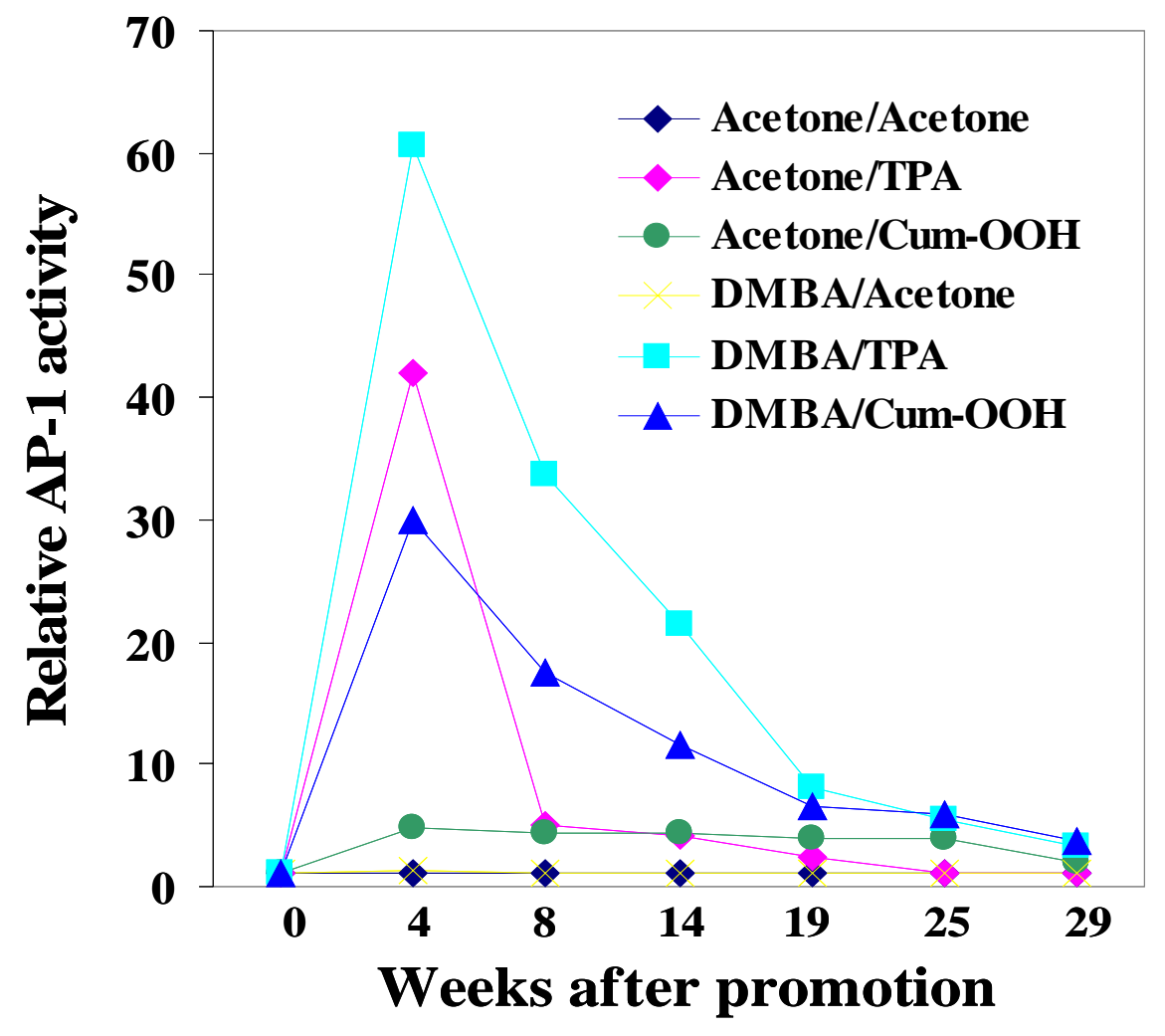

Figure 3.6. AP-1 transactivation in the skin of AP-1 - luciferase transgenic mice treated with DMBA/Cum-OOH and DMBA/TPA. Mice were exposed to DMBA $(51.2 \mu \mathrm{g}$ dissolved in $100 \mu \mathrm{l}$ of acetone for each mouse), which was used as a tumor initiator. Fourteen days following initiation, the mice were promoted twice a week with acetone, $17 \mathrm{nmol} \mathrm{TPA}$, or $82.6 \mu \mathrm{mol} \mathrm{Cum-OOH}$ dissolved in $100 \mu \mathrm{l}$ of acetone for the next 29 weeks. AP-1-luciferase activity in the skin was measured by dorsal skin punch biopsy using biopsy punch every 4 weeks. 


\section{References}

Adams, R. M. 1999. Occupational Skin Disease. W.B. Saunders. Philadelphia, PA. pp 491-500.

Alam, A., Iqbai, M., Saleem, M., Ahmed, S., and Sultana S. 2000. Myrica nagi attenuates Cumene hydroperoxide-induced cutaneous oxidative stress and toxicity in Swiss Albino Mice. Pharmacol Tox. 86: 209-214.

Allen, R. G., and Tresini, M. 2000. Oxidative stress and gene regulation. Free Rad Biol Med. 28:463-499.

Amstad, P. A., Liu, H., Ichimiya, M., Chang, S., Berezesky, I. K., and Trump, B. F. 1997. bcl-2 enhancement of malignant transformation in mouse epidermal JB6 cells. Mol Carcinog. 20(2) : 231-9.

An, K. P., Athar, M., Tang, X., Katiyar, S. K., Russo, J., Beech, J., Aszterbaum, M., Kopelovich, L., Epstein Jr, E. H., Mukhtar, H., and Bickers, D. R. 2002. Cyclooxygenase-2 expression in murine and human nonmelanoma skin cancers: implications for therapeutic approaches. Photochem Photobiol. 76(1): 73-80.

Angel, P., Imagawa, M., Chiu, R., Stein, B., Imbra, R. J., Rahmsdorf, H. J., Jonat, C., Herrlich, P., and Karin, M. 1987. Phorbol ester-inducible genes contain a common cis element recognized by a TPA-modulated trans-acting factor. Cell. 49(6) : 729-39.

Angel, P., and Karin, M. 1991. The role of Jun, Fos and the AP-1 complex in cellproliferation and transformation. Biochem Biophys Acta. 1072 (2-3) : 129-57.

Angel, J. M., Caballero, M., and DiGiovanni, J. 2001. Confirmation of the mapping of a 12-O-tetradecanoylphorbol-13-acetate promotion susceptibility locus, Psl1, to distal mouse chromosome 9. Mol Carcinog. 32(4):169-75.

Athar, M., Lloyd, J. R., Bickers, D. R., and Mukhtar, H. 1989. Malignant conversion of UV radiation and chemically-induced mouse skin benign tumors by free-radicalgenerating compounds. Carcinogenesis. 10(10): 1841-5.

Barbasid, M. 1987. Ras genes. Annu Rev Biochem. 56: 779-827.

Bhasin, G., Kauser, H., and Athar, M. 2004. Free radical generating agents lead to the rapid progression of benign skin tumors to carcinoma in iron-overloaded mice. Arch Tox. $78: 139-146$.

Bowden, G. T., Finch, J., Domann, F., and Krieg, P. Molecular mechanisms involved in skin tumor initiation, promotion, and progression. 1995. Mukhtar H. eds. In: Skin Cancer: Mechanisms and Human Relevance. CRC Press, Inc. Boca Raton, FL. pp 99111. 
Buege, J. A., Aust, S. D. 1978. Microsomal lipid peroxidation. Methods Enzymol. 52: 302-10.

Chinery, R., Coffey, R. J., Graves-Deal, R., Kirkland, S. C., Sanchez, S. C., Zackert, W. E., Oates, J. A., and Morrow, J. D. 1999. Prostaglandin J2 and 15-deoxy-delta12, 14prostaglandin $\mathrm{J} 2$ induce proliferation and cyclooxygenase-depleted colorectal cancer cells. Cancer Res. 59: 2739-2746.

Cimino, F., Esposito, F., Ammendola, R., and Russo, T. 1997. Gene regulation by reactive oxygen species. Curr Top Cell Reg. 35: 123-148.

Dhar, A., Young, M. R., and Colburn, N. H. 2002. The role of AP-1, NF-kB and ROS/NOS in skin carcinogenesis: The JB6 model is predictive. Mol Cell Biochem. 234/235: 185-193.

Domann Jr., F. E., Levy, J. P., Finch, J. S., and Bowden, G.T. 1994. Constitutive AP-1 DNA binding and transactivating ability of malignant but not benign mouse epidermal cells. Mol Carcinog. 9(2) : 61-6.

Dong, Z., Lavrovsky, V., and Colburn, N. H. 1995. Transformation reversion induced in JB6 RT101 cells by AP-1 inhibitors. Carcinogenesis. 16(4) : 749-56.

Floyd, R. A. 1982. Free radicals and cancer. New York, Marcel Dekker, Inc.

Hennings, H., Glick, A. B., Lowry, D. T., Krsmanovic, L. S., Sly, L. M., and Yuspa, S. H. 1993. FVB/N mice: an inbred strain sensitive to the chemical induction of squamous cell carcinomas in the skin. Carcinogenesis 14: 2353-2358.

Hirai, S. I., Ryseck, R. P., Mechta, F., Bravo, R., and Yaniv, M. 1989. Characterization of junD: a new member of the jun proto-oncogene family. EMBO J. 8(5): 1433- 9.

Huang, C., Ma, W. Y., and Dong, Z. 1996. Requirement for phosphatidylinositol 3kinase in epidermal growth factor-induced AP-1 transactivation and transformation in JB6 P+ cells. Mol Cell Biol. 16(11) : 6427-35.

Huang, C., Ma, W. Y., Hecht, S. S., and Dong, Z. 1997. Inositol hexaphosphate inhibits cell transformation and activator protein-1 activation by targeting phosphatidylinositol-3 kinase. Cancer Res. 57(14): 2873-8.

Isbir, T., Yaylim, I., Aydin, M., Ozturk, O., Koyuncu, H., Zeybek, U., Agachan, B., and Yilmaz, H. 2000. The effects of Brassica oleraceae var capitata on epidermal glutathione and lipid peroxides in DMBA-initiated-TPA-promoted mice. Anticancer Res. 20(1A) : 219-24. 
Jochum, W., Passeque, E., and Wagner, E. F. 2001. AP-1 in mouse development and tumorigenesis. Oncogene. 20(19) : 2401-12.

Kensler, T., Guyton, K., Egner, P., McCarthy, T., Lesko, S., and Akman, S. 1995. Role of reactive intermediates in tumor promotion and progression. Prog Clin Biol Res. 391: 103-116.

Kisella, A. R., Gainer, H. S., and Butler, J. 1983. Investigation of a possible role for superoxide anion production in tumour promotion. Carcinogenesis. 4(6) : 717-9.

Lewis, R. J. 1993. Hawley's Condensed Chemical Dictionary. $12^{\text {th }}$ ed. Van Nostrand Reinhold. New York, New York. p 133.

Nakamura, Y., Murakami, A., and Ohigashi, H. 2000. Search for naturally-occurring antioxidative chemopreventors on the basis of the involvement of leukocyte-derived reactive oxygen species in carcinogenesis. Asian Pac J Cancer Prev. 1(2):115-120.

Nguyen-Ba, G., and Vasseur, P. 1999. Epigenetic events during the process of cell transformation induced by carcinogens. Oncol Rep. 6: 925-932.

Niki, E. 1990. Free radical initiators as a source of water- or lipid-soluble peroxyl radicals. Methods Enzymol. 186: 100-108.

Nonaka, T., Mio, M., Doi, M., and Tasaka, K. 1992. Histamine-induced differentiation of HL-60 cells. The role of cAMP and protein kinase A. Biochem Pharmacol. 11151121.

O’Connell, J. F., Klein-Szanto, A. J. P., DiGiovanni, D. M., Fries, J. W., and Slaga, T. J. 1986. Enhanced malignant progression of mouse skin tumors by free-radical generator benzoyl peroxide. Cancer Res. 46: 2863-2865.

Oberley, L. V. W., and Oberley, T. D. 1986. Free radical, cancer, and aging. In: Free radicals, aging, and degenerative diseases. Eds: JE Johnson, Jr, R Walford, D Harman, J Miquel. New York, Alan R. Liss, Inc., 1986. pp.325-371.

Perchellet, J., and Perchellet, E. M. 1992. Antioxidants and multistage carcinogenesis in mouse skin. Free Rad Biol Med. 7: 377-408.

Perchellet, J. P., Abney, N. L., Thomas, R. M., Guislain, V. L., and Perchellet, E. M. 1987. Effects of combined treatments with selenium, glutathione, and vitamin E on glutathione peroxidase activity, ornithine decarboxylase induction, and complete and multistage carcinogenesis in mouse skin. Cancer Res. 47(2) : 477-85.

Remacle, J., Raes, M., Toussaint, O., Renard, P., and Rao, G. 1995. Low levels of reactive oxygen species as modulators of cell function. Mutat Res. 316: 117-129. 
Rincon, M., and Flavell, R. A. 1994. AP-1 transcriptional activity requires both T-cell receptor-mediated and co-stimulatory signals in primary T-lymphocytes. EMBO J. 13(18): 4370-81.

Shvedova, A. A., Kommineni, C., Jeffries, B. A., Castranova, V., Tyurina, Y. Y., Tyurin, V. A., Serbinova, E. A., Fabisiak, J. P., and Kagan, V. E. 2000. Redox cycling of phenol induces oxidative stress in human epidermal keratinocytes. J Invest Dermatol. 114: 354364.

Shvedova, A. A., Kisin, E. R., Murray, A. R., Kommineni, C., Castranova, V., Mason R. P., Kadiiska, M. B., and Gunther, M. R. 2002. Antioxidant balance and free radical generation in vitamin $\mathrm{E}$ deficient mice after dermal exposure to cumene hydroperoxide. Chem Res Toxicol. 15(11): 1451-9.

Shvedova, A. A., Kisin, E. R., Murray, A., Kommineni, C., Vallyathan, V., and Castranova, V. 2004. Pro/antioxidant status in murine skin following topical exposure to cumene hydroperoxide throughout the ontogeny of skin cancer. Biochem (Moscow). 69(1): 30-40.

Slaga, T. J., Klein-Szanto, J. P., Triplett, L., Yotti, I. P., and Tresko, I. F. 1981. Skin tumor promotion activity of benzoyl peroxide, a widely used free radical generating compound. Science. 213: 1023-1025.

Solanki, V., and Slaga, T. J. 1981. Specific binding of phorbol ester tumor promoters to intact primary epidermal cells from Sencar mice. Proc Natl Acad Sci USA. 78(4) : 254953.

Sultana, S., Shahid, P., Iqbal, M., and Athar, M. 1995. Crude extracts of hepatoprotective plants Solanum nigrum and Cichorium intybus inhibit free radical-mediated DNA damage. J Enthnopharmacol. 45: 189-192.

Sun, Y. 1990. Free radicals, antioxidant enzymes, and carcinogenesis. Free Rad Biol Med. 8: 583-599.

Taffee, B. G., and Kensler, T. W. 1986a. Generation of free radicals from organic hydroperoxide tumor promoter by mouse epidermial cells. Pharmacologist. 28: 175.

Taffee, B. G., and Kensler, T. W. 1986b. Modification of cellular antioxidant defense mechanisms in mouse skin by multiple applications of TPA. Proc Amer Assoc Cancer Res. 27: 148.

Timmins, G. S., and Davies, M. J. 1993. Free radical formation in isolated murine keratinocytes treated with organic peroxides and its modulation by antioxidants. Carcinogenesis. 14(8): 1615-20. 
van Rossum, G. S. A. T., Drummen, G. P. C., Verkleij, A. J., Post, J. A., and Boonstra, J. 2004. Activation of cytosolic phopholipase A2 in Her14 fibroblasts by hydrogen peroxide: a p42/44 MAPK-dependent and phosphorylation-independent mechanism. Biochimica Biophysica Acta. 1636: 183-195. 
STUDY 4: SIMULATED SOLAR UV LIGHT (SSL) INDUCES INFLAMMATION AND OXIDATIVE STRESS IN THE SKIN OF SKH-1 HAIRLESS MICE 


\section{$\underline{\text { Abstract }}$}

The skin is continuously exposed to a variety of hazardous environmental insults, such as ultraviolet light, ozone, and ionizing radiation. These exposures can result in the production of free radicals and reactive oxygen species (ROS), which have been implicated in the development of inflammatory skin disorders, skin cancer, cutaneous autoimmune diseases, phototoxicity, and premature aging. A variety of antioxidant defense mechanisms are present in skin to cope and prevent oxidative injury; however, when environmental stressors, e.g. UV irradiation, overwhelm these defense mechanisms, skin injury may occur. We hypothesized that solar light exposure, in particular a dose not causing burns, results in the formation of free radicals and oxidative stress with depletion of antioxidants, accelerated lipid peroxidation and DNA damage. To experimentally assess whether simulated solar light (SSL) caused these alterations, SKH-1 hairless mice were exposed to SSL $\left(13.7 \mathrm{~mJ} \cdot \mathrm{CIE} / \mathrm{cm}^{2} /\right.$ day) for 1 hour, 5 days a week for 3 weeks. Twenty-four hours following the last exposure, mice were sacrificed and the skin was evaluated for changes in several parameters of oxidative stress as well as histopathological alterations. A significant amount of GSH oxidation as well as decreases in the levels of protein thiols, total antioxidant reserves, and vitamin E were observed as a result of exposure to SSL. A significant increase in lipid peroxidation and elevated myeloperoxidase activity (MPO), indicating infiltration of neutrophils into the skin, were observed following SSL irradiation. Pyrimidine dimer formation indicating DNA damage was detected in the skin following SSL irradiation. Histological observation of the skin following SSL irradiation revealed an increase in skin thickness and inflammatory cell infiltration. We concluded that DNA damage, oxidative stress and antioxidant depletion 
as observed by decreases in GSH, vitamin E, and total antioxidant reserves, along with inflammatory cell infiltration in the skin of SKH-1 following SSL exposure contributed to the detrimental effects of SSL. 


\section{Introduction}

Solar radiation reaching the earth consists mainly of UVA (315-400 nm) and UVB (280$315 \mathrm{~nm})$ light and is a major environmental and occupational exposure risk. The skin is easily and constantly exposed to air, solar radiation, and ozone. As a result of reduction of the stratospheric ozone layer, there has been an increase in dermal exposure to ultraviolet radiation (UVR) accompanied by an increase in the development of associated skin diseases (Miyachi et al., 1995; Jurkiewcz and Buettner, 1994). UVR has been shown to be a source of exogenous and environmental ROS. ROS, such as superoxide anion, hydroxyl radical, hydrogen peroxide and molecular oxygen, have been shown to be involved in cell proliferation, apoptosis, immune responses, and cell differentiation (Trouba et al., 2002); however, overproduction of ROS can result in the development and progression of a variety of skin maladies in which inflammatory mediators are implicated (Alder et al., 1999). An upregulation in the production and release of pro-inflammatory cytokines, such as IL-1, IL-6, IL-8 and TNF- $\alpha$, have been shown to occur due to oxidative stress (Alder et al., 1999; Effendy et al., 2000). The presence of these inflammatory mediators are able to stimulate the production and release of other chemokines/cytokines and further propagate and amplify the inflammatory response in skin (Effendy et al., 2000).

The skin has a developed and sophisticated system to withstand oxidative damage (Beckman and Ames, 1998). This complex antioxidant defense system detoxifies ROS via the reduction of antioxidants that have been shown in several cases to inhibit cytokine production by intracellular thiols. Glutathione $(\mathrm{GSH})$ is an important sulfur-containing 
antioxidant which maintains the intracellular redox status by efficiently regulating the cellular defenses protecting against the development of oxidative stress by directly scavenging ROS (Schafer and Buettner, 2001; Sies, 1999; Kohen and Nyska, 2003; Haddad, 2000, 2002a, 2002b; Hudson, 2001; Petroff et al., 2001). Cellular depletion of GSH has been shown to increase ROS formation, thereby resulting in enhanced cytokine secretion (Gossett et al., 1999). The generation of free radicals and subsequent oxidative stress are considered to be the central mechanisms involved in the development of a variety of skin disorders, such as photosensitivity and phototoxicity, photoaging, carcinogenesis, and cutaneous autoimmune diseases (Lopez-Torres et al., 1998; Halliwell and Cross, 1994; Nachbar and Korting, 1995).

Elevated ROS have been shown to induce lipid peroxidation, DNA mutations and damage, enzymatic activation or deactivation, protein oxidation and/or degradation found in animal and human tissues (Miyachi and Imamura, 1990; Shindo et al., 1994; Matsumoto et al., 1991; Chew et al., 1988; Record et al., 1991). To evaluate whether simulated solar light (SSL) induced oxidative stress and damage in the skin of SKH-1 hairless mice, we assessed: 1) accumulation of peroxidative products, changes in GSH, oxidation of protein thiols, vitamin E, and total antioxidant reserves, 2) DNA oxidative damage assessed by the formation of pyrimidine dimers, and 3) morphological alterations and inflammation evaluated by neutrophilic infiltration along with myeloperoxidase activity assayed in the skin of mice irradiated with SSL. 


\section{Materials and Methods}

\section{Chemicals}

Fatty acid-free human serum albumin (hSA), luminol, sodium dodecyl sulfate (SDS), thiobarbituric acid, trichloroacetic acid, glutathione, cetylmethylammonium bromide, guaiacol, 3-AT, thiobarbituric acid, tricholoracetic acid, ammonium formate, and orthophosphoric were purchased from Sigma Chemicals Co. (St. Louis, MO). Methanol, ethanol, hexane (HPLC grade), and water (HPLC grade) were purchased from Aldrich Chemical Co. (Milwaukee, WI). ThioGlo- $1^{\mathrm{TM}}$ was obtained from Covalent Inc. (Wobum, MA). 2,2'-azobis (2-amonodinopropane)-dihydrochloride (AAPH) was purchased from Wako Chemicals USA Inc. (Richmond, VA). 10\% neutral buffered formalin was purchased from Fisher Scientific (Pittsburgh, PA).

\section{Animal Exposures to Simulated Solar Light (SSL)}

Female SKH-1 hairless mice (8 weeks old) were exposed to SSL as described by Sams et al (2002). Briefly, animals were exposed to light emitted from a 6.5-kW xenon arc lamp (Atlas Electric Devices, Chicago, IL) filtered through a WG320 glass filter (Schott Glass Technologies, Durea, PA). Animals were exposed unrestrained in Lenderking cages to an average of $1.52 \times 10^{-5} \mathrm{~W} / \mathrm{cm}^{2} \mathrm{UVB}$ and $3.15 \times 10^{-4} \mathrm{UVA} \mathrm{W} / \mathrm{cm}^{2}$ for an average UVA:UVB ratio of 20.9:1. Mice ( $\mathrm{n}=6$ mice per group) were exposed to 13.7 $\mathrm{mJ} \cdot \mathrm{CIE} / \mathrm{cm}^{2} /$ day simulated solar light for 1 hour 5 days a week for 3 weeks.

\section{Skin Collections and Preparation of Homogenates}

Twenty-four hours following the last treatment, the mice were sacrificed. Skin flaps from the intrascapular area of the back of mouse were excised. Skin was taken for biochemical analysis and was immediately frozen at $-80^{\circ} \mathrm{C}$ until processed. The skin 
homogenates for biochemical assays were prepared from frozen tissues with ice-cold phosphate-buffered saline (PBS, 7.4) using a tissue tearer (model 985-370, Biospec Products, Inc., Racine, WI).

\section{Skin Preparation for Histopathological Evaluation}

Skin sections for histopathological evalutation were fixed in $10 \%$ neutral buffered formalin, and then embedded in paraffin. Skin sections were cut at 5-6 $\mu \mathrm{m}$, mounted on silanized slides, dewaxed in xylene, dehydrated through an ethanol series, and stained with hematoxylin and eosin. Photomicrographs were prepared using an Olympus 300 double-headed microscope (Japan).

\section{Fluorescence Assay for Low Molecular Weight Thiols and Protein Sulfhydryls}

Low molecular weight thiols and protein sulfhydryl concentration in skin homogenates was

determined using ThioGlo ${ }^{\mathrm{TM}}-1$, a maleimide reagent, which produces a highly fluorescent adduct upon its reaction with sulfhydryl groups (Shvedova et al., 2000). Low molecular weight thiol content was estimated by an immediate fluorescence response registered upon addition of ThioGlo ${ }^{\mathrm{TM}}-1$ to the skin homogenate. Protein sulfhydryls were determined as an additional increase in fluorescence response after addition of SDS (4 mM) to the same skin homogenate. A standard curve was established by addition of GSH $(0.04-4 \mu \mathrm{M})$ to $100 \mathrm{mM}$ disodium phosphate buffer ( $\mathrm{pH}$ 7.4) containing $10 \mu \mathrm{M}$ ThioGlo $^{\mathrm{TM}}-1$ (DMSO solution). A CytoFluor multiwell plate reader Series 4000 (Applied BioSystems, Foster City, CA) was employed for the assay of fluorescence using excitation at $360 / 40 \mathrm{~nm}$ and emission at 530/25 $\mathrm{nm}$ with a gain of 50 . The data obtained were exported and analyzed using CytoFluor Software (Applied BioSystems, Foster City, CA). 


\section{Chemiluminescence Measurements of Total Antioxidant Reserve}

A water-soluble azo-initiator, 2,2'-azobis (2-aminodinopropane)-dihydrochloride (AAPH), was used to produce peroxyl radicals (Niki, 1990). Oxidation of luminol by AAPH-derived peroxyl radicals was assayed by chemiluminescence in the presence of luminol. A delay in the chemiluminescence response produced by the interaction of endogenous antioxidants with AAPH-derived peroxyl radicals was observed upon addition of the skin homogenates. Based on the known rate of peroxyl radical generation by AAPH, the amount of peroxyl radicals scavenged by endogenous antioxidants was evaluated. The incubation medium contained $0.1 \mathrm{M}$ phosphate buffer $(\mathrm{pH} 7.4)$ at $37^{\circ} \mathrm{C}$, AAPH $(50 \mathrm{mM})$, and luminol $(0.4 \mathrm{mM})$. The reaction was started by the addition of AAPH. The luminescent analyzer 633 (Coral Biomedical, Inc., San Diego, CA) was employed for the determination.

\section{HPLC Assay of $\alpha$-Tocopherol}

$\alpha$-Tocopherol from skin homogenates was extracted using the procedure described by Lang et al. (1986). A Waters HPLC system with an HP ODS Hypersil column (5 $\mu \mathrm{m}, 200$ $\mathrm{mm} \times 4.6 \mathrm{~mm}$ ) was employed to measure $\alpha$-tocopherol (Waters Associates, Milford, MA). A Waters HPLC system with a 717 autosampler, Waters 600 controller pump and a 474 fluorescence detector was used. The wavelengths employed in the assay were 292 $\mathrm{nm}$ (excitation) and $324 \mathrm{~nm}$ (emission). Eluent was methyl alcohol $\left(\mathrm{CH}_{3} \mathrm{OH}\right)$ and the flow rate was $1 \mathrm{ml} / \mathrm{min}$. Under these conditions, the retention time for $\alpha$ - tocopherol was $8.5 \mathrm{~min}$. The data acquired were exported from the Waters 474 detector using Millennium 2000 software for further analysis (Waters Associates, Milford, MA). 


\section{Measurements of Peroxidative Products}

Accumulation of lipid peroxidation products reacting with 2-thiobarbituric acid (TBARS) in skin homogenates was measured spectophotometrically using a method described by Buege and Aust (1978). Skin homogenates containing $0.5 \mathrm{mg}$ of protein were mixed with $1 \mathrm{ml}$ of $0.67 \%$ thiobarbituric acid and $30 \%$ trichloroacetic acid (1:1). The samples were heated at $100^{\circ} \mathrm{C}$ for 20 minutes and then centrifuged for 15 minutes at $5,000 \mathrm{x} \mathrm{g}$. The absorbency of the supernatant was determined at $535 \mathrm{~nm}$ using a 2401-PC Shimadzu spectrophotometer (Kyoto, Japan) interfaced with a Dell OptiPlex GX 400 personal computer. A molar extinction of $1.56 \times 10^{5} \mathrm{M}^{-1} \mathrm{~cm}^{-1}$ was used for calculations.

\section{Measurement of Myeloperoxidase Activity (MPO)}

To measure changes in myeloperoxidase activity (MPO) in skin homogenates, a spectrophotometric assay was used (Nonaka et al., 1992). Skin homogenates were mixed with PBS (100 mM, pH 7.0) containing cetylmethylammonium bromide $(0.02 \%)$, guaiacol (13 mM), and 3-AT ( $3.75 \mathrm{mM})$. The reaction was started by the addition $\mathrm{H}_{2} \mathrm{O}_{2}$ $(0.6 \mathrm{mM})$. Oxidation of guaiacol was monitored by changes of absorbance at $470 \mathrm{~nm}(\varepsilon$ $=26.6 \mathrm{mM}^{-1} \mathrm{~cm}^{-1}$ ) using as Shimadzu UV 160U spectrometer (Kyoto, Japan). Activity of MPO was calculated and expressed as nmoles of tetraguaiacol per minute per mg of protein.

\section{Determination of Pyrimidine Dimer Formation}

Pyrimidine dimer formation was determined using a method adapted from $\mathrm{Xu}$ et al. (2000). Briefly, DNA was isolated as described by Bykov et al. (1998) and hydrolyzed to bases. ${ }^{32} \mathrm{P}$ was then attached to the ${ }^{5}$-position of the ribose using ${ }^{32} \mathrm{P}$-ATP and polynucleotide kinase. This results in ${ }^{32} \mathrm{P}$ labeling of the pyrimidine dimers. These 
labeled pyrimidine dimers are then detected by HPLC. Gradient elution with of buffer (0.5 M ammonium formate, $20 \mathrm{mM}$ orthophosphoric acid, $\mathrm{pH}$ 4.6) mixed with methanol was used to separate the photoproducts. The flow rate through the column (Luna C18 $2 \mathrm{X} 250 \mathrm{~mm} 5 \mu \mathrm{m}$ particle size; Phenomenex Torrance, CA) was $0.2 \mathrm{ml} / \mathrm{min}$.

\section{Protein Assay}

Measurements of protein in homogenates of tissue and cells were conducted using a BioRad protein assay kit, cat. \# 500-0006 (Richmond, CA).

\section{Statistics}

Data were expressed as the mean \pm standard error of the mean for each group. One-way ANOVA was employed to compare the responses between treatments. Statistical significance was set at $\mathrm{p}<0.05$.

\section{$\underline{\text { Results }}$}

\section{GSH and Protein Thiol Levels in Skin of Mice following Exposure to SSL}

In order to determine the cellular redox status of the skin following exposure to SSL, the level of cellular thiols were measured. Addition of Thio-Glo- $1^{\mathrm{TM}}$ to skin homogenates produces an instantaneous increase in fluorescence as a result of the formation of GSHThioGlo- $1^{\mathrm{TM}}$ reaction products. No change in the intensity of this response was observed unless SDS was added to the incubation system. Addition of SDS causes protein sulfhydryls groups to unfold and produces a slow increase in the observed fluorescence. The increasing fluorescence levels off 45-60 minutes following the addition of SDS. The latter fluorescence is a result of the interaction of protein sulfhydryls groups with ThioGlo-1 ${ }^{\mathrm{TM}}$ (Shvedova et al., 2000). As shown in Figure 4.1A, exposure to SSL caused a 
significant $24.6 \%(\mathrm{p}<0.05)$ reduction in the level of GSH as compared to controls. SSL exposure also caused a significant reduction $(\mathrm{p}<0.05)$ in the level of protein thiols found in the skin of SKH-1 hairless mice (Figure 4.1B).

\section{$\alpha$-Tocopherol Levels in the Skin of Mice Irradiated with SSL}

Measurements of the lipid-soluble antioxidant, $\alpha$-tocopherol, were assessed by HPLC. Assay of the skin homogenates revealed that exposure of SKH-1 mice to SSL caused a significant $26 \%$ decrease $(\mathrm{p}<0.05)$ in the level of $\alpha$-tocopherol as compared to those found in the skin of control mice (Figure 4.2).

\section{Total Antioxidant Reserve Levels in the Skin of Mice Exposed to SSL}

To assess changes in total antioxidant reserve in the skin of SKH-1 mice following SSL exposure a luminol-enhanced chemiluminescence assay was applied. A water-soluble azo-initiator, AAPH, was used to produce peroxyl radicals at a constant rate (Niki, 1990). Interaction of the peroxyl radicals generated by AAPH with luminol in phosphate buffer $\left(0.1 \mathrm{M}, \mathrm{pH} 7.4\right.$ at $\left.37^{\circ} \mathrm{C}\right)$ produced a characteristic luminol response (Figure 4.3, Inset). The addition of skin homogenate to the incubation system resulted in a lag period during which the chemiluminescence response was not observed. Skin homogenates from control animals produced a greater lag period than skin homogenates from the SSL irradiated mice. This lag period results because of the competition of endogenous skin antioxidants with luminol for the AAPH-derived peroxyl radicals (Kagan, 1998). We observed that total antioxidant reserve was significantly $(\mathrm{p}<0.05)$ decreased by $55.8 \%$ in skin of mice exposed to SSL as compared to controls (Figure 4.3). 


\section{Peroxidative Products in Skin of Mice Exposed to SSL}

Decreases in vitamin E levels are often accompanied by increases in lipid peroxidation. A significant increase in the level of lipid peroxidative products was observed following exposure to SSL. In particular, the skin of mice irradiated with SSL had $45.7 \%$ more accumulated lipid peroxidative products (TBARS) as compared to control animals (Figure 4.4).

\section{Pyrimidine Dimers Formed as a Result of SSL Exposure}

The formation of pyrimidine dimers was used to determine DNA oxidative damage after SSL exposure. We found that exposure to SSL resulted in the formation of DNA pyrimidine dimers $(92 \mathrm{pg} / \mu \mathrm{g})$ while no pyrimidine dimers were detected in the skin of control animals (Figure 4.5).

\section{Histological Evaluation of Murine Skin Following Exposure to SSL}

Examination of SKH-1 mouse skin following exposure to SSL revealed an increase in skin thickness as a result of SSL exposure (Figure 4.6). SSL irradiation also induced the recruitment and infiltration of inflammatory cells, particularly neutrophils, (Figure 4.6B) that were not seen in control skin (Figure 4.6A).

\section{Myeloperoxidase Activity in Skin of Mice Exposed to SSL}

Myeloperoxidase activity was used to quantitatively assess the inflammatory neutrophilic response in the skin of SKH-1 mice after exposure to SSL. We found a significant increase $(194.5 \% ; \mathrm{p}<0.05)$ in myeloperoxidase activity observed in the skin of SKH-1 mice post-treatment with SSL as compared to the control group (Figure 4.6C). 


\section{$\underline{\text { Discussion }}$}

Excessive exposure to ultraviolet light can cause both acute and chronic skin damage (Miyachi, 1987). Acute dermal exposure to ultraviolet light has a variety of side effects known as erythema, inflammation, and/or sunburn while chronic UV exposure can cause pigmentary changes, premature photoaging, and an increased risk for the formation of cutaneous melanoma and nonmelanoma skin cancer (Fuchs and Kern, 1998; Kligman and Kligman, 1986; Longstreth et al., 1998). The combination of UVA (315-400 nm) and UVB (280-315nm) exposure has previously been shown to directly cause DNA damage, increased generation of free radicals, and induce the expression and release of inflammatory mediators (Herrling et al., 2003).

Measurable edema dose $\left(\mathrm{MED}^{\text {biol }}\right)$ is the dose of SSL causing a significant increase in skin-fold thickness of exposed mice. The dose we used in this study (13.7 $\mathrm{mJ} \cdot \mathrm{CIE} / \mathrm{cm}^{2} /$ day $)$ was below the irradiation level $\left(0.2 \mathrm{MED}^{\text {biol }} /\right.$ day $)$ with no appearance of edema in naïve SKH-1 mice (Sams II et al., 2002). Treatment of mice with a suberythemal dose of UV light has been shown to cause a thickening of the epidermis (Berton et al., 1996; Sams II et al., 2002). The observed thickening of the epidermis is an adaptive skin response to UV light (Sams et al., 2002). Sams et al. (2002) found that exposure of SKH-1 mice with a similar dose range of SSL $\left(14 \mathrm{~mJ} \cdot \mathrm{CIE} / \mathrm{cm}^{2} / \mathrm{day}, 5\right.$ days/week for 6 weeks) caused a significant increase in the dose of SSL required to induce edema $\left(90 \mathrm{~mJ}\right.$ to $\left.180 \mathrm{~mJ} \cdot \mathrm{CIE} / \mathrm{cm}^{2}\right)$. In our study, when $\mathrm{SKH}-1$ mice were exposed to SSL (1 hour, 5 days a week for 3 weeks; 20.9:1 UVA: UVB), we also observed an increase in skin thickness as a result of UV exposure. This increase in skin thickness was 
accompanied by neutrophil recruitment into the dermal tissue as well as an increase in myeloperoxidase activity.

It has been previously shown that exposure of dermal tissue ex vivo or in vivo to UV light resulted in the generation of free radicals (Black, 1987; Darr and Fridovich, 1994; Jurkiewicz and Buettner, 1994). UV light has been found to produce ESR detectable lipid-derived free radicals in intact skin (Jurkiewicz and Buettner, 1994). The presence and formation of ROS is able to damage biomolecules (Kvam and Dhale, 2003) during cellular oxidative stress (Darr and Fridovich, 1994). It has also been demonstrated that UV light-induced ROS were also able to cause structural and functional alterations in cutaneous proteins, e.g. collagen, elastin and glycosaminoglycans, probably contributing to dermal phototoxicity and photoaging of the skin (Carbonare and Pathak, 1992).

It is interesting to note that vitamin E, a well known potent lipid soluble antioxidant, has been shown to be able to generate free radicals after UV light exposure in the skin. Kagan et al. (1992) found that $\alpha$-tocopheroxyl radicals are capable of being generated directly by solar UV light. This formation of the $\alpha$-tocopheroxyl radicals along with other ROS formed by UV light were subsequently reduced by GSH and ascorbate which donate a hydrogen atom to recycle $\alpha$-tocopheroxyl radicals back to $\alpha$-tocopherol.

The complex antioxidant network present within the skin is able to prevent UV damage induced by ROS (Catani et al., 2001). The overproduction of ROS either directly by UVR or via vitamin E oxidation is able to overwhelm the total antioxidant capacity of the 
skin thereby resulting in oxidative stress. The synergistic GSH and ascorbate-dependent recycling of vitamin E (Packer, 1991; Martensson et al., 1991; Kagan and Packer, 1994; Guo and Packer, 2000; Shvedova et al., 2000; Shvedova et al., 2001) results in the depletion of low molecular weight antioxidants of the skin. We observed that exposure to SSL induced oxidative stress evaluated by decreases in GSH, vitamin E, and total antioxidant reserves, and caused the accumulation of peroxidative products found in the skin of SKH-1 mice. This decrease in antioxidant capabilities in the skin promotes ROSdependent oxidative protein damage, DNA modification, and lipid peroxidation, and also contributes to the release of inflammatory mediators (Catani et al., 2001). The compromise of antioxidant capabilities, particularly depletion of vitamin $\mathrm{E}$ in the tissue also affects the skin's susceptiblity to lipid peroxidation as has been observed after exposure to other chemicals and mixtures (metal working fluid) (Shvedova et al., 2002a, b).

DNA is able to directly absorb light within the UVB and UVC regions of the spectra (245-290 nm). The outer layers of the skin prevent UVC from reaching the proliferating cells in the epidermis; however, UVB is capable being absorbed by DNA thus causing damage directly. The UVA and UVB components of solar radiation have also been shown to be able to interact with endogenous skin compounds, e.g. $\alpha$-tocopherol, present within the skin and produce ROS which are capable of damaging DNA via oxidation (Ahmed, 1999; Berneburg et al., 1999; Kvam and Tyrrell, 1997). Cyclobutane pyrimidine dimers are the most common form of UV-induced DNA base damage that occurs between C-4 and C-5 carbons of adjacent thymine or cytosine residues. In our 
study, we observed a significant increase in the formation of pyrimidine dimers that probably results from the direct interaction of SSL and DNA.

Short-term exposure to low-dose SSL has been shown to result in the formation of ROS (Black, 1987; Darr and Fridovich, 1994; Jurkiewicz and Buettner, 1994). ROS-induced depletion of antioxidants, and lipid peroxidation which subsequently trigger skin inflammation. We have also demonstrated that SSL affects antioxidant balance, caused the accumulation of lipid peroxidative products, oxidized DNA and triggered dermal inflammation. The data support the hypothesis that oxidative stress is an important mechanism for UV light-induced skin injury found even during relatively short-term UVR. The combination of DNA modifications along with chronic inflammation found due to not only short but long-term SSL exposure could contribute to dermal toxicity potentially leading to the initiation, promotion, and progression of skin cancer. 


\section{Figures}
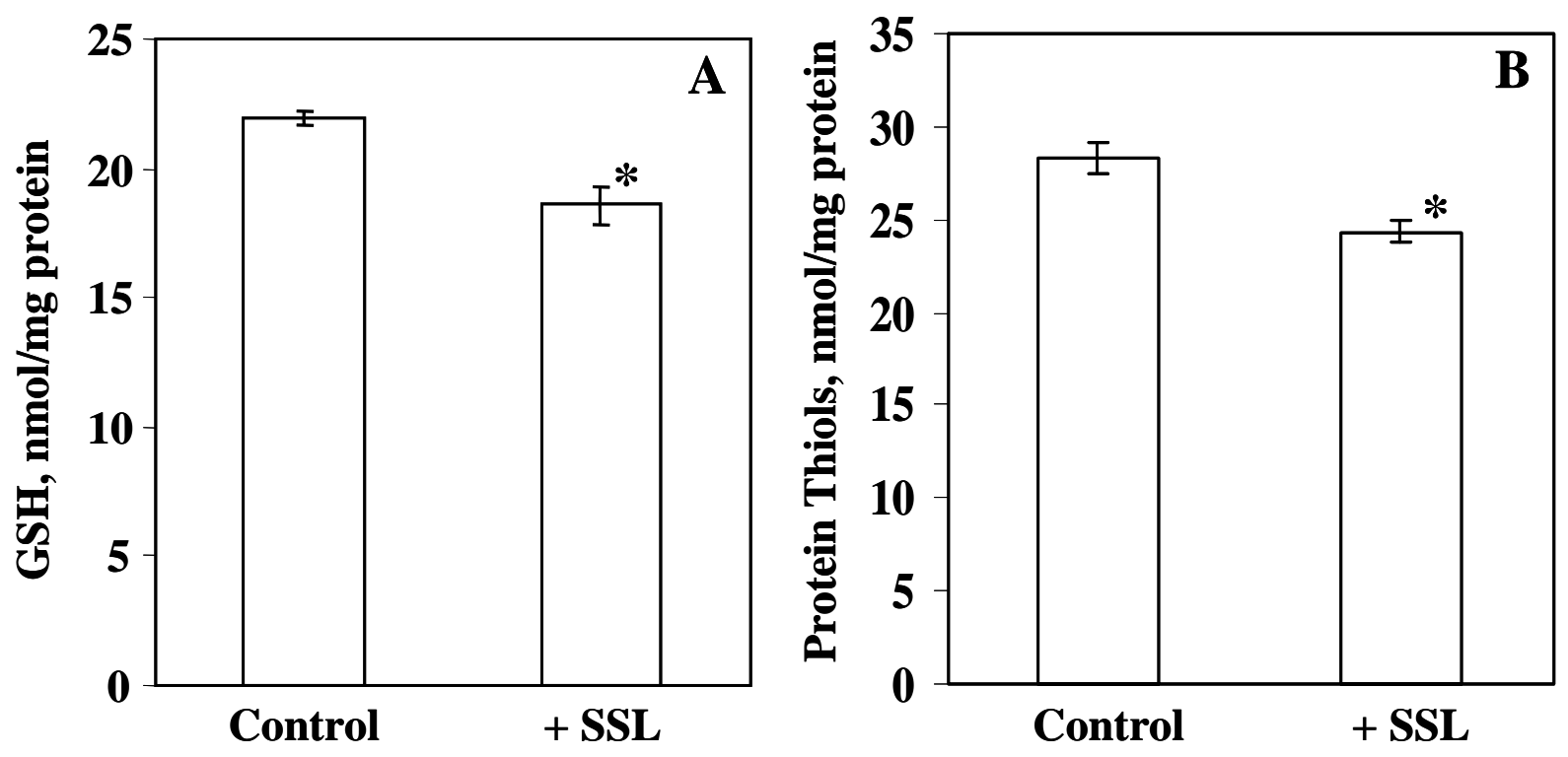

Figure 4.1. Effects of simulated solar light on the levels of glutathione (A) and protein thiols (B) in skin homogenates of SKH-1 mice. Animals were exposed to SSL (13.7 $\mathrm{mJ} \cdot \mathrm{CIE} / \mathrm{cm}^{2} /$ day) for 1 hour, 5 days a week for 3 weeks. Values are means \pm SEM of 3 experiments. ${ }^{*} \mathrm{p}<0.05$ vs control mice. 


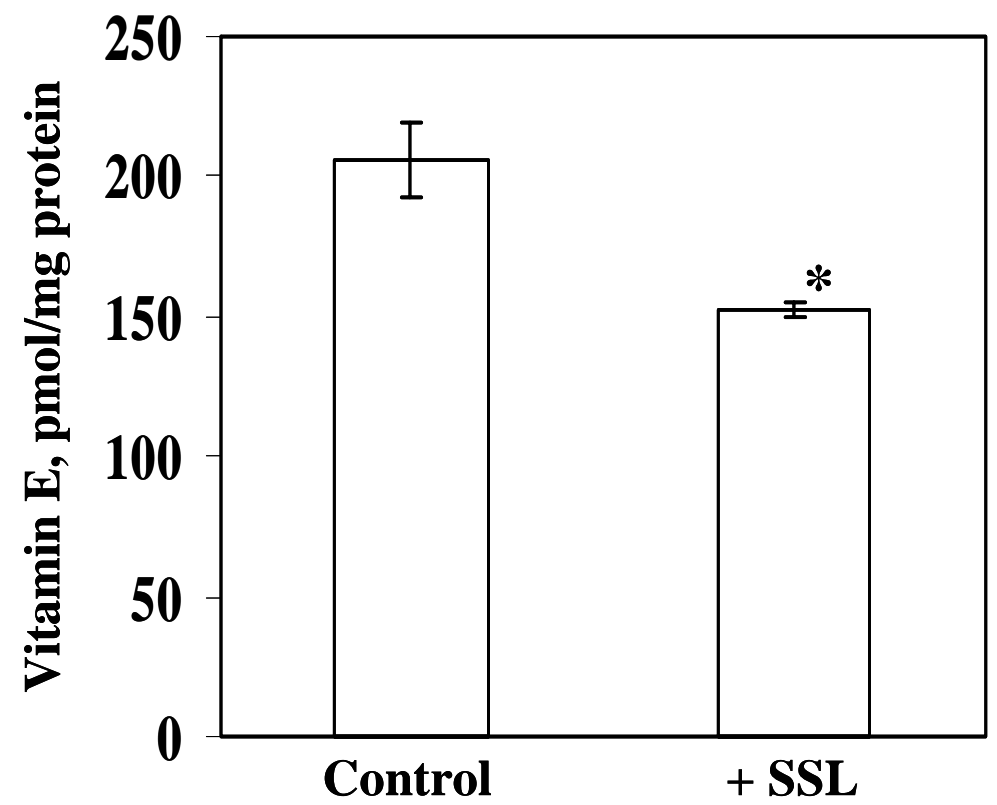

Figure 4.2. Effects of simulated solar light on the level of vitamin $\mathrm{E}$ in skin homogenates of SKH-1 mice. SKH-1 hairless mice, animals were exposed to SSL (13.7 $\mathrm{mJ} \cdot \mathrm{CIE} / \mathrm{cm}^{2} /$ day; 1 hour, 5 days a week for 3 weeks). Values are means $\pm \mathrm{SEM}$ of 3 experiments. ${ }^{*} \mathrm{p}<0.05$ vs control mice.

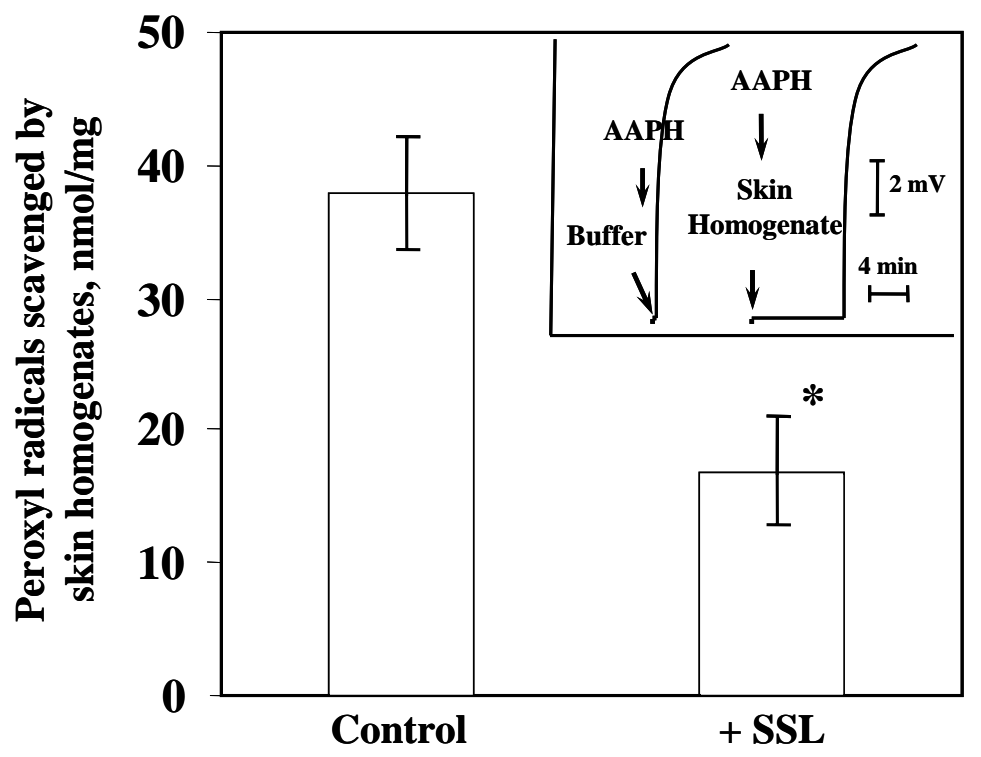

Figure 4.3. Total antioxidant reserve in skin homogenates of SKH-1 mice exposed to simulated solar light. SKH-1 hairless mice, animals were exposed to SSL (13.7 $\mathrm{mJ} \cdot \mathrm{CIE} / \mathrm{cm}^{2} /$ day; 1 hour, 5 days a week for 3 weeks).Values are means $\pm \mathrm{SEM}$ of 3 experiments. ${ }^{*} \mathrm{p}<0.05$ vs control mice. Inset- Characteristic chemiluminscence response generated by AAPH with luminol in the presence and in the absence of skin homogenates. The inset is the original recording showing the measurements of total antioxidant reserve of the skin homogenates. In the presence of AAPH-derived peroxyl radicals, luminol is oxidized and produces a chemiluminescence response. 


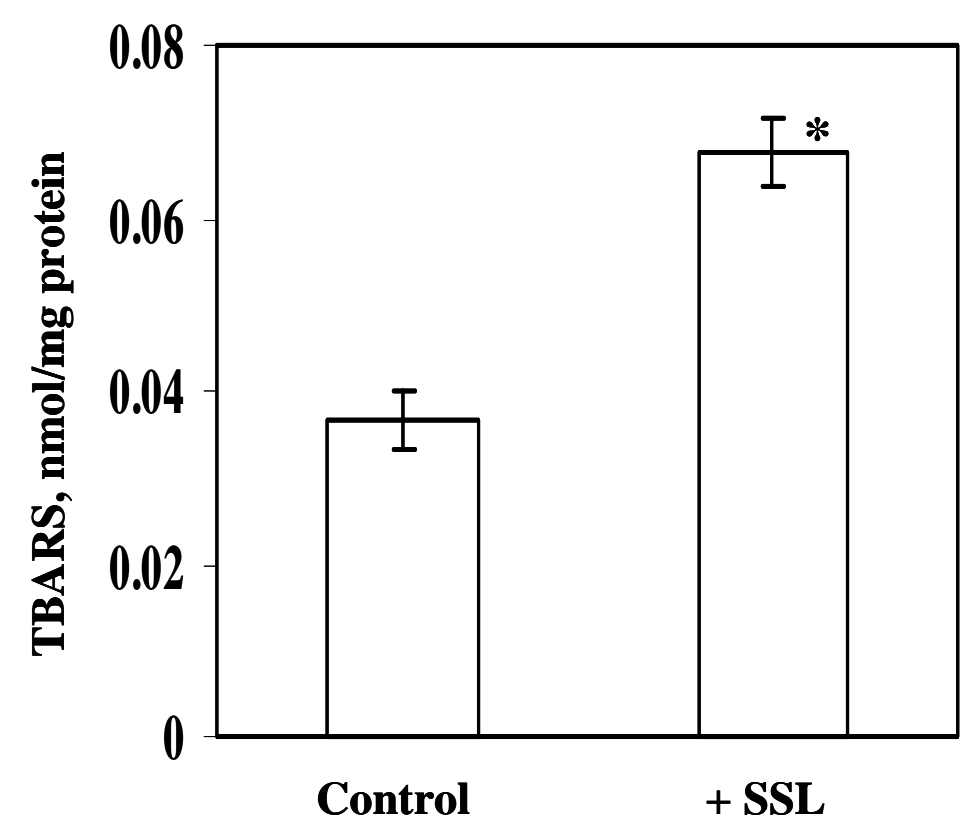

Figure 4.4. Accumulation of lipid peroxidation products in skin homogenates of SKH-1 mice exposed to SSL. SKH-1 hairless mice, animals were exposed to SSL (13.7 $\mathrm{mJ} \cdot \mathrm{CIE} / \mathrm{cm}^{2} /$ day; 1 hour, 5 days a week for 3 weeks).Values are means $\pm \mathrm{SEM}$ of 3 experiments. ${ }^{*} \mathrm{p}<0.05$ vs control mice.

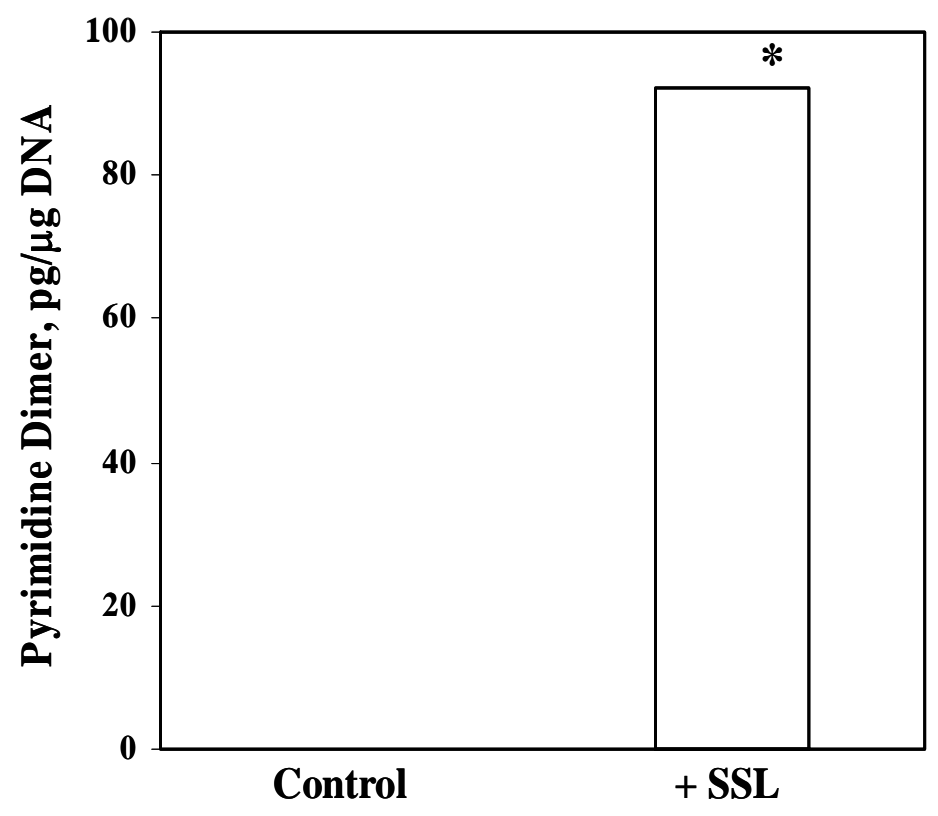

Figure 4.5. Pyrimidine dimer formation in the skin of SKH-1 mice after exposure to SSL. SKH-1 hairless mice, animals were exposed to SSL $\left(13.7 \mathrm{~mJ} \cdot \mathrm{CIE} / \mathrm{cm}^{2} /\right.$ day; 1 hour, 5 days a week for 3 weeks). Values are means \pm SEM of 3 experiments. ${ }^{*} \mathrm{p}<0.05$ vs control mice. 

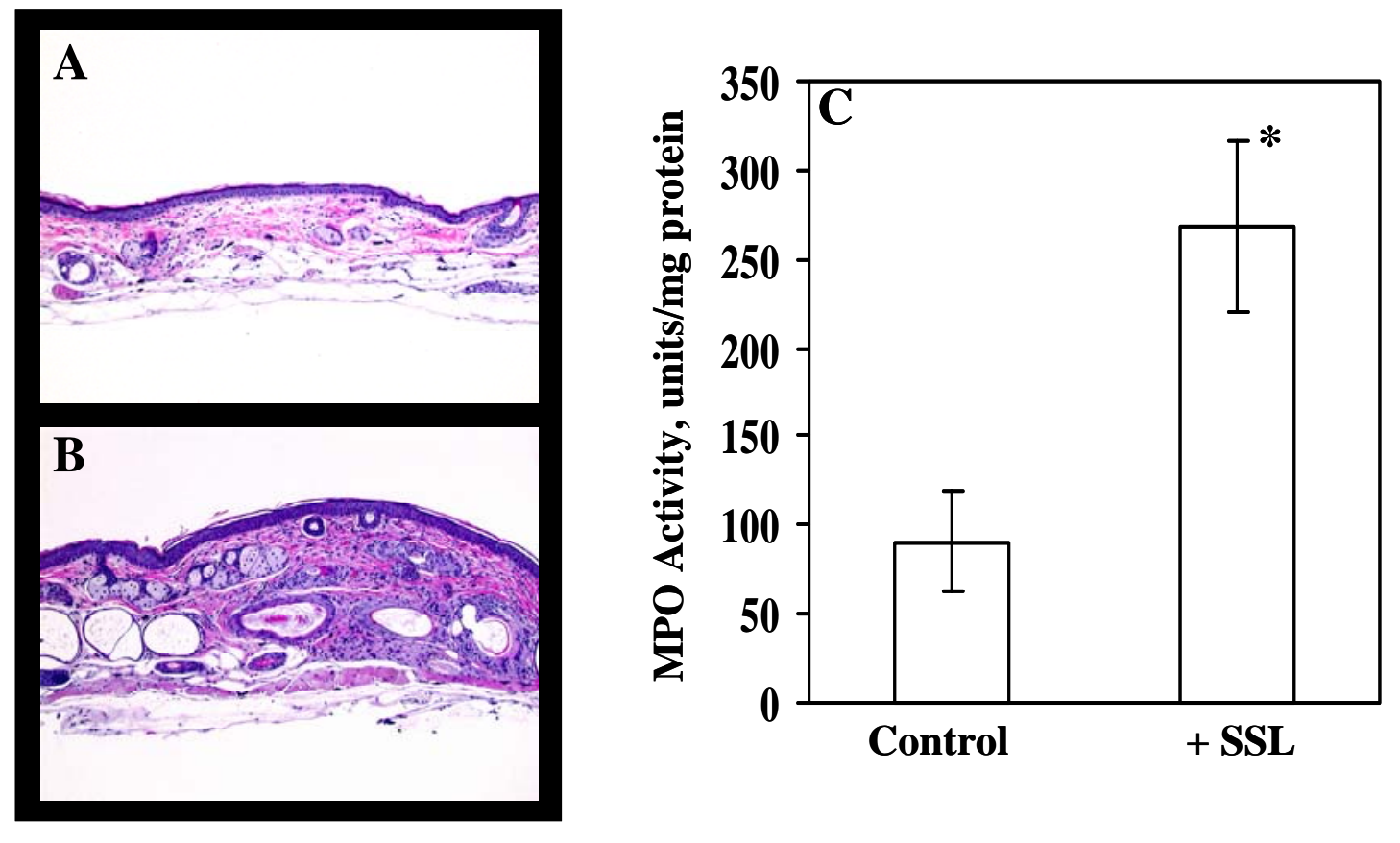

Figure 4.6. (A, B). Photomicrographs of skin of SKH-1 mice after exposure to SSL: A. Control; B. SSL. (C). Myeloperoxidase activity in skin homogenates of SKH-1 mice exposed to simulated solar light. SKH-1 hairless mice, animals were exposed to SSL $\left(13.7 \mathrm{~mJ} \cdot \mathrm{CIE} / \mathrm{cm}^{2} /\right.$ day) for 1 hour, 5 days a week for 3 weeks. Values are means \pm SEM of 3 experiments. ${ }^{*} \mathrm{p}<0.05$ vs control mice. 


\section{References}

Ahmed, N. U., Ueda, M., Nikaido, O., Osawa, T., and Ichihashi, M. 1999. High levels of 8-hydroxy-2'-deoxyguanosine appear in normal human epidermis after a single dose of UV radiation. Br J Dermatol. 140: 226-31.

Alder, V., Yin, Z., Tew, K. D., and Ronai, Z. 1999. Role of redox potential and reactive oxygen species in stress signaling. Oncogene. 18: 6104-6111.

Beckman, K. B., and Ames, B. N. 1998. The free radical theory of aging matures. Physiol Rev. 78: 547-581.

Berneburg, M., Grether-Beck, S., Kurten, V., Ruzika, T., Briviba K., Sies, H., and Krutman, J. 1999. Singlet oxygen mediates the UV-induced generation of the photoaging-associated mitochondrial common deletion. J Biol Chem. 274: 15345-9.

Berton, T. R., Fischer, S. M., Conti, C. J., and Locniskar, M. F. 1996. Comparison of ultraviolet light-induced ornithine decarboxylase activity in SENCAR and hairless SKH1 mice fed a constant level of dietary lipid varying in corn and coconut oil. Nutr Cancer. 26: 353-363.

Black, H. S. 1987. Potential involvement of free radical reactions in ultraviolet lightmediated cutaneous damage. Photochemistry and Photobiology. 46: 213-221.

Buege, J. A., and Aust, S. D. 1978. Microsomal lipid peroxidation. Methods Enzymol. 52: 302-10.

Bykov, B. J., Jansen, C. T., and Hemminki, K. 1998. High levels of pyrimidine dimers are induced in human skin by solar-stimulating UV radiation. Cancer Epidemiol Biomarkers Prev. 7:199-202.

Catani, M.V., Rossi, A., Costanzo, A., Sabatini, S., Levrero, M., Melino, G., and Avigliano, L. 2001. Induction of gene expression via activator protein-1 in the ascorbate protection against UV-induced damage. Biochem J. 356: 77-85.

Carbonare, M. D., and Pathak, M. A. 1992. Skin photosensitizing agents and the role of reactive oxygen species in photoaging. J Photochem Photobiol B Biol. 14: 105-124.

Chew, S., DeLeo, V. A., and Harber, L. C. 1988. Longwave UV radiation (UVA)induced alteration of epidermal DNA synthesis. J Photochem Photobiol B Biol. 47: $383-90.1$

Darr, D., and Fridovich, I. 1994. Free radicals in cutaneous biology. J Invest Dermatol. 102: 671-675. 
Effendy, I., Loffler, H., and Maibach, H. I. 2000. Epidermal cytokines in murine cutaneous irritant responses. J Appl Toxicol. 20(4): 335-41.

Fuchs, J., and Kern, H. 1998. Modulation of UV-light-induced skin inflammation by Dalpha-tocopherol and L-ascorbic acid: a clinical study using solar simulated radiation. Free Radic Biol Med. 25: 1006-12.

Gosset, P., Wallaert, B., Tonnel, A. B., and Fourneau, C. 1999. Thiol regulation of the production of TNF- $\alpha$, IL-6, and IL-8 by human alveolar macrophages. Eur Respir J. 14: 98-105.

Guo, Q., and Packer, L. 2000. Ascorbate-dependent recycling of the vitamin E homologue Trolox by dihyrolipoate and glutathione in murine skin homogenates. Free Radical Biol Med. 29: 368-374.

Haddad, J. J. 2000. Glutathione depletion is associated with augmenting a proinflammatory signal: evidence for an antioxidant/pro-oxidant mechanism regulating cytokines in the alveolar epithelium. Cytokine Cell Mol Ther. 6:177-87.

Haddad, J. J. 2002. Science review: redox and oxygen-sensitive transcription factors in the regulation of oxidant-mediated lung injury: role for nuclear factor-kappa B. Crit Care. 6(6): 481-90.

Haddad, J. J. 2002. Antioxidant and prooxidant mechanisms in the regulation of redox(y)-sensitive transcription factors. Cell Signal. 14(11): 879-97.

Halliwell, B., and Cross, C. E. 1994. Oxygen-derived species: their relationship to human disease and environmental stress. Environ Health Perspect. 102 (Suppl 10): 512 .

Herrling, T., Fuchs, J., Rehberg, J., and Groth, N. 2003. UV-induced free radicals in the skin detected by ESR spectroscopy and imaging using nitroxides. Free Rad Biol Med. 35: 59-67

Hudson, V. M. 2001. Rethinking cystic fibrosis pathology: the critical role of abnormal reduced glutathione (GSH) transport caused by CFTR mutation. Free Radic Biol Med. 30:1440-61.

Jurkiewicz, B. A., and Buettner, G. R. 1994. Ultraviolet light-induced free radical formation in skin: an electron paramagnetic resonance study. Photochem Photobiol. 59: $1-4$.

Kagan, V., Witt, E., and Goldman, R. 1992. Ultraviolet light-induced generation of vitamin $\mathrm{E}$ radicals and their recycling. A possible photosensitizing effect of vitamin $\mathrm{E}$ in skin. Free Rad Res Comm. 16: 51-64. 
Kagan, V. E., and Packer, L. 1994. Light-induced generation of vitamin E radicals: assessing vitamin E regeneration. Methods Enzymol. 234: 316-320.

Kligman, L. H., and Kligman, A. M. 1986. The nature of photoaging: its prevention and repair. Photodermatology. 3: 215-227.

Kohen, R., and Nyska, A. 2003. Oxidation of biological systems: oxidative stress phenomena, antioxidants, redox reactions, and methods for their quantification. Toxicol Pathol. 30(6): 620-50.

Kvam, E., and Dhale, J. 2003. Pigmented melanocytes are protected against ultravioletA-induced membrane damage. J Invest Dermatol. 121: 564-569.

Kvam, E., and Tyrrell, R. M. 1997. Induction of oxidative DNA base damage in human skin cells by UV and near visible radiation. Carcinogenesis. 18: 2379-84.

Lang, J.K., Gohil, K., and Packer, L. 1986. Simultaneous determination of tocopherols, ubiquinols, and ubiquinones in blood, plasma, tissue homogenates, and subcellular fractions. Anal Biochem. 157:106-16.

Longstreth, J., de Gruijl, F. R., Kripke, M. L., Abseck, S., Arnold, F., Slaper, H. I., Velders, G., Takizawa, Y., and van der Leun, J. C. 1998. Health Risks. J Photochem Photobiol B. 46: 20-39.

Lopez-Torres, M., Thiele, J. J., Shindo, Y., Han, D., and Packer, L. 1998. Topical application of a-tocopherol modulates the antioxidant network and diminishes ultravioletinduced oxidative damage in murine skin. Br J Dermatol. 138: 207-15.

Martensson, J., Meister, A., and Martensson, J. 1991. Glutathione deficiency decreases tissue ascorbate levels in newborn rats: ascorbate spares glutathione and protects. ProC Natl Acad Sci USA. 88: 4656-4660.

Matsumoto, K., Sugiyama, M., and Ogura, R. 1991. Non-dimer DNA damage in Chinese hamster V-79 cells exposed to ultraviolet-B light. J Photochem Photobiol B Biol. 54: 389-92.

Miyachi, Y. 1987. Reactive oxygen species in photodermatology. The Biological Role of Reactive Oxygen Species in Skin, pp. 37-41. New York: Elsevier Science.

Miyachi, Y., and Imamura, S. 1990. Photo-oxidative skin damage and antioxidants. Photodermal Photoimmunol Photomed. 7: 49-50.

Nachbar, F., and Korting, H. C. 1995. The role of vitamin E in normal and damaged skin. J Mol Med. 73(1): 7-17. 
Niki, E. 1990. Free radical initiators as a source of water- or lipid-soluble peroxyl radicals. Methods Enzymol. 186: 100-108.

Nonaka, T., Mio, M., Doi, M., and Tasaka, K. 1992. Histamine-induced differentiation of HL-60 cells. The role of cAMP and protein kinase A. Biochem Pharmacol. 11151121.

Packer, L. 1991. Protective role of vitamin E in biological systems. Am J Clin Nutr. 53: 1050S-1055S.

Petroff, M. G., Petroff, B. K., and Pate, J. L. 2001. Mechanisms of cytokine-induced death of cultured bovine luteal cells. Reproduction. 121:753-60.

Record, I. R., Dreosti, I. E., Konstantinopoulos, M., and Buckley, R. A. 1991. The influence of topical and systemic vitamin $\mathrm{E}$ on ultraviolet light-induced skin damage in hairless mice. Nutr Cancer. 16: 219-26.

Sams II, R. L., Couch, L. H., Miller, B. J., Okerberg, C. V., Warbritton, A. R., Wamer, W. G., Beer, J. Z., and Howard, P. C. 2002. Effects of a- and b-hydroxy acids in the edemal response induced in female SKH-1 mice by simulated solar light. Tox Appl Pharmacol. 184: 136-43.

Schafer, F. Q., and Buettner, G. R. 2001. Redox environment of the cell as viewed through the redox state of the glutathione disulfide/glutathione couple. Free Radic Biol Med. 30: 1191-212.

Shindo, Y., Witt, E., Han, D., and Packer, L. 1994. Dose-response effects of acute ultraviolet irradiation on antioxidants and molecular markers of oxidation in murine epidermis and dermis. J Invest Dermatol. 102: 470-5.

Shvedova, A. A., Kommineni, C., Jeffries, B. A., Castranova, V., Tyurina, Y. Y., Tyurin, V. A., Serbinova, E. A., Fabisiak, J. P., and Kagan, V. E. 2000. Redox cycling of phenol induces oxidative stress in human epidermal keratinocytes. J Invest Dermatol. 114: 354364.

Shvedova, A. A., Tyurina, Y. Y., Tyurin, V. A., Kikuchi, Y., Kagan, V. E., and Quinn, P. J. 2001. Quantitative analysis of phospholipid peroxidation and antioxidant protection in live human epidermal keratinocytes. Biosci Rep. 21: 33-43.

Shvedova, A. A., Kisin, E., Murray, A., Smith, C., Castranova, V., and Kommineni, C. 2002. Enhanced oxidative stress in the skin of vitamin $\mathrm{E}$ deficient mice exposed to semisynthetic metal working fluids. Toxicology 176(1-2): 135-43. 
Shvedova, A.A., Kisin, E.R., Murray, A.R., Kommineni, C., Castranova, V., Mason, R.P., Kadiiska, M.B., and Gunther, M.R. 2002. Antioxidant balance and free radical generation in vitamin e-deficient mice after dermal exposure to cumene hydroperoxide. Chem Res Toxicol 15(11): 1451-9.

Sies, H. 1999. Glutathione and its role in cellular function. Free Radic Biol Med. 27: 916-21.

Trouba, K. J., Hamadeh, H. K., Amin, R. P., and Germolec, D. R. 2002. Oxidative stress and its role in skin disease. Antioxid Redox Signal. 4(4): 665-73.

Xu, G., Snellman, E., Bykov, V. J., Jansen, C. T., and Hemminki, K. 2000. Cutaneous melanoma patients have normal repair kinetics of ultraviolet-induced DNA repair in skin in situ. J Invest Dermatol. 114: 628-631. 


\section{GENERAL DISCUSSION}

A growing body of evidence suggests that exposure to a number of occupational and environmental toxicants causes oxidative stress leading to short or long-term antioxidant deficiency and cellular dysfunction. Antioxidants, including vitamin E, vitamin $\mathrm{C}$, and glutathione, are among the body's natural defense mechanisms against oxidative stress. The skin is recognized as a barrier to limit the penetration and absorption of biological, chemical and physical agents into the body. The skin is considered a primary target and route of entry for environmental and occupational insults. The skin cells may create an oxidative environment, depending on predominance of redox processes catalyzed by both enzymatic and non-enzymatic systems. Exposure to chemical and environmental factors is capable of causing dermal toxicity. It is believed that these chemical and environmental stressors work through a similar peroxidative mechanism by which they are able to exert their toxic outcomes. Following exposure, the overproduction of free radicals could result in the development of antioxidant imbalance and oxidative stress, skin inflammation and injury eventually leading to DNA, protein, and lipid damage affecting the skin's integrity and in some cases serving as a hallmark of carcinogenesis.

Physical and chemical insults of importance in occupational and environmental exposures, e.g. UVR, Cum-OOH and $\mathrm{PhOH}$, have been shown to induce dermal toxicity. Exposure of skin to UVR has been reported to induce the generation of lipid-derived free radicals ex vivo and in vivo (Black, 1987; Darr and Fridovich, 1994; Jurkiewicz and Buettner, 1994). UV light exposure has also been shown to readily and easily oxidize 
vitamin $\mathrm{E}$ to form $\alpha$-tocopheroxyl radicals (Kagan et al., 1992) thus contributing to antioxidant deficiency and oxidative skin damage.

Previous published work has shown that exposure to $\mathrm{Cum}-\mathrm{OOH}$ results in the formation of lipid-derived free radicals in vitro in murine keratinocytes and skin flaps and skin in vivo. Murine keratinocytes and skin flaps exposed to $\mathrm{Cum}-\mathrm{OOH}$ in vitro form metalcatalyzed alkoxyl, alkyl, and aryl radicals (Taffe et al., 1987; Timmins and Davies, 1993). We have demonstrated that topical exposure to $\mathrm{Cum}-\mathrm{OOH}$ induced the formation of two radical species identified as methyl and methoxyl radical adducts detected in the skin. The observed radical production in skin was clearly validated to occur due to the metabolic oxidation of Cum-OOH. Depletion of vitamin E in skin via alimentary deprivation increased the radical production showing the importance of $\alpha$-tocopherol in quenching the Cum-OOH-induced radical formation (Murray et al., 2005).

$\mathrm{PhOH}$ exposure has been shown to easily contact and penetrate the skin. Through the skin, it is able to enter the body and exert not only dermal effects but also systemic toxicity. One proposed mechanism of $\mathrm{PhOH}$ toxicity is via a "futile thiol pumping" pathway. Phenol and phenolic compounds are able to undergo one-electron oxidation to yield phenoxyl radicals. This reaction is hypothesized to be catalyzed by the oxidative enzymes: peroxidase, prostaglandin synthetase, and tyrosinase present in the skin (Einstein et al., 1992). Phenoxyl radicals derived by oxidative metabolism are reduced by thiols thereby regenerating $\mathrm{PhOH}$. As a result, $\mathrm{PhOH}$ is able to undergo repeated one electron oxidation. Thiols, e.g. GSH, ameliorated the formation of phenoxyl radicals 
which consequently yielded the formation of a thiyl radical. These thiyl radicals are subsequently able to interact with other thiol groups and/or oxygen to initiate new oxidative cascades to form new ROS (Stoyanovsky et al., 1995).

It has been known that an important function of GSH lies in its antioxidant properties that are able to detoxify highly reactive peroxides via the conjugation of electrophiles and metals (Coles and Kadlubar, 2003; Fujii et al., 2003; Miyamoto et al., 2003; Zelck and Von Janowsky, 2004). Therefore, reduction in GSH content in cutaneous cells and tissues make the skin vulnerable to oxidative injury. The results of our study revealed that $\mathrm{PhOH}$ exposure to skin caused enhanced radical generation due to glutathione depletion with BSO or BCNU. The data provide evidence of the importance of GSH in the skin's antioxidant defense system against phenol-induced damage oxygen radicals formed during the oxidative metabolism of phenols.

Presented data demonstrated that $\mathrm{PhOH}$ exposure to skin resulted in the formation of carbon-centered radical adducts derived from the skin lipids of topically exposed mice. The presence of the detected radicals was amplified when the skin environment was weakened as a result of depletion of GSH prior to $\mathrm{PhOH}$ exposure. Computer simulation of the detected radical adducts revealed the presence of 2 radical species found in $\mathrm{BCNU} / \mathrm{PhOH}$ and $\mathrm{BSO} / \mathrm{PhOH}$ exposed mice. Carbon-centered lipid radical adducts, i.e. methyl radicals, were the major radicals present in both $\mathrm{BCNU} / \mathrm{PhOH}$ and $\mathrm{BSO} / \mathrm{PhOH}$ exposed mice. BCNU/PhOH-exposed mice also had an ESR-detectable oxygen-centered lipid radical adducts, i.e. lipoxyl radicals; while $\mathrm{BSO} / \mathrm{PhOH}$-exposed animals had an 
ascorbyl radicals present in the ESR spectra. The difference found in radical formation after $\mathrm{BSO} / \mathrm{PhOH}$ and $\mathrm{BCNU} / \mathrm{PhOH}$ treatements is most likely due to the transfer of the oxygen-centered radical present in the lipids to the aqueous phase where the latter is able to oxidize ascorbate yielding the formation of a detected ascorbyl radicals after $\mathrm{BSO} / \mathrm{PhOH}$ exposure.

A complex antioxidant system is present in skin and is imperative for the prevention of free radical-induced skin injury (Catani et al., 2001). Overproduction of ROS formed either directly after chemical exposures, or via vitamin E oxidation in the case of UVR, and/or from infiltrating inflammatory cells that are able to exhaust the antioxidant capacity of the skin causing oxidative stress and skin injury. The synergistic GSH and ascorbate-dependent recycling of vitamin E (Packer, 1991; Martensson et al., 1991; Kagan and Packer, 1994; Guo and Packer, 2000; Shvedova et al., 2000; Shvedova et al., 2001) consumes both GSH and ascorbate thereby affecting total antioxidant capacity thus making the skin vulnerable to occupational and environmental stressors. Exposure of murine skin to SSL, Cum-OOH, and $\mathrm{PhOH}$ resulted in a significant depletion of $\mathrm{GSH}$, vitamin $\mathrm{E}$, and total antioxidant reserve throughout these exposures. A decrease in vitamin E levels, the major lipid-soluble antioxidant, also increases the skin's susceptibility to lipid peroxidation. As a result, accumulation of lipid peroxidative products occurred in the skin of mice following exposure to SSL and Cum-OOH (Murray et al., 2005). 
This imbalance in the antioxidant status of the skin tissue could trigger enhanced generation of ROS which is able to trigger oxidative damage to proteins, DNA, and lipids (Selassie et al., 1998). ROS overproduction and antioxidant imbalance are known to cause DNA modifications and damage. Under normal conditions, altered DNA is repaired by DNA glycosylase; however, overproduction of ROS and the resulting oxidative stress have been shown to circumvent DNA repair by glycosylases inducing mutagenesis and carcinogenesis (Chung et al., 1991). DNA damage is able occur as a result of direct absorbtion of UVB radiation as well as mediated by ROS generation and interaction with DNA (Floyd, 1982; Sultana et al., 1995; Ahmed, 1999; Berneburg et al., 1999; Kvam and Tyrell, 1997). Cyclobutane pyrimidine dimers are a common form of UV-induced DNA base damage and were observed after dermal exposure of murine skin to SSL (Floyd, 1982; Sultana et al., 1995; Ahmed, 1999; Berneburg et al., 1999; Kvam and Tyrell, 1997). Treatment of mice with Cum-OOH has also resulted in oxidative DNA damage as was determined by the formation of another commonly used indicator of DNA damage, 8-OHdG. We also observed that oxidative DNA damage (8-OHdG) after Cum-OOH treatment was age-dependent with exposure causing formation of 8-OHdG in older animals while no oxidative DNA occurred in younger animals. This difference was independent on the skin vitamin $\mathrm{E}$ status. The observed differences in DNA damage occurring in young and old mice were most likely due to a decreased efficiency in DNA repair mechanisms as a result of aging (Chung et al., 1991).

ROS overproduction and oxidative stress could interfere with a number of redoxsensitive genes affecting signal transduction pathways. It has been demonstrated that 
nuclear factor kappa-b (NFKB) (Blanchard et al., 2001) and activator protein-1 (AP-1) are redox-sensitive and redox-responsive (Remacle et al., 1995; Allen et al., 2000; Cimino et al., 1997; Dhar et al., 2002). It has been proposed that antioxidants are capable of regulating cytokine production via an NFkB-dependent pathway. GSH depletion prior to $\mathrm{PhOH}$ exposure served as a background for an over-abundance of ROS thereby leading to an induction of skin inflammation (Gossett et al., 1999; Catani et al., 2001). Cytokines, chemokines, and prostaglandins are effective mediators of oxidative stress and inflammation (Nussler et al., 1992; Desmarquest et al., 1998; Yamashita et al., 1999) which alter the cellular and tissue redox equilibrium (Chen et al., 1998). This was supported by current studies showing that $\mathrm{PhOH}$ exposure induced the release of prostaglandin $E_{2}$ and IL-1 $\beta$ found in the supernatants recovered from exposed JB6 epidermal cells. Depletion of GSH occurring prior to $\mathrm{PhOH}$ exposure further upregulated the release of inflammatory mediators.

The different stages of the development and progression of melanoma have been correlated to changes in AP-1 activity (Angel et al., 2001). AP-1 has been highlighted as a mediator of growth factors, oncogenes and the tumor promoter, TPA. AP-1 and its regulated gene expression are involved in pre-neoplastic to neoplastic progression in different cellular models (Domann et al., 1994; Dong et al., 1995; Huang et al., 1996; Jochum et al., 2001). OP, including Cum-OOH, have been shown to reveal tumor promoting properties in murine skin (Slaga et al., 1981; Athar et al., 1989; Timmins and Davies, 1993). It has been shown that application of antioxidants ameoliorated cancer promotion (Perchellet and Perchellet, 1989; Taffe and Kensler, 1986a, b; Timmins and 
Davies, 1993) indicating the critical role of free radicals in the promotion and development of tumors. In our studies, animals initiated with DMBA and promoted with TPA had increased AP-1 activation yielding formation of papilloma. DMBA/Cum-OOH exposure has been shown to induce carcinoma formation while no carcinoma formation was observed in animals exposed to DMBA/TPA. The observed papilloma and carcinoma formation was related to changes in the oxidative capacity in the skin of the animals. It is believed that this occurs via a cyclooxygenase-2-(COX-2) mediated pathway which has been shown to play a prominent role in the pathophysiology of inflammation, tumor promotion, cell proliferation, and cancer (Chinery et al., 1999). ROS-induced DNA damage may also contribute to the observed increase in malignant transformation (O'Connell et al., 1986).

The combination of ROS production, oxidative stress, and inflammation following different chemical exposures have been proposed to cause the development of a variety skin disorders and diseases (Miyachi et al., 1986; Kang et al., 2001; Oztas et al., 2003; Lontz et al., 1995; Filipe et al., 1997; Maresca et al., 1997; Kokcam and Naziroglu, 1999; Pereira et al., 1999; Wolber et al., 1996; DeLuca et al., 1998; Mundt et al., 1999; Niwa and Iizawa, 1994; Antille et al., 2002; Miyachi et al., 1985; Sharkey et al., 1991; Finnen et al., 1984; Schmidt et al., 1990; Senaldi et al., 1994; Fuchs and Milbradt, 1994; Hirai et al., 1997; Lange et al., 1998; Somani and Babu, 1989; Camera et al., 1998; Willis et al., 1998; Kimura et al., 1998; Sarnstrand et al., 1999; Fuchs et al., 2001). Decreases in antioxidant capabilities due to inhibition of GSH synthesis or GSSG reduction, vitamin E 
deficiency, or aging significantly accelerated the skin damage found to occur following exposure to SSL, $\mathrm{PhOH}$, and $\mathrm{Cum}-\mathrm{OOH}$.

In conclusion, these studies found that exposure to chemical and physical agents caused the production of lipid-derived free radicals which are subsequently able to induce antioxidant imbalance and oxidative stress providing a background for dermal toxicity, extended inflammation, reduced skin integrity, and cancer as shown in the case of Cum$\mathrm{OOH}$ exposure. The antioxidant network in the skin controls and regulates the formation of free radicals; however, excessive ROS formation could overwhelm the antioxidant function of the tissue. ROS-induced upregulation of AP-1 and NFkB pathways stimulates cytokine/chemokine production thus amplifying the inflammatory responses. It should also be noted that long-term exposure to oxidizable chemicals, e.g. OP including Cum$\mathrm{OOH}$, is capable of inducing carcinogenesis. Finally, these studies show that altered antioxidant balance of the skin could be considered a key factor affecting skin integrity during oxidative injury induced by environmental and occupational exposures. 


\section{GENERAL REFERENCES}

ACGIH. 1991. Documentation of the threshold limit values and biological exposure indices. $6^{\text {th }}$ edition. American Conference of Governmental Industrial Hygienists. Cincinnati, OH. 1204-1208, BEI155-BEI158.

American Cancer Society. 2006. Detailed Guide: Skin Cancer-Melanoma. What are the key statistics about Melanoma?

http://www.cancer.org/docroot/CRI/content/CRI_2_4_1X_What_are_the_key_statistics_f or_melanoma_50.asp?sitearea=

Adams, R. M. 1980. Plastics, paints, varnishes, and lacquers. In: Occupational Skin Disease. Grune and Stratton, New York, NY, pp. 267-278.

Adams, R. M. 1999. Occupational Skin Disease. W. B. Saunders, Philadelphia, PA, pp. 491-500.

Aggarwal, B. B., Ichikawa, H., Garodia, P., Weerasinghe, P., Sethi, G., Bhatt, I. D., Pandey, M. K., Shishodia, S., and Nair, M. G. 2006. From traditional Ayurvedic medicine to modern medicine: identification of therapeutic targets for suppression of inflammation and cancer. Expert Opin Ther Targets. 10: 87-118.

Ahmed, N. U., Ueda, M., Nikaido, O., Osawa, T., and Ichihashi, M. 1999. High levels of 8-hydroxy-2'-deoxyguanosine appear in normal human epidermis after a single dose of UV radiation. Br J Dermatol. 140: 226-31.

Akamatsu, H., Oguchi, M., Nishijima, S., Asada, Y., Takahashi, M., Ushijima, T., and Niwa, Y. 1990. The inhibition of free radical generation by human neutrophils through the synergistic effects of metronidazole with palmitoleic acid: a possible mechanism of action of metronidazole in rosacea and acne. Arch Dermatol Res. 282: 449-54.

Akamatsu, H., and Horio, T. 1998. The possible role of reactive oxygen species generated by neutrophils in mediating acne inflammation. Dermatol. 196: 82-5.

Allen, R.G., and Tresini, M. 2000. Oxidative stress and gene regulation. Free Radic Biol Med. 28: 463-499.

Ames, B. N., Kammen, H. O., and Yamasaki, E. 1975. Hair dyes are mutagenic: identification of a variety of mutagenic ingredients. Proc Natl Acad Sci USA. 72: 24232427.

Ames, B. N. 1983. Dietary carcinogens and anticarcinogens. Science. 221: 1256-64.

Ananthaswamy, H. N., and Pierceall, W. E. 1990. Molecular mechanisms of ultraviolet radiation carcinogenesis. Photochem Photobiol. 52: 1119-1136. 
Anderson, R. R., and Parrish, J. A. 1981. The optics of human skin. J Invest Dermatol. 77: 13-19.

Angel, P., Imagawa, M., Chiu, R., Stein, B., Imbra, R. J., Rahmsdorf, H. J., Jonat, C., Herrlich, P., and Karin, M. 1987. Phorbol ester-inducible genes contain a common cis element recognized by a TPA-modulated trans-acting factor. Cell. 49(6) : 729-39.

Antille, C., Sorg, O., Lubbe, J., and Saurat, J. H. 2002. Decreased oxidative state in nonlesional skin of atopic dermatitis. Dermatol. 204: 69-71.

Athar, M., Lloyd, J. R., Bickers, D. R., and Mukhtar, H. 1989. Malignant conversion of UV radiation and chemically-induced mouse skin benign tumors by free-radicalgenerating compounds. Carcinogenesis. 10(10): 1841-5.

Athar, M., Mukhtar, H., Bickers, D. R., Khan, I. U., and Kalyanaraman, B. 1989. Evidence for the metabolism of tumor promoter organic hydroperoxides into free radicals by human carcinoma skin keratinocytes: an ESR spin-trapping study. Carcinogenesis. 10: 1499-1503.

ATSDR: Toxicologic Profile for Phenol: Draft for Public Comment (Update). Atlanta, GA. US Department of Public Health and Human Services, Public Health Service, Agency for Toxic Substances and Disease Registry (ATSDR). 1997

Azzi, A., Breyer, I., Feher, M., Pastori, M., Ricciarelli, R., Spycher, S., Staffieri, M., Stocker, A., Zimmer, S., and Zingg, J. M. 2000. Specific cellular responses to alphatocopherol. J Nutr. 130: 1649-52.

Barardesca, E., Distante, E., Vignoli, G. P., Oresayo, C., and Green, B. 1997. Alpha hydroxyacids modulate stratum corneum barrier function. Br J Dermatol. 137: 934-938.

Bauerle, P. A., and Henkel, T. 1994. Function and activation of NF-kB in the immune system. Annu Rev Immunol. 12: 141-179.

Beehler, B. C., Przybyszewski, J., Box, H. B., and Kulesz-Martin, M. F. 1992. Formation of 8-hydroxydeoxyguanosine within DNA of mouse keratinocytes exposed in culture to UVB and $\mathrm{H}_{2} \mathrm{O}_{2}$. Carcinogenesis. 13: 2003-2007.

Bekerecioglu, M., Kutluhan, A., Demirtas, I., and Karaayvaz, M. 1998. Prevention of adriamycin-induced skin necrosis with various free radical scavengers. J Surg Res. 75: 61-65.

Berneburg, M., Grether-Beck, S., Kurten, V., Ruzika, T., Briviba K., Sies, H., and Krutman, J. 1999. Singlet oxygen mediates the UV-induced generation of the photoaging-associated mitochondrial common deletion. J Biol Chem. 274: 15345-9. 
Beyer, R. E. 1994. The role of ascorbate in antioxidant protection of biomembranes: Interaction with vitamin $\mathrm{E}$ and coenzyme Q. J Bioenerg Biomembr. 26: 349.

Biesalski, H. K., and Obermueller-Jevic, U. C. 2001. UV Light, Beta-carotene, and human skin-Beneficial and potentially harmful effects. Arch Biochem Biophys. 389: 1-6.

Black, H. S. 1987. Potential involvement of free radical reactions in ultraviolet lightmediated cutaneous damage. Photochemistry and Photobiology. 46: 213-221.

Black, H. S. 1993. The defensive role if antioxidants in skin carcinogenesis. In: Fuchs, J., Packer, L. (eds.) Oxidative stress in Dermatology. New York: Marcel Dekker, 243269.

Blanchard, J. A. 2nd, Barve, S., Joshi-Barve, S., Talwalker, R., and Gates, L. K. Jr. 2001. Antioxidants inhibit cytokine production and suppress NF-kappaB activation in CAPAN1 and CAPAN-2 cell lines. Dig Dis Sci. 46(12):2768-72.

Bogadi-Sare, A., Brumen, V., Turk, R., Karacic, V., and Zavalic, M. 1997. Genotoxic effects in workers exposed to benzene: with special reference to exposure biomarkers and confounding factors. Ind Health. 35: 367-373.

Bos, J. D., and Kapsenberg, M. L. 1993. The Skin Immune System: Progress in Cutaneous Biology. Immunology Today. 14: 75-78.

Bracher, M., Faller, C., Grotsch, W., Marshall, R., and Spengler, J. 1990. Studies on the potential mutagenicity of p-phenylenediamine in oxidative hair dye mixtures. Mutat Res. 241: 313-323.

Brash, D. E., Rudolph, J. A., Simon, J. A., Lin, A., McKenna, G. J., Baden, H. P., Halperin, A. J., and Ponten, J. 1991. A role for sunlight in skin cancer: UV-induced p53 mutations in squamous cell carcinomas. Proc Natl Acad Sci USA. 88: 10124-10128.

Brennan, R. J., and Schiestl, R. H. 1997. Aniline and its metabolites generate free radicals in yeast. Mutagenesis. 12: 215-220.

Briganti, S., Cristaudo, A., D’Argento, V., Cassano, N., Turbino, L., Guarrera, M, Vena, G., and Picardo, M. 2001. Oxidative stress in physical urticarias. Clin Exp Dermatol. 26: $284-288$.

Briganti, S., and Picardo, M. 2003. Antioxidant activity, lipid peroxidation, and skin diseases. What's new. J Eur Acad Dermatol Vener. 17: 663-669.

Brown, V. K. H., Box, V. L., and Simpson, B. J. 1975. Decontamination procedures for skin exposed to phenolic substances. Arch Environ Health. 30: 1-6. 
Camera, E., Jensen, C., Stab, L. S., Scala, G., Baadsgaard, O., and Picardo, M. 1998. Correlation between antioxidant levels and skin reactivity to irritants. J Dermatol Sci. 16(Suppl 1): S193.

Carr, A., and Frei, B. 1999. Does Vitamin C act as a pro-oxidant under physiological conditions? FASEB J. 13: 1007-1024.

Catani, M. V., Rossi, A., Costanzo, A., Sabatini, S. Levrero, M., Melino, G., Avigliano, L. 2001. Induction of gene expression via activator protein-1 in the ascorbate protection against UV-induced damage. Biochem J. 356: 77-85.

Cavalieri, E. L., and Rogan, E. 1985. Role of radical cations in aromatic hydrocarbon carcinogenesis. Environ Health Perspect. 64: 69-84.

Chaudiere, J., and Ferrari-Iliou, R. 1999. Intracellular antioxidants: from chemical to biochemical mechanisms. Food Chem Toxicol. 37: 949-62.

Chen, C. Y., Huang, Y. L., and Lin, T. H. 1998. Association between oxidative stress and cytokine production in nickel-treated rats. Arch Biochem Biophys. 356: 127-132.

Chignel, C. F. 1985. Structure activity relationships in the free radical metabolism of xenobiotics. Environ Health Perspect. 61: 133-137.

Chow, C. K. 1990. Increased activity of pyruvate kinase in plasma of vitamin E deficient rats. J Nutr. 105: 183-194.

Chung, M. H., Kasai, H., Jones, D. S., Inoue, H., Ishikawa, H., Ohtsuka, E., and Nishimura, S. 1991. An endonuclease activity of Escherichia coli that specifically removes 8-hydroxyguanine residues from DNA. Mutat Res. 254: 1-12.

Cimino, F., Esposito, F., Ammendola, R., and Russo, T. 1997. Gene regulation by reactive oxygen species. Curr Top Cell Reg. 35: 123-148.

Cohen, A. M., Aberdoth, R. E., and Hochstein, P. 1984. Inhibition of free radicalinduced DNA damage by uric acid. Fed Eur Biomed Soc. 174(1): 147.

Coles, B. F., and Kadlubar, F. F. 2003. Detoxification of electrophilic compounds by glutathione S-transferase catalysis: determinants of individual response to chemical carcinogens and chemotherapeutic drugs? Biofactors. 17: 115-130.

Colven, R. M., and Pinnell, S. R. 1996. Topical vitamin C in aging. Clin Dermatol. 14: 227-34.

Condaminet, B., Redziniak, G., Monsigny, M., and Kieda, C. 1997. Ultraviolet rays induced expression of lectins on the surface of a squamous carcinoma keratinocyte cell line. Exp Cell Res. 232: 216-224. 
Conning, D. M., and Hayes, M. J. 1970. The dermal toxicity of phenol: an investigation of the most effective first-aid measures. Br J Ind Med. 27: 155-159.

Corsini, E., and Galli, C. L. 1998. Cytokines and irritant contact dermatitis. Toxicol Lett. 102-103: 277-282.

Coussens, L. M., and Werb, Z. 2002. Inflammation and cancer. Nature. 420: 860-867.

Cunningham, M. L., Krinsky, N. I., Giovanazzi, S. M., and Peak, M. J. 1985. Superoxide anion is generated from cellular metabolites bysolar radiation and its components. J Free Radic Biol Med. 1: 381-385.

Curnutte, J. T., and Babior, B. M. 1987. Chronic granulomatous disease. Adv Hum Genet. 16: 267-275.

Dahl, M. V. 2001. Pathogenesis of rosacea. Adv Dermatol. 17: 29-45.

Darr, D., and Fridovich, I. 1994. Free radicals in cutaneous biology. J Invest Dermatol. 102: 671-675.

Daugherty, J. P., and Khurana, A. 1985. Amelioration of doxorubicin induced skin necrosis in mice by butylated hydroxytoluene. Cancer Chemother Pharmacol. 14: 243246.

Davidson, J. M., Luvalle, P. A., Zoia, O., Quaglino, D., and Giro, M. G. 1997. Ascorbate differentially regulates elastin and collagen biosynthesis in vascular smooth muscle cells and skin fibroblasts by pre-translational mechanisms. J Biol Chem. 272: 345-52.

Davies, R. E., and Forbes, P. D. 1986. Effect of UV radiation on survival of non-haired mice. Photochem Photobiol. 43: 267-274.

Davies, K. J. A. 1987. Protein damage and degradation by oxygen radicals: I. General Aspects. J Biol Chem. 262: 9895-9901.

Day, B. W., Tyurin, V. A., Tyurina, Y. Y., Liu, M., Facey, J. A., Carta, G., Kisin, E. R., Dubey, R. K., and Kagan, V. E. 1999. Peroxidase-catalyzed pro- versus anti-oxidant effects of 4-hydroxytamoxifen-enzyme specificity and biochemical squelae. Chem Res Toxicol. 12: 28-37.

Dean, R. T., Fu, S., Stocker, R., and Davies, M. J. 1997. Biochemistry and pathology of radical-mediated protein oxidation. Biochem J. 324: 1-18.

De Fabo, E. C., and Kripke, M. L. 1979. Dose-response characteristics of immunologic unresponsiveness to UV-induced tumors produced by the UV irradiation of mice. Photochem Photobiol. 30: 385-390. 
De Fabo, E. C., and Kripke, M. L. 1980. Wavelength dependence and dose-rate independence of UV radiation induced suppression of immunologic unresponsiveness of mice to a UV-induced fibrosarcoma. Photochem Photobiol. 32:183-188.

De Leve, L. D., and Kaplowitz, N. 1991. Glutathione metabolism and its role in hepatotoxicity. Pharmacol Ther. 52: 287-305.

DeLuca, C., Stancato, A., Carbone, S., Guarnieri, D., and Passi, S. 1998. Blood oxidative stress in children with atopic dermatitis. J Invest Dermatol. 110: 534.

Desmarquest, P., Chadelat, K., Corroyer, S., Cazals, V., and Clement, A. 1998. Effect of hyperoxia on human macrophage cytokine response. Respir Med. 92: 951-960.

Dhar, A., Young, M. R., and Colburn, N. H. 2002. The role of AP-1, NF-kB and ROS/NOS in skin carcinogenesis: The JB6 model is predictive. Mol Cell Biochem. 234/235: 185-193.

Domann Jr., F. E., Levy, J. P., Finch, J. S., and Bowden, G.T. 1994. Constitutive AP-1 DNA binding and transactivating ability of malignant but not benign mouse epidermal cells. Mol Carcinog. 9(2) : 61-6.

Dong, Z., Lavrovsky, V., and Colburn, N. H. 1995. Transformation reversion induced in JB6 RT101 cells by AP-1 inhibitors. Carcinogenesis. 16(4) : 749-56.

Doniger, J., Jacobsen, E. D., Krell, K., and DiPaolo J. A. 1981. Ultraviolet light action spectra for neoplastic transformation and lethality of Syrian hamster embryo cells correlate with spectrum for pyrimidine dimer formation in cellular DNA. Proc Natl Acad Sci USA. 78: 2378-2382.

Dow Chemical. 1952. Results of range finding toxicological studies with cumene hydroperoxide. Conducted July 1952. Submitted to U.S. EPA on April 10, 1986.

Dunford, H. B., and Adeniran, A. J. 1986. Hammett rho sigma correlation for reactions of horseradish peroxidase compound II with phenols. Arch Biochem Biophys. 251: 536542.

Dunford, H. B. 1995. One-electron oxidations by peroxidases. Xenobiotica. 25: 725733.

Eastman Kodak. 1964. Toxicity and health hazard summary for cumene hydroperoxide. Submitted to U. S. EPA. April 28, 1986.

Eisenstein, O., Giessner-Prettre, C., Maddaluno, J., Stussi, D., and Weber, J. 1992. Theoretical study of oxyhemocyamin active site: a possible insight on the first step of phenol oxidation by tyrosinase. Arch Biochem Biophys. 296:247-255. 
Elmets, C. A., Trefzer, U., and Mukhtar, H. 1994. Immunotoxicology and Immunopharmacology of the Skin Immune System. In: Immunotoxicology and Immunopharmacology. Dean, J. H., Luster, M. I., Munson, A. E., and Kimber, I., eds. Pp. 761. Raven Press, Ltd., New York.

Evelson, P., Ordonez, C. P., Llesuy, S., and Boveris, A. Oxidative stress and in vivo chemiluminescence in mouse skin exposed to UVA radiation. J Photochem Photobiol. 38: 215-9.

Filipe, P., Emerit, I., Youssefi, A., Alaoui, M., Levy, A., Cernjavski, L., Freitas, J., and de Castro, J. L. 1997. Oxyradical-mediated clastogenic plasma factors in psoriasis: Increase in clastogenic activity after PUVA. Photochem Photobiol. 66: 497-501.

Finnen, M. J., Lawrence, C. M., and Shuster, S. 1984. Inhibition of dithranol inflammation by free radical scavengers. Lancet. 217: 1129-1130.

Fisher, M. S., and Kripke, M. L. 1977. Systemic alteration induced in mice by ultraviolet irradiation and its relationship to ultraviolet carcinogenesis. Proc Natl Acad Sci USA. 74: $1688-1692$.

Fisher, M. S., and Kripke, M. L. 1982. Suppressor T lymphocytes control the development of primary skin cancers in ultraviolet-irradiated mice. Science. 216: 11221134.

Flohe, L., Brigelius-Flohe, R., Saliou, C., Traber, M. G., and Packer, L. 1997. Redox regulation of NF-kappa B activation. Free Radic Biol Med. 22: 1115-1126.

Floyd, E. P., and Stokinger, H. E. 1958. Toxicity studies of certain organic peroxides and hydroperoxides. Ind Hyg J. 6: 205-212.

Floyd, R. A. 1982. Free radicals and cancer. New York, Marcel Dekker, Inc.

Floyd, R. A. 1990. The role of 8-hydroxyguanosine in carcinogenesis. Carcinogenesis. 11: 1447-50.

Fraga, C. G., Shigenaga, M. K., Park, J., Deagan, P., and Ames, B. N. 1990. Oxidative damage to DNA during aging: 8-hydroxy-2 -deoxyguanosine in rat organ DNA and urine. Proc Natl Acad Sci USA. 87: 4533-7.

Fridovich, I. 1974. Superoxide dismutases. Adv Enzymol. 41: 35-48.

Fuchs, J., Huflejt, M., Rothfuss, L., Wilson, D., Caramo, G., and Packer, L. 1989. Acute effects of near ultraviolet light on the cutaneous antioxidant defense system. Photochem Photobiol. 50: 739-744. 
Fuchs, J., Huflejt, M. E., Rothfuss, L. M., Wilson, D. S., Carcamo, G., and Packer, L. 1989. Impairment of enzymic and nonenzymic antioxidants in skin by UVB irradiation. J Invest Dermatol. 93: 769-73.

Fuchs, J., and Milbradt, R. 1994. Antioxidant inhibition of skin inflammation induced by reactive oxidants: evaluation of the redox couple dihyrolipoate/lipoate. Skin Pharmacol. 7: 278-284.

Fuchs, J., and Kern, H. 1998. Modulation of UV-light-induced skin inflammation by Dalpha-tocopherol and L-ascorbic acid: a clinical study using solar simulated radiation. Free Rad Biol Med. 25: 1006-1012.

Fuchs, J., Zollner, T. M., Kaufmann, R., and Podda, M. 2001. Redox-modulated pathways in inflammatory skin diseases. Free Rad Biol Med. 30: 337-353.

Fuchs, J., Weber, S., Podda, M., Groth, N., Herrling, T., Packer, L., and Kaufmann, R. 2003. HPLC analysis of vitamin E isoforms in human epidermis: correlation with minimal erythema dose and free radical scavenging activity. Free Radic Biol Med. 34: $330-6$.

Fujii, T., Ikeda, Y., Yamashita, H., and Fujii, J. 2003. Transient elevation of glutathione peroxidase 1 around the time of eyelid opening in the neonatal rat. J Ocul Pharmacol Ther. 19: 361-369.

Furuse, K. 1987. Vitamin E: biological and clinical aspects of topical treatment. Cosmetics Toiletries. 102: 99-116.

Gasparro, F. P. 2000. Sunscreens, skin photobiology, and skin cancer: the need for UVA protection and evaluation of efficacy. Environ Health Perspect. 108: 71-8.

Gate, L., Paul, J., Nguyen Ba, G., Tew, K. D., and Tapiero, H. 1999. Oxidative stress induced in pathologies: the role of antioxidants. Biomed Pharmacother. 53: 169-80.

Ghezzi, P., Bonetto, V., and Fratella, M. 2005. Thiol-Disulfide Balance: From the concept of oxidative stress to that of Redox Regulation. Antioxid Redox Signal. 7(7-8): 964-972.

Gius, D., Botero, A., Shah, S., and Curry, H. A. 1999. Intracellular oxidation/reduction status in the regulation of transcription factors NF-kappaB and AP-1. Toxicol Lett. 106: 93-106.

Gohil, K., Godzdanker, R., O’Roark, E., Schock, B. C., Kaini, R. R., Packer, L., Cross, C. E., and Traber, M. G. 2004. Alpha-tocopherol transfer protein deficiency in mice causes multi-organ deregulation of gene networks and behavioral deficits with age. Ann N Y Acad Sci. 1031: 109-26. 
Goldman, R., Claycamp, G. H., Sweetland, M. A., Sedlov, A. V., Tyurin, V. A., Kisin, E. R., Tyurina, Y. Y., Ritov, V. B., Wenger, S. L., Grant, S. G., and Kagan, V. E. 1999. Myeloperoxidase-catalyzed redox cycling of phenol promotes lipid peroxidation and thiol oxidation in HL-60 cells. Free Radic Biol Med. 27: 1050-1063.

Gosset, P., Wallaert, B., Tonnel, A. B., and Fourneau, C. 1999. Thiol regulation of the production of TNF- $\alpha$, IL-6, and IL-8 by human alveolar macrophages. Eur Respir J. 14: 98-105.

Gniadecki, R., Thorn, T., Vicanova, J., Petersen, A., and Wulf, H. C. 2000. Role of mitochondria in ultraviolet-induced oxidative stress. J Cell Biochem. 80: 216-222.

Goodman, L. S., and Gilman, A. eds. Vitamin E. In Goodman and Gilman's the pharmacological basis of therapeutics . $8^{\text {th }}$ ed. New York: Pergamon Press, 1990: 15661571.

Grayson, M. Ed. 1985. Kirk-Othmer Concise Encyclopedia of Chemical Technology. New York: John Wiley and Sons, pp. 847-849, 866.

Grune, T., Reinheckel, T., and Davies, K. J. 1997. Degradation of oxidized proteins in mammalian cells. FASEB J. 11: 526-534.

Guo, Q., and Packer, L. 2000. Ascorbate-dependent recycling of the vitamin E homologue Trolox by dihyrolipoate and glutathione in murine skin homogenates. Free Radical Biol Med. 29: 368-374.

Gutteridge, J. M., and Halliwell, B. 2000. Free radicals and antioxidants in the year 2000. A historical look to the future. Ann N Y Acad Sci. 899: 136-47.

Hajarizadeh, H., Lebredo, L., Barrie, R., and Woltering, E. A. 1994. Protective effect of doxorubicin in vitamin $\mathrm{C}$ or dimethyl sulphoxide against skin ulceration in the pig. Ann Surg Oncol. 1: 411-414.

Halliwell, B., and Gutteridge, J. M. C. 1993. The importance of iron in lipid peroxidation. Free radicals in biology and medicine ( $2^{\text {nd }}$ ed.) pp 200-205. Oxford, England: Clarendon Press.

Halliwell, B., and Cross, C. E. 1994. Oxygen-derived species: their relation to human disease and environmental stress. Environ Health Perspect. 102: 5-12.

Halliwell, B. 1999. Antioxidant defence mechanisms: from the beginning to the end (of the beginning. Free Radic Res. 31: 261-72.

Halliwell, B. 2000. The antioxidant paradox. Lancet. 355: 1179-80. 
Hanselmann, C., Mauch, C., and Werner, S. 2001. Haem oxygenase-1: a novel player in cutaneous wound repair and psoriasis? Biochem J. 353: 459-466.

Hathaway, G. J., Proctor, N. H., and Hughes, J. P. 1996. Proctor and Hughes' Chemical Hazards of the Workplace, $4^{\text {th }}$ ed., Van Nostrand Reinhold, New York, pp. 169-170.

Herrling, T., Fuchs, J., Rehberg, J., and Groth, N. 2003. UV-induced free radicals in the skin detected by ESR spectroscopy and imaging using nitroxides. Free Rad Biol Med. 35: 59-67.

Hershey, P., Bradley, M., Hasic, E., Haran, G., Edwards, A., and McCarthy, W. H. 1983. Immunological effects of solarium exposure. Lancet. 1: 545-548.

Hess, J. A., Molinari, J. A., Gleason, M. J., and Radecki, C. 1991. Epidermal toxicity of disinfectants. Am J Dent. 4: 51-56.

Hewson, W. D., and Dunford, H. B. 1976. Stoichiometry of the reaction between horseradish peroxidase and p-cresol. J Biol Chem. 251: 6043-6052.

Hirai, A., Minamiyama, Y., Hamada, T., Ishii, M., and Inoue, M. 1997. Glutathione metabolism in mice is enhanced more with haptene induced allergic contact dermatitis than with irritant contact dermatitis. J Invest Dermatol. 109: 314-318.

Hlavica, P., Golly, I., Lehnerer, M., and Schulze, J. 1997. Primary aromatic amines: their N-oxidative bioactivation. Hum Exp Toxicol. 16: 441-448.

Horch ,R., Spilker, G., and Stark, G. B. 1994. Phenol burns and intoxications. Burns. 20: $45-50$.

Huang, N., Lineberger, B., and Steiner, M. 1988. Alpha-tocopherol, a potent modulator of endothelial cell function. Thromb Res. 50: 547-557.

Huang, C., Ma, W. Y., and Dong, Z. 1996. Requirement for phosphatidylinositol 3kinase in epidermal growth factor-induced AP-1 transactivation and transformation in JB6 P+ cells. Mol Cell Biol. 16(11) : 6427-35.

Hussain, S. P., Hofseth, L. J., and Harris, C. C. 2003. Radical causes of cancer. Nat Rev Cancer. 3: 276-285.

Hwang, C., Sinskey, A. J., and Lodish, H. F. 1992. Oxidized redox state of glutathione in the endoplasmic reticulum. Science. 257: 1496-1502.

Iannone, A., Marconi, A., Zambruno, G., Giannetti, A., Vannini, V., and Tomasi, A. 1993. Free radical production during metabolism of organic peroxides by normal human keratinocytes. J Invest Dermatol. 101(1): 59-63. 
Jimbow, K., Chen, H., Park, J. S., and Thomas, P. D. 2001. Increased sensitivity of melanocytes to oxidative stress and abnormal expression of tyrosinase-related protein in vitiligo. Br J Dermatol. 144: 55-65.

Jochum, W., Passeque, E., and Wagner, E. F. 2001. AP-1 in mouse development and tumorigenesis. Oncogene. 20(19) : 2401-12.

Jurkiewicz, B. A. and Buettner, G. R. 1994. Ultraviolet light-induced free radical formation in skin: an electron paramagnetic resonance study. Photochem Photobiol. 59: $1-4$.

Kagan, V., Witt, E., and Goldman, R. 1992. Ultraviolet light-induced generation of vitamin $E$ radicals and their recycling. A possible photosensitizing effect of vitamin $E$ in skin. Free Rad Res Comm. 16: 51-64.

Kagan, V. E., and Packer, L. 1994. Light-induced generation of vitamin E radicals: assessing vitamin E regeneration. Methods Enzymol. 234: 316-320.

Kamal-Eldin, A., and Appelqvist, L. A. 1996. The chemistry and antioxidant properties of tocopherols and tocotrienols. Lipids. 31:671-701.

Kang, S., Fisher, G. J., and Voorhees, J. J. 2001. Photoaging: pathogenesis, prevention and treatment. Clin Geriatr Med. 643-659, v-vi.

Kasai, H., Crain, P. F., Kuchino, Y., Nishimura, S., Ootsuyama, A., and Tanooka, H. 1986. Formation of 8-hydroxyguanine in cellular DNA by agents producing oxygen radicals and evidence for its repair. Carcinogenesis. 8: 1849-51.

Kawanishi, S., Hiraku, Y., Oikawa, S. 2001. Mechanism of guanine-specific DNA damage by oxidative stress and its role in carcinogenesis and aging. Mutat Res. 488: 6576.

Kelly, D. A., Young, A. R., McGregor, J. M., Seed, P. T., Potten, C. S., and Walker, S. L. 2000. Sensitivity to sunburn is associated with susceptibility to ultraviolet radiationinduced suppression of cutaneous cell-mediated immunity. J Exp Med. 191: 561-566.

Kensler, T. W. 1989. Free radical metabolism and toxicity of organic peroxide tumor promoters. Toxicol Path. 19(4): 822-823.

Kensler, T., Guyton, K., Egner, P., McCarthy, T., Lesko, S., and Akman, S. 1995. Role of reactive intermediates in tumor promotion and progression. Prog Clin Biol Res. 391: 103-116.

Kimura, J., Hayakari, M., Kumano, T., Nakano, H., Satoh, K., and Tsuchida, S. 1998. Altered glutathione transferase levels in rat skin inflamed due to contact hypersensitivity: induction of the alpha-class subunit 1. Biochem J. 335: 605-610. 
Klaunig, J. E., and Kamendulis, L. M. 2004. The role of oxidative stress in carcinogenesis. Ann Rev Pharmacol Toxicol. 44: 239-267.

Kohen, R., and Gati, I. 2000. Skin low molecular weight antioxidants and their role in aging and oxidative stress. Toxicology. 148: 149-157.

Kojo, S. 2004. Vitamin C: basic metabolism and its function as an index of oxidative stress. Curr Med Chem. 11: 1041-1064.

Kokcam, I., and Naziroglu, M. 1999. Antioxidants and lipid peroxidation status in the blood of patients with psoriasis. Clin Chim Acta. 289: 23-31.

Kress, S., Sutter, C., Strickland, P. T., Mukhtar, H., Schweizer, J., and Schwarz, M. 1992. Carcinogen-specific mutational pattern in the p53 gene in ultraviolet-B radiation-induced squamous cell carcinomas of mouse skin. Cancer Res. 52: 6400-6403.

Kivirikko, K. I., and Myllyla, R. 1985. Post-translational processing of procollagens. Ann N Y Acad Sci. 11: 250-3.

Kupper, T. S. 1990. Immune and inflammatory process in cutaneous tissues. Mechanisms and speculations. J Clin Invest. 86: 1783-1789.

Kvam, E., and Dahle, J. 2003. Pigmented melanocytes are protected against ultravioletA-induced membrane damage. J Invest Dermatol. 121: 564-569.

Kvam, E., and Tyrrell, R. M. 1997. Induction of oxidative DNA base damage in human skin cells by UV and near visible radiation. Carcinogenesis. 18: 2379-84.

Lange, R. W., Germolec, D. R., Foley, J. F., and Luster, M. I. 1998. Antioxidants attenuate anthralin-induced skin inflammation in BALB-c mice: role of specific proinflammatory cytokines. J Leukoc Biol. 64: 170-176.

LePoole, I. C., Das, P. K., van den Wijngaard, R. M., Bos, J. D., and Westerhof, W. 1993. Review of the etiopathomechanism of vitiligo: a convergence theory. Exp Dermatol. 2: 145-53.

Lerner, A. 1971. On the etiology of vitiligo and gray hair. Am J Med. 51: 141-147.

Levander, O. A. 1987. A global view of human selenium nutrition. Ann Rev Nutr. 7: 227-250.

Leverkus, M., Yaar, M., Eller, M. S., Tang, E. H., and Gilchrest, B. A. 1998. Posttranscriptional regulation of UV induced TNF-alpha expression. J Invest Dermatol. 110: 353-357. 
Lewis, R. J. 1993. Hawley's Condensed Chemical Dictionary. New York: Van Nostrand Reinhold Co., p. 329.

Loft, S., and Poulsen, H. E. 1996. Cancer risk and oxidative DNA damage in man. $J$ Mol Med. 74: 297-312.

Lontz, W., Sirsjo, A., Liu, W., Lindberg, M., Rollman, O., and Torma, H. 1995. Increased mRNA expression of manganese superoxide dismutase in psoriasis skin lesions and in cultured human keratinocytes exposed to IL-1-beta and TNF-a. Free Radic Biol Med. 18: 349-355.

Lopez-Lluch, G., Blazquez, M. V., Perez-Vicente, R., Macho, A., Buron, M. I., Alcain, F. J., Munoz, E., and Navas, P. 2001. Cellular redox state and activating protein-1 are involved in ascorbate effect on calcitriol-induced differentiation. Protoplasma. 217: 129-36.

Lopez-Torres, M., Thiele, J. J., Shindo, Y., Han, D., and Packer, L. 1998. Topical application of a-tocopherol modulates the antioxidant network and diminishes ultravioletinduced oxidative damage in murine skin. Br J Invest Dermatol. 138: 207-15.

Martensson, J., Meister, A., and Martensson, J. 1991. Glutathione deficiency decreases tissue ascorbate levels in newborn rats: ascorbate spares glutathione and protects. Proc Natl Acad Sci USA. 88: 4656-4660.

MacKie, R. M. and Rycroft, M. J. 1988. Health and the ozone layer. Br Med J. 297: 369-70.

Maeda, K., and Fukuda, M. 1996. Arbutin: mechanism of its depigmenting action in human melanocyte culture. J Pharmacol Exp Ther. 276: 765-9.

Maresca, V., Mussi, A., Carducci, M., Bonifati, C., Ameglio, F., Fazio, M., and Picardo, M. 1997. Involvement of antioxidants in psoriasis. Int J Immunopathol Pharmacol. 10: 77-80.

Marks, R. 1968. Concepts in the pathogenesis of rosacea. Br J Dermatol. 80: 170-177.

Marnett, L. J. 2000. Oxyradicals, DNA damage. Carcinogensis. 21: 361-370.

Masella, R., Di Benedetto, R., Vari, R., Filesi, C., and Giovannini, C. 2005. Novel mechanisms of natural antioxidant compounds in biological systems: involvement of glutathione and glutathione-related enzymes. J Nutr Biochem. 16: 577-586.

Mates, J. M., Perez-Gomez, C., and De Castro, I. N. 1999. Antioxidant enzymes and human diseases. Clin Biochem. 32: 595-603. 
McCartney, L. P. 1996. Chemical agents that cause depigmentation. In: Marsala, F. N., and Mailbcach, H. I. (eds). Dermatotoxicology. Taylor \& Francis, Washington, D. C., pp. 275-281.

McCord, J. M., and Fridovich, I. 1969. Superoxide dismutase as enzymic function for erythrocuprein (hemocuprein). J Biol Chem. 244: 60409-60455.

McKenzie, R. C., and Sauder, D. N. 1990. The role of keratinocytes cytokines in inflammation and immunity. J Invest Dermatol. 95: 1055-1075.

Meister, A. 1988. Glutathione metabolism and its selective modification. J Biol Chem. 263(33): 17205-8.

Merliss, R. R. 1972. Phenol marasmus. Occup Med. 14:55-56.

Millikan, L. 2003. The proposed inflammatory pathophysiology of rosacea: implications for treatment. Skinmed. 2: 43-47.

Miyachi, Y., Uchida, K., Komura, J., Asada, Y., and Niwa, Y. 1985. Auto oxidative damage in cement dermatitis. Arch Dermatol Res. 277: 288-292.

Miyachi, Y., Yoshioka, A., Imamura, S., and Niwa, Y. 1986. Effect of antibiotics on the generation of reactive oxygen species. J Invest Dermatol. 86: 449-453.

Miyachi, Y., Imamura, S., and Niwa Y. 1986. Anti-oxidant action of metronidazole: a possible mechanism of action in rosacea. Br J Dermatol. 114: 231-234.

Miyachi, Y. Reactive oxygen species in photodermatology. In: Hayaishi, O., Imamura, S., Miyachi, Y. (eds.) 1987. The biological role of reactive oxygen species in skin. Elsevier, New York, 1987, pp 37-41.

Miyamoto, S., Dupas, C., Murota, K., and Terao, J. 2003. Phospholipid hydroperoxides are detoxified by phophoplipase A2 and GSH peroxidase in rat gastric mucosa. Lipids. 38: 641-649.

Monks, T. J., Hanzlik, R. P., Cohen, G. M., Ross, D., and Graham, D. G. 1992. Quinone chemistry and toxicity. Toxicol Appl Pharmacol. 112: 2-16.

Morreale, M., and Livrea, M. A. 1997. Synergistic effect of glycolic acid on the antioxidant activity of alpha-tocopherol and melatonin in lipid bilayers and in human skin homogenates. Biochem Mol Biol Int. 42: 1093-102.

Mundt, C., Blatt, T., Wolber, R., Gercken G., Foelster-Holst, H., Schachtschabel, D., and Staeb, F. 1999. Oxidative stress response in normal human skin versus noninvolved atopic dermatitis skin. J Invest Dermatol. 112: 572. 
Munkres, K. D., and Colvin H. J. 1976. Ageing of Neurospora crassa. II. Organic hydroperoxide toxicity and the protective role of antioxidant and the antioxygenic enzymes. Mech Ageing Dev. 5:99-107.

Munne-Bosch, S., and Alegre, L. 2002. The function of tocopherols and tocotrienols in plants. Creit Rev Plant Sci. 21: 31-57.

Murray A. R., Kisin E., Kawai K., Kagan V. E., Kommineni C., Castranova V., and Shvedova A. A. 2005. Antioxidant defense in the skin of old and young mice exposed to cumene hydroperoxide. Toxicologist. 79 (1): 448

Nackbar, F., and Korting, H. C. 1995 . The role of vitamin E in normal and damaged skin. J Mol Med. 73: 7-17.

National Ag Safety Database. 1997. UV Index: Nature of UV Radiation. http://www.cdc.gov/nasd/docs/d000901-d001000/d000979/2.html.

Neumann, E., and Frithz, A. 1998. Capillaropathy and capillaroneogenesis in the pathogenesis of rosacea. Int J Dermatol. 263-266.

Nishi, J., Ogura, R., Sugiyama, M., Hidaka, T., and Kohno, M. 1991. Involvement of active oxygen in lipid peroxide radical reaction of epidermal homogenate following ultraviolet light exposure. J Invest Dermatol. 97: 115-119

Nishikimi, M., Fukuyama, R., Minoshima, S., Shimizu, N., and Yagi, K. 1994. Cloning and chromosomal mapping of the human nonfunctional gene for L-gulono-gammalactone oxidase, the enzyme for L-ascorbic acid biosynthesis missing in man. J Biol Chem. 269: 13685-8.

Niwa, Y., and Iizawa O. 1994. Abnormalities in serum lipids and leucocyte superoxide dismutase and associated cataract formation in patients with atopic dermatitis. Arch Dermatol. 130: 1387-1392.

Noonan, F. P., Konrad Muller, H., Fears, T. R., Kusewitt, D. F., Johnson, T. M., and De Fabo, E. C. 2003. Mice with genetically determined high susceptibility to ultraviolet (UV)-induced immunosuppression show enhanced UV carcinogenesis. $J$ Invest Dermatol. 121: 1175-1181.

Nussler, A. K., Di Silvio, M., Billiar, T. R., Hoffman, R. A., Geller, D. A., Selby, R., Madariaga, J., and Simmons, R. L. 1992. Simulation of the nitric oxide synthetase pathway in human hepatocytes by cytokines and endotoxin. J Exp Med. 176: 261-264.

O’Connell, J. F., Klein-Szanto, A. J. P., DiGiovanni, D. M., Fries, J. W., and Slaga, T. J. 1986. Enhanced malignant progression of mouse skin tumors by free-radical generator benzoyl peroxide. Cancer Res. 46: 2863-2865. 
Ogura, R., Sugiyama, M., Nishi, J., and Haramaki, N. 1991. Mechanism of lipid radical formation following exposure of epidermal homogenate to ultraviolet light. $J$ Invest Dermatol. 97: 1044-1047.

Ordman, A. B., Cleaveland, J. S., and Boutwell, R. K. 1985. 12-O-tetradecanoylphorbol13-acetate promotes tumors prior to initiation in two-stage promotion. Cancer Lett. 29: $79-84$.

Ormedod, A., Copeland, P., and Shah, S. 2000. Treatment of psoriasis with topical NGmonomethyl-L-arginine, an inhibitor of nitric oxide synthesis. Br J Dermatol. 142: 985990.

Oztas, M. O., Balk, M., Ogus, E., Bozkurt, M., Ogus, I. H., and Ozer, N. 2003. The role of free oxygen radicals in the aetiopathogenesis of rosacea. Clin Exp Dermatol. 28: 188192.

Packer, J. E., Slater, T. F., and Willson, R. L. 1979. Direct observation of a free radical interaction between vitamin E and vitamin C. Nature. 278: 737-8.

Packer, L. 1991. Protective role of vitamin E in biological systems. Am J Clin Nutr. 53: $1050 \mathrm{~S}-1055 \mathrm{~S}$.

Packer, L., Weber, S. U., and Rimbach, G. 2001. Molecular aspects of alpha-tocotrienol antioxidant action and cell signaling. J Nutr. 131(Suppl): 369-73S.

Packer, L., and Valacchi, G. 2002. Antioxidants and the response of skin to oxidative stress: vitamin E as a key indicator. Skin Pharmacol Appl Skin Physiol. 15: 282-90.

Pasonen-Seppanen, S., Suhonen, T. M., Kirjavainen, M., Suihko, E., Urtti, A., Miettinen, M., Hyttinen, M., Tammi, M., and Tammi, R. 2001. Vitamin C enhances differentiation of a continuous keratinocyte cell line (REK) into epidermis with normal stratum corneum ultrastructure and functional permability barrier. Histochem Cell Biol. 116: 287-97.

Pathak, M. A., and Stratton, K. 1968. Free radicals in human skin before and after exposure to light. Arch Biochem Biophys. 123: 468-476.

Patrick, E., Maibach, H. I., and Burkhalter, A. 1985. Mechanisms of chemically induced skin irritation. I. Studies of time course, dose response, and components of inflammation in the laboratory mouse. Toxicol Appl Pharmacol. 81: 476-490.

Perchellet, J., and Perchellet, E. M. 1992. Antioxidants and multistage carcinogenesis in mouse skin. Free Rad Biol Med. 7: 377-408.

Pereira, P., Rocha, R. L., Santos-Silva, A., Figueiredo, A., Ferra, M. I. A., Quintanilha, A., and Teixeira, F. 1999. Leukocyte activation and oxidative stress in psoriasis. $\mathrm{Br} J$ Pharmacol. 127: 83P. 
Peristeris, P., Clark, B. D., Gatti, S., Faggioni, R., Mantovani, A., Mengozzi, M., Orencole, S. F., Sironi, M., and Ghezzi, P. 1992. N-Acetylcysteine and glutathione as inhibitors of tumor necrosis factor production. Cell Immunol. 140: 390-399.

Persoon-Rothert, M., Egas-Kenniphaas, J. M., van der Valk-Kokshoorn, E. J. M., and van der Laarse, A. 1992. Cumene hydroperoxide induced changes in calcium homeostasis in cultured neonatal rat heart cells. Cardiovasc Res. 26: 706-12.

Peus, D., Vasa, R. M., Meves, A., Pott, M., Beyerle, A., Squillace, K., and Pittelkow, M. R. 1998. $\mathrm{H}_{2} \mathrm{O}_{2}$ is an important mediator of UVB-induced EGF-receptor phosphorylation in cultured keratinocytes. J Invest Dermatol. 110:966-971.

Peus, D., Beyerle, A., Rittner, H. L., Pott, M., Meves, A., Weyand, C., Pittlekow, M. R. 2000. Anti-psoriatic drug anthralin activates JNK via lipid peroxidation: mononuclear cells are more sensitive than keratinocytes. J Invest Dermatol. 114: 688-692.

Peus, D., and Pittelkow, M. R. 2001. Reactive oxygen species as mediators of UVBinduced mitogen-activated protein kinase activation in keratinocytes. Curr Probl Dermatol. 29: 114-127.

Pinnell, S. R. 2003. Cutaneous photodamage, oxidative stress, and topical antioxidant protection. J Am Acad Dermatol. 48: 1-19.

Piotrowski, J. K. 1971. Evaluation of exposure to phenol: Absorption of phenol vapor in the lungs through the skin and excretion of phenol in urine. Br J Ind Med. 28: 172-178.

Podda, M., Weber, C., Traber, M. G., and Packer, L. 1996. Simultaneous determination of tissue tocopherols, tocotrienols, ubiquinols, and ubiquinones. J Lipid Res. 37: 893901.

Podda, M., Traber, M. G., Weber, C., Yan, L. J., and Packer, L. 1998. UV-irradiation depletes antioxidants and cause damage in a model of human skin. Free Rad Biol Med. 24: 55-6.

Podda, M., and Grundmann-Kollmann, M. 2001. Low molecular weight antioxidants and their role in skin ageing. Clin Exp Dermatol. 26: 578-82.

Ponec, M., Weerheim, A., Kempenaar, J., Mulder, A., Gooris, G. S., Bouwstra, J., and Mommaas, A. M. 1997. The formation of competent barrier lipids in reconstructed human epidermis requires the presence of vitamin C. J Invest Dermatol. 109: 348-55.

Powers, S. K., and Hamilton, K. 1999. Antioxidants and exercise. Clin Sports Med. 18: 525-536. 
Powis, G. 1989. Free radical formation by antitumor quinones. Free Radic Biol Med. 6: 63-101.

Pugliese, P. T. 1998. The Skin's Antioxidant Systems. Dermatol Nurs. 10(6): 401-418.

Punnonen, K., Puntala, A., Jansen, C. T., and Ahotupa, M. 1991. UVB irradiation induces lipid peroxidation and reduces antioxidant enzyme activities in human keratinocytes in vitro. Acta Derm Venereol. 71: 239-273.

Quintanilla, M., Brown, K., Ramsden, M., and Balmain, A. 1986. Carcinogen-specific mutation and amplification of Ha-ras during mouse skin carcinogenesis. Nature. 322: 78-80.

Remacle, J., Raes, M., Toussaint, O., Renard, P., and Rao, G. 1995. Low levels of reactive oxygen species as modulators of cell function. Mutat Res. 316: 117-129.

Retsky, K. L., Chen, K., Zeind, J., and Frei, B. 1999. Inhibition of copper-induced LDL oxidation by vitamin $\mathrm{C}$ is associated with decreased copper-binding to LDL and 2-oxohistidine formation. Free Radic Biol Med. 26: 90-98.

Ross, D., Melhorn, R. J., Moldeus, P., and Smith, M. T. 1985. Metabolism of diethylstilbestrol by horseradish peroxidase and prostaglandin-H synthase. Generation of a free radical intermediate and its interaction with glutathione. J Biol Chem. 260: 1621016214.

Rumsey, S. C., Wang, Y., and Levine, M. Vitamin C. In: Papas AM, editor. Antioxidant status, diet, nutrition, and health. Boca Raton: CRC Press, p. 159-88.

Sage, E. 1993. Distribution and repair of photolesions in DNA: genetic consequences and the role of sequence context. Photochem Photobiol. 57: 163-174.

Sakurada, J., Sekiguchi, R., Sato, K., and Hosoya, T. 1990. Kinetic and molecular orbital studies on the rate of oxidation of monosubstituted phenols and anilines by horseradish peroxidase compound II. Biochemistry. 29: 4093-4098.

Sander, C. S., Chang, H., Salzmann, S., Muller, C. S., Ekanayake-Mudiyanselage, S., Elsner, P., and Thiele, J. J. 2002. Photoaging is associated with protein oxidation in human skin in vivo. J Invest Dermatol. 118: 618-25.

Sarnstrand, B., Jansson, A. H., Matusiviciene, G., Scheynius, A., Pierrou, S., and Bergstrand, H. 1999. N, N'-diacetyl-L-cysteine-the disulfide dimer of N-acetylcysteine is a potent modulator of contact sensitivity/delayed type hypersensitivity reactions in rodents. J Pharmacol Exp Ther. 288: 1174-1184. 
Savini, I., Catani, V., Rossi, A., Duranti, G., Melino, G., and Avigliano, L. 2002. Characterization of keratinocyte differentiation induced by ascorbic acid: protein kinase $\mathrm{C}$ involvement and vitamin C homeostasis. J Invest Dermatol. 118: 372-9.

Schafer, F. Q., and Buettner, G. R. 2001. Redox environment of the cell as viewed through the redox state of the glutathione disulfide/glutathione couple. Free Radic Biol Med. 30: 1191-1212.

Schallreuter, K. U., Pittelkow, M. R., and Wood, J. M. 1986. Free radical reduction by thioredoxin reductase at the surface of normal and vitiliginous human keratinocytes. $J$ Invest Dermatol. 87: 728-732.

Schallreuter, K. U., Hordinsky, M. K., and Wood, J. M. 1987. Thioredoxin reductase: role in free radical reduction in different hypopigmentation disorders. Arch Dermatol. 615-619.

Schallreuter, K. U., Wood, J. M., and Berger, J. 1991. Low catalase levels in the epidermis of patients with vitiligo. J Invest Dermatol. 97: 1081-1085.

Schmidt, R. J., Khan, L., and Chung, L. Y. 1990. Are free radicals and not quinines the haptenic species derived from urushiols and other contact allergenic mono- and dihydric alkybenzenes? The significance of NADH, glutathione, and redox cycling in the skin. Arch Dermatol Res. 282: 56-64.

Schreiber, J., Foureman, G. L., Hughes, M. F., Mason, R. P., and Eling, T. E. 1989. Detection of glutathione thiyl free radicals catalyzed by prostaglandin $\mathrm{H}$ synthase present in keratinocytes: study of cooxidation in a cellular system. J Biol Chem. 264: 79367943.

Selassie, C. D., DeSoyza, T. V., Rosario, M., Gao, H., and Hansch, C. 1998. Phenol toxicity in leukemia cells: a radical process? Chemico-Biological Interactions. 113: 175190.

Sen, C. K., and Packer, L. 1996. Antioxidant and redox regulation of gene transcription. FASEB J. 10: 709-720.

Senaldi, G., Pointaire, P., Piguet, P. F., and Grau, G. E. 1994. Protective effect of Nacetylcysteine in haptene-induced irritant and contact hypersensitivity reactions. J Invest Dermatol. 102: 934-937.

Shacter, E., Williams, J. A., Lim, M., Levine, R. L. 1994. Differential susceptibility of plasma proteins to oxidative modification: examination by western blot immunoassay. Free Radic Biol Med. 17: 429-437. 
Sharkey, P., Eedy, D. J., Burrows, D., McCaigue, M. D., and Bell, A. L. A. 1991. A possible role for superoxide production in the pathogenesis of contact dermatitis. Acta Derm Venereol. 71: 156-159.

Shindo, Y., Witt, E., and Packer, L. 1993. Antioxidant defense mechanisms in murine epidermis and dermis and their responses to ultraviolet light. J Invest Dermatol. 100: 260-265.

Shindo, Y., Witt, E., Han, D., Epstein, W., and Packer, L. 1994. Enzymatic and nonenzymatic antioxidants in epidermis and dermis of human skin. J Invest Dermatol. 102: $122-4$.

Shvedova, A. A., Kommineni, C., Jeffries, B. A., Castranova, V., Tyurina, Y. Y., Tyurin, V. A., Serbonova, E., Fabisiak, J. B., and Kagan, V. 2000. Redox cycling of phenol induces oxidative stress in human epidermal keratinocytes. J Invest Dermatol. 114: 354364.

Shvedova, A. A., Tyurina, Y. Y., Tyurin, V. A., Kikuchi, Y., Kagan, V. E., and Quinn, P. J. 2001. Quantitative analysis of phospholipid peroxidation and antioxidant protection in live human epidermal keratinocytes. Biosci Rep. 21: 33-43.

Sies, H. 1999. Glutathione and its role in cellular functions. Free Radic Biol Med. 27(9-10): 916-21.

Sipowicz, M. A., Chomarat, P., Diwan, B. A., Anver, M. A., Awasthy, Y. C., and Ward, J. M. 1997. Increased oxidative DNA damage and hepatocyte overexpression of specific cytochrome P450 isoforms in hepatitis of mice infected with Helicobacter hepaticus. Am J Pathol. 4: 933-41.

Slaga, T. J., Klein-Szanto, J. P., Triplett, L., Yotti, I. P., and Tresko, I. F. 1981. Skin tumor promotion activity of benzoyl peroxide, a widely used free radical generating compound. Science. 213: 1023-1025.

Somani, S. M., and Babu, S. R. 1989. Toxicodynamics of sulfur mustard. Int J Clin Pharmacol Ther Toxicol. 27: 419-435.

Stadtman, E. R. 1992. Protein oxidation and aging. Science. 257: 1220-1224.

Stocker, R., Weidemann, M. J., and Hunt, N. H. 1986. Possible mechanisms responsible for the increased ascorbic acid content of Plasmodium vinckei-infected mouse erythrocytes. Biochim Biophys Acta. 881: 391-397.

Stoyanovsky, D. A., Osipov, A. N., Quinn, P. J., and Kagan, V. E. Ubiquinone-dependent recycling of vitamin E radicals by superoxide. Arch Biochem Biophys. 323: 343-51. 
Stoyanovsky, D. A., Goldman, R., Claycamp, H. G., and Kagan, V. E. 1995. Phenoxyl radical-induced thiol-dependent generation of reactive oxygen species: implications for benzene toxicity. Arch Biochem Biophys. 317: 315-323.

Stoyanovsky, D. A., Goldman, R., Jonnalagadda, S. S., Day, B. W., Claycamp, H. G., and Kagan, V. E. 1996. Detection and characterization of the electron paramagnetic resonance-silent glutathionyl-5,5-1-pyrroline N-oxide adduct derived from redox cycling of phenoxyl radicals in model systems. Arch Biochem Biophys. 330: 3-11.

Subrahmanyam, V. V., and O'Brien, P. J. 1985. Peroxidase catalyzed oxygen activation by arylamine carcinogens and phenol. Chem-Biol Interactions. 56: 186-199.

Subrahmanyam, V. V., Ross, D., Eastmond, D. A., and Smith, M. T. 1991. Potential role of free radicals in benzene-induced myelotoxicity and leukemia. Free Rad Biol Med. 11: 495-515.

Sultana, S., Shahid, P., Iqbal, M., and Athar, M. 1995. Crude extracts of hepatoprotective plants Solanum nigrum and Cichorium intybus inhibit free radical-mediated DNA damage. J Enthnopharmacol. 45: 189-192.

Svingen, B. A., Powis, G. P., Appel, P. L., and Scot, M. 1981. Protection against adriamycin induced skin necrosis in the rat by dimethyl sulfoxide and a-tocopherol. Cancer Res. 41: 3395-3399.

Taffee, B. G., and Kensler, T. W. 1986a. Generation of free radicals from organic hydroperoxide tumor promoter by mouse epidermial cells. Pharmacologist. 28: 175.

Taffee, B. G., and Kensler, T. W. 1986b. Modification of cellular antioxidant defense mechanisms in mouse skin by multiple applications of TPA. Proc Amer Assoc Cancer Res. 27: 148.

Taffe, B. G., Takahashi, N., Kensler, T. W., and Mason, R. P. 1987. Generation of free radicals from organic hydroperoxide tumor promoters in isolated murine keratinocytes. JBiol Chem. 262: 12143-12149.

Taffe, B. G., and Kensler, T. W. 1989. Free radicals and signal transduction in tumor promotion. In: Colburn, N. H. (ed.) Genes and Signal Transduction in Multistage Carcinogenesis. New York: Marcel Dekker, 391-397.

Thiele, J. J., Traber, M. G., Tsang, K. G., Cross, C.E., and Packer, L. 1997. In vivo exposure to ozone depletes vitamin $\mathrm{C}$ and $\mathrm{E}$ and induces lipid peroxidation in epidermal layers of murine skin. Free Rad Biol Med. 23: 385-91.

Thiele, J. J., Traber, M. G., Polefka, T. G., Cross, C. E., and Packer, L. 1997. Ozone exposure depletes vitamin $\mathrm{E}$ and induces lipid peroxidation in murine stratum corneum. $J$ Invest Dermatol. 108: 753-7. 
Thiele, J. J., Weber, S. U., and Packer, L. 1999. Sebaceous gland secretion is a major physiologic route of vitamin E delivery to skin. J Invest Dermatol. 113: 1006-1010.

Thiele, J. J., Weber, S. U., and Packer, L. 1999. Sebaceous gland secretion is a major physiologic route of vitamin E delivery to skin. J Invest Dermatol. 113: 1006-10.

Thiele, J. J., Dreher, F., and Packer L. 2000. Antioxidant defense systems in skin. In: Eisner P, Maibach HI, editors. Cosmeceuticals; drugs vs. cosmetics. New York: Marcel Dekker. p. 145-87.

Thiele, J. J. 2001. Oxidative targets in the stratum corneum: a new basis for antioxidative strategies. Skin Pharmacol Appl Skin Physiol. 14: 87-91.

Thiele, J. J., Schroeter, C., Hsieh, S. N., Podda, M., and Packer, L. 2001. The antioxidant network of the stratum corneum. Curr Probl Dermatol. 29: 26-42.

Theile, J. J., Hsieh, S. N., and Ekanayake-Mudiyanselage, S. 2005. Vitamin E: Critical review of its current use in cosmetic and clinical dermatology. Dermatol Surg. 31: 805813.

Thompson, D. C., Perera, K., and London, R. 1995. Quinone methide formation from para isomers of methylphenol (cresol), ethylphenol, and isopropylphenol: relationship to toxicity. Chem Res Toxicol. 8: 55-60.

Timmins, G. S., and Davies, M. J. 1993. Free radical formation in isolated murine keratinocytes treated with organic peroxides and its modulation by antioxidants. Carcinogenesis. 14(8): 1615-20.

Toro, J. R., Engasser, P. G., and Mailbach, H. I. 1996. Cosmetic reactions. In: Marsala, F. N., and Mailbach, H. I. (eds). Dermatotoxicology. Taylor \& Francis, Washington, D. C., pp. 607-642.

Trenam, C. W., Blake, D. R., and Morris, C. J. 1992. Skin inflammation: reactive oxygen species and the role of iron. J Invest Dermatol. 99: 675-682.

Trouba, K. J., Hamadeh, H. K., Amin, R. P., and Germolec, D. R. 2002. Oxidative stress and its role in skin disease. Antioxid Redox Signal. 4: 665-673.

Trupmann , E. S., and Ellenby, J. D. 1979. Major electrocardiographic changes during chemical face peeling. Plast Reconstr Surg. 63: 44-48.

Trush, M. A., and Kensler, T. W. 1991. An overview of the relationship between oxidative stress and chemical carcinogenesis. Free Radical Biol Med. 10: 201-209. 
Tsai, M. C., Chen, Y. H., and Chiang, L. Y. 1997. Polyhydroxylated C60, fullerenol, a novel free-radical trapper, prevented hydrogen peroxide- and cumene hydroperoxideelicited changes in rat hippocampus in vitro. J Pharm Pharmacol. 49: 438-445.

Tyrell, R. M., and Pidoux, M. 1986. Endogenous glutathione protects human skin fibroblasts against the cytotoxic action of UVB, UVA, and near visible radiations. Photochemistry and Photobiology. 42: 561.

Tyrrell, R. M. 1994. The molecular and cellular pathology of solar ultraviolet radiation. Mol Aspects Med. 15: 1-77.

Valacchi, G., Rimbach, G., Saliou, C., Weber, S. U., and Packer, L. 2001. Effect of benzoyl peroxide on antioxidant status, NK- $\mathrm{BB}$ activity and interleukin-1 $\alpha$ gene expression in human keratinocytes. Toxicology. 165: 225-234.

Valko, M., Rhodes, C. J., Moncol., J., Izakovic, M., and Mazur, M. 2006. Free radicals, metals, and antioxidants in oxidative stress-induced cancer. Chem Biol Inter. 160: 1-40.

Vessey, D. A., Lee, K. W., and Blacker, K. L. 1992. Characteristization of the oxidative stress initiated in cultured human keratinocytes by treatment with peroxides. J Invest Dermatol. 99: 859-863.

Vessey, D. A., and Lee, K. H. 1993. Inactivation of enzymes of the glutathione antioxidant system by treament of cultured human keratinocytes with peroxides. J Invest Dermatol. 100: 829-833,

Wakem, P., and Gaspari, A. A. 2000. Mechanisms of allergic and irritant contact dermatitis. In: Kydonieus, A. F., Wille, J. J., eds. Biochemical modulations of skin reactions. Boca Raton, FL: CRC press. pp. 83-106.

Warren, B. S., Naylor, M. F., Winberg, L. D., Yoshimi, N., Volpe, J. P., Gimenez-Conti, I., and Slaga, T. J. 1993. Induction and inhibition of tumor progression. Proc Soc Exp Biol Medical. 202: 9-15.

Weber, S. U., Thiele, J. J., Cross, C. E., and Packer, L. 1999. Vitamin C, uric acid, and glutathione gradients in murine stratum corneum and their susceptibility to ozone exposure. J Invest Dermatol. 113: 1128-32.

Wefers, H., and Sies, H. 1988. The protection by ascorbate and glutathione against microsomal lipid peroxidation is dependent on vitamin E. Eur J Biochem. 2: 353-7.

Willis, C. M., Reiche, L., and Wilkinson, J. D. 1998. Immunocytochemical demonstration of reduced $\mathrm{Cu}, \mathrm{Zn}$-superoxide dismutase levels following topical application of dithranol and sodium lauryl sulphate: an indication of the role of oxidative stress in acute irritant contact dermatitis. Eur J Dermatol. 8: 8-12. 
Wiseman, H., and Halliwell, B. 1996. Damage to DNA by reactive oxygen and nitrogen species: role in inflammatory disease and progression to cancer. Biochem J. 313: 17-29.

Wolber, R., Staeb, F., Abeck, D., Bleck, O., Schreiner, V., Untiedt, S., Sauermann, G., and Hoppe, U. 1996. Antioxidant status and role of oxidative stress in atopic dermatitis. J Invest Dermatol. 106: 888.

Wolf, R., Wolf, D., and Ruocco, V. 1998. Vitamin E: the radical protector. J Eur Acad Derm Vener. 10: 103-117.

Yamashita, N., Hoshida, S., Otsu, K., Asahi, M., Kuzuya, T., and Hori, M. 1999. Exercise provides direct biphasic cardioprotection via manganese superoxide dismutase activation. J Exp Med. 189: 1699-1706.

Yasui, H., and Sakurai, H. 2000. Chemiluminescent detection and imaging of reactive oxygen species in live mouse skin exposed to UVA. Biochem Biophys Res Commun. 269: 131-136.

You, W. C., Zhang, L., Gail, M. H., Chang, Y. S., Liu, W. D., Ma, J. L., Li, J. Y., Jin, M. L., Hu, Y. R., Yang, C. S., Blaser, M. J., Correa, P., Blot, W. J., Fraumeni, J. F., and Xu, G. W. 2000. Gastric cancer: Helicobacter pylori, serum Vitamin C, and other risk factors. J Natl Cancer Inst. 92: 1607-1612.

Zelck, U. E., and Von Janowsky, B. 2004. Antioxidant enzymes in intramoluscan Schistosoma mansoni and ROS-induced changes in expression. Parasitology. 128: 493501.

Zimmerman, R. J., Marafino, B. J., Jr, Chan, A., Landre, P., and Winkelhake, J. L. 1989. The role of oxidant injury in tumor cell sensitivity to recombinant human tumor necrosis factor in vivo. Implications for mechanisms of action. J Immunol. 142: 1405-1409. 


\section{CURRICULUM VITAE}

\section{Ashley Rebecca Murray}

\section{Education}

2001-present

1996-2001

\section{Training Positions}

2001-present

\author{
West Virginia University \\ School of Medicine \\ Department of Physiology and Pharmacology \\ Morgantown, WV \\ West Virginia University \\ Eberly College of Arts and Sciences \\ Morgantown, WV; GPA: 3.5/4.0 \\ Bachelor of Arts in Biology and Chemistry
}

\author{
Department of Physiology and Pharmacology \\ West Virginia University \\ Morgantown, WV \\ Chairman: Robert Goodman \\ Advisor: Anna Shvedova
}

Graduate Student: Responsibilities within the department included leading physiology small group discussions with first year medical students.

Graduate Student Research: As a graduate student, I have had the opportunity to conduct my research at the National Institute of Occupational Safety and Health (NIOSH). I have been studying the mechanism of the toxic outcomes induced by in vitro and in vivo exposure of phenolic compounds and organic peroxides to skin. There is several modern technique e.g. ESR spectroscopy with PBN-spin trapping applied to detect lipid-derived and oxygen radicals formed following dermal exposure to the latter compounds. Additionally, lipid, RNA/DNA, protein and antioxidants bio-chemical methods were employed to determine the role of oxidative mediators and biomarkers responsible for the toxic outcomes and inflammatory injury caused by above chemicals to skin.

Pathology and Physiology Research Branch (PPRB)

National Institute of Occupational Safety and Health (NIOSH)

Morgantown, WV

Supervisor: Anna Shvedova 
Laboratory Assistant: Studied the mechanisms of the toxic effects of exposure to phenolic compounds and organic peroxides on skin of mice. Tested antioxidant levels in different tissues from mice exposed to 4-allyl-methoxyphenol and metal working fluid (MWF). Studied inflammatory cell responses in pulmonary tissue after inhalation exposure to MWF.

\section{Career Related Training}

Radiation Safety Training

National Institute for Occupational Safety and Health, Morgantown, WV

Blood Borne Pathogens

National Institute for Occupational Safety and Health, Morgantown, WV

Hazardous Waste Training

National Institute for Occupational Safety and Health, Morgantown, WV

Hazard Communication Training

National Institute for Occupational Safety and Health, Morgantown, WV

Laboratory Safety Course

National Institute for Occupational Safety and Health, Morgantown, WV

Chemical Storage Training

National Institute for Occupational Safety and Health, Morgantown, WV

Animal Use and Handling

National Institute for Occupational Safety and Health, Morgantown, WV

\section{Professional Organizations and Service}

- Society of Toxicology (SOT) Member

- Dermal Toxicology Specialty Section (DTSS) Member

- Allegheny-Erie Regional Chapter of Society of Toxicology

- Student Representative from the Allegheny-Erie Regional Chapter of the Society of Toxicology

- Student Representative to the Women in Toxicology Specialty Section of the Society of Toxicology

- Student Advisory Council Liaison to the Specialty Section Student Representatives within the Society of Toxicology

\section{$\underline{\text { Awards }}$}

- 2006 Young Investigator Award, $1^{\text {st }}$ International Nanotoxicology: Biomedical Aspects Meeting

- 2005 Graduate Student Travel Award from the Society of Toxicology

- 2004 Student Award from the Dermal Toxicology Specialty Section of the Society of Toxicology

- 2004 Best Overall Poster Award from the Allegheny-Erie Regional Chapter, SOT

- 2001 Student Travel Award from the Dermal Toxicology Specialty Section of the Society of Toxicology 


\section{$\underline{\text { Presentations }}$}

Murray A.R., Kisin E., Castranova V., Kommineni C., Shvedova A.A. 2006. Antioxidant defense and toxic effects of occupational chemicals to skin. $45^{\text {th }}$ Annual Society of Toxicology Meeting, March, 2006, San Diego, CA.

Murray A.R. Oxidative Stress and Inflammatory Response in Dermal Toxicity of Single Wall Carbon Nanotubes. 2006. $1^{\text {st }}$ International Nanotoxicology: Biomedical Aspects Meeting. January, 2006, Miami, FL.

Murray A.R., Kisin E., Kawai K., Kagan V.E., Kommineni C., Castranova V., Shvedova A.A. 2005. Antioxidant defense in the skin of old and young mice exposed to cumene hydroperoxide. $44^{\text {th }}$ Annual Society of Toxicology Meeting, March, 2005, New Orleans, LA.

Murray A.R., Kisin E., Castranova V., Miller B.J., Howard P.C., Shvedova A.A. 2004. Simulated Solar Light (SSL) Induces Inflammation and Oxidative Stress in the Skin of SKH-1 Hairless Mice. $43^{\text {th }}$ Annual Society of Toxicology Meeting, March, 2004, Baltimore, MD.

Murray A.R. 2003. Cytotoxic and Genotoxic Effects of Single Walled Carbon Nanotube Exposure In Vitro and In Vivo. Department of Physiology and Pharmacology Student Seminar Series; Morgantown, WV.

Murray A.R. 2002. Phenol Induced Oxidative Stress In vivo: Evidence For Enhanced Free Radical Generation, Thiol Oxidation, and Antioxidant Depletion in Skin. Department of Physiology and Pharmacology Student Seminar Series; Morgantown, WV.

Murray A.R. 2001. Phenol Induced Oxidative Stress In vivo: Evidence For Enhanced Free Radical Generation, Thiol Oxidation, and Antioxidant Depletion in Skin. Dermal Interest Group Seminar; NIOSH/HELD; Morgantown, WV.

Murray A.R., Shvedova A.A., Kisin E., Castranova V., Kommineni C., Gunther M.R. 2001. Phenol Induced In Vivo Oxidative Stress in Skin: Evidence for Enhanced Free Radical Generation, Thiol Oxidation and Antioxidant Depletion. 40th Annual Society of Toxicology Meeting, March, 2001, San Francisco, CA.

\section{Abstracts}

Murray A. R., Kisin E., Castranova V., Kommineni C., Shvedova A. A. 2006. Antioxidant defense and toxic effects of occupational chemicals to skin. Toxicologist. 90(1): 172 . 
Kisin E., Murray A. R., Castranova V., Kagan V. E., Shvedova A. A. 2006. Single wall carbon nanotubes induce oxidative stress, acute inflammation, and progressive pulmonary fibrosis. Toxicologist. 90(1): 318 .

Murray A. R., Kisin E., Kawai K., Kagan V. E., Kommineni C., Castranova V., Shvedova A. A. 2005. Antioxidant defense in the skin of old and young mice exposed to cumene hydroperoxide. Toxicologist. 79 (1): 448

Kisin E., Murray A. R., Johnson V., Gorelik O., Arepalli S., Gandelsman V. Z., Hubbs A. F., Mercer R. R., Baron P., Kagan V. E., Castranova V., Shvedova A. A. 2005. Pulmonary toxicity of single wall carbon nanotubes. Toxicologist. 79 (S-1): 212.

Mercer R., Scabilloni J., Kisin E., Gorelik O., Arepalli S., Murray A. R., Castranova V., Shvedova A. A. 2005. Responses of lung parenchyma to carbon nanotubes. Toxicologist. 79 (S-1): 213.

Shvedova A. A., Kisin E., Murray A.R., Gorelik O., Arepalli S., Gandelsman V.Z., Mercer R., Hubbs A., Kagan V. E., Castranova V. 2004. Oxidative stress and pulmonary toxicity of carbon nanotubes. $11^{\mathrm{TH}}$ Annual meeting SFRBM, November 17-21, 2004

Shvedova A. A., Kisin E., Keshava N., Murray A. R., Gorelik O., Arepalli S., Gandelsman V. Z., Castranova V. 2004. Cytotoxic and genotoxic effects of single wall carbon nanotube exposure on human keratinocytes and bronchial epithelial cells, $227^{\text {th }}$ ACS National Meeting, March 28-April 1, 2004, Anaheim, CA

Keshava N., Murray A.R., Gorelik O., Arepalli S., Gandelsman V. Z., Castranova V., Shvedova A. A.. 2004. Transcriptional Regulation in Response to Carbon Nanotubes in Human Bronchial Epithelial Cells as Detected by Microarray Analysis. Toxicologist. 78 (S-1): 145 .

Kisin, E., Murray A.R., Schwegler-Berry D., Gandelsman V.Z., Gunther M.R., Castranova V., Shvedova A.A.. 2004. Carbon Nanotube Exposure caused Formation of Free Radicals, Induction of Oxidative Stress and Cytotoxicity in Human Keratinocytes and Bronchial Epithelial Cells. Toxicologist 78 (S-1): 305.

Murray, A.R., Kisin E., Castranova V., Miller B.J., Howard P.C., Shvedova A.A. 2004. Simulated Solar Light (SSL) Induces Inflammation and Oxidative Stress in the Skin of SKH-1 Hairless Mice. Toxicologist 78(S-1): 325.

Xu, M., Kisin E., Murray A. R., Kommineni C., Vallyathan V., Castranova V., Shvedova A.A.. 2004. Activation of AP-1 and Pro/Antioxidant Status in Skin of AP-1 Transgenic Mice During Cancer Promotion with Cumene Hydroperoxide. Toxicologist 78(S-1): 338.

Shvedova A. A., Murray A. R., Kisin E. R., Kagan V. E., Gandelsman V. Z., Castranova V. 2003. Exposure of human bronchial epithelial cells to carbon nanotubes caused 
oxidative stress and cytotoxicity. Free Radicals and Oxidative Stress: Chemistry, Biochemistry and Pathophysiological Implications, SFRR Meeting, June 26-29, 2003, Ioannina, Greece.

Shvedova A. A., Kisin E. R., Murray A. R., Kommineni C., Gunther M. R., Rao K.M.K., Castranova V. 2003. Inflammatory Response and Free Radical Formation in Skin of B6C3F1 Mice with Diminished Levels of Glutathione after Phenol Exposure. Toxicologist. 70(1): 378.

Shvedova A. A., Kisin E. R., Murray A. R., Mason R. P., Kadiiska M., Castranova V., Gunther M. 2002. In vivo detection of vitamin E-dependent protection against free radical formation and oxidative stress in skin treated with cumene hydroperoxide. 9th Annual Meeting, Oxygen Society, San Antonio, TX, Nov. 20-24, 2002.

Shvedova A. A., Kisin E. R., Murray A. R., Kawai K., Castranova V., Howard P. C. 2002. Oxidation biomarkers and antioxidant protection of skin against UV-irradiation and chemical exposure. Reactive Oxygen and Nitrogen Species: Diagnostic, Preventive, and Therapeutic Values. International Symposium, Russia, July 9-13, 2002.

Kommineni C., Kisin E., Murray A., Smith C.A., Goldsmith T., Reynolds J.S., Castranova V., Frazer D.G., Shvedova A.A.. 2002. Sub-Chronic Effect of Metal Working Fluids on Pulmonary Functions in B6C3F1 Mice: Role of Vitamin E. Toxicologist 66(S-1): 89.

Murray A., Shvedova A.A., Kisin E., Castranova V., Kommineni C., Gunther M.R.. 2001. Phenol Induced In Vivo Oxidative Stress in Skin: Evidence for Enhanced Free Radical Generation, Thiol Oxidation, and Antioxidant Depletion. Toxicologist 60 (1): 42 .

Smith C., Murray A., Kisin J., Kommineni C., Castronova V., Kisin E., Kagan V., Shvedova A.A.. 2001. Phenolic Compounds Cause Depletion of GSH, Oxidative Stress, and Cytotoxicity in Normal Human Dermal Cells. Toxicologist 60 (1): 169.

Kisin E., Smith C., Murray A., Castronova V., Kommineni C., Shvedova A.A. 2001. Enhanced Oxidative Stress in the Skin of Vitamin E Deficient Mice Exposed to Metal Working Fluid. Toxicologist 60 (1): 60.

\section{Publications}

Shvedova A., Kisin E., Mercer R., Murray A., Johnson V.J., Potapovich A., Tyurina Y., Gorelic O., Arepalli S., Schwegler-Berry D., Antonini J., Evans D.E., Ku B-K., Ramsey D., Maynard A., Kagan V.E., Castranova V., Baron P. 2005. Unusual inflammatory and fibrogenic pulmonary responses to single walled carbon nanotubes in mice. Am J Physiol Lung Cell Mol Physiol. 2005 Jun 10; [Epub ahead of print], 2005 
Shvedova A., Kisin E., Murray A., Schwegler-Berry D., Gandelsman V., Baron P., Maynard A., Gunther M., Kagan V.E., Castranova V. 2004. Assessment of

Carbon Nanotube Cytotoxicity Using Human Cells and Animal Models. Proceeding of the Toxicology Forum $29^{\text {th }}$ Annual meeting, p. $697-710$ (Feb, 2-4, Washington, DC, 2004), 2004.

Shvedova A., Kisin E., Murray A., Schwegler-Berry D., Gandelsman V., Baron P., Maynard A., Gunther M., Castranova V. 2003. Exposure of human bronchial cells to carbon nanotubes caused oxidative stress and cytotoxicity. Proceedings of the Meeting of the SFRR Europe (June 26-29, 2003), Vol. ISBN 88-7587-002; CD ISBN 88-7587-003$9,2004$.

Shvedova A.A., Kisin E.R., Murray A., Kommineni C., Vallyathan V., Castranova V. 2004. Pro/antioxidant status in murine skin following topical exposure to cumene hydroperoxide throughout the ontogeny of skin cancer. Biochemistry (Moscow), 2004, $69(1), 23-31$.

Shvedova A.A., Castranova V., Kisin E.R., Schwegler-Berry D., Murray A.R., Gandelsman V.Z., Maynard A., Baron P. 2003. Exposure to Carbon Nanotube Material: Assessment of Nanotube Cytotoxicity using Human Keratinocyte Cells. J Toxicol Environ Health A 66(20): 1909-26.

Shvedova A.A., Kisin E.R., Murray A.R., Kommineni C., Castranova V., Mason R.P., Kadiiska M.B., Gunther M.R. 2002. Antioxidant balance and free radical generation in vitamin e-deficient mice after dermal exposure to cumene hydroperoxide. Chem Res Toxicol 15(11): 1451-9.

Shvedova A.A., Kisin E., Murray A., Goldsmith T., Reynolds J.S., Castranova V., Frazer D.G., Kommineni C. 2002. Metal working fluids: sub-chronic effects on pulmonary functions in $\mathrm{B} 6 \mathrm{C} 3 \mathrm{~F} 1$ mice given vitamin $\mathrm{E}$ deficient and sufficient diets. Toxicology 177(2-3): 285-97.

Shvedova A.A., Kisin E., Murray A., Smith C., Castranova V., Kommineni C. 2002. Enhanced oxidative stress in the skin of vitamin $E$ deficient mice exposed to semisynthetic metal working fluids. Toxicology 176(1-2): 135-43. 